\title{
Alcohol consumption in relation to cardiovascular risk and mortality
}

Citation for published version (APA):

Costanzo, S. (2012). Alcohol consumption in relation to cardiovascular risk and mortality. [Doctoral Thesis, Maastricht University]. Maastricht University. https://doi.org/10.26481/dis.20120126sc

Document status and date:

Published: 01/01/2012

DOI:

$10.26481 /$ dis.20120126sc

Document Version:

Publisher's PDF, also known as Version of record

\section{Please check the document version of this publication:}

- A submitted manuscript is the version of the article upon submission and before peer-review. There can be important differences between the submitted version and the official published version of record.

People interested in the research are advised to contact the author for the final version of the publication, or visit the DOI to the publisher's website.

- The final author version and the galley proof are versions of the publication after peer review.

- The final published version features the final layout of the paper including the volume, issue and page numbers.

Link to publication

\footnotetext{
General rights rights.

- You may freely distribute the URL identifying the publication in the public portal. please follow below link for the End User Agreement:

www.umlib.nl/taverne-license

Take down policy

If you believe that this document breaches copyright please contact us at:

repository@maastrichtuniversity.nl

providing details and we will investigate your claim.
}

Copyright and moral rights for the publications made accessible in the public portal are retained by the authors and/or other copyright owners and it is a condition of accessing publications that users recognise and abide by the legal requirements associated with these

- Users may download and print one copy of any publication from the public portal for the purpose of private study or research.

- You may not further distribute the material or use it for any profit-making activity or commercial gain

If the publication is distributed under the terms of Article $25 \mathrm{fa}$ of the Dutch Copyright Act, indicated by the "Taverne" license above, 
Alcohol Consumption in Relation to Cardiovascular Risk and Mortality 
(c) Simona Costanzo, Maastricht 2012

Thesis Maastricht University

ISBN: $978-88-88102-44-3$

Layout: Simona Costanzo

Cover: Vincent van Gogh, The Drinkers, or the Four Ages of Man, 1890. Art Institute of Chicago

Printed by: $\quad$ ARTI GRAFICHE, Campobasso, Italy

All rights reserved. No part of this thesis may be reproduced, stored in a retrieval system or transmitted in any form or by any means, without the permission in writing from the author, or, when appropriate, of the publishers of the publications. 


\section{Alcohol Consumption in Relation to Cardiovascular Risk and Mortality}

\section{PROEFSCHRI FT}

ter verkrijging van de graad van doctor

aan de Universiteit Maastricht

op gezag van de Rector Magnificus,

Prof. Mr. G.P.M.F.Mols,

Volgens het besluit van het College van Decanen,

In het openbaar te verdedigen op

Donderdag 26 Januari 2012 om 12.00 uur

door

Simona Costanzo 


\section{Promotoren}

Em. Prof. dr. HC. Hemker

Prof. dr. G. de Gaetano, Campobasso, Italy.

Prof. dr. H. ten Cate

Beoordelingscommissie

Prof. dr. A. Bast (Chairman)

Prof. dr. R. de Bie

Dr. B. de Laat

Prof. dr. R. van Oostenbrugge

Prof. dr. K. Westerterp

The research described in this thesis was partially supported by the Cuore Sano ONLUS, Campobasso, I taly.

This thesis was printed with the generous support of The European Foundation for Alcohol Research (ERAB), Belgium and Assobirra, I taly. 
Sn. llomory of tly Grandparents

To. lly. Family 



\section{Contents}

1. Planning of the thesis. General Introduction 9

2. Chapters A to J (from selected publications) 13

3. Discussion 135

$\begin{array}{ll}\text { 4. Conclusions } & 138\end{array}$

5. Summary 139

$\begin{array}{ll}\text { 6. Selected publications } & 141\end{array}$

7. Curriculum vitae 142

8. Publications 144

$\begin{array}{ll}\text { 9. Acknowledgments } & 147\end{array}$ 



\section{Planning of this thesis}

Scientific evidence of benefit from moderate drinking only began to accumulate in the 20th century. It is now clearer than ever that the health effects of alcohol are like a double-edged sword, with harm predominating among heavy drinkers and net benefit in light-moderate drinkers. Since individual effects cannot reliably be predicted, and harm from heavy drinking can be catastrophic, some experts and governmental bodies have difficulty to accept that there can be any benefit at all in alcohol consumption.

Epidemiological studies consistently suggest a protective effect of regular and moderate alcohol consumption in coronary heart disease and ischemic stroke. The association between alcohol consumption and cardiovascular morbidity and mortality is usually described through a "J-shaped" relationship, where teetotallers and heavy drinkers are at the highest risk whereas light-moderate drinkers are at the lowest risk. Total mortality is also reduced in middle-aged and older moderate drinkers as compared to abstainers. Excess of drinking, however, is definitely harmful.

Mechanisms underlying an antithrombotic effect of alcohol have been extensively investigated. Anti-atherogenic alterations in plasma lipoproteins, particularly increase in high-density and decrease in low-density lipoprotein cholesterol, are considered to be the most plausible mechanisms of the protective effect of alcohol consumption on coronary artery disease. Furthermore, alcohol may reduce the tendency to thrombosis (down regulation of blood platelet function and decrease in plasma fibrinogen levels, improving also the efficiency of fibrinolytic pathways), improve endothelial function and reduce insulin resistance.

There is an intense interest in additional effects of non-alcoholic components of specific alcoholic beverages. Anti-atherogenic and anti-thrombotic effects and regulation of endothelial function were mainly ascribed to polyphenolic and phenolic constituents of (red) wine and beer, respectively. Some epidemiological data support greater benefit from drinking of wine than of other beverage types, but there is no epidemiological consensus on the issue.

The absence and the unfeasibility for ethical considerations of randomized controlled trials leave room for residual uncertainty about cardiovascular and total 
mortality protection by alcohol consumption and consequently there has been a point-counterpoint debate on this topic in the scientific literature.

In the last decade, several open questions have been addressed: the impact on health of different alcoholic beverages, the effects of alcohol in women and men, or in patients (e.g. cardiovascular patient, diabetic or hypertensive subject).

The purpose of this thesis was to examine the complex relationship between alcohol drinking and health, considering the association of alcohol consumption with primary and secondary cardio-cerebro-vascular morbidity and mortality and total mortality. Systematic reviews and meta-analyses have been used to dissect these issues.

The relationship between alcohol consumption and cardiovascular events in apparently healthy people has been shown as a J-shaped curve attributed to a dose-related combination of beneficial and harmful effects. The evidence for this association and possible limitations have been reviewed in the introductory manuscripts of this thesis (references A, B, C).

While the benefit of moderate alcohol consumption on coronary heart disease is well established, the specific relationship with cerebrovascular disease, mainly stroke, is still controversial. Risk factors differ for the two major stroke types (hemorrhagic and ischemic) and several subtypes of each and alcohol appears to have different associations with these various types. A systematic review on alcohol consumption and cerebrovascular disease concludes the first part of this thesis ( reference D).

Without any doubt, if moderate and regular alcohol consumption decreases the risk for cardiovascular disease, conversely heavy and irregular alcohol consumption increases risk for certain cancers, cirrhosis and death for accidents. An updated meta-analysis of prospective studies was performed to investigate the relationship between alcohol dosing and all-cause mortality, separately in men and women ( reference E). The all-causes mortality was considered as a global endpoint that describes in the best way the balance between the benefits and the harms of "alcohol-dosing" consumption.

Since the proposal of a "French paradox" in the early Nineties, the possibility that consuming alcohol in the form of wine might confer a protection against coronary 
artery disease above that expected from its alcohol content was extensively investigated, while the question whether wine is a better protecting beverage than beer or spirits was addressed by a large meta-analysis of the available literature ( reference F).

Secondary prevention of cardiovascular events in survivors of primary vascular events as well as in hypertensive or diabetic patients is crucial. Among factors implicated in secondary prevention, a substantial positive role is recognized to improved lifestyle and dietary habits. However, guidelines in this area are based either on data from studies on apparently healthy subjects or on few studies on patients. Data on the relation between light-to-moderate alcohol consumption and mortality in patients with previous cardiovascular disease are sparse.

For the sake of this thesis, three meta-analyses were performed to define and quantify a possible association between alcohol consumption with secondary events (fatal or not-fatal vascular event and all-cause mortality) in patients at high cardiovascular risk (diabetics or hypertensive subjects or cardiovascular patients) (references G, H).

Two reviews on the epidemiological perspectives of alcohol consumption and cardiovascular risk and total mortality in apparently healthy populations and subjects at high cardiovascular risk conclude the thesis (references I, J). 



\section{Chapters - Publications}

\section{Chapter - Reference A}

MODERATE ALCOHOL CONSUMPTION AND CARDI OVASCULAR RISK REDUCTION: OPEN ISSUES

Costanzo S, Di Castelnuovo A, Donati MB, Iacoviello L, de Gaetano G. Moderate alcohol consumption and cardiovascular risk reduction: open issues. Italian J Pub Health $2006 ; 3: 21-28$. 



\title{
Moderate alcohol consumption and cardiovascular risk reduction: open issues
}

\author{
Simona Costanzo, Augusto Di Castelnuovo, Maria Benedetta Donati, Licia lacoviello, \\ Giovanni De Gaetano
}

\begin{abstract}
Laboratori di Ricerca, Centro di Ricerca e Formazione ad Alta Tecnologia nelle Scienze Biomediche "Giovanni Paolo II", Università Cattolica del Sacro Cuore, Campobasso

Correspondence to: Simona Costanzo, Laboratorio di Epidemiologia Genetica e Ambientale, Laboratori di Ricerca, Centro di Ricerca e Formazione ad Alta Tecnologia nelle Scienze Biomediche “Giovanni Paolo II”, Università Cattolica del Sacro Cuore, Campobasso. Italia. Email: simona.costanzo@rm.unicatt.it
\end{abstract}

\begin{abstract}
Background: The inverse relationship between low to moderate alcohol consumption and several favorable health outcomes has been well established in many epidemiological studies and meta-analyses. However, several questions still remain controversial.

Aims: To discuss a number of open questions relating to the healthy effect of a moderate intake of alcohol (especially wine) on cardiovascular disease and total mortality. This will be based on findings from the literature, with a particular emphasis on meta-analyses.

Results and Conclusion: The role of different alcoholic beverages, age and sex, confounding, former drinkers and study design has been discussed.

Whether wine is better than beer or spirits, though suggestive, remains to be established.

Cardiovascular morbidity and total mortality is significantly reduced both in men and women who are regular drinkers of low amounts of alcohol; however, the predicted protection in women disappears at lower doses than in men.

The primary protection of alcohol decreases after adjustment for known variables, thus confirming the importance of confounding in assessing drinking effects, but it remains significant and of undoubted public health value.

As the cardiovascular protection by moderate alcohol consumption might have been unduly overestimated by inclusion in control groups of former drinkers, we compared studies that used as a reference group the category of no alcohol intake and/or formally excluded former drinkers with studies which did not: the protection was indeed somewhat lower in the former than in the latter studies, but was still statistically significant.

We conclude that the dose-response relationship between alcohol intake and cardiovascular risk or total mortality, consistently described by J-shaped curves, can be reasonably attributed to a combination of both real beneficial (at lower doses) and harmful (at higher doses) effects of alcohol or wine consumption.
\end{abstract}

Key words: alcohol, wine, cardiovascular disease, all-cause mortality, meta-analysis

\section{Introduction}

The protective effect of moderate alcohol consumption in coronary heart disease (CHD) and cerebrovascular disease has been consistently shown in many epidemiological studies and confirmed in meta-analyses. [1-9] Several nonvascular or non primarily vascular diseases are also known to be less frequent in moderate drinkers than in non drinkers. These include diabetes, [10,11] osteoporosis, [12] gall bladder disease [13] and other pathological conditions. [4] Finally, total mortality rates were also reduced in moderate drinkers. [6,14-18] However, excess of drinking is definitely harmful. [14,19]

Anti-atherogenic alterations in plasma lipoproteins, which are particularly increased in high density lipoprotein (HDL) cholesterol, are considered as the most plausible mechanism of the protective effect of alcohol consumption on CHD. Other potential mechanisms contributing to the cardio-protective effect of moderate alcohol consumption include anti-thrombotic downregulation of blood platelet function, as well as of the coagulation factors with concomitant fibrinolysis activation. [20]

However, several questions still remain controversial. In particular, we will discuss a number of open questions concerning the role of different alcoholic beverages, age and sex, confounding, former drinkers and study design.

\section{Alcohol: wine, beer or spirit?}

The influence of separate wine, beer, and spirit intake on heath outcomes has been examined in various conditions but with somewhat different results. 


\section{TALIAN JOURNAL OF PUBLIC HEALTH}

\section{Cardiovascular Disease}

Many epidemiological studies have explored the hypothesis that consuming alcohol in the form of wine might confer significant protection against CHD above that expected from its alcohol content. Wine might indeed conceivably show additional non-ethanol related beneficial effects. In fact, while the mechanisms underlying the effects of alcohol have been essentially limited to lipid metabolism and the haemostatic system, those related to wine consumption have been extended to specific antioxidant and vasorelaxant properties of its polyphenolic constituents. [21,22] In spite of a large number of experimental studies that confirm this hypothesis, epidemiological evidence of a greater effect of wine has not been definitely established. A metaanalysis from our group [6] tested such a hypothesis. The main outcome measure was wine or beer consumption versus the relative risk of morbidity and mortality from vascular disease. From 13 studies (209 418 subjects) only reporting relative risk of moderate (1-2 drinks a day) versus no wine consumption, the overall relative risk was 0.68 (95\% CI: 0.59-0.77; Figure 1). In addition, there was strong evidence from 10 studies (involving 176,042 persons) to support a J-shaped relationship between different amounts of wine intake and vascular risk. A statistically significant inverse association was found up to a daily intake of $150 \mathrm{ml}$ of wine. On the other hand, the overall relative risk of moderate beer consumption, measured in 15 studies (involving 208,036 persons), was 0.78 (95\%CI: $0.70-0.86$ ). More importantly, no significant relationship between different amounts of beer intake and vascular risk was found after performing a meta-analysis of 7 studies involving 136,382 persons.

\section{Total Mortality}

Epidemiological studies have shown that light and moderate wine drinking, in contrast with beer or spirit drinking, was associated with a dose-dependent decrease in all-cause mortality rates, attributable to a decrease in mortality not only from cardiovascular and cerebrovascular disease but also from other causes. A moderate intake of alcohol from beer was also associated with a lower risk of cardiovascular mortality, but did not reduce death from cancer. All-cause mortality was unchanged. [17] This finding suggests that wine might contain one or several substances that add to the beneficial effect of alcohol intake (e.g., both in vitro and in vivo resveratrol from grapes inhibits initiation, promotion, and progression of cancer). [23] Intake of beer and spirits was even reportedly associated with a dose-dependent increase in risk for death from cancer. [24]

Whether wine is better than beer or spirits remains however to be definitely established. Future studies addressing this issue should be of large sample size and carefully designed, because differences between beverages, if any, are expected to be limited and might reflect differences in the risk factor patterns among categories of drinkers rather than a true difference in CHD risk and total mortality.

Figure 1.

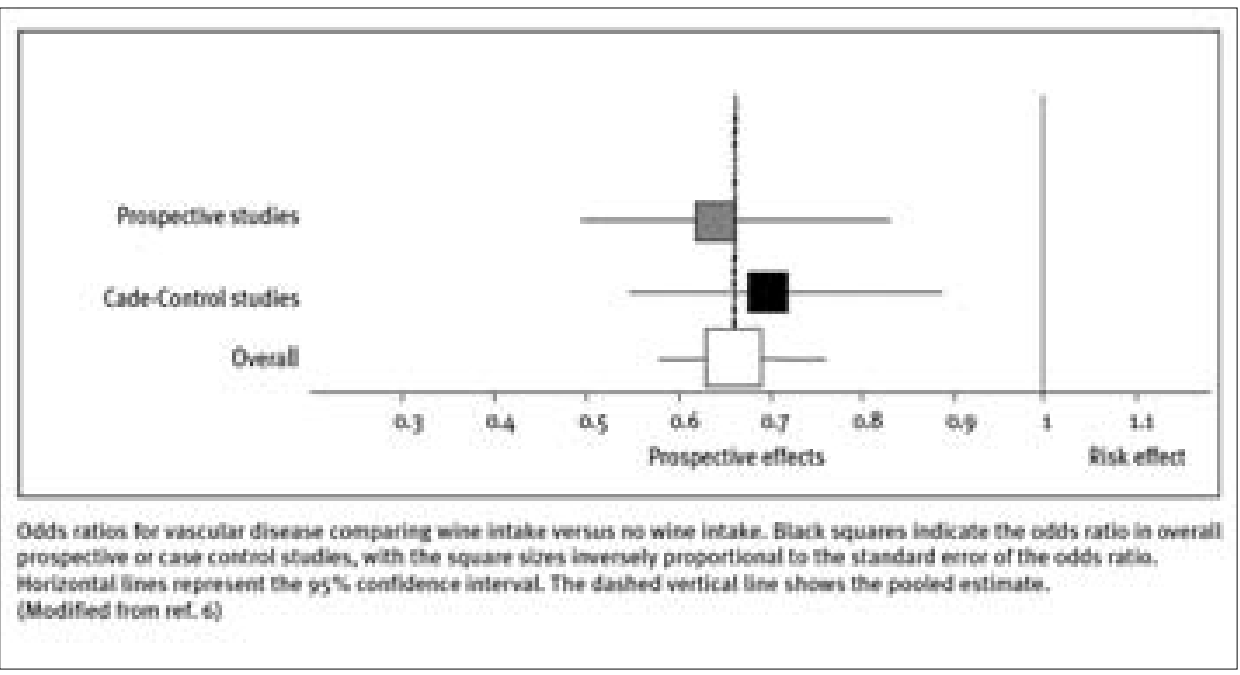




\section{TALIAN J O U RAL OF P U L I C H EALTH}

\section{Are the effects of alcohol different in males and females?}

\section{Cardiovascular Disease}

A possible gender difference in the protective effect of alcohol on vascular risk might exist and explain apparently controversial results in different epidemiological studies. In a report [25] on mortality and alcohol consumption in a large cohort in the USA (128 934 adults, 16431 deaths in 20 years of follow up), the protective effect of moderate alcohol intake against cardiovascular deaths was essentially restricted to women $(20 \%$ reduced risk versus a non significant $10 \%$ reduction in men). On the contrary, a meta-analysis of Corrao et al. [26] found a lower protective effect of alcohol consumption against coronary artery disease risk in women. We performed a metaanalysis of studies reporting "trend" (doseresponse) effect of alcohol intake on vascular risk, separately for males and females. [27] To allow meaningful comparisons between sexes, only studies that separately analyzed males and females, recruited from the same population, and that used the same categories of alcohol consumption for both sexes were selected, in all 12 such studies were identified (altogether 184791 persons were enrolled). Half were case-control and half were follow up studies. The end-points were cerebrovascular disease, coronary heart disease and peripheral arterial disease. "Dose-response" curves (relative risks at different amounts of alcohol intake) for each study were used to construct an average "trend" curve, for both men and women. The predicted dose-response models were very similar for both sexes. A maximum reduction $(\mathrm{RR}=0.80 ; 95 \% \mathrm{CI}$ : 0.57-1.12 in males and $\mathrm{RR}=0.66$; 95\%CI: $0.39-1.12$ in females; Figure 2) was predicted in both groups at 18-24 grams of ethanol per day, but statistical significance was only reached up to the amount of 12 grams of ethanol per day.At 12 grams of ethanol per day the relative risk was

Figure 2.

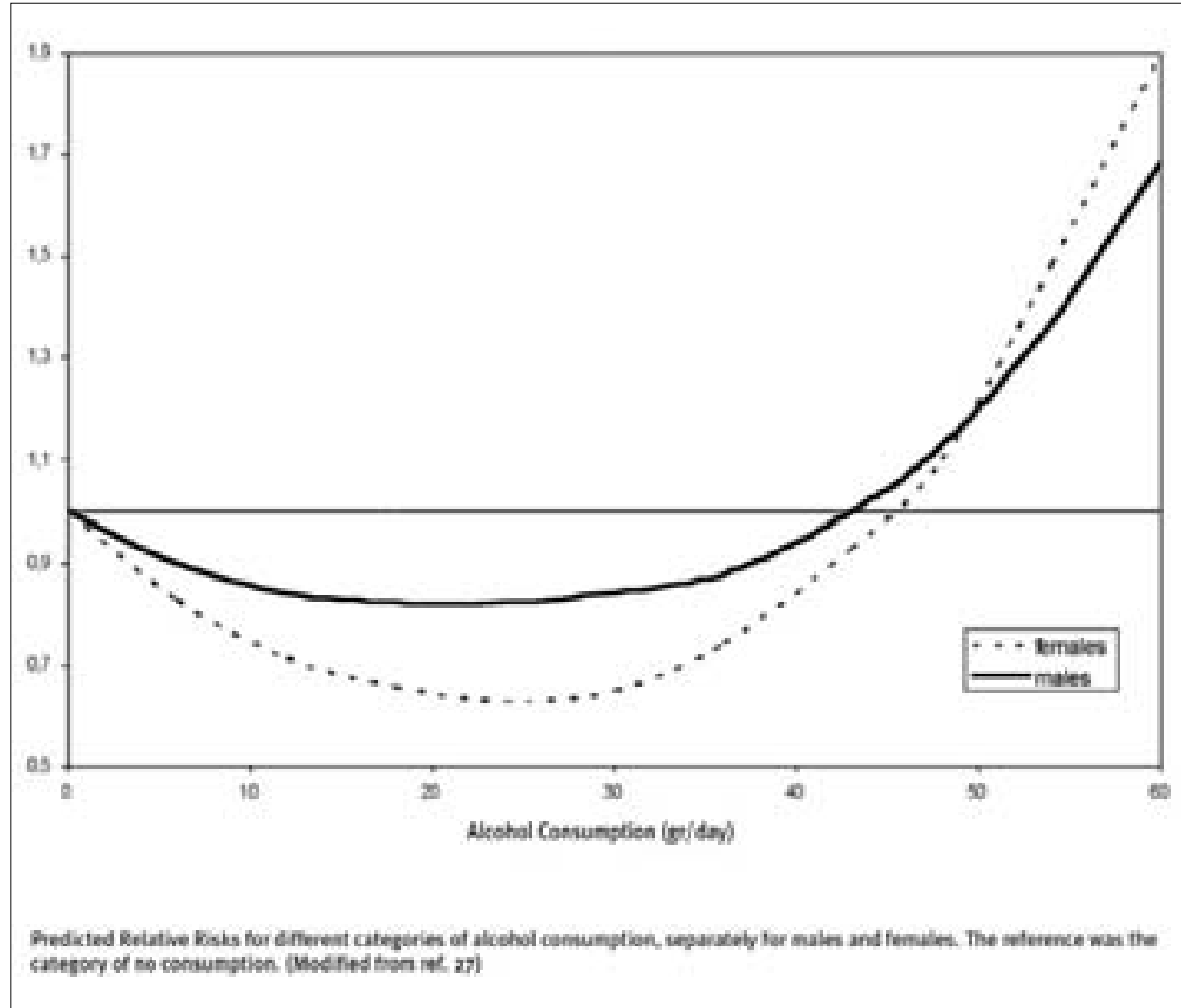




\section{TALIAN J O U R A L O F P U B L I C H EALTH}

0.83 (95\%CI: 0.69-0.99) in males and 0.72 (95\%CI: 0.54-0.96) in females.

The apparent greater effect of alcohol in women may be explained by several factors, such as increased HDL cholesterol levels or a better endothelial protective effects, or decreased insulin resistance; it is also known that equivalent alcohol doses result in higher blood levels of alcohol in women because the average size of a women is smaller, they have a higher proportion of body fat, as well as reduced gastric metabolism of ethanol. [28] One should also consider that men binge drink more frequently than women.As a different genderrelated protective role of alcohol was observed in our meta-analysis on wine consumption, [6] and in the study of Klatsky et al. [25] in which women were more likely to drink wine, we cannot exclude that sex-related differences might be linked not only to alcohol, but also to additional properties of specific wine components. $[21,22]$

\section{Total mortality}

In a recently completed meta-analysis including 34 prospective studies, [29] we pooled findings from about one million subjects and 100,000 deaths from any cause. The expected J-shaped relationship between total mortality and increasing amounts of alcohol consumed, showed that low to moderate consumption of alcohol ( $\leq 1 \mathrm{drink} / \mathrm{day}$ in females and $\leq 2 \mathrm{drink} /$ day in males) significantly reduces total mortality, while higher doses increase it. Our meta-analysis provides a definite confirmation of previous results, [30-32] in a set of data including 10 studies published after the year 2000 that could not be considered in less recent meta-analyses. Data were analysed using a recently proposed approach, [32] and special attention was given to differences between gender and to the possible effect of confounding. The predictive dose-response models were very similar for both sexes when the intake of alcohol was light, but they did differ with heavier intake (Table 1).

To better compare the effect of alcohol in males and females, a subsequent analysis was restricted to 13 studies that analysed males and females, recruited from the same population, separately. Our results indicate that total mortality is reduced in both men and women; however, the predicted protection in women disappears earlier than in men (Figure 3), which is in keeping with previous findings. [31] It means that women are more exposed to all causes of death at moderate to high level of alcohol consumption than men, probably due - as mentioned above - to different metabolism of alcohol and/or increasing risk of various cancers (e.g., breast cancer). [33] Women are known to metabolize ethanol differently, resulting in higher blood ethanol levels for a given intake. [34] They have a lower gastric alcohol dehydrogenase activity, and consequently a higher amount of alcohol reaches the liver directly, increasing the risk of liver disease.

\section{The influence of age}

A small number of prospective studies explored the influence of age on the relationship between

Table 1. A meta-analysis of 34 studies: general characteristics and main results

\begin{tabular}{|c|c|c|c|c|c|c|c|}
\hline \multirow[t]{2}{*}{ Subgroup } & \multirow[t]{2}{*}{$\begin{array}{c}\text { Number } \\
\text { of subjects }\end{array}$} & \multirow[t]{2}{*}{$\begin{array}{l}\text { Number } \\
\text { of deaths }\end{array}$} & \multicolumn{3}{|c|}{$\begin{array}{l}\text { Maximum } \\
\text { protection }\end{array}$} & \multirow{2}{*}{$\begin{array}{c}\begin{array}{c}\text { Reversion } \\
\text { Point* }\end{array} \\
\text { gr/day }\end{array}$} & \multirow[t]{2}{*}{$\begin{array}{l}\text { P for } \\
\text { difference }\end{array}$} \\
\hline & & & $\%$ & $99 \% \mathrm{Cl}$ & gr/day & & \\
\hline All & 1015835 & 94533 & 19 & $17-20^{\dagger}$ & 6 & 42 & - \\
\hline \multicolumn{8}{|l|}{ Level of adjustment } \\
\hline Not adjusted & 107653 & 7592 & 36 & $21-40$ & 10 & 68 & \\
\hline Adjusted (at least for age) & 908182 & 86941 & 17 & $15-18$ & 6 & 37 & $<0.0001^{\mathrm{a}}$ \\
\hline Adjusted for social status too & 414680 & 29560 & 18 & $15-21$ & 9 & 46 & $<0.0001^{\mathrm{b}}$ \\
\hline Adjusted for social status & 126712 & 7916 & 18 & $12-24$ & 6 & 30 & $0.0252^{c}$ \\
\hline Sex $^{\ddagger}$ & & & & & & & 0.0004 \\
\hline Females & 285490 & 13448 & 18 & $13-22$ & 5 & 18 & \\
\hline Males & 622692 & 73493 & 17 & $15-19$ & 6 & 38 & \\
\hline Type of reference group $^{\ddagger}$ & & & & & & & $<0.0001$ \\
\hline $\begin{array}{l}\text { With small and/or } \\
\text { formers drinkers }\end{array}$ & 247194 & 23937 & 23 & $20-26$ & 8 & 52 & \\
\hline $\begin{array}{l}\text { Without small and/or } \\
\text { formers drinkers }\end{array}$ & 660988 & 63004 & 16 & $14-18$ & 5 & 30 & \\
\hline
\end{tabular}

*The reversion point is defined as the dose of alcohol at which the protection against total mortality is no

longer statistically significant at $99 \%$ confidence level. ${ }^{\dagger} 95 \%$ confidence interval. ${ }^{\ddagger}$ In 29 adjusted studies.

${ }^{\text {aP }}$ for the comparison: adjusted $v s$ not adjusted; ${ }^{\mathrm{b}} \mathrm{P}$ for the comparison: adjusted for social status vs adjusted except for social status; ${ }^{\mathrm{P}} \mathrm{f}$ for the comparison: adjusted for social status and dietary factors vs adjusted for social status but not for dietary factors.

(Modified from ref. 29) 


\section{TALIAN J O U RAL OF P U L I C H EALTH}

Figure 3.

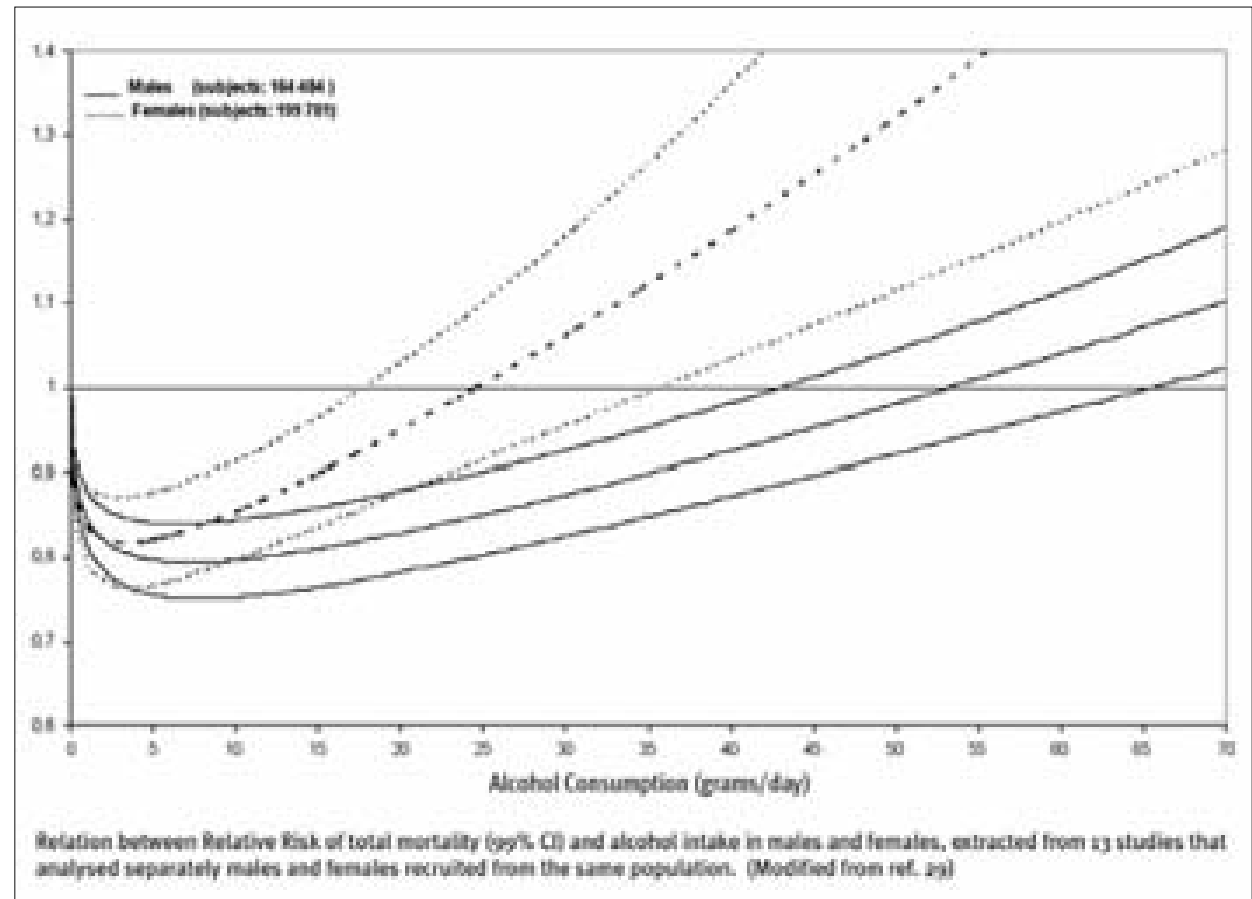

alcohol consumption and mortality. While in a cohort of young men, [35] no J-shaped curve was able to describe the association between alcohol and mortality, the J-shaped was confirmed in elderly cohorts.

In a study performed by Goldberg et al. [36], relating to the effects of alcohol in middle-aged and elderly men, trends for a beneficial effect of very light drinking on total cardiovascular and cancer mortality were apparent in both groups, with the exception of deaths due to stroke in the elderly.

As causes of death have different incidences for different age categories (e.g., cardiovascular deaths in young cohorts are lower than in the elderly) the effect of alcohol on health and disease may differ in different life periods.

\section{The effect of confounding}

A recent comment in The Lancet [37] has made the provocative statement that any coronary protection from moderate alcohol drinking is very small and unlikely to outweigh the known harms, mainly because of uncontrolled confounding by associated lifestyle factors. Quoting data obtained in the USA, [38] Jackson et al. [37] argue that drinkers have many healthier characteristics than non drinkers and thus have lower ischemic heart disease risk. While a similar observation was previously made in Denmark, it could not be confirmed in Italy, suggesting that association of moderate drinking with "protective" lifestyles does not necessarily occur in countries, where alcohol is a traditional beverage uniformly consumed across socio-economic status or education. [27,29,39] Moderate alcohol intake decreases the risk of cardiovascular disease, but the other side of the coin shows an increased risk of certain cancers, cirrhosis and death for accidents with increasing alcohol consumption. [33] Uncontrolled confounding, if present, could not substantially change the scenario; in our metaanalysis, [29] for example, 29 studies (908 182 subjects and 86941 deaths) showed adjusted relative risks at least for age; among them, 15 were adjusted for social status too, and 6 for social status and dietary markers. Table 1 shows relative risks of total mortality for different levels of adjustment. $P$ for difference was highly significant $(\mathrm{P}<0.0001)$, showing that part of heterogeneity is attributable to adjustment. While the protection decreased in adjusted studies (the maximum protection fell from $36 \%$ to $17 \%$, Table 1), it remained substantial and statistically significant. 


\section{ITALIAN JOURNAL OF PUBLIC HEALTH}

Moreover, as the observed difference between the five not adjusted and the 29 adjusted studies could not be only due to the level of adjustment these results coming from different studies- we compared adjusted or not unadjusted data from the same studies. Therefore, when adjusted and unadjusted data from the same studies were compared, the effect due to known confounders (age, smoking, social status, dietary factors) resulted in the reduction of the maximum protection from $19 \%$ to $16 \%$; for analogy, even in the pessimistic hypothesis that residual confounding would have a similar strength as the known one in lowering the protection, one can assume that the "real" (maximum) protection against total mortality associated with low consumption of alcohol would be largely higher than $10 \%$.

Although the protection of alcohol or wine decreases when data are adjusted, thus confirming the importance of confounding in assessing drinking effects, it would nevertheless remain in a range of undoubted public health value.

\section{The influence of study design}

A recent meta-analysis of 54 studies [40] on moderate alcohol and total mortality investigated the extent to which the inclusion of abstainers in control group affect the results. Most of the prospective studies - these Authors argue included as abstainers people who had reduced or stopped drinking owing to ageing or illness. The analysis of the studies judged to be error-free did not show any significant cardiovascular and total mortality protection, suggesting that the cardiovascular protection by moderate alcohol consumption may have been unduly overestimated.

However, in our meta-analysis on alcohol dosing and total mortality, [29] we tested the same hypothesis by comparing studies that used as reference group the category of no alcohol intake and/or excluded former drinkers with studies which, in contrast, included in the reference group occasional or former drinkers or people reporting low alcohol intake: the protection was indeed lower in the first studies, but remained statistically significant (Table 1).

\section{Alcohol consumption and stroke}

The relationship between alcohol consumption and stroke risk is controversial. Epidemiological studies and meta-analysis report a dose-dependent protective effect of alcohol (described by the classic J-shaped curve) on the risk of ischemic stroke owing to the anti-thrombotic effect of moderate alcohol consumption. [9] Otherwise, the same anti-thrombotic action may be associated with an increase in hemorrhagic stroke, although epidemiologic evidence is not clear.A meta-analysis of Corrao et al. [33] shows there was evidence of a not significant threshold beneficial effect against both ischemic and hemorrhagic stroke (53 and 28 $\mathrm{g} /$ day, respectively).

Reynolds et al. [9] affirms that heavy alcohol consumption increases the relative risk of stroke while light or moderate consumption may be protective against total and ischemic stroke.

Nonetheless, Mazzaglia et al. [41] conclude that there is insufficient evidence that high-to-moderate alcohol or wine intake have beneficial affects on stroke, and the risk of stroke in binge drinkers is reportedly higher than in regular drinkers.

It is necessary to better investigate the effects of alcohol consumption on cerebrovascular disease. Prevention of the risk of stroke in heavy and irregular alcohol drinkers should be the first health step.

\section{Alcohol consumption in the secondary prevention of cardiovascular disease}

The beneficial effect of moderate alcohol consumption on cardiovascular risk was mainly studied in healthy cohorts. Few studies show controversial data on the impact of moderate alcohol consumption in patients with previous cardiovascular disease.

Mukamal et al. [5] studied the effect of prior alcohol consumption on long-term mortality among early survivors of acute myocardial infarction and concluded that a moderate alcohol consumption in the year prior to myocardial infarction was associated with reduced mortality during follow-up. Muntwyler et al. [42] observed that men with myocardial infarction who consumed small to moderate amounts of alcohol had a lower total mortality, and de Lorgeril et al [43] confirmed that moderate alcohol consumption was associated with a significant reduction in the risk of cardiovascular complications. In contrast, a study of Shaper [44] et al. showed that regular light alcohol consumption (1-14 drinks per week) in men with established coronary heart disease was not associated with any significant benefit or deleterious effect for coronary or cardiovascular disease or all-cause mortality while higher levels of intake ( $>3$ drinks per day) were associated with increased mortality in men with previous myocardial infarction.

Further studies on secondary prevention of cardiovascular disease by moderate wine or alcohol intake are obviously needed. 


\section{Conclusion}

In conclusion, a review of the most recent literature confirms that light-to-moderate alcohol consumption is protective for cardiovascular morbidity and total mortality, both in males and females. In contrast, both heavy and binge drinkers have higher vascular and mortality risks than regular and moderate drinkers.

The influence of the type of alcohol consumption on health outcomes has been examined under various conditions; however, whether wine possesses some additional beneficial properties in respect to other alcoholic beverages, although highly suggestive, still remains to be definitely established.

Some currently controversial questions such as possible differential protection by alcohol and wine of men and women, methodological limitations of observational study design or the role of uncontrolled confounding have been discussed on the basis of recent extensive metaanalyses. It is concluded that the dose-response relationship between alcohol intake and mortality, invariably described by J-shaped curves, can be reasonably attributed to a variable combination of both real beneficial (at lower doses) and harmful (at higher doses) effects of alcohol or wine consumption.

Acknowledgements: Supported by a grant from the Italian Ministry of University, Research and Education: MIUR-Programma Triennale di Ricerca, Decreto $\mathrm{n}^{\circ} 1588$.

We are grateful to Professor Giuseppe La Torre, Catholic University, Rome, for fruitful discussion.

\section{References}

1) Maclure M. Demonstration of deductive meta-analysis: ethanol intake and risk of myocardial infarction. Epidemiol Rev. 1993; 15:328-51.

2) Rimm EB, Klatsky A, Grobbee D, et al. Review of moderate alcohol consumption and reduced risk of coronary heart disease: is the effect due to beer, wine, or spirits. BMJ 1996; 312:731-6. 3) Cleophas TJ. Wine, beer and spirits and the risk of myocardial infarction: a systematic review. Biomed Pharmacother 1999; 53:417-23.

4) Corrao G, Bagnardi V, Zambon A, et al. Exploring the doseresponse relationship between alcohol consumption and the risk of several alcohol-related conditions: a meta-analysis. Addiction 1999;94:1551-73.

5) Mukamal JK, Rimm EB.Alcohol's effects on the risk for coronary heart disease. Alcohol Research \& Health 2001;25:255-61.

6) Di Castelnuovo A, Rotondo S, Iacoviello L, et al. Meta-analysis of wine and beer consumption in relation to vascular risk. Circulation 2002; 105:2836-44.

7) Djoussè L, Ellison CR, Beiser A, et al. Alcohol consumption and risk of ischemic stroke: the Framingham study. Stroke 2002;33:907-12.

8) Mukamal JK, Conigrave KM, Mittleman MA, et al. Roles of drinking pattern and type of alcohol consumed in coronary heart disease in men. N Engl J Med 2003;348:109-18.
9) Reynolds K, Lewis BL, Nolen JDL, et al.Alcohol consumption and risk of stroke: a meta-analysis. JAMA 2003;289:579-88. 10) Stampfer MJ, Colditz GA, Willett WC, et al. A prospective study of moderate alcohol drinking and riskof diabetes in women. Am J Epidemiol 1998; 128:549-58.

11) Wannamethee SG, Camargo CA Jr, Manson JE, et al.Alcohol drinking patterns and risk of type 2 diabetes mellitus among younger women. Arch Intern Med 2003;63:1329-36.

12) Felson DT, Zhang Y, Hannan MT, et al. Alcohol intake and bone mineral density in elderly men and women.The Framingham Study Am J Epidemiol, 1995;142:485-92.

13) La Vecchia C, Decarli A, Ferraroni M, et al.Alcohol drinking and prevalence of self-reported gallstone disease in the 1983 Italian National Health Survey. Epidemiology 1994;5:533.

14) Klatsky AL, Armstrong MA, Friedman GD. Alcohol and mortality. Ann Intern Med 1992;117:646-54

15) Doll R, Peto R, Hall E, Wheatley K, Gray R. Mortality in relation to consumption of alcohol: 13 years' observations on male British doctors. BMJ 1994;309:911-18.

16) La Vecchia C.Alcohol in the Mediterranean diet; assessing risks and benefits. Eur J Cancer Prev 1995;4:3-5.

17) Renaud SC, Gueguen R, Schenker J, et al. Wine, beer, and mortality in middle-aged men from eastern France.Arch Intern Med 1999;159:1865-70.

18) Jackson VA, Sesso HD, Buring JE, et al.Alcohol consumption and mortality in men with preexisting cerebrovascular disease. Arch Intern Med 2003;163:1189-93.

19) Laatikainen T, Manninen L, Poikolainen K, et al. Increased mortality related to heavy alcohol intake pattern. J Epidemiol Community Health 2003;57:379-84

20) Rimm EB, Williams P, Fosher $K$, et al. Moderate alcohol intake and lower risk of coronary heart disease: meta-analysis of effects on lipids and haemostatic factors. BMJ 1999;319:1523-8.

21) Rotondo S, de Gaetano G. Protection from cardiovascular disease by wine and its derived products: epidemiological evidence and biological mechanisms. In: Visioli F, Simopoulos AP, eds. Characteristics of Mediterranean Diet. World Rev Nutr and Diet. Basel: Karger, 2000;87:90-113.

22) de Gaetano G, De Curtis A, Di Castelnuovo A, et al. Antithrombotic Effect of Polyphenols in Experimental Models: a Mechanism of the Reduced Vascular Risk by Moderate Wine Consumption. In: Das DK, Ursini F eds. Alcohol and wine in health and disease. Ann NY Acad Sci, New York; 2002:174-88.

23) Jang M, Cai L, Udeani GO et al. Cancer chemopreventive activity of resveratrol, a natural product derived from grapes. Science $1997 ; 275: 218-20$.

24) Grønbæk M, Becker U, Johansen D, et al. Type of alcohol consumed and mortality from all causes, coronary heart disease, and cancer. Ann Intern Med 2000;33:411-19.

25) Klatsky AL, Friedman GD, Armstrong MA, et al.Wine, liquor, beer, and mortality. Am J Epidemiol. 2003;158:585-95

26) Corrao G, Rubbiati L, Bagnardi V, et al.Alcohol and coronary heart disease: a meta-analysis. Addiction 2000;95:1505-23.

27) Grønbæk M, Di Castelnuovo A, Iacoviello L, et al. Wine, alcohol and cardiovascular risk: open issue. J Thromb Haemost 2004;2:2041-8.

28) Paoletti R, Klatsky AL, Poli A, et al. (Eds) Moderate alcohol consumption and cardiovascular disease. Dordrecht, The Netherlands: Kluwer Academic Publishers, , 2000.

29) Di Castelnuovo A, Costanzo S, Bagnardi V, Donati MB, Iacoviello L, de Gaetano G.Alcohol and Total Mortality in Males and Females: an Updated Meta-Analysis of Prospective Studies. 46th Annual Conference on Cardiovascular Disease Epidemiology and Prevention. AHA National Center, Phoenix 2006. (http://www.americanheart.org).

30) White IR,Altmann DR, Nanchahal K.Alcohol consumption and mortality: modelling risks for men and women at different ages. BMJ 2002;325:191.

31) Gmel G, Gutjahr E, Rehm J. How stable is the risk curve between alcohol and all-cause mortality and what factors 


\section{TALIAN J O U R A L OF P U B I C HEALTH}

influence the shape? A precision-weighted hierarchical metaanalysis. Eur J Epidemiol 2003;18:631-42.

32) Bagnardi V, Zambon A, Quatto P, Corrao G. Flexible metaregression functions for modeling aggregate dose-response data, with an application to alcohol and mortality. Am J Epidemiol.2004;159:1077-86.

33) Corrao G, Bagnardi V, Zambon A, La Vecchia C. A metaanalysis of alcohol consumption and the risk of 15 diseases. Prev Med 2004:38:613-9.

34) Ely M, Hardy R, Longford N T, Wadsworth MEJ. Gender differences in the relationship between alcohol consumption and drink problems are largely accounted for by body water. Alcohol.1999;34:894-902.

35) Andreasson S, Romelsjo A, Allebeck P.Alcohol, social factors and mortality among young men. Br J Addiction. 1991;86:877-87. 36) Goldberg RJ, Burchfiel CM, Reed DM, et al. A prospective study of the health effects of alcohol consumption in middleaged and elderly men: the Honolulu Heart Program. Circulation 1994;89:651-9

37) Jackson R, Broad J, Connor J, et al. Alcohol and ischaemic heart disease: probably no free lunch. The Lancet 2005;366:1911-2.
38) Naimi TS, Brown DW, Brewer RD, et al Cardiovascular risk factors and confounders among nondrinking and moderatedrinking U.S. adults. Am J Prev Med 2005;28:369-73.

39) de Gaetano G, Di Castelnuovo A, Costanzo S, et al.Alcohol, cardiovascular risk, and health: there is a window for benefits J Thromb Haemost. 2006;4:1156-7.

40) Fillmore KM, Kerr WC, Stockwell T et al. Moderate alcohol use and reduced mortality risk: Systematic error in prospective studies. Addiction Research and Theory 2006;1-31.

41) Mazzaglia G, Britton Annie R, Altmann DR et al. Exploring the relationship between alcohol consumption and no-fatal stroke: a systematic review. Addiction 2001;96:1743-56.

42) Muntwyler J, Hennekens $\mathrm{CH}$, Buring JE, et al. Mortality and light to moderate alcohol consumption after myocardial infarction. Lancet 1998;352:1882-5.

43) de Lorgeril M, Salen P, Martin JL et al. Wine drinking and risks of cardiovascular complications after recent acute myocardial infarction. Circulation 2002;106:1465-9.

44) Shaper AG, Wannamethee SG. Alcohol intake and mortality in middle aged men with diagnosed coronary heart disease Heart 2000;83:394-9. 
Chapter - Reference B

\section{ALCOHOL CONSUMPTION AND CARDIOVASCULAR RISK: AN EPI DEMI OLOGI CAL PERSPECTIVE}

Di Castelnuovo A, Costanzo S, Donati MB, Iacoviello L, de Gaetano G. Alcohol consumption and cardiovascular risk: an epidemiological perspective. Nutr Metab Cardiovasc Dis. 2007;17:561-4 



\section{Alcohol consumption and cardiovascular risk: An epidemiological perspective}

The association of moderate alcohol consumption and cardiovascular disease (CVD) has been consistently shown in many epidemiological studies [1-6]. In addition, several other, not primarily vascular diseases, are also known to occur less frequently in moderate drinkers than in non-drinkers [3,7-9]. As a consequence, total mortality was reduced in moderate drinkers [4,10-14] whereas excess drinking is unquestionably harmful [14].

Anti-atherogenic alterations in plasma lipoproteins, particularly an increase in high-density lipoprotein (HDL) cholesterol, are considered as the most plausible mechanism of the protective effect of alcohol consumption on CVD. Other potential mechanisms contributing to the cardio-protective effect of moderate alcohol consumption include anti-thrombotic down-regulation of blood platelet function coagulation factors with concomitant fibrinolysis activation [15]; in addition, experimental data on animal models showed that a chronic low dose of ethanol induced in the rat heart a chronic protective condition (preconditioning effect), independent of traditional lipid and coagulation risk factors [16].

In this issue of Nutrition, Metabolism and Cardiovascular Disease, Schroder et al. [17] report a case-control study of alcohol intake and nonfatal myocardial infarction (MI) among Spanish men. The authors conclude that moderate alcohol consumption, independent of both the type of alcoholic beverage and cardiovascular risk factors, was associated with non-fatal Ml risk reduction. These findings are in line with most of the current epidemiological evidence; nonetheless, the article from Schroder et al. [17] may be used as a proxy to discuss a number of questions that still remain controversial in the hot topic of alcohol and health.

\author{
Wine, beer or spirits?
}

Many epidemiological studies have explored the hypothesis that consuming alcohol in the form of wine might confer a significant protection against CVD above that expected from its alcohol content [18]. Wine might indeed conceivably show additional non-ethanol related beneficial effects. In fact, while the mechanisms underlying the effects of alcohol have been essentially limited to lipid metabolism, the haemostatic system and the so-called preconditioning effect, those related to wine consumption have been extended to specific antioxidant and vaso-relaxant properties of its polyphenolic constituents [19]. In spite of a large number of experimental studies that confirm this hypothesis, epidemiological evidence of a greater effect of wine has not been definitely established. A meta-analysis from our group [4] tested such a hypothesis. The overall protective effect against vascular disease was $32 \%$ (95\% Cl 23-41\%; 13 studies, 209,418 subjects) in favour of moderate (1-2 drinks a day) wine drinkers versus abstainers and somewhat inferior $(22 \%, 95 \% \mathrm{Cl}$ $14-30 \%$; 15 studies, 208,036 persons) in favour of moderate beer drinkers versus abstainers.

In addition, there was strong evidence from 10 studies (involving 176,042 persons) to support a $\mathrm{J}$-shaped relationship between different amounts of wine intake and vascular risk (a statistically significant inverse association was found up to a daily intake of $150 \mathrm{ml}$ of wine), whereas no significant relationship between different amounts of beer intake and vascular risk could be found.

Schroder et al. [17] observed that the risk of MI for wine and beer consumers was not different from mixed alcoholic beverage consumers, whereas preference for spirits increased the risk. In addition, they reported that an intake of spirit 
$>20$ g/day, at variance with wine or beer, was not significantly associated with MI.

Whether wine is better than beer or spirits remains therefore to be definitely established. Future studies addressing this issue should be of large sample size and carefully designed, because differences between beverages, if any, are expected to be limited and might reflect differences in the risk factor patterns among categories of drinkers rather than a true difference in CVD risk.

\section{The role of confounding}

Schroder et al. [17] correctly reported analyses of their data adjusted for some important covariates such as age, smoking and indicators of educational level and physical activity.

Some authors [20-21] investigated the hypothesis that any coronary protection from moderate alcohol drinking is unlikely to outweigh the known harms, mainly because of uncontrolled confounding by associated lifestyle factors; the hypothesis is that drinkers may have many healthier characteristics than non-drinkers and thus may have lower ischaemic heart disease risk. Mukamal et al. [22] recently addressed this important question in a large USA population, and found that moderate drinking is only modestly associated with healthier lifestyle characteristics, the association being lower after adjustment for race and education. Interestingly, Mukamal et al. [22] reported that physical activity too is related to healthier characteristics and that moderate drinking is not unique in this respect, at least when compared to physical activity, which definitely reduces cardiovascular risk.
We paid special attention to the possible effect of confounding in a very recent meta-analysis including 34 prospective studies on alcohol and mortality [14]. We pooled findings from more than one million subjects and about 95,000 deaths from any cause. The expected J-shaped relationship between total mortality and increasing amounts of alcohol consumed, showed that low to moderate consumption of alcohol ( $\leq 1$ drink/day in women and $\leq 2$ drinks/ day in men) significantly reduces total mortality, while higher doses increase it. Twenty-nine studies showed adjusted relative risks at least for age; among them, 15 were also adjusted for social status, and six for social status and dietary markers. Fig. 1 shows relative risks of total mortality for different levels of adjustment. $P$ for difference was highly significant $(P<0.0001)$, showing that part of the heterogeneity is attributable to adjustment. However, while the protection decreased in adjusted studies (the maximum protection fell from $36 \%$ to $17 \%$ ), it remained substantial and statistically significant. Moreover, as the observed difference between the five unadjusted and the 29 adjusted studies could not be only due to the level of adjustment (these results coming from different studies) we compared adjusted or unadjusted data from the same studies. In this case the effect due to known confounders (age, smoking, social status, dietary factors) led to the reduction of the maximum protection from $19 \%$ to $16 \%$; for analogy, even in the pessimistic hypothesis that residual confounding would have a similar strength as the known one in lowering the protection, one can assume that the "real" (maximum) protection against total mortality associated with low consumption of alcohol would be largely higher than $10 \%$.

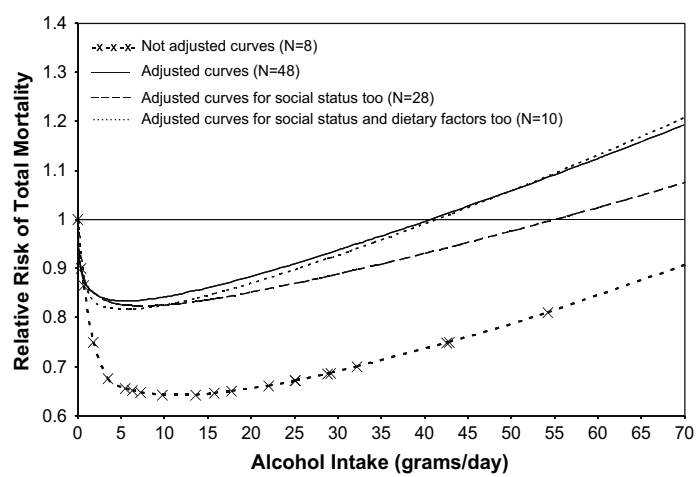

Figure 1 Relative risk of total mortality and alcohol intake according to the level of adjustment (adapted from [14]). 
Although the protection from alcohol or wine decreases when data are adjusted, thus confirming the importance of confounding in assessing drinking effects, it remains in a range of undoubted public health value $[14,23,24]$.

\section{The optimal study design}

A meta-analysis of 54 studies [25] on moderate alcohol and total mortality investigated the degree to which the inclusion of abstainers in a control group influences the results. Most of the prospective studies analysed-these authors argue-were plagued by the error of including in the control group people who had stopped drinking owing to illness. The analysis of the studies judged to be error-free did not show any significant cardiovascular protection, suggesting that the cardiovascular protection by moderate alcohol consumption may have been overestimated.

However, in our meta-analysis on alcohol dosing and total mortality [14], we tested the same hypothesis by comparing studies that used as a reference group the category of no alcohol intake and/ or excluded former drinkers with studies which, in contrast, included in the reference group occasional or former drinkers or people reporting low alcohol intake: the protection was indeed lower in the first studies, but remained statistically significant.

The fact that in the study of Schroder et al. [17] former drinkers were included in the control group should be considered a limitation of the study, explaining, at least in part, the somewhat increased magnitude of the positive association between alcohol intake and MI.

\section{Conclusions}

In conclusion, the results from Schroder et al. [17] and a review of the most recent literature confirms that light-to-moderate alcohol consumption is protective for cardiovascular morbidity and total mortality, in the context of a healthy dietary pattern [26].

Whether wine possesses some additional beneficial properties with respect to other alcoholic beverages is highly suggestive but remains to be definitely established.

Methodological limitations of observational study design, the role of uncontrolled confounding and the optimal choice of the referent group are important issues to be considered in future studies on alcohol and health.

\section{Acknowledgements}

The support of an ERAB grant (ref EA 04 07) is gratefully acknowledged.

\section{References}

[1] Maclure M. Demonstration of deductive meta-analysis: ethanol intake and risk of myocardial infarction. Epidemiol Rev 1993;15:328-51.

[2] Rimm EB, Klatsky A, Grobbee D, Stampfer MJ. Review of moderate alcohol consumption and reduced risk of coronary heart disease: is the effect due to beer, wine, or spirits. BMJ 1996;312:731-6.

[3] Corrao G, Bagnardi V, Zambon A, Arico S. Exploring the dose-response relationship between alcohol consumption and the risk of several alcohol-related conditions: a meta-analysis. Addiction 1999;94:1551-73.

[4] Di Castelnuovo A, Rotondo S, lacoviello L, Donati MB, de Gaetano G. Meta-analysis of wine and beer consumption in relation to vascular risk. Circulation 2002;105:2836-44.

[5] Mukamal JK, Conigrave KM, Mittleman MA, Camargo Jr CA, Stampfer MJ, Willett WC, et al. Roles of drinking pattern and type of alcohol consumed in coronary heart disease in men. N Engl J Med 2003;348(109):118.

[6] Reynolds K, Lewis B, Nolen JD, Kinney GL, Sathya B, He J. Alcohol consumption and risk of stroke: a meta-analysis. JAMA 2003;289:579-88.

[7] Stampfer MJ, Colditz GA, Willett WC, Manson JE, Arky RA, Hennekens $\mathrm{CH}$, et al. A prospective study of moderate alcohol drinking and risk of diabetes in women. Am J Epidemiol 1988;128:549-58.

[8] Corella D. Gene-alcohol interactions in the metabolic syndrome. Nutr Metab Cardiovasc Dis 2006 [Sep 25 E-pub ahead of print].

[9] La Vecchia C, Decarli A, Ferraroni M, Negri E. Alcohol drinking and prevalence of self-reported gallstone disease in the 1983 Italian National Health Survey. Epidemiology 1994;5:533.

[10] Klatsky AL, Armstrong MA, Friedman GD. Alcohol and mortality. Ann Intern Med 1992;117:646-54.

[11] Doll R, Peto R, Hall E, Wheatley K, Gray R. Mortality in relation to consumption of alcohol: 13 years' observations on male British doctors. BMJ 1994;309:911-8.

[12] La Vecchia C. Alcohol in the Mediterranean diet; assessing risks and benefits. Eur J Cancer Prev 1995;4:3-5.

[13] Renaud SC, Gueguen R, Siest G, Salamon R. Wine, beer, and mortality in middle-aged men from eastern France. Arch Intern Med 1999;159:1865-70.

[14] Di Castelnuovo A, Costanzo S, Bagnardi V, Donati MB, lacoviello L, de Gaetano G. Alcohol dosing and total mortality in males and females: an updated meta-analysis of 34 prospective studies. Arch Intern Med 2006;166: 2437-45.

[15] Rimm EB, Williams P, Fosher K, Criqui M, Stampfer MJ. Moderate alcohol intake and lower risk of coronary heart disease: meta-analysis of effects on lipids and haemostatic factors. BMJ 1999;319:1523-8.

[16] Guiraud A, de Lorgeril M, Boucher F, Berthonneche C, Rakotovao A, de Leiris J. Cardioprotective effect of chronic low dose ethanol drinking: insights into the concept of ethanol preconditioning. J Mol Cell Cardiol 2004; 36:561-6. 
[17] Schroder H, Masabeu A, Marti MJ. Myocardial infarction and alcohol consumption: a population-based case-control study. Nutr Metab Cardiovasc Dis 2007;17(8):609-15

[18] Burns J, Crozier A, Lean ME. Alcohol consumption and mortality: is wine different from other alcoholic beverages? Nutr Metab Cardiovasc Dis 2001;11:249-58.

[19] de Gaetano G, De Curtis A, Di Castelnuovo A, Donati MB, lacoviello L, Rotondo S. Antithrombotic effect of polyphenols in experimental models: a mechanism of reduced vascular risk by moderate wine consumption. In: Das DK, Ursini F, editors. Alcohol and wine in health and disease. Ann N Y Acad Sci 2002;957:174-88.

[20] Jackson R, Broad J, Connor J, Wells S. Alcohol and ischaemic heart disease: probably no free lunch. Lancet 2005; 366:1911-2.

[21] Naimi TS, Brown DW, Brewer RD, Giles WH, Mensah G, Serdula MK, et al. Cardiovascular risk factors and confounders among non-drinking and moderate-drinking U.S. adults. Am J Prev Med 2005;28:369-73.

[22] Mukamal KJ, Ding EL, Djousse L. Alcohol consumption, physical activity, and chronic disease risk factors: a population-based cross-sectional survey. BMC Public Health 2006; $6: 118$.

[23] de Gaetano G, Di Castelnuovo A, Costanzo S, Donati MB, lacoviello L. Alcohol, cardiovascular risk, and health: there is a window for benefits. J Thromb Haemost 2006;4: 1156-7.

[24] Villegas R, Salim A, O'Halloran D, Perry IJ. Alcohol intake and insulin resistance. A cross-sectional study. Nutr Metab Cardiovasc Dis 2004;14:233-40.
[25] Fillmore KM, Kerr WC, Stockwell T, Chikritzhs T, Bostrom A. Moderate alcohol use and reduced mortality risk: systematic error in prospective studies. Addiction Res Theory 2006;14:1-31.

[26] Pala V, Sieri S, Masala G, Palli D, Panico S, Vineis P, et al. Associations between dietary pattern and lifestyle, anthropometry and other health indicators in the elderly participants of the EPIC-Italy cohort. Nutr Metab Cardiovasc Dis $2006 ; 16: 186-201$.

Augusto Di Castelnuovo Simona Costanzo

Maria Benedetta Donati

Licia lacoviello

Giovanni de Gaetano*

Research Laboratories, "John Paul II" Centre for

High Technology Research and Education in

Biomedical Sciences, Catholic University, 86100 Campobasso, Italy

*Corresponding author. Tel.: +39 0874312 280; fax: +390874312 710 .

E-mail address: gdegaetano@rm.unicatt.it

(G. de Gaetano)

30 January 2007 
Chapter - Reference C

ALCOHOL CONSUMPTION AND CARDIOVASCULAR RISK: MECHANISMS OF ACTION AND EPIDEMIOLOGIC PERSPECTIVES

Di Castelnuovo A, Costanzo S, di Giuseppe R, de Gaetano G, Iacoviello L. Alcohol consumption and cardiovascular risk: mechanisms of action and epidemiologic perspectives. Future Cardiol. 2009 Sep;5(5):467-77. Review 



\section{Alcohol consumption and cardiovascular risk: mechanisms of action and epidemiologic perspectives}

\section{Augusto Di Castelnuovo, Simona Costanzo, Romina di Giuseppe,} Giovanni de Gaetano \& Licia lacoviello'

Author for correspondence: Laboratory of Genetic \& Environmental Epidemiology 'RE ARTU' Research Laboratories, 'John Paul II' Center for High Technology Research \& Education in Biomedical Sciences. Catholic University, Largo Gemelli 1.86100 Campobasso, Italy = Tel. : +39 874312274 m Fax: +39874312710 licia iacoviello@rm unicattit

An inverse association between moderate alcohol intake and cardiovascular risk, in particular coronary disease and ischemic stroke, has been demonstrated in many epidemiologic studies. In addition, several not primarily vascular diseases are also known to occur less frequently in moderate drinkers than in nondrinkers, whereas excess drinking is unquestionably harmful. As a consequence, strong concern exists on the possibility that at any dosage the benefit of alcohol could overcome its harmful effects. Alcohol affects several biochemical factors that have potential cardioprotective benefits, including lipids, platelet aggregation, fibrinogen, tissue-plasminogen activator, plasminogen-activator inhibitor and omega-3 fatty acids. Wine possibly acts through mechanisms that might provide additional cardiovascular benefits. Mechanisms supporting the protective effect of moderate alcohol intake against cardiovascular disease, and epidemiologic evidence concerning the relationship between alcohol dosing and vascular and

all-cause mortality are discussed in this review.

There is strong and consistent epidemiological evidence of an inverse association between moderate alcohol consumption and cardiovascular disease (CVD), in particular coronary disease and ischemic stroke [1-6]. In addition, several not primarily vascular diseases are also known to occur less frequently in moderate drinkers than in nondrinkers [3,7-14], whereas excess drinking is unquestionably harmful [14]. Although the protective effect of moderate alcohol consumption on atherothrombotic vascular disease is generally widely accepted by the scientific community, some concern exists, particularly at regulatory agencies level, on the possibility that at any dosage the harmful effects of alcohol could overcome its benefit $[15,16]$. The relationship between alcohol and vascular risk or total mortality has been repeatedly depicted as a J-shaped curve: the risk is lower at light-to-moderate alcohol consumption, but increases at higher doses [1,4,17-20] However, if low alcohol intake is inversely related to CVD, the other side of the coin shows an increased risk of certain cancers, cirrhosis and death from accidents associated with increasing alcohol consumption [21].

After wine intake was suggested as a possible explanation for the lower than expected CVD mortality rates in France [22], many studies have dealt with the question whether wine might offer a greater protection, most likely related to its nonalcoholic components [23].

The aim of this article is to review possible mechanisms supporting the protective effect of moderate intake of alcohol (and especially wine) against $\mathrm{CVD}$ and selected epidemiologic evidence concerning the relationship of alcohol dosing with vascular risk and all-cause mortality.

\section{Mechanisms of action of alcohol}

Alcohol affects several vascular and biochemical factors that have potential cardioprotective benefits. An increase in HDL cholesterol (HDL-C) levels, decrease in platelet aggregation via inhibition of prostaglandin synthesis and changes in fibrinogen, tissue-plasminogen activator ( $t-P A)$, and plasminogen-activator inhibitor (PAI)-1 levels, are thought to represent major mechanisms to reduce the risk for CVD events [24]. Alcohol also inhibits the development of atherosclerotic lesions in a dose-dependent fashion in animal and human studies [22-26].

\section{Increased HDL levels}

The concentration of plasma HDL and its sub-fraction HDL3 mass decreased in temporary abstainers, but not in moderate alcohol

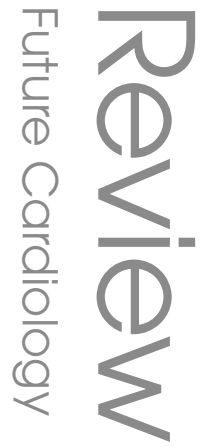

\section{Keywords \\ alcohol $=$ meta-analysis $=$ total mortality = vascular risk = wine}

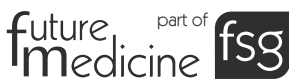


drinkers [25]. When the abstainers group restarted drinking, there were increased levels in HDL cholesterol and HDL3 mass, but no change in HDL2 mass. In stratified and multivariate regression analyses [26], HDL-C levels increased with increased frequency of consumption of beer, wine and spirits in a representative sample of the US adult population of whites and blacks of both sexes. After adjustment for common factors, there were higher age-adjusted HDL-C levels with increasing reported quantities of alcohol consumed. In a study including 4918 Spanish men and women aged 25-74 years, total alcohol intake was significantly associated with increased HDL-C in both sexes [27].

The increase of HDL associated with alcohol has been considered one of the main mechanisms of alcohol action for a long time. However, recent data indicate that increased HDL-C through medicaments has no effect on vascular risk [28,29]. By inference, the association of alcohol with elevation of HDL per se - without considering the effects on its function - appears nowadays of reduced value.

Conversely, reduction in LDL cholesterol (LDL-C) still appears to be the primary target for lipid-modifying interventions [29]. In particular, oxidized LDL may play a major role in atherosclerosis and cardiovascular disease and is a commonly used marker for oxidative damage [30]. As will be discussed in the following sections, consumption of alcohol (especially in the form of wine), is associated with a reduction of the LDL susceptibility to both oxidation and aggregation. In addition, alcohol-induced elevations in HDL may enable the transport of LDL-C back to the liver for reprocessing, reducing the amount of cholesterol offered for endothelial activation and atheroma formation [30]. As a consequence, we can infer that moderate alcohol intake promotes reduction of the toxic effects of elevated LDL.

\section{Antithrombotic properties}

An explanation for the 'French paradox' [22] involved inhibition of platelet aggregation by alcohol, at consumption levels associated with reduced risk of coronary heart disease (CHD). Alcohol would act through inhibition of prostaglandin synthesis, similar to aspirin. Subsequent studies have demonstrated that several polyphenols, mainly contained in red wine rather than alcohol, are able to inhibit platelet arachidonic acid metabolism and biosynthesis of thromboxane $\mathrm{A}_{2}$, a potent platelet aggregation inducer and a vasoconstrictor [31-34].
Moderate alcohol consumption may affect fibrinogen concentration, platelet aggregation, t-PA and PAI-1 [35] while a positive association between moderate alcohol intake and plasma concentration of endogenous t-PA was independent of HDL-C levels [36].

In a study conducted on 3158 men aged 60-79 years without history of acute myocardial infarction, stroke or diabetes, a positive doseresponse relationship was observed between total alcohol consumption and t-PA antigen and an inverse dose-response relationship between alcohol intake and fibrinogen levels [37].

\section{Antiatherogenic properties}

Antiatherogenic properties of alcohol were described in animal and human studies. Moderate alcohol consumption is independently associated with less coronary atherosclerosis in humans [38]. In a study on 1676 men and 465 women undergoing coronary angiography [39], multivariate analyses demonstrated that alcohol consumption was associated with a lower percentage of lumen narrowing in the main coronary vessels, suggesting that moderate alcohol consumption is independently associated with reduced coronary atherosclerosis. In LDLR2/2 mice, alcohol impeded early atherosclerosis in a dose-dependent manner [40].

\section{Alcohol consumption \& omega-3 \\ polyunsaturated fatty acids}

More recently, an original mechanism to explain the protective effect of alcohol has been proposed by de Lorgeril and colleagues: the 'fish-like effect of moderate wine drinking' hypothesis [41]. Omega-3 fatty acids ( $\omega 3$ FA) consumption reduces risk of sudden cardiac death in humans [42,43] and induces myocardial protection in animal experiments [44]. The Lyon Diet Heart Study (a cross-sectional study on French men with CHD), demonstrated that moderate wine consumption was associated with higher levels of 'marine' $\omega 3 \mathrm{FA}$ in plasma [41] independent from the dietary intake of specific plant and marine $\omega 3$. The authors concluded that the protection resulting from moderate alcohol drinking may be mediated through increased $\omega 3$ FA. These results were confirmed in a recent study on experimental animals by the same research group [45]. They showed that moderate alcohol consumption was associated with increased levels of $\omega 3$ FA both in plasma and in red blood cell membranes.

The association of alcohol consumption with $\omega 3 \mathrm{FA}$ in both plasma and red blood cells was 
also separately studied in women and men enrolled in Italy, Belgium and England, in the framework of the IMMIDIET study [46]. Eicosapentanoic acid (EPA), docosahexanoic acid (DHA) and EPA + DHA in plasma, and $\mathrm{EPA}$ and EPA + DHA in red blood cells were all positively associated with alcohol intake. The association was stronger in women than in men. Again the association between alcohol intake and $\omega 3$ FA was independent from fish intake and other possible confounders related to lifestyles associated with alcohol drinking.

In the whole population, the association between different beverages (wine or beer) and levels of $\omega 3 \mathrm{FA}$ was also investigated; in wine drinkers, the association was confirmed both in plasma and red blood cells, while in beer and spirits drinkers only a weak association with DHA in plasma could be found [47].

\section{Mechanisms of action of wine}

Wine possibly acts through mechanisms that might provide additional cardiovascular benefits than that provided by ethanol. Red wine contains many substances such as phenols and tannins that influence LDL oxidation, platelet aggregation, endothelial function and smooth muscle cell proliferation [48]. It also contains a wide variety of polyphenols, including phenolic acids, trihydroxy stilbenes (resveratrol) and flavonoids (catechin epicatechin and quercetin) [49]. Some of these molecules inhibit lipoprotein oxidation, promote nitric oxide formation by vascular endothelium, inhibit thromboxane $\mathrm{A}_{2}$ biosynthesis in platelets and leukotriene biosynthesis in neutrophils, and regulate lipoprotein production and secretion. These actions occur through the inhibition of various enzymes such as phospholipase $A_{2}$, cyclooxygenases, phosphodiesterase and several protein kinases involved in cell signaling.

\section{Antioxidant properties}

Atherosclerotic plaque formation involves lipoprotein oxidation inside arterial walls. Resveratrol attenuated oxidized-LDL-induced cytotoxicity, apoptotic features, generation of reactive oxygen species and intracellular calcium accumulation [50].

A small group of patients with acute coronary syndrome undergoing percutaneous coronary interventions was randomized to red wine (250 $\mathrm{ml}$ daily) or control (abstinence from any alcoholic beverage). While the endotheliumdependent/independent dilation ratio significantly improved after 2 months, in both groups, wine drinking only demonstrated benefits on parameters of oxidative stress [51].

The effects of moderate red wine consumption on antioxidant status were also investigated in a randomized controlled study on 20 healthy volunteers [52]. Total plasma phenolic concentrations increased significantly after 2 weeks of daily moderate red wine consumption. The maximum concentrations of conjugated dienes and thiobarbituric acid-reactive substances in $\mathrm{Cu}$-oxidized LDL were reduced, but HDL-C concentrations increased after red wine consumption.

\section{Antithrombotic properties}

Platelet aggregation plays a crucial role in atherosclerosis and the progression of coronary artery disease (CAD). Drugs that attenuate platelet aggregation, such as aspirin, are protective for ischemic heart disease [53]. Although alcohol by itself inhibits platelet function or potentiates platelet inhibitory drugs [54], red wine inhibits human platelet aggregation, possibly owing to its polyphenolic compounds, resveratrol and quercitin having the greatest effects [55]. Aggregation of human platelets and the biosynthesis of thromboxane $\mathrm{A}_{2}$ are strongly inhibited by red wine [56], while quercitin potentiates prostaglandin I2 inhibitory effects by increasing platelet levels of cAMP. In human volunteers, moderate red wine consumption for a few weeks decreased platelet aggregation [56] and plasma thromboxane $\mathrm{B}_{2}$ concentration [52]. As the mechanism of platelet inhibition by red wine might be different from that of other platelet-inhibiting substances, the effect of its moderate consumption in the prevention of CAD might be additive to that of aspirin or other drugs. According to this hypothesis, Rotondo and colleagues demonstrated that transresveratrol further inhibited human platelet aggregation already inhibited by aspirin [57,58]. Trans-resveratrol also prevented polymorphonuclear leukocyte (PMN) homotypic aggregation and formation of mixed cell conjugates between PMN and platelets. Transresveratrol thus appears to interfere with the release of inflammatory mediators by activated PMN and downregulates adhesion-dependent thrombogenic PMN function, providing further biological plausibility to the protective effect of red wine consumption against CHD.

Tissue factor (TF) expression by endothelial and mononuclear cells from healthy donors, challenged in vitro by different stimuli, was inhibited in a dose-dependent fashion by resveratrol or quercetin [59]. Both polyphenols strongly reduced TF mRNA in both cell types, by reducing nuclear binding activity of the transacting 
factor $\mathrm{c}-\mathrm{Rel} / \mathrm{p} 65$, which was induced by the agonists. The diminished c-Rel/p65 activity was, in turn. dependent upon inhibition of degradation of the c-Rel/p65 inhibitory protein I $\mathrm{B} B \alpha$. These findings provide an additional molecular basis to explain the protective activity of red wine against cardiovascular disease.

At variance with resveratrol and quercetin, little is known on the platelet effect of gallic acid, a polyphenol structurally similar to salicylic acid, the major aspirin metabolite. These three polyphenols shared a similar platelet antioxidant activity, although resveratrol and quercetin, but not gallic acid, inhibited platelet aggregation and platelet thromboxane biosynthesis [60]. In interaction experiments, gallic acid, similarly to salicylic acid, blunted the inhibitory effect on platelet function of aspirin and the other two polyphenols. The latter, in contrast, potentiated the antiplatelet effect of low concentrations of aspirin. Molecular modeling studies suggested that all three polyphenols, similar to salicylate, formed into stable COX-1 channel complexes with slightly different interaction geometries, compatible with the functional results mentioned above. The observed polyphenol-aspirin and polyphenol-polyphenol interactions at the platelet level might be relevant to the healthy value of dietary intake of polyphenols and to the observed variable response of both healthy individuals and patient to aspirin treatment.

\section{Anti-inflammatory properties}

An association between alcohol consumption and concentrations of high-sensitivity C-reactive protein (hs-CRP) and leukocyte count was reported in 781 men and 995 women aged 18-88 years in former West Germany [61] Among men, alcohol consumption demonstrated a U-shaped association with mean values of hs-CRP and leukocyte count in multivariate analysis. In women, the associations were less strong. Nondrinkers and heavy drinkers had higher hs-CRP concentrations than moderate drinkers, suggesting an anti-inflammatory action of moderate alcohol consumption.

Estruch and colleagues performed a randomized, crossover, single-blinded trial to evaluate the effects of wine and gin on inflammatory biomarkers of atherosclerosis [62]. A total of 40 healthy men (mean age: 38 years) consumed $30 \mathrm{~g}$ ethanol per day as either wine or gin for 28 days. After either gin or wine consumption, plasma fibrinogen and cytokine IL-10 significantly decreased. The expression of cell inflammatory markers such as LFA-1, Mac-1,
VLA-4 and MCP-1 decreased significantly after wine, but not after gin. Wine also reduced the serum concentrations of hs-CRP, VCAM-1 and ICAM-1. Although both wine and gin demonstrated anti-inflammatory effects, wine had the additional effect of decreasing hs-CRP, as well as monocyte and endothelial adhesion molecules.

In the same group of volunteers, Badia and colleagues found that TNF- $\alpha$-induced adhesion of monocytes to endothelial cells was virtually abolished after red wine consumption, but was only partially reduced after gin consumption, supporting the anti-inflammatory properties of alcohol and in particular of red wine [63].

\section{Antiatherogenic properties}

Phenolic compounds in red wine may also have antiatherogenic properties. In a study on ApoEdeficient mice [64], smaller atherosclerotic lesion areas and reduced susceptibility to oxidation of LDL were observed after either red wine or polyphenol chronic consumption, as compared with placebo. The susceptibility of LDL to aggregation was also reduced.

In an in vivo study on hypercholesterolemic rabbits, dealcoholized or whole red wine showed a cardiovascular protective effect as red wine without affecting plasma lipid levels [65], a finding similar to that reported in hypercholesterolemic rats [66]. Human studies also suggest that the consumption of red wine [67] or alcohol-free red wine $[68,69]$ leads to a significant increase in serum antioxidant activity and in the susceptibility of LDL to oxidation in vivo, limiting the extent of atheroma formation [69]. However, to date, the results of large randomized clinical trials assessing the use of antioxidant therapies (mainly vitamin E, rather than winederived polyphenols) to reduce cardiovascular events have been disappointing [70].

\section{Mechanisms by which alcohol may increase cardiovascular risk}

Alcohol consumption is associated with several adverse effects; among them, fetal alcohol syndrome, liver cirrhosis, pancreatitis, certain cancers, cardiomyopathy, hypertriglyceridemia, hypertension, hemorrhagic stroke, overweight, alcohol intoxication and dependence [71,72]. The large majority of these detrimental effects arise at heavy consumption levels or as a consequence of irregular (binge) drinking [72,73]. Blood pressure levels and prevalence of hypertension linearly increase with alcohol consumption [21]. Alcohol intake is the second main cause of hyperlipidemia in the population [74]. Overweight subjects 
should limit or avoid alcohol to reduce unnecessary energy intake. Increased clotting and a reduced threshold for ventricular fibrillation after heavy drinking occasions are the main mechanisms explaining the negative effects of heavy drinking on CVD [73].

\section{Epidemiologic evidence}

In spite of the fact that the healthy effect of moderate intake of alcohol is by now well accepted [75,76], important issues remain to be discussed regarding the relationship between alcohol and CVD. Among these are, the possible effect of confounding factors such as the differences in types of alcoholic beverages, the optimal amount of alcohol intake, the individual or environmental modulation of the alcohol-related effect and the pattern of drinking.

Does lifestyle confounding play a role? It has been argued that uncontrolled lifestyle factors play a major role in the association between moderate alcohol drinking and coronary protection [15], based on results demonstrated that drinkers have many healthier characteristics than nondrinkers and thus have lower ischemic heart disease risk [77]. However Mukamal et al. demonstrated that the differences between abstainers and drinkers were attenuated, eliminated or reversed by additional adjustment for sociodemographic factors [78]. Moreover, a similar pattern was apparent for physical activity, a widely recommended behavior for prevention of cardiovascular disease. Despite this fact, concerns regarding the possibility of confounding factors in studies on physical activity have been largely overshadowed.

\section{Is wine different from beer or liquor?}

Many epidemiologic studies have explored the hypothesis that consuming alcohol in the form of wine might confer a protection against $\mathrm{CHD}$ above that expected from its alcohol content (see [4]). As mentioned above, wine might indeed conceivably have additional non-ethanol-related beneficial effects. In spite of a large number of experimental studies that confirm such a hypothesis, epidemiologic evidence of a greater effect of wine has not been definitely established. To test such a hypothesis, our group performed two metaanalyses based on 26 studies reporting comparisons between different alcoholic beverages (wine and beer) and the relative risk (RR) of CVD [4]. A first meta-analysis was conducted on studies that investigated the relation between vascular events and specific alcoholic beverages, whatever the amount consumed. A total of 15 studies were included, involving 208,096 persons. The overall $\mathrm{RR}$ of wine drinkers in respect to nondrinkers was 0.68 (95\% CI: 0.59-0.77), whereas the protection associated with beer drinkers demonstrated an overall RR of 0.78 ( $95 \%$ CI: $0.70-0.86$ ). However, after the exclusion of the studies that did not simultaneously adjust for different types of alcoholic beverages (the most unbiased method to control for confounding factors), there was no meaningful difference in the RRs of CVD between wine and beer drinkers ( 0.75 vs 0.77 ) as compared with abstainers. An important difference between wine and beer consumption was observed in the second meta-analysis conducted on studies reporting trend (dose-response) analysis. Ten studies were included involving 176,042 persons. In contrast with wine, in which a clear inverse dose-effect curve was found, the fitted models failed to show any significant relationship between different amounts of beer intake and vascular risk.

Whether wine is better than beer or spirits remains to be elucidated. Further studies addressing this issue should be of large sample size and carefully designed, because differences between beverages, if any, are expected to be limited and might reflect differences in the risk factor patterns among categories of drinkers rather than a true difference in CVD risk.

\section{What is the optimal amount of} alcohol intake?

The dose-response relationship between alcohol intake and rate of CVD has been depicted as a J-shaped curve [1,4-6,13]. The J-shaped relationship between alcohol consumption and clinical events reflects nondrinkers having higher incidence and mortality rates than light or moderate drinkers, but similar or lower rates than heavy drinkers. In our meta-analysis [6] an average dose-response curve was obtained fitting nonlinear model. The relationship found confirmed a 'J-shaped' curve since, after an initial decrease in the vascular risk by increasing amounts of wine, the curve reaches a plateau at higher intake, and tends to be reverted at the highest amounts explored. A maximum reduction was predicted at $750 \mathrm{ml} /$ day, but statistical significance was only reached up to the amount of $150 \mathrm{ml} /$ day, equivalent to $12-18 \mathrm{~g}$ of ethanol per day. In conclusion, epidemiologic evidence indicates that the amount of wine/alcohol for which the balance between risk and benefit is the best is in the range of one to two drinks a day, in agreement with American Heart Association 


\section{Review Di Castelnuovo, Costanzo, di Giuseppe, de Gaetano \& Iacoviello}

guidelines [79].

\section{Is the effect of wine different in men} \& women?

In our meta-analysis of studies that enrolled only men [6], the protection offered by wine was found to be surprisingly small (13\%) and not significant, in contrast with studies enrolling both sexe (47\%). No sex-related difference was observed for beer consumption. In the Health Professional Follow-Up Study, conducted on men in the USA the effect of wine was small and not significant [5]. A further analysis of the two US studies included in our meta-analysis where only men had been enrolled [6], demonstrated no protective effect of wine (RR: 1.02 ; 95\% CI: 0.65-1.60). However, in the five studies conducted in the USA, enrolling both sexes, overall $\mathrm{RR}$ reduction in favor of wine drinkers was 0.46 [20]. In a metaanalysis of studies on alcohol and stroke [6], a greater protection in women than in men was apparent. On the contrary, in a meta-analysis on alcohol and total mortality that we will further discuss below [14], we found that the pooled dose-response curves of alcohol against total mortality for men and women were different at alcohol ranges in which alcohol was protective in fact, the inverse association in women apparently disappeared at alcohol doses lower than in men - but were comparable if the maximum protection was considered.

Thus, a possible sex difference in the protective effect of alcohol might exist and explain apparently controversial results in different epidemiologic studies. Large studies are needed to test whether women are more susceptible indeed to the benefit of alcohol or whether they are more likely to drink lower amounts, and thus receive its maximal advantage $[1,4,7]$.

\section{Does the effect of alcohol depend on pattern of drinking?}

Experimental studies [80] suggest that drinking wine at meals provides maximal health effect, by preventing the development of atheromatous lesions, while a binge pattern of alcohol drinking has been associated with higher risk of CHD [81-83]. In the large Health Professional Follow-Up Study [5], the investigators failed to observe any correlation between health effect of alcohol and the proportion consumed with meals. On the contrary, a role of drinking frequency was found, with the highest protective effect among men who consumed alcohol 3 or more days a week, whatever the amount consumed.

Moderate regular drinking, possibly during meals, appears as the ideal behavior while binge drinking is to be absolutely avoided.

Protection against total mortality: is there a window for benefit?

If low alcohol intake is inversely related to CVD, the other side of the coin shows an increased risk of certain cancers, cirrhosis and death from accidents associated with increasing alcohol consumption [21]. As a consequence, one could suspect that even at lower dosages the benefit of alcohol could be overcome by its harmful effects $[15,16]$. To test such a hypothesis, we performed a meta-analysis including 34 prospective studies on alcohol and all-cause mortality [14]. We pooled findings from more than one million subjects and approximately 95,000 deaths from any cause as measured outcomes. The J-shaped relationship observed between total mortality and increasing amounts of alcohol consumed indicate that low-to-moderate consumption of alcohol ( $\leq$ one drink/day in women and $\leq$ two drinks/day in men) significantly reduces total mortality, while higher doses increase it.

As mentioned above, we paid special attention to the possible effect of confounding factors. A total of 29 studies showed adjusted RR at least for age; among them, 15 were adjusted for social status too, and six for social status and dietary markers. Pooled curves for different levels of adjustment were significantly different $(\mathrm{p}<0.0001)$, showing that part of heterogeneity is attributable indeed to adjustment. However, while the protection decreased in adjusted studies (the maximum protection fell from 36 to $17 \%$ ), it remained substantial and statistically significant. Moreover, as the observed difference between the five not adjusted and the 29 adjusted studies could be not only due to the level of adjustment - the results coming from different studies - we compared adjusted or not adjusted data from the same studies. In this case the effect due to known confounders (age, smoking, social status and dietary factors) led to the reduction of the maximum protection from 19 to $16 \%$; for analogy, even in the pessimistic hypothesis that residual (possibly unknown) confounding factors would have a similar strength as the known one in lowering the protection, one can assume that the 'real' (maximum) protection against total mortality associated with low consumption of alcohol would be largely higher than $10 \%$. Although the protection by alcohol or wine decreases when data are adjusted, thus confirming the importance of confounding factors in assessing drinking effects, it largely remains in a range of undoubted public health value $[14,84,85]$. 
We also investigated the degree to which the inclusion of ex-drinkers in the control group could influence the results [14]. The inclusion in the control group of people who had stopped drinking owing to illness might induce an overestimation of the protection offered by drinking in moderation. We tested this hypothesis by comparing studies that used as reference group the category of no alcohol intake and/or excluded former drinkers with studies which, in contrast, included in their reference group occasional or former drinkers or people reporting low alcohol intake: the protection was indeed lower in the first studies, but still remained statistically significant.

Analysing dose-response curves separately in men and women, we observed that the protection was apparent up to three drinks/day in men but only up to two drinks/day in women whereas the maximum risk reduction was similar (RR: $17 \%$; $99 \%$ CI: $15-19 \%$ and $18 \%$; $99 \%$ CI: $13-22 \%$, respectively). The pooled curves for men and women were different at the range at which alcohol was protective, in fact the inverse association in women apparently disappears at doses lower than in men, but comparable regarding the maximum protection.

In women, pooled curves obtained using data from USA or Europe or other countries (Australia, Japan and China) were comparable. By contrast, strong differences were observed in men ( $p$ for difference was highly significant for each pairwise comparison), showing that part of heterogeneity in men is attributable to the set of the study. In particular, maximum RR was in the range of 20 to $28 \%$ in European but only 14 to $19 \%$ in US studies, and the protection extended up to six drinks/day in European but only up to three drinks/day in US studies. Further subgrouping of US data according to ethnicity provided no evidence of heterogeneity [14].

\section{Public health perspective}

In a general public health perspective, wine, beer or other alcoholic beverages should be avoided whenever consumption would put an individual or others at risk, such as during pregnancy or before driving.

In conclusion, besides insisting on the control of risk factors, abstainers should be informed that in the absence of contraindications and in the context of healthy eating and lifestyle, lowto-moderate alcohol consumption may contribute to a better health. People who are already regular light-to-moderate alcohol consumers should be encouraged to continue. The hazards of excess drinking should be always highlighted, and heavy drinkers pushed to cut their consumption to a moderate level [86].

\section{Conclusion}

The rates of vascular and total mortality are lower for people who drink low-to-moderate amounts of alcohol than for people who do not drink at all or drink heavily.

The cardioprotective nature of alcohol has been attributed to both its antithrombotic properties and its ability to decrease LDL levels and/or their oxidation. Moreover, wine and especially red wine, owing to its polyphenol content, might offer additional advantages and greater cardiovascular benefits than alcohol alone.

Available epidemiologic data, which are limited at the moment to observational studies, confirm the hazards of excess drinking, but also indicate the existence of potential windows of alcohol intake that may confer a net beneficial effect of drinking, at least in terms of survival, both in men and in women. Methodological limitations of observational study design, the role of uncontrolled confounding factors and the optimal choice of the reference group are important issues to be considered. However, the protection by alcohol would anyway remain in a range of undoubted public health value, even considering all possible confounding factors.

Randomized controlled trials could offer a more solid answer than observational studies to many questions in medicine, but have mainly been restricted to the efficacy of drugs; controlled intervention trials on diet in general and on alcohol in particular, are difficult, mainly because of selection, blinding or compliance problems, and are ethically questionable to perform $[16,87]$. One has, therefore, to rely upon observational studies such as those analyzed here or prospective studies where participants spontaneously decrease or stop drinking. Interestingly enough, the first study of the latter type supports the inverse relation of moderate alcohol intake with CVD [88]. A large randomized controlled trial on alcohol, comparing a reference group of long-term abstainers, devoid of former or occasional drinkers and an 'intervention' group of low-to-moderate no-binging drinkers, with appropriate follow-up, collecting not only vascular but total mortality too, will without doubt help in clarifying the effect of alcohol on health. Randomized controlled trials on intermediate end points could also be more feasible and likely alternative. Genetic regulation of the individual response to alcohol has recently been 


\section{Review Di Castelnuovo, Costanzo, di Giuseppe, de Gaetano \& lacoviello}

\section{Executive summary}

\section{Introduction}

- The aim of this article is to review mechanisms supporting the protective effect of moderate intake of alcohol against cardiovascular disease (CVD), and epidemiologic evidence concerning the relationship of alcohol dosing with vascular risk and all-cause mortality.

Mechanisms of action of alcohol

- Alcohol induces healthy changes in lipid profile, vascular, hemostatic and endothelial cell function, platelet aggregation, fibrinogen, tissue-plasminogen activator, plasminogen-activator inhibitor and omega-3 polyunsaturated fatty acids.

\section{Additional mechanisms of action of wine}

- Wine contains many substances that might provide additional cardiovascular benefits than that provided by ethanol alone, such as phenols and tannins, which favorably influence LDL oxidation, platelet aggregation, endothelial function, smooth muscle cell proliferation, lipoprotein oxidation, nitric oxide formation, thromboxane $A_{2}$ biosynthesis in platelets and leukotriene biosynthesis in neutrophils.

\section{Epidemiologic evidence: is wine different from beer or liquor?}

- The meta-analytic overall relative risk of wine drinkers in respect to nondrinkers was $0.68(0.59-0.77)$, whereas the protection associated with beer drinkers was $10 \%$ lower.

- In contrast with wine, in which a clear dose-response curve was found, the fitted models failed to show any significant relationship between different amounts of beer intake and vascular risk. Whether wine is better than beer or spirits remains to be fully elucidated.

Epidemiologic evidence: what is the optimal amount of alcohol intake?

- The J-shaped relationship between alcohol consumption and clinical events reflects nondrinkers having higher incidence and mortality rates than light or moderate drinkers, but similar or lower rates than heavy drinkers.

- Epidemiological evidence indicates that the amount of alcohol for which the balance between risk and benefit is the best is in the range one to two drinks per day for women and two to three for men.

\section{Epidemiologic evidence: is the effect of wine different in men \& women?}

- In meta-analyses on alcohol and vascular risk, a greater protection in women than in men was apparent.

- In a meta-analysis on alcohol and total mortality, the inverse association in women apparently disappears at lower doses than in men.

- A possible sex difference in the protective effect of alcohol remains to be elucidated.

Epidemiologic evidence: does the effect of alcohol depend on pattern of drinking?

- Moderate regular drinking, possibly during meals and avoiding binge drinking appears as the ideal behavior

Epidemiologic evidence: protection against total mortality - is there a window for benefit?

- If low alcohol intake is inversely related to CVD, the other side of the coin shows an increased risk of certain cancers, cirrhosis and death from accidents associated with increasing alcohol consumption.

- A J-shaped relationship between total mortality and increasing amounts of alcohol consumed was observed in meta-analyses, showing that low-to-moderate consumption of alcohol ( $\leq$ one drink/day in women and $\leq$ two drinks/day in men) significantly reduces total mortality, while higher doses increase it.

\section{Conclusion}

- The rates of vascular and total mortality are lower for people who drink low-to-moderate amounts of alcohol than for people who do not drink at all or drink heavily.

- The cardioprotective nature of alcohol has been attributed to both its antithrombotic properties and its ability to increase HDL levels

- Moreover, wine due to its polyphenols content, might offer additional advantages and greater cardiovascular benefits than alcohol alone.

- Available epidemiologic data, based at the moment on observational studies, confirm the hazards of excess drinking, but also indicates the existence of potential windows of alcohol intake that may confer a net beneficial effect of drinking, at least in terms of survival, both in men and in women.

- Methodological limitations of observational study design, the role of uncontrolled confounding factors, and the optimal choice of the referent group are important issues to be carefully considered in future studies on alcohol and health.

- Besides insisting on the control of risk factors, abstainers should be informed that in the absence of contraindications and in the context of healthy eating and lifestyle, low-to-moderate, nonbinging alcohol consumption may contribute to a better health.

- People who are already regular light-to-moderate alcohol consumers should be encouraged to continue.

- The hazards of excess drinking should always be highlighted, and heavy drinkers should be to pushed to cut their consumption to a low-to-moderate level.

Financial \& competing interests disclosure

The authors have no relevant affiliations or financial

involvement with any organization or entity with a

financial interest in or financial conflict with the subject

matter or materials discussed in the manuscript.
This includes employment, consultancies, honoraria, stock ownership or options, expert testimony, grants or patents received or pending, or royalties.

No writing assistance was utilized in the production of this manuscript. 
proposed [89,90]. Further investigations in this emerging field will hopefully assist in interpreting heterogeneous findings in different settings and populations.

\section{Bibliography}

Papers of special note have been highlighted as: - of interest

1. Maclure M: Demonstration of deductive meta-analysis: ethanol intake and risk of myocardial infarction. Epidemiol. Rev. 15, 328-351 (1993).

2. Rimm EB, Klatsky A, Grobbee D et al:: Review of moderate alcohol consumption and reduced risk of coronary heart disease: is the effect due to beer, wine, or spirits. BMJ 312 , 731-736 (1996).

3. Corrao G, Bagnardi V, Zambon A et al.: Exploring the dose-response relationship between alcohol consumption and the risk of several alcohol-related conditions: a meta-analysis. Addiction 94, 1551-1573 (1999).

4. Di Castelnuovo A, Rotondo S, Iacoviello L et al:: Meta-analysis of wine and beer consumption in relation to vascular risk. Circulation 105, 2836-2844 (2002).

- First and to date the only meta-analysis of the association of specific alcoholic beverages with vascular risk.

5. Mukamal JK, Conigrave KM, Mittleman MA et al: : Roles of drinking pattern and type of alcohol consumed in coronary heart disease in men. $N$. Engl. J. Med. 348, 109,118 (2003).

6. Reynolds K, Lewis BL, Nolen JDL et al: Alcohol consumption and risk of stroke: a meta-analysis. JAMA 289, 579-588 (2003).

7. Stampfer MJ, Colditz GA, Willett WC et al.: A prospective study of moderate alcohol drinking and risk of diabetes in women. Am. J. Epidemiol. 128, 549-558 (1998).

8. Corella D: Gene-alcohol interactions in the metabolic syndrome. Nutr. Metab. Cardiovasc. Dis. 17(2), 140-147 (2007).

9. La Vecchia C, Decarli A, Ferraroni M et al.: Alcohol drinking and prevalence of self-reported gallstone disease in the 1983 Italian National Health Survey. Epidemiology 5, 533 (1994).

10. Klatsky AL, Armstrong MA, Friedman GD: Alcohol and mortality. Ann. Intern. Med. 117, 646-654 (1992).

11. Doll R, Peto R, Hall E et al.: Mortality in relation to consumption of alcohol: 13 years' observations on male British doctors. BMJ 309, 911-918 (1994)

12. La Vecchia C: Alcohol in the Mediterranean diet; assessing risks and benefits.
Eur. J. Cancer Prev. 4, 3-5 (1995).

13. Renaud SC, Gueguen R, Schenker J et al:: Wine, beer, and mortality in middle-aged men from eastern France. Arch. Intern. Med. $159,1865-1870$ (1999).

14. Di Castelnuovo A, Costanzo S, Bagnardi V et al: : Alcohol Dosing and total mortality in men and women: an updated meta-analysis of 34 prospective studies. Arch. Intern. Med. 166, 2437-2445 (2006)

- An updated and comprehensive metaanalysis on alcohol and total mortality, in men and women.

15. Jackson R, Broad J, Connor J et al.: Alcohol and ischaemic heart disease: probably no free lunch. Lancet 366, 1911-1912 (2005).

16. Gronbaek M, Di Castelnuovo A, Iacoviello L et al.: Wine, alcohol and cardiovascular risk: open issue. J. Thromb. Haemost. 2, 2041-2048 (2004)

17. White IR, Altmann DR, Nanchahal K Alcohol consumption and mortality: modelling risks for men and women at different ages. BMJ 325, 191 (2002).

18. Gmel G, Gutjahr E, Rehm J: How stable is the risk curve between alcohol and all-cause mortality and what factors influence the shape? A precision-weighted hierarchical meta-analysis. Eur. J. Epidemiol. 18, 631-642 (2003).

19. Bagnardi V, Zambon A, Quatto P et al.: Flexible meta-regression functions for modeling aggregate dose-response data, with an application to alcohol and mortality. $\mathrm{Am}$. J. Epidemiol.159, 1077-1086 (2004)

20. Di Castelnuovo A, Iacoviello L, de Gaetano G: Alcohol and coronary heart disease. N. Engl. J. Med. 348, 1719-1722 (2003).

21. Corrao G, Bagnardi V, Zambon A et al: : A meta-analysis of alcohol consumption and the risk of 15 diseases. Prev. Med. 38 613-619 (2004)

22. Renaud S, de Lorgeril M: Wine, alcohol, platelets, and the French paradox for coronary heart disease. Lancet 339 , 1523-1526 (1992).

- First article in which the 'French Paradox' was proposed and discussed.

23. de Gaetano G, De Curtis A, Di Castelnuovo A et al: Antithrombotic effect of polyphenols in experimental models: a mechanism of the reduced vascular risk by moderate wine consumption. In: Alcohol and wine in health and disease. Das DK, Ursini F (Eds.). Ann. NY Acad. Sci. NY, USA, 174-188 (2002).

24. Rimm EB, Williams P, Fosher K et al: Moderate alcohol intake and lower risk of coronary heart disease: meta-analysis of effects on lipids and haemostatic factors. BMJ 319, 1523-1528 (1999).

- Comprehensive quantitative review on the effect of drinking in moderation on lipids and hemostatic factors.

25. Haskell WL, Camargo C Jr, Williams PT et al:: The effect of cessation and resumption of moderate alcohol intake on serum high-density-lipoprotein subfractions: a controlled study. N. Engl. J. Med. 310, 805-810 (1984).

26. Linn S, Carroll M, Johnson C et al. High-density lipoprotein cholesterol and alcohol consumption in US white and black adults: data from NHANES II. Am. J. Public Health 83, 811-816 (1993)

27. Schroder H, Ferrandez O, Jimenez Conde J et al: : Cardiovascular risk profile and type of alcohol beverage consumption: a populationbased study. Ann. Nutr. Metab. 49, 100-106 (2005)

28. Barter PJ, Caulfield M, Eriksson M et al.: Effects of torcetrapib in patients at high risk for coronary events. N. Engl. J. Med. 357(21), 2109-2122 (2007).

29. Briel M, Ferreira-Gonzalez I, You JJ et al: Association between change in high density lipoprotein cholesterol and cardiovascular disease morbidity and mortality: systematic review and meta-regression analysis. $B M J$ b 92 (2009).

30. Holvoet P, Peeters K, Lund-Katz S et al.: Circulating oxidized LDL is a useful marker for identifying patients with coronary artery disease. Arterioscler. Thromb. Vasc. Biol. 21 , 844-848 (2001)

31. Pace-Asciak CR, Hahn S, Diamandis EP et al: : The red wine phenolics transresveratrol and quercetin block human platelet aggregation and eicosanoid synthesis: implications for protection against coronary heart disease. Clin. Chim. Acta 235, 207-219 (1995)

32. Formica JV, Regelson W: Review of the biology of quercetin and related bioflavonoids. Food Chem. Toxicol. 33 , 1061-1080 (1995).

33. Ruf JC, Berger JL, Renaud S: Platele rebound effect of alcohol withdrawal and wine drinking in rats. Relation to tannins and lipid peroxidation. Arterioscler. Thromb. Vasc. Biol. 1, 140-144 (1995).

34. Polette A, Lemaitre D, Lagardem et al: : N-3 Fatty acid-induced lipid peroxidation in human platelets is prevented by catechins. Thromb. Haemost. 75, 945-949 (1996).

35. Hendriks HF, van der Gaag MS: Alcohol, coagulation and fibrinolysis. Novartis Found Symp. 216, 111-120; discussion 120-124 (1998). 


\section{Review Di Castelnuovo, Costanzo, di Giuseppe, de Gaetano \& lacoviello}

36. Ridker PM, Vaughan DE, Stampfer MJ et al: Association of moderate alcohol consumption and plasma concentration of endogenous tissue-type plasminogen activator. JAMA 272, 929-933 (1994)

37. Wannamethee SG, Lowe GD, Shaper G et al:: The effects of different alcoholic drinks on lipids, insulin and haemostatic and inflammatory markers in older men. Thromb. Haemost. 90, 1080-1087 (2003).

38. Saremi A, Arora R: The cardiovascular implications of alcohol and red wine. $A m$ J. Ther. 15(3), 265-277 (2008)

39. Femia R, Natali A, L'Abbate A et al.: Coronary atherosclerosis and alcohol consumption: angiographic and mortality data. Arterioscler. Thromb. Vasc. Biol. 26 1607-1612 (2006).

40. Dai J, Miller BA, Lin RC: Alcohol feeding impedes early atherosclerosis in low-density lipoprotein receptor knockout mice: factors in addition to high-density lipoproteinapolipoprotein A1 are involved. Alcohol Clin. Exp. Res. 21(1), 11-18 (1997).

41. de Lorgeril M, Salen P, Martin JL et al: Interactions of wine drinking with omega-3 fatty acids in coronary heart disease patients. A fish-like effect of moderate wine drinking. Am. Heart J. 155, 175-181 (2008).

42. Albert CM, Campos H, Stampfer MJ et al:: Blood levels of long-chain n-3 fatty acids and the risk of sudden death. N. Engl. J. Med. 346, 1113-1118 (2002).

43. GISSI-Prevenzione Investigators: Dietary supplementation with $\mathrm{n}-3$ polyunsaturated fatty acids and vitamin $\mathrm{E}$ after myocardial infarction: results of the GISSI-Prevenzione trial. Lancet 354, 447-455 (1999).

44. Oskarsson HJ, Godwin J, Gunnar RM et al. Dietary fish oil supplementation reduces myocardial infarct size in a canine model of ischaemia and reperfusion. J. Am. Coll. Cardiol. 21, 1280-1285 (1993)

45. Guiraud A, de Lorgeril M, Zeghichi S et al:: Interactions of alcohol drinking with n-3 fatty acids in rats: potential consequences for the cardiovascular system. Br. J. Nutr. 29, 1-8 (2008)

46. Iacoviello L, Arnout J, Buntinx F et al. European Collaborative Group of the IMMIDIET Project. Dietary habit profile in European Communities with different risk of myocardial infarction: the impact of migration as a model of gene-environment interaction-the IMMIDIET study. Nutr. Metab. Cardiovasc. Dis. 11, 122-126 (2001).

47. di Giuseppe R, de Lorgeril M, Salen P et al: European Collaborative Group of the IMMIDIET Project. Alcohol consumption and $\mathrm{n}-3$ polyunsaturated fatty acids in healthy men and women from 3 European populations. $A m$. J. Clin. Nutr. 89(1), 354-362 (2009).

- Demonstrates that alcohol increases n-3 polyunsaturated fatty acids in healthy subjects.

48. Flesch M, Rosenkranz S, Erdmann E et al: Alcohol and the risk of myocardial infarction. Basic Res. Cardiol. 96, 128-135 (2001).

49. Soleas GJ, Diamandis EP, Goldberg DM: Wine as a biological fluid: history, production, and role in disease prevention. J. Clin. Lab. Anal. 11, 287-313 (1997)

50. Ou HC, Chou FP, Sheen HM et al: Resveratrol, a polyphenolic compound in red wine, protects against oxidized LDL-induced cytotoxicity in endothelial cells. Clin. Chim. Acta 364, 196-204 (2006).

51. Guarda E, Godoy I, Foncea R et al.: Red wine reduces oxidative stress in patients with acute coronary syndrome. Int. J. Cardiol. 104, 35-38 (2005).

52. Tsang C, Higgins S, Duthie GG et al:: The influence of moderate red wine consumption on antioxidant status and indices of oxidative stress associated with CHD in healthy volunteers. Br. J. Nutr. 93, 233-240 (2005).

53. Demrow HS, Slane PR, Folts JD: Administration of wine and grape juice inhibits in vivo platelet activity and thrombosis in stenosed canine coronary arteries. Circulation 91, 1182-1188 (1995).

54. Di Minno G, Silver JM: Mouse antithrombotic assay: a simple method for the evaluation of antithrombotic agents in vivo. Potentiation of antithrombotic activity by ethyl alcohol. J. Pharmacol. Exp. Ther. 225, 57-60 (1983).

55. Pace-Asciak CR, Rounova O, Hahn SE et al. Wines and grape juices as modulators of platelet aggregation in healthy human subjects. Clin. Chim. Acta 246, 163-182 (1996)

56. Seigneur M, Bonnet J, Dorian B et al.: Effect of the consumption of alcohol, white wine, and red wine on the platelet function and serum lipids. J. Appl. Cardiol. 5, 215-222 (1990).

57. Rotondo S, Rotilio D, Cerletti C et al:: Red wine, aspirin and platelet function. Thromb. Haemost. 76, 818-819 (1996).

58. Rotondo S, Rajtar G, Manarini S et al: : Effect of trans-resveratrol, a natural polyphenolic compound, on human polymorphonuclear leukocyte function. Br. J. Pharmacol. 123, 1691-1699 (1998).

59. Di Santo A, Mezzetti A, Napoleone E et al.: Resveratrol and quercetin down-regulate tissue factor expression by human stimulated vascular cells. J. Thromb. Haemost. 1 , 1089-1095 (2003)
60. Crescente M, Jessen G, Momi S et al.: Interactions of gallic acid, resveratrol, quercetin and aspirin at the platelet COX-1 level: functional and modelling studies Thromb. Haemost. 102(2), 336-346 (2009).

61. Imhof A, Froehlich $\mathrm{M}, \mathrm{Brenner} \mathrm{H}$ et al.: Effect of alcohol consumption on systemic markers of inflammation. Lancet 357(9258), 763-767 (2001).

62. Estruch R, Sacanella E, Badia E et al.: Different effects of red wine and gin consumption on inflammatory biomarkers of atherosclerosis: a prospective randomized crossover trial. Effects of wine on inflammatory markers. Atherosclerosis 175(1), 117-123 (2004)

63. Badía E, Sacanella E, Fernández-Solá J et al.: Decreased tumor necrosis factor-induced adhesion of human monocytes to endothelial cells after moderate alcohol consumption. Am. J. Clin. Nutr. 80(1), 225-230 (2004).

64. Hayek T, Fuhrman B, Vaya J et al.: Reduced progression of atherosclerosis in apolipoprotein E-deficient mice following consumption of red wine, or its polyphenols quercetin or catechin, is associated with reduced susceptibility of LDL to oxidation and aggregation. Arterioscler. Thromb. Vasc. Biol. 17, 2744-2752 (1997).

65. Wang Z, Zou J, Cao K et al: : De-alcoholized red wine containing known amounts of resveratrol suppresses atherosclerosis in hypercholesterolemic rabbits without affecting plasma lipid levels. Int. J. Mol. Med. 16, 533-540 (2005).

66. De Curtis A, Murzilli S, Di Castelnuovo A et al: : Alcohol-free red wine prevents arterial thrombosis in dietary-induced hypercholesterolemic rats: experimental support for the 'French paradox'. J. Thromb. Haemost. 3, 346-350 (2005).

67. Maxwell S, Cruickshank A, Thorpe G: Red wine and antioxidant activity in serum. Lancet 344, 193-194 (1994).

68. Serafini M, Maiani G, Ferro-Luzzi A: Alcohol-free red wine enhances plasma antioxidant capacity in humans. J. Nutr. 128, 1003-1007 (1998).

69. Nigdikar SV, Williams NR, Griffin BA et al.: Consumption of red wine polyphenols reduces the susceptibility of low-density lipoproteins to oxidation in vivo. Am. J. Clin. Nutr. 68, 258-265 (1998).

70. Miller ER, Pastor-Barriuso R, Dalal D et al.: Meta-analysis: high-dosage vitamin $\mathrm{E}$ supplementation may increase all-cause mortality. Ann. Int. Med. 142, 40 (2005)

71. Saremi A, Arora R: The cardiovascular implications of alcohol and red wine. $A m$. J. Ther. 15, 265-277 (2008)

72. Rehm J, Mathers C, Popova S et al.: Global 
burden of disease and injury and economic cost attributable to alcohol use and alcoholuse disorders. Lancet 373, 2223-2233 (2009).

- Exhaustive overview of the negative aspects related to alcohol use and misuse.

73. McKee M, Britton A: The positive relationship between alcohol and heart disease in eastern Europe: potential physiological mechanisms. J. R. Soc. Med. 91, 402-407 (1998)

74. Feinman L, Lieber C: Ethanol and lipid metabolism. Am. J. Clin. Nutr. 70, 791-792 (1999).

75. Collins MA, Neafsey EJ, Mukamal KJ et al.: Alcohol in moderation, cardioprotection, and neuroprotection: epidemiological considerations and mechanistic studies. Alcohol Clin. Exp. Res. 33(2), 206-219 (2009)

- Complete review on mechanistic studies about protection from alcohol in moderation.

76. Grønbaek MJ: The positive and negative health effects of alcohol and the public health implications. Intern. Med. 265(4), 407-420 (2009).

77. Naimi TS, Brown DW, Brewer RD et al. Cardiovascular risk factors and confounders among nondrinking and moderate-drinking U.S. adults. Am. J. Prev. Med. 28, 369-373 (2005).

78. Mukamal KJ, Ding EL, Djoussé L: Alcoho consumption, physical activity, and chronic disease risk factors: a population-based cross-sectional survey. BMC Public Health 6, 118 (2006).

79. Pearson TA, Blair SN, Daniels SR et al.: AHA Guidelines for Primary Prevention of Cardiovascular Disease and Stroke: 2002 Update Consensus Panel Guide to Comprehensive Risk Reduction for Adult Patients Without Coronary or Other Atherosclerotic Vascular Diseases. Circulation 106, 388-391 (2002).

80. Ursini F, Zamburlini A, Cazzolato G et al.: Postprandial plasma lipid peroxides: a possible link between diet and atherosclerosis. Free Radic. Biol. Med. 25, 250-252 (1998)

81. Dejong W: Definitions of binge drinking JAMA 289, 1635 (2003).
82. McElduff P, Dobson AJ: How much alcohol and how often? Population based casecontrol study of alcohol consumption and risk of a major coronary event. BMJ 314 1159-1164 (1997).

83. Kauhanen J, Kaplan GA, Goldberg DE et al. Beer binging and mortality: results from the Kuopio ischaemic heart disease risk facto study, a prospective population based study. BMJ 315, 846-851 (1997).

84. Liao Y, McGee DL, Cao G et al.: Alcohol intake and mortality: findings from the National Health Interview Surveys (1988 and 1990). Am. J. Epidemiol. 151, 651-659 (2000).

85. Gaziano JM, Gaziano TA, Glynn RJ et al.: Light-to-moderate alcohol consumption and mortality in the Physicians' Health Study enrollment cohort. J. Am. Coll. Cardiol. 35 , 96-105 (2000)

86. American Heart Association Nutrition Committee, Lichtenstein AH, Appel LJ et al:: Diet and lifestyle recommendations revision 2006: a scientific statement from the American Heart Association Nutrition Committee. Circulation 114, 82-96 (2006).

- Statement from the American Heart Association Nutrition Committee in which clear recommendations concerning alcohol use are proposed.

87. Rehm J, Gmel G, Sempos CT et al: Alcohol-related morbidity and mortality. Alcohol Res. Health 27, 39-51 (2003).

88. Gronbaek M, Johansen D, Becker U et al: A Changes in alcohol intake and mortality: a longitudinal population-based study. Epidemiology 15, 222-228 (2004).

- Trial in which participants spontaneously decreased or stopped drinking, whose findings support the inverse relationship of moderate alcohol intake with cardiovascular disease.

89. Hines LM, Stampfer MJ, Ma J et al.: Genetic variation in alcohol dehydrogenase and the beneficial effect of moderate alcohol consumption on myocardial infarction. N. Engl. J. Med. 344(8), 549-555 (2001)

- Demonstration that a polymorphism in alcohol dehydrogenase gene regulate the effect of alchol on myocardial infarction.
90. Latella MC, Di Castelnuovo A, de Lorgeril $M$ et al:: On behalf of the European Collaborative Group of the IMMIDIET. Genetic variation of alcohol dehydrogenase type 1C (ADH1C), alcohol consumption, and metabolic cardiovascular risk factors: Results from the IMMIDIET study. Atherosclerosis. DOI: $10.1016 / \mathrm{j}$. atherosclerosis.2009.04.022 (2009) (Epub ahead of print).

\section{Affiliations}

" Augusto Di Castelnuovo

RE ARTU' Research Laboratories,

'John Paul II' Center for High Technology Research \& Education in Biomedical Sciences, Catholic University, Largo Gemelli 1, 86100 Campobasso, Italy

Tel.: +39874312 274 Fax: +39874312 710

- Simona Costanzo RE ARTU' Research Laboratories, 'John Paul II' Center for High Technology Research \& Education in Biomedical Sciences, Catholic University, Largo Gemelli 1, 86100 Campobasso, Italy Tel.: +39874312 274 Fax: +39874312 710

- Romina di Giuseppe

RE ARTU' Research Laboratories, 'John Paul II' Center for High Technology Research \& Education in Biomedical Sciences, Catholic University, Largo Gemelli 1, 86100 Campobasso, Italy Tel.: +39 874312274 Fax: +39874312 710

Giovanni de Gaetano RE ARTU' Research Laboratories, 'John Paul II' Center for High Technology Research \& Education in Biomedical Sciences, Catholic University, Largo Gemelli 1, 86100 Campobasso, Italy Tel.: +39874 312274 Fax: +39 874312710

- Licia Iacoviello

Laboratory of Genetic and Environmenta Epidemiology, 'RE ARTU' Research Laboratories, 'John Paul II' Center for High Technology Research \& Education in Biomedical Sciences, Catholic University, Largo Gemelli 1, 86100 Campobasso, Italy Tel.: +39874312 274 Fax: +39874312710 licia.iacoviello@rm.unicatt.it 

Chapter - Reference D

\section{THE RELATI ONSHIP BETWEEN ALCOHOL CONSUMPTION AND CEREBROVASCULAR RISK: FROM EPIDEMIOLOGICAL EVI DENCE TO BI OLOGI CAL PLAUSI BI LI TY}

Costanzo S, Di Castelnuovo A, Donati MB, de Gaetano G, Iacoviello L. The relationship between alcohol consumption and cerebrovascular risk: from epidemiological evidence to biological plausibility. In: Cerebral ischemia in Young Adults. Neurology - Laboratory and Clinical Research Developments A. Pezzini and A .Padovani Eds.. Nova Biomedica, New York 2009; Chapter 6: 149-165. 



\title{
The Relationship between Alcohol Consumption and Cerebrovascular Risk: From Epidemiological Evidence to Biological Plausibility
}

\author{
Simona Costanzo, Augusto Di Castelnuovo, Maria Benedetta Donati, \\ Giovanni de Gaetano, and Licia Iacoviello* \\ Research Laboratories, John Paul II Center for High Technology Research, \\ Care and Education in Biomedical Sciences, Catholic University, Campobasso, Italy
}

\begin{abstract}
Several epidemiological studies have consistently shown an inverse association between light to moderate akowol consumption $(1-2$ drinks/day) and cardiovascular discase moetidity and mortality.

While the benefit of moderate alcohol consumption en overall cardiovascular discase is well established, the specifie relationship with cerebrovaseular disease, mainly stroke, is still controversial. Risk facton differ for the two majof stroke types (hemoerhagic and ischemic) and several subtypes of each. Alkohol appears to have different associations with these various types.

The overall evidence suggests a reduced risk of ischemic stroke in light-moderate drinkers, but little of no protection apainst hemorrhagie stroke. All serebrovascular events suthstantially increase in beavy alcothol and binge consumen: mortover, heavy alcohol consumption is a risk factor foe both hemornhagic and ischemic stroke in young adults.
\end{abstract}

\footnotetext{
"Comespondence: Likia Loviello, Laboratory of Genets and Enviromental Epidemiology, Lanpo Gemelif, I.

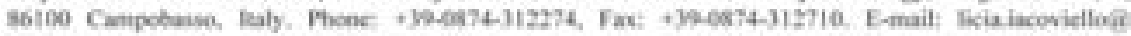
municatit.
} 
Numerous mechanisms have been proposed that mediate the protective effect of alcohol in cartiovascular disease (e.e., increased levels of high-densify lipoprotein cholesterol, decreased levels of low-density lipoprotein cholesterol, reduction in platelet agyregation, brneficial effects on inflammation). On the ofher hand anti-atherogenic and anti-thrombotie effects and regulation of endothetial function (e.g, enhanced release of nitric axide) were mainly ascribed to (red) wine polyphenols.

\section{Introduction}

Studies on alcohol and its effects on health have a long history, starting from anecdotal accounts in biblical times to more recent rigorous studies of populations.

Many epideniological studies have consistently shown an inverse association between light to moderate alcohol consumption (1-2 drinks/day) and cardiovascular disease morbidity and mortality, independently from age, sex, and majoe cardiovascular risk factors, such as smoking [1-3]. The beneficial effect of alcobol also applies to total mortality [4-6]. The doseresponse relationship between alcohol inake and rate of cardiovascular events or of all-cause mortality has been depicted as a U- or J-shaped curve (Figure 1), in relation to different populations of subgroups (gender, age classes) or reference groups (abstainers us oceasional drinkers) [4-7]. The U- or J-shaped relationship between alcohol consumption and clinical events reflects non drinkers or occasional drinkers baving higher incidence and mortality rates than light or moderate drinkers, but similar or lower rates than heavy drinkers.

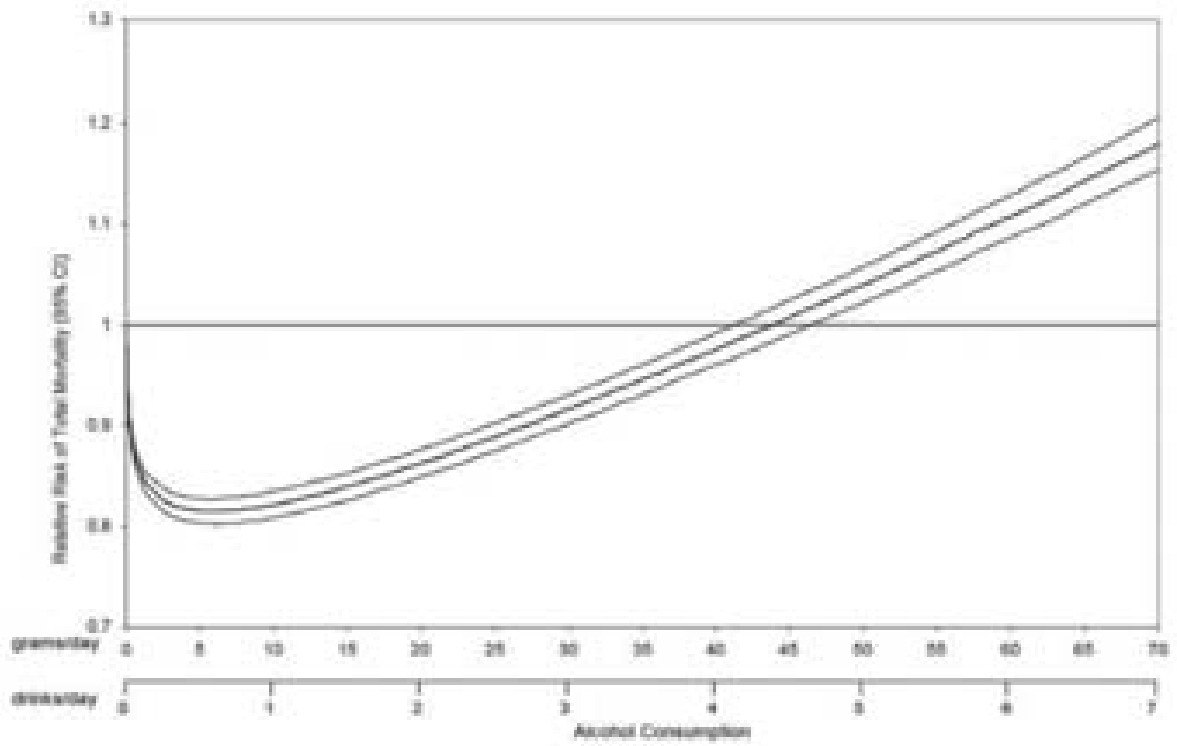

From figuee 1, Di.Castelnoovo and Coll. 2006, with permission.

Figure 1, Relative risk of botal mortality (95\% confidence inceval) and alcohol intakc. 
Renaud and de Lorgeril [8] proposed that wine intake was one possible explanation for the lower than expected coronary heart disease mortality rates in France, despite the high prevalence of risk factors (the "French Paradox"). Subsequently, many ecological and observational studies have dealt with the question whether different alcoholic beverages were equivalent in their ability to protect against cardiovascular disease, or a specific beverage, wine in particular, might offer a greater protection $[2,3,9]$ most likely related to its nonalcoholic components.

While the benefit of moderate alcobol consumption on overall cardiovascular disease (CVD) is well established, the specific relationship with cercbrovascular disease, mainly stroke, is controversial.

Earlier studies on relationships of alcobol drinking with stroke were made difficult by imprecise diagnosis of stroke types, before modern imaging techniques improved diagnostic accuracy.

Risk factors differ somewhat for the two major stroke types (hemornagie and ischemic stroke) and several subtypes of each (e.g., atherothrombotic, lacunar, embolic, subarachnoid bemorrhage, intracerebral hemorrtage). Hemorthagic stroke is consequent to ruptured blood vessels on the brain surface and within the brain substance, while ischemic stroke is the result of vascular occlusion of an intracerebral artery (clot formation in the brain blood vessels, blood clot emboli to the brain from the beart or elsewhere, or blockaye of blood vessels (carotid arteries) outside the beain) [10].

Alcobol appears to have elearly different associations with various stroke types. Moreover, studies on alcohol and stroke are also made complicated by the different relationships of stroke and alcohol with other cardiovascular conditions. Age and bypertensioe are majoe risk factoes for all stroke types, and most cardiovascular conditions have differing relations to various types of stroke. In particular two of the strongest chronic risk factors for ischemic stroke, hypertension and atrial fibrillation [11], have been associated to heavy drinking.

In the first part of this report we shall discuss recent major epidemiological studies reporting specific data on alcohol consumption and cerebrovascular disease, in the second part we will focus on younger subjects. Finally, possible pathogenetic mechanisms explaining the alcohol effect on eerebrovascular disease will be discussed.

\section{Epidemiological Evidence}

\section{Alcohol Consumption and Cerebrovascular Disease. Total, Ischemic and Hemorrhagic Stroke}

Several reports sugest that aloohol use, especially beavy drinking, is associated with higher risk of stroke. Sonse stodies examined only binge drinking, some others did not differentiate between hemorthagie and ischemic strokes.

The overall evidence suggests a reduced risk of ischemic stroke, but litule or no protection against hemorrhagie stroke in light-moderate drinkers. All cercbrovascular events substantially increase in heavy alcohol consumers. 
The Nurse's Health Study, (more than 87,000 women, aged $34-59$ years) [12] suggests that among middle-aged women, moderate alcohol consumption decreases the risks of ischemic stroke but may increase the risk of subarachnoid bensorthage, although in the latter, the number of cases was small. The relative risks (RR) of ischemic strode were $0.305 \%$ confidence interval $(95 \% \mathrm{CD}), 0.1$ to 0.7$)$ for alcohol intake of 5.14 gramsiday and $0.5(95 \%$ $\mathrm{Cl}, 0.2$ to 1.1) for intake $\geq 15$ grams/day. In contrast, the consumption of 5-14 grams/day was associated with increased risk of subarachnoid hemorrhage (RR, $3.7(95 \% \mathrm{Cl}, 1,0$ to 13.8$)$ ).

In The Kaiser Permanente Study, alcohol consumption was associated with lower hospitalization rates for ischemie stroke, an inverse relation present in both jenders, in whites and blacks, for both extracranial and intracertbral occlusive lesions [13]. Later, analysing a longer follow-up of the same study. Klatsky and Coll. reported a U-shaped association between alcohol intake and bospitalization for ischemic stroke. Relative risks were 0.8 (95\%C1, 0.7 to 1.0) among those who consumed between one drink a month and one drink a day and $1.0(95 \% \mathrm{Cl}, 0.8$ to 1.2$)$ among those who consumed 3 or more drinks/day [13,14]. In a supplementary Kaiser Permanente study analysis [15], the Authors showed that heavier drinkers, but not figher drinkers, were at increased risk of hemonthagie stroke. Higher blood pressure in heavier drinkers appeared to be a partial mediator of this relationship.

Another recent report from a large study in Americans (38,156 men who were free of known CVD or cancer at baseline, The Health Professionals Follow-Up Study) [16], concluded that light-moderate alcohol intake ( 30 grams/day) was generally not associated with an increased risk for ischemic stroke, but intake of more than 2 drinks/day may be associated with a higher risk. As the heterogeneity of ischemic stroke may influence its association with alcohol intake, Mukamal and Coll. examined the risks for thrombotic and embolic stroke according to alcobol consumption. Although their analyses were limited by the small number of each stroke subtype, risk for embolic stroke appeared to have a positive association with alcohol use. In contrast, alcohol consumption was not associated with the risk for thrombotic stroke. However, this recent large study did not evidence an effective protection by alcohol consumption on ischemic cerebrovascular events.

Djousse and Coll. [17] used data collected oe participunts in the Framingham Study to evaluate the association between total alcohol intake, type of alcoholic beverage and developenent of ischemic stroke, overall and according to age. Overall, compared with never drinkers in a multivariate Cox regression, current alcohol consumption was not significantly related to ischemic stroke in either sex. Former drinking of $\geq 12$ grams/day of alsolol was associated with a 2.4 times higher risk of ischemic stroke among men but not among women. After stratification by age, alcohol intake was associated with lower risk of ischemie stroke among subjects aged $60-69$ years. However, the resalts of this study were limited by the insufficient statistical power for analyses, even if the Authors used a "pooling method": In other words, each subjoct contributed to 1 ( $(\mathrm{n}=1,110), 2(\mathrm{n}-1,203)$ or 3 (n $=1,885)$ otservations in the analyses, if he/she was free of stroke at the beginning of the three 10 year periods of observation. In this way, a "virtual cohort" was obtained and the final data set consisted of 9,171 person-observations, against 4,198 cnrolled subjects.

The limitations of these last two studies $[16,17]$ show as it would be important to design large studies with effective and powered classification of ischemic stroke subtypes. 
Several and specific meta-analyses on the relation between alcohol consumption and total, ischemic and/or hemornhagic stroke risk report statistical synthesis of the data from recent and peeviously published studies and yield a quantitative sumunary of the pooled results about this topic.

In a first systematic review of the relationship between alcohol consumption and stroke, Mazsaglia and Coll. [18] coneluded that there was not sufficient evidence that high-tomoderate alcohol or wine intake had beneficial effects on stroke, while the risk of stroke in binge drinkers was repontedly higher than in rtgular drinkers.

In 2003, Reynolds and Coll. [19] performed an oritinal meta-analysis on alcohol consumption and risk of stroke. They selected 35 observational studies (colsort of casecontrol, with more than 10,000 events divided into total stroke, ischemic (15 studies), of bemorrhagie (12 stadies) stroke. They suggested, that, compared with abstention, consumption of less than 12 grams day was associated with a reduced relative risk of total stroke (RR, 0.83; $95 \% \mathrm{Cl}, 0.75$ to 0.91$)$ and ischemic stroke $\left(\mathrm{RR}, 0.80 ; 95 \% \mathrm{Cl}_{1}, 0.67\right.$ to $0.96)$; consumption of 12.24 grams/day was associated with a reduced relative risk of ischemic stroke (RR, $0.72 ; 95 \% \mathrm{Cl}, 0.57$ to 0.91 ); while consumption of more than 60 grams/day was associated with an increased risk of total stroke (RR, 1.64, 95\% Cl, 1.39 to 1.93); ischemic stroke (RR, 1.69; $95 \% \mathrm{Cl}, 1.34$ to 2.15) and bemorrhagic stroke (RR, 2.18; $95 \%$ C., 1.48 to 3.20 ). Performing a meta-regression analysis, they revealed a significant non-finear relationship (J-shape curve) between alcohol consumption and both total (p = $0.002)$ and ischemic stroke $(p=0,004)$ and a linear relationship between alcohol consuataption and bemocrhagic stroke $(p=0,004$ ) (Figure 2). Their main conclusion was that beavy alcobol consumption increased the relative risk of stroke while light to moderate alcobol consumption might be protective against total and ischemic stroke.

Corrao and Coll. [20]. while confirming the protective action of low dose of alcohol on the risk of coronary beart disease, could not find any association between ischemic and bemorrhagic stroke, and moderate alcohol intake. For ischemic ( 893 cases, 6 studies) and bemorthagic stroke ( 1,192 cases, 9 studies), the nadirs (the maximum protection) were reached at 15 and 3 grams/day, respectively, but no evidence of significant protective effect was observed. Significantly increased risks were obtained starting from 53 to 28 grams/day. respectively.
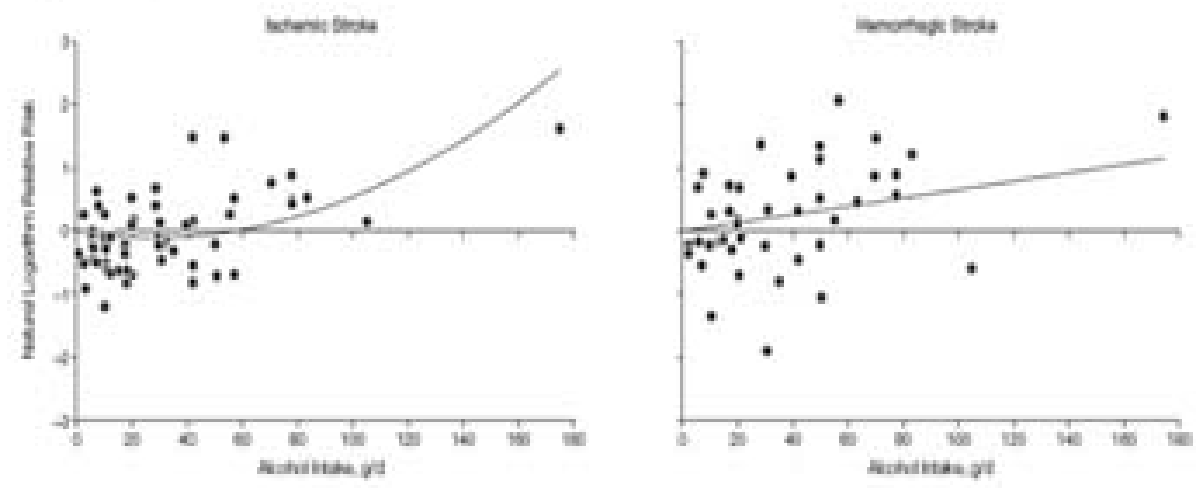
From figure 1; Regnolds and Coll, 2003, with permiesion.

Figure 2. Meta-regession curve of stroke associatod with alcohol consumption by subtype stroke.

In a meta-analysis of longitudinal and case-control studies on subarachnoid hemorrhage, Feigin and Coll. [21] found an increased risk restricted to beavier intake (>150 grams/week). For heavy drinkers, the pooled relative risk was $2.1(95 \% \mathrm{Cl}, 1.5$ to 2.8$)$ in the meta-analysis of cohort stadies, and $1.5(95 \% \mathrm{Cl}, 1.3$ to 1.8$)$, in casc-control studies, with greater hazards effocts in women in both meta-analyses. In a similar meta-analysis of 8 case-control studies of intracerebral hemorthage, Ariesen and Coll. [22] found a overall odds ratios (OR) of 2.05 (95\% Cl, 1.35 to 3.11 ) for "moderate intake" (556 grams/day) and $4.11(95 \% \mathrm{Cl}, 2.54$ to 6.65) for higher intake ( $>56$ grams/day). In the meta-analysis of 3 cobort studies (average alcohol intake 36 grams/day), they could not find any strong association between alcohol consumption and intracerebral hemorrhage. The difference in strength of association might be that the alcohol intake in the cohort studies was lower (about 36 grams/day) than in the casecontrol studies (average 56 gramsiday).

\section{Wine and Beer Consumption and Cerebrovascular Disease}

Only a small number of studies have evaluated whether the beneficial or harmful effects of alcohol on the risk of stroke depends on the type of beverage consumed.

The Copenhagen City Heart Study [23] prospectively examined a cobort of 13,329 subjects for 16 years and showed that the effect of drinking beer, wine, and spirits on risk of total stroke varied among the 3 types of alcoholie beverages. Weekly wine consumption (compared with subjects who never hardly ever drank wine) was significantly associated to a reduced risk of stroke (ischemic and bemorrhagic) and the association for daily wine consumption was statistically boederline $(p=0.06)$. Intake of either beer of spirits was not associated with reduced risk of stroke; on the other hand subjects who drunk $\geq 42$ units per week had a 1.5 fold, significant, increase in risk.

Table 1. Subgroup analysis usiag studies ineluded in a" Wine or Beer drinkers versus non-driakers" meta-analysis

\begin{tabular}{|c|c|c|c|c|c|c|}
\hline & \multicolumn{3}{|c|}{ WINE } & \multicolumn{3}{|c|}{ BUER } \\
\hline & $\mathbf{N}$ & RR & $9 \mathrm{Ch} \times \mathrm{CI}$ & $\mathbf{N}$ & RR & $9 \mathrm{micl}$ \\
\hline Vancular Events & 13 & 0.68 & $0.59-0.77 *$ & 15 & 0.78 & $0.70-0.86^{\circ}$ \\
\hline \multicolumn{7}{|l|}{ Type ef event } \\
\hline Ceronary heart diseane & 11 & 0,71 & 0.590 .85 & 13 & 0.79 & $0.65-0.91$ \\
\hline Cerebrovaseulat disease & 2 & 0.43 & 0.240 .78 & 2 & 0.67 & $0.41-1.10$ \\
\hline
\end{tabular}




\begin{tabular}{|c|c|c|c|c|c|c|}
\hline Nen-faul vakular coents & $\mathrm{s}$ & 0.71 & $0.56-0.90$ & 7 & 0,74 & $0.57-0.96$ \\
\hline Candiovascolar mortality & 2 & 0.40 & $0.34-0.70$ & 3 & 0.76 & $0.55-1.05$ \\
\hline
\end{tabular}
controls, drinking up to 2 drinks/day of any type of alcoholic beverages was significantly associated with a lower risk of a first ischemic stroke, in a elderly multiethnic population. However, those who were predominantly wine drinkers had the lowest risk (RR, 0.40; 95\% CI, 0.23 to 0.70 ) and consumed, on average, less alcohol than those who drank beer or spirits or were drinkers of all types of alcoholic beverages. Intake of 7 of moee drinks of alcothol per dxy was significantly associated to an almost 3 fold increased risk.

From an Australian stady [25] among 331 matched case-control pairs, wine, beer, and spirit consumption were associated with a lowsr intracerebral hemorrhage risk, but the relation was statistically significant only for wine drinkers; in a separate analysis by gender. both wine and spirits were associaled to a lower intracerebral hemorrhage risk in men

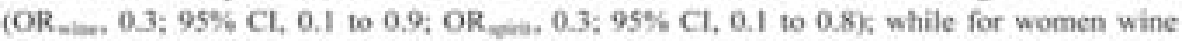
only was protective, although not significantly. This study too confirmed that heavy drinking of alcohol (more than 6 units/day) was significantly associated to a 3,4 fold increased risk of stroke.

In the Framingham Study population Djousse and Coll. $[17]$ assessed the effects of beer, wine, and spirits on the risk of ischemic stroke and observed a borderline association of current wine drinking with ischemic stroke (HR, $0.8 ; 95 \% \mathrm{C1}, 0.6$ to 1.0 ) but no effects foe beer (HR, 1.0; $95 \% \mathrm{Cl}_{1} 0.8$ to 1.4 ) or spirits (HR, $0.9 ; 95 \% \mathrm{Cl}, 0.7$ to 1.2 ). Mukamal and Coll. [16], with a semi-quantitative food-frequency questionnaire, ascertained regular and light consumption of beer, red and white wine, and liquor in a large prospective cohort study of male bealth professionalk. Red wine consumption was inversely associated with risk of ischemic stroke in a graded manner $(p=0,02$ for trend), while the other beverages were not.

The most important difference between wine and beer consumption was observed by our group in a meta-analysis of studies reporting wine and beer consumption in relation to vascular risk [9]. Pooling data from 13 prospective and case-control studies reporting relative risk of moderate (1-2 drinks per day, $150-300 \mathrm{ml}$ per day) wersas no wine consumption, the overall effect was a significant risk reduction of $32 \%(\mathrm{RR}, 0.68 ; 99 \% \mathrm{Cl}, 0.59$ to 0.77$)$, in a subgroup analysis where the main endpoint was cerebrovascular disease the pooled relative risk was $0.43(99 / 6 \mathrm{Cl}, 0.24$ to 0.78$)$ for wine intake, and $0.67(95 \% \mathrm{Cl}, 0.41$ to 1.10$)$ for beer intake (Table 1).

Overall these reports suggest a benefit on the risk of stroke for wine intake only; bowever at the present, a rigorous estimation of the ischemic and hemorthagic stroke risk associated with any specific alcoholic beverage is lacking.

\section{Ischemic Stroke in Young Subjects: is alcohol consumption a real risk factor?}


More than $10 \%$ of patients with stroke due to cerebral infarction are aged 55 years or less [26]. Stroke in the young is particularly detrimental for the lifetime disablement and requires a deeper evaluation in terms of risk. Indeed, an effective stroke prevention in the young cannot be attempted until the risk factors are clearly documented

While a number of studies have addressed the issue of stroke mechanism in the young. quantitation of major risk factors foe stroke has farely been undertaken and has not been systematically studied. Reasons for this probably include difficulties in making precise diagnoses before modern imaging techniques, selection of appropriate controls, and availability of sufficient sample size.

Heavy alcohol consumption as a risk factor for stroke in young adults has been observed in both hemorthagic and ischemie subtypes studies, In young woenen light-moderate alcohol consumption had protective effect on ischemic stroke.

In The Melboume Risk Factor Study [27], a total of 201 consecutive patients with firstonset stroke due to cerebral infarction, aged 15 to 55 years (mean, 45.5 years) wete recruited from four teaching hospitals during 1985 to 1992 and compared with age- and sex-matched neighbourhood controls. Significantly increased risk of stroke was found among those with diabetes, hypertension, heart disease, current cigarette smoking and long-term beavy alcohol consumption (more than 60 grams/day) (odds ratio (OR), 15.3; 95\% C1, 1.0 to 232.0). However, heavy alcohol ingestion within 24 bours precefing stroke onset was not a risk factor $(\mathrm{OR}, 0.9 ; 95 \% \mathrm{Cl}, 0.3$ to 3,4$)$.

The Hemorrhagic Stroke Project is a case-control study of hemornhagic stroke among men and women aged 18 to 49 years, with the main purpose of identifying risk factors for intracerebral hemorthage [28]. A total of 1,714 patients with bemorrhagic stroke were identified. Out of them, 217 cases met the criteria for primary intracerebral bemorrhage and were matched to 419 controls. Independent risk factors for intracerebral hemorrhage included hypertension, diabetes, current cigarette smoking, caffeinated drinks $5 /$ day and more than 2 alcoholic drinks for day (OR, $2.23 ; 95 \% \mathrm{Cl}, 1.16$ to 4.32 ).

The incidence of ischemic stroke in young women ranges from 4.3 to 8.9700000 per year in the United States and continental Europe [29,30]. In a recent study, Nightingale and Coll. [31] determined the ineidence and risk factors for ischemic stroke in young women (aged $15-49$ years) in the UK. The incidence of ischemic stroke was 3.56100000 per year. Among factors asseciated with an increased risk they found heavy alcohol consumption (more than 168 grams/week of alcohol; $\mathrm{OR}, 8.5 ; 95 \% \mathrm{Cl}, 3.6$ to 20.0), however light alcohot consumption was found to be protective ( $<72$ grams/week of alcohol; OR, $0.17 ; 95 \%$ CI. 0.09 10 0.34 ).

In The Stroke Prevention in Young Women Study [32], a popalation-based case-control study on stroke in young women, light to moderate alcobol consumption appeared to be associated with a reduced risk of ischemic stroke in young women. Alcohol consumption, up to 24 gramsiday, during the past year was associated with fewer ischemic strokes $\quad(<12$ grams/day: $\mathrm{OR}, 0.57,95 \% \mathrm{Cl}, 0.38$ to $0.86 ; 12$ to 24 grams/day: $\mathrm{OR}, 0.38 ; 95 \% \mathrm{Cl}, 0.17$ to 0.86 ; $>24$ gramvday: $\mathrm{OR}, 0.95 ; 95 \% \mathrm{Cl}, 0.43$ to 2.10 ) in comparison to never drinking. Analysis of beverage type (beer, wine, liquor) indicated a protective effect for light wine consumption in the previous year ( $<12$ grams/week: $0 R, 0.58 ; 95 \% \mathrm{Cl}, 0.35$ to 0.97 ). 
The majority of the cerebrovascular risk factors identified in these studies are modifiable. Thus, appropriate prevention strategies should have the potential to reduce the occurrence of stroke. In particular primary prevention initiatives addressed to beavy and binge drinkers in young population should be launched and supported.

\section{Biological Mechanisms of the Protective Effects of Alcohol and Wine-derived Products}

\section{Anti-atherogenic Effects}

Alterations in plasma lipoproteins, particularly increase in high density lipopeotein (HDL.) cholesterol, was considered as the nost plausible mechanism of the peotective effect of alcohol consumption from coronary heart disease (CHD) [33-35]. Commonly referred to as "good" cholesterol, HDL. bind to cholesterol into the bloodstream and bring it back to the liver for elimination or reprocessiag. lowering total cholesterol levels in body tissues and reducing the cholesterol build-up on the arterial wall.

However, the mechanisms through which wine might exert anti-atherogenic effects appear to be distinct from those of alcohol, and mainly attributable to the biological activities of its noth-alcobolic constituents.

Reactive oxygen species (ROS), generated by redox reaction pathwsys in aerobic eells are considered important mediators that regulate cell signalling and response. Excessive ROS production, at the site of vascular injury or inflammation, overwhelming the antioxidant defence of the organism, may be pathogenic for a variety of human discascs [36], including cardiovascular disease. Epidemiologic and laboratory studies have linked the intake of antioxidants to the reduction of CHD risk [37]. According to the exidative hypothesis of atherosclerosis, low density lipoproteins (L.DL) initially aceumulating in the extracellular subendothelial space of arteries, are mildly oxidized by local generation of ROS [38,39]. This minimally modified LDL are per se potent indacers of inflammatory molecules and therefore can stimulate vascular cells to produce monocyte-chemotactic and granulocyte- and macrophage-colony stimulating factors, leading to monocyte recruitment and differentiation in arterial wall. The accumulating monocytes and macrophages stimulate further L.DL. peroxidation and, simultaneously the protein component of LDL becomes more negatively charged. These highly modified LDL are avidly recognized by scavenger receptors on macrophages and internalized to form wo-called foam cells, a very early event in the patbogenesis of atheroma. Furthernore oxidized LDL also play a role in thrombus development, since they stimulate procougulant activities in endothelial cells and in monocytes, and inhibit vasodilation by down regulating the expression of endothelial nitric oxide (NO)-synthase [40],

Some of the observed effects of polyphenots on cellular systems involved in the pathogenesis of CVD can be therefore reconducted to their recognized antioxidant and radical scavenging properties [41]. Which may delay the exset of atberogenesis by reducing chemically and enzimatically mediated peroxidative reactions. 
The potential in vivo antioxidant properties of wine and its derived product have been evaluated in terms of their ability to enhance plasma antioxidant status, considered as an index of the capacity of the organism to generally counteract oxidative processes, as well as to reduce specific oxidative processes, these related to atherogenic L.DL, modifications in particular.

Studies in human volunteers showed increased plasma antioxidant capacity or protection of L.DL. from oxidation after consumption of red wine [42.43] marked suppression of plasma post-prandial hydroperoxide increase was found in volunteers when a fatty meal was consumed with wine, instead of water [44]. Other relevant antiatherogenie modifications concern the reported ability of red wine to increase plasma levels of HDL at levels above that obtained after alcobol consumption [45], or to reduce lipid deposition, in animal models, independently of their effects on lipid peroxidation [46]. As inflammation is a enveial component of the atherosclerotic process, it is of interest that resveratrol, a wine-derived polyphenol, significantly reduces the degree of colon injury, neutrophil infiltration, the levels of eytokines and the COX-2 expession in an animal model of experimentally indoced colitis [47].

\section{Anti-thrombotic Effects}

Other potential mechanisms contributing to the cardio-protective effect of moderate alcohol consumption include alterations of blood platelet function, coagulation and fibrinolysis. Alcohol seems to affect several factors involved in maintaining the delicate equilibrium between clos formation (to protect against bleeding) and clot dissolution (to prevent blood clots from forming in arteries), which have been implicated in the risk for myocandial infarction [48].

Alcohol consumption has been associated with increased levels of tissue plasminogen activator (tPA), the clot dissolving enryme, and lower levels of fibrinogen and antithrombin III [49-52]: reduced suseeptibility of platelets to agsregation has also been reported after alcohol consumption [53,54].

Polyphenols have been shewn to be able to modulate the finction of the different cellular components involved in the process of thrombosis in several systems. Interference with the arachidonic acid metabolism in both platelets and leukocytes have been reported, which resulted in inhibition of platelet aggregation and reduced synthesis of pro-thrombotic and pro-inflammatory modiators [55-57].

Polyphenols ean also down-regulate the expression of adthesive molecules and tissue factor activity, induced by several agonists, sach as cytokines or chemotactic agents, in both endothelial cells and leukocytes, resulting in functional modulation of cell-cell interactions and procoagulant activities $[58-60)$.

\section{Nitric Oxide}


Hypertension is associated with increased risk for atherosclerotic diseases such as stroke, and heart and kidney disease. Essential hypentension involves endothelial dysfunction with alierations in nitric oxide (NO) bioavailability and calcium handling, smooth muscle cell proliferation, thickening of the vessel walls, and increased peripheral vascular resistance and blood pressure [61,62].

Preserving normal endothelial function is crucial to blood pressure homeostasis and vessel integrity. One of the major factor involved in regulation of endothelial function is NO. Endothelium-derived NO is not only a potent vasodilator but inhibits platelet aguregation, vascular smooth muscle cell protiferation and intimal migration, and monocyte adhesion, thus regulating blood pressure and protecting vascular furstion [62]. Abnormalities in NO have been demonstrated in both hypertension and atheroselerosis.

The vasodilator effect of alcohol is related to a higher expression of the endothelial nitric oxide synthase (eNOS) and NO production [63]. Wine polyphenois were also shown to modulate NO-mediated responses. Fiszpatrick and Coll. $[64]$ first showed that certain wine extracts were able to relax pre-contracted smooth muscle of intact acrtic ring. and Andriambeloson and Coll. [65] demonstrated that the endothelium-dependent vaso-relaxation of rat aorta was mediated by an increase of NO aortic content. In addition, incuhation of endothelial cells with red wines up regulated NO synthase mRNA and protein expression, and produced up to there times more bioactive NO than did control cells [66]. Wallerath and Coll. [67] provides evidence that a blend of polyphenolic compounds in red wine likely stimulate the expression of the eNOS gene (and peeserve eNOS activity), thus leading to an enhanced production of vascular NO. Martin and Coll. [68] showed that both delphinidin and anthocyanidin (two polyphenols from red wine), inhäbit endothelial cell apoptosis via NO pathway and regulation of calcium boeneostasis. Wine itself may ameliocate endothelial dysfunction. A work of Wollny and Coll. [69] provides evidence that red wine rather than white wine or alcohol by itself modulates primary hacmostasis and prevents experimental thrombosis in rats, independently of its alcohol content, by a NO-mediated mechanism.

The different acute and chronic responses of vascular endothelium to alcohol may reflect an enhanced release of NO with low intakes of alcohol, but endothelial injury with acute heavier intake.

\section{Alcohol Consumption and Omega-3 Polyunsaturated Fatty Acids}

More recently an original mechanism to explain the peotective effect of alcohol has been proposed by de Longeril and Coll: the "fish-like effect of moderate wine drinking" hypothesis [70].

Omega-3 fatty acids (en3 FA) consumption reduces risk of sudden cardiac death in bumans $[71,72]$ and induces myocardial protection in animal experiments [73]. The Lyon Diet Heart Study (a cross-sectional study on French male patients with CHD), showed that moderate wine consumption was associated with higher levels of "marine" e.3 FA in plasma [70] independently from the dietary intake of specific plant and marine $\omega 3$. The Authors concluded that the protection resulting from moderate alcobol drinking may be mediated through increased $m 3$ FA. These results were confirmed in a recent animal study of the same 
research group [74]. They showed that moderate alcobol consumption was associated with increased levels of $\omega 3$ FA both in plasma and in red blood cell membranes.

The association of alcohol consumption with 63 FA in both plasma and red blood cells was also separately stadied in women and in men enrolled in Italy, Belgium and England, in the framewoek of the IMMIDIET study [75] Eicosapentanoic acid (EPA), docosahexanoic acid (DHA) and EPA+DHA in plasma, and EPA and EPA+DHA is red blood cells were all positively associated with alcohol intake. The association was stronger in woenen than in men. In whole population the association between different beverages (wine or beer) and levels of 23 FA was also investigated in wine drinkers, the association was confirmed both in plasma and red cell, while in ber and spirits drinkers only a weak association with DHA in plasma was found [76].

\section{Conclusions}

The relationship between aleobol consumption and exrebrovascular disease, and in particular stroke, is complex, in part reflecting the heterogeneity of vascular diseases.

Evidence suggests a J-shaped relationship betwoen aleohol consumption and ischemic stroke, with lower risk for moderate alcohol constumers (1-2 drinksiday). Heavy alcohol consamption increases the relative risk of total stroke (both ischemic and hemomhagic).

Up to now, the relationship between alcohol consumption and the different subtypes of ischemic and hemorrhagic stroke (i.e. atherothrombotic, lacunar, embolic, suburachnoid hemorrhage, intracerebral hemorrhage) has not been extensively investigated. Today, the modcm imaging techniques, by improving diagnostic accuracy of stroke subtypes, might allow a rightly designed epidcmiologic study and hopefully bring robust results.

Alcohol consumption should not be encouraged for those who do not already drink because of the harm associated with potential heavy use. Further research is needed to determine whether moderate alcohol consumption has a beneficial effect for specific subtypes of ischemic and bemorrhagic stroke.

An imensive programme is barely needed to reduce the gap between effective preventive strategies on the risk of stroke associated with irregular of heavy alcohol consumption and the joint effects with other risk factors, especially in young population.

\section{Acknowledgments}

The support of European Research Advisory Bourd (ERAB) grants (EA 0520 and EA 0S 27) is gratefully acknowledged.

\section{References}

[1] Maclure M. Demonstration of deductive meta-analysis: ethanol intake and risk of myocardial infarction. Endemiol. Rev. 1993:15:328-51. 
[2] Rimm EB, Klatsky A, Grobbee D, Stampfer M. Review of moderate alcohol consumption and reduced risk of coronary heart disease: is the effect due to beer, wine, or spirits. BMU 1996;312:731-6.

[3] Cleophas TJ. Wine, beer and spirits and the risk of myocardial infarction: a systematic review, Blomed Pharmacother, 1999;53:417-23.

[4] Di Castelnuovo A, Costanzo S, Bagnardi V, Donati MB, lacoviello L., de Gactano G. Alcohol dosing and total mortality in men and women: an updated meta-analysis of 34 prospective studies. Arch Imern. Mesl. 2006:166(22):2437-45.

[5] Thus M., Peto R, Loper AD, Monace JH, Henley SJ, Heath CW Jr, Doli R. Aleohol coesumption and mortality among middle-aged and elderly U.S. adults. $N$, Engl. $J$. Med, 1997;337:1705-14.

[6] White IR, Altmann Di, Nanchahal $K$. Alcohol consumption and mortality? modelling risks for men and women at different ages. BMU 2002;325:191.

[7] Corrao G, Bagnardi V, Zambon A, Arico S, Exploring the dose-response relationship between alcobol consumption and the risk of several alcohol-related conditions: a metaanalysis. Addiction 1999; 94:1551:73.

[8] Renaud S, De Lorgeril M. Wine, alcobol, platelets, and the French paradox for coronary heart disease, Lumcef 1992;339:1523-6.

[9] Di Castelnuovo A, Rotondo S, lacoviello L., Donati MB, de Gactano G. Meta-analysís of wine and beer consumption in relation to vascular risk. Cinculation 2002;105:28362844.

[10] Donnan GA, Fisher M, Macleod M. Davis SM. Stroke, Lancet 2008;371:1612-23.

[11] Mukamal KJ. Tolstrup JS, Friberg J, Jensen G, Granback M. Alcohol Consumption and risk of atrial fibrillation in men and women: the Copenhagen City Heart Study. Cinculation 2005; 112:1736-1742.

[12] Stampfer MJ, Colditz GA, Willett WC, Speizer FE, Hennekens CH. Prospective study of moderate alcohol consumption and the risk of coronary disease and stroke in women. N. Enel. J. Med, 1988:319:267-73.

[13] Klatsky AL, Amstrong MA, Friedman GD. Alcohol use and subsequent cerebrovascular disease hospitalizations. Stroke 1989;20;741-6.

[14] Klatsky AL, Armatrong MA, Sidney S, Friedman GD. Alcohol drinking and risk of ischemic stroke, Am, I. Candiol, 2001;88;703-6.

[15] Klatsky AL. Armstrong MA. Friedman GD, Sidney S. Alcohol and risk of hemorrhagie stroke, Neurospidemiology 2002;21:115-22.

[16] Mukamal KJ. Aseherio A, Mittieman MA, Conigrave KM, Camaryo CA Jr, Kawachi I, Stampfer MJ, Willet WC, Rimm EB. Alcohol and risk for ischemic stroke in men: the role of drinking patterns and usual beverage. Amn. Intern. Med, 2005:142:11-9.

[17] Djousse L, Ellison RC, Beiser A, Scaramocei A, D'Agostino R, Wolf PA. Alcohol consumption and risk of ischemic stroke: the Framingham Study. Srroke 2002:33:907912.

[18] Marzaglia G, Britton Annie R, Altmann DR, Chenct L. Exploring the relationship between alcohol consumption and non-fatal stroke: a systematic review. Addiction 2001; 96:1743-56. 
[19] Reynolds K, Lewis B, Nolen JD, Kinney GL., Sathya B, He J. Alcohol consumption and risk of stroke: a meta-analysis. JAAMA 2003;289:579-588.

[20] Corrao G, Bagrardi V, Zambon A, La Vecchia C. A meta-analysis of alcohol consumption and the risk of 15 diseases. Prov, Med. 2004;38:613-619.

[21] Feigin VI., Rinkel GJ, Lawes CM, Algra A, Beanett DA, van Gijn J, Andersoen CS.Risk factors for subarachnoid hemorrhage: an updated systematic review of epidemiological studies. Surake 2005: 36: 2773-2780.

[22] Ariesen M., Claus SP, Rinkel G., Algra A. Risk factors for intracerebral hemorrhage in the general population: a systematic review. Sirode 2003:34:2060-2065.

[23] Truelsen T, Gromback M, Schnohr P, Boysen G. Intake of ber, wine, and spirits and risk of stroke. The Copenhagen eity heart study. Siroke 1998;29:2467-72.

[24] Saceo RL, Flkind M, Boden-Albala B, Lin IF, Karyman DE, Hauser WA, Shea S,Paik MC. The protective effect of moderate aleohol consumption on ischemic stroke. J.AMA 1999:281:53-60.

[25] Thrif AG, Donnan GA, McNeil J. Heavy drinking, but not moderate of intermediate drinking, increases the risk of intracerebral hemorrhage. Epidemiology 1999;10:307-12.

[26] Gunzerath L., Faden V, Zakhari S, Warnen K. National Institute on Alcohol Abuse and Alcoholism report on moderale drinking. Alcahol. Clin. Exp. Rex. 2004; 28(6):829-47.

[27] You RX, MeNeil J, OMalley HM, Davis SM, Thrift AG, Domnan GA. Risk Factors for Stroke Due to Cerehral Infurction in Young Adults, Siroke 1997 28(10):1913-8.

[28] Feldmann E, Broderick IP, Kernan WN, Viscoli CM, Brass L.M, Brot T,Morgenstem LB, Wilherdink Л. Horwitz RL. Major risk factors for intracerebral hemorthage in the young are modifiable.Stroke $2005 ; 36(9): 1881-5$.

[29] Schwartz SM, Siscovick DS, Longstreth WT Jr, Poty BM, Beverly RK, Raghunathan TE, Lin D, Kocpsell TD. Use of low-dose oral contraceptives and stroke in young women, Anu. Jntern. Med, 1997;127(8 Pt 1):596-603.

[30] Kristensen B, Malm J, Carlberg B, Stegmayr B, Backanan C, Fagerland M, Olsson T. Epidemiology and etiology of ischemic stroke in young adults aged $18-44$ years in northem Sweden. Sirnode 1997;28:1702-9.

[31] Nightingale AL. Farmer R. Ischemic Stroke in Young Women A Nested Case-Control Study Usine the UK General Practice Research Database Stroke, 2004;35:1574-1578.

[32] Malarcher AM, Giles WH, Croft JB, Worniak MA, Wityk RJ, Stolley PD, Stern BJ, Sloan MA, Sherwin R, Price TR, Macko RF, Johnson CJ, Earley CJ, Buchhole DW, Kittner SJ. Alcohol intake, type of beverage, and the risk of eerebral infarction in young women. Strode 2001;32(1):77-83.

[33] Gariano JM, Buring JE, Breslow J., Goldhaber S7, Rosner B, VanDenburgh M, Willet W, Hennekens $\mathrm{CH}$. Moderate alcohol intake, increased levels of high-density lipoprotein and its subfractions, and decreased risk of myocardial infarction. $N$, Engl. J. Med. 1993: 329:1829-1834.

[34] Langer RD, Criqui MH, Reed DM. Lipoproteins and blood pressure as biological pathways for effect of moderate alcohol consumption on coronary heart disease. Circulation 1992;85:910-915. 
[35] Suh I. Shaten B., Cutler JA, Kuller LH. Alcobol use and mortality from coronary heart disease: the role of high- density lipoprotein cholesterol. The Multiple Risk Factor Intervention Trial Research Group. Amn. Intern. Mes/. 1992;116:881-887.

[36] Halliwell B. Free radicals, antioxidants, and human disease: curiosity, cause, or consequence? Lancet 1994;344:721-724.

[37] Diaz MN, Frei B, Vita JA, Keancy JF Jf, Antioxidants and atheroselerotic heart disease. N. Enel, J. Aed. 1997:337:408-416.

[38] Steinberg D. Arterial metabolism of lipoproteins in relation to aherogenesis. Amu. N. $Y$. Acod Sc. 1990:598:125-135.

[39] Ross R. The pathogenesis of atheroselerosis: a perspective for the 1990s. Nafure 1993; 362:801-809.

[40] Ballantyne CM. Low-density lipoproteins and risk for coronary artery disease. Am. $J$. Candiol. 1998;82:3Q-12Q.

[41] Riee-Evans C, Miller NJ, Paganga G. Antioxidant properties of phenolic compounds. Trends Plout Sci. 1997:2:152-159.

[42] Serafini M, Maiani G, Ferro-Luzei A. Alcohol-free red wine enhanees plasena antioxidant capacity in humans. J. Nutr. 1998;128(6):1003-7.

[43] Cao G, Russell RM, Lischner N, Prior RL_ Serum antioxidant capacity is increased by consumption of strawberries, spinach, red wine or vitamin $\mathrm{C}$ in elderly women. $J$. Nutr. $1998 ; 128(12): 2383-90$.

[44] Ursini F, Zamburlini A, Caczolato G, Maioerino M, Bon GB, Sevanian A. Postprandial plasma lipid hydroperoxides: a possible link between diet and atherosclerosis. Free Radic. Bial. Med, 1998;25(2):250-2.

[45] de Gaetano G, De Curtis A, di Castelnoovo A, Doeati MB, lacoviello L, Rotondo S. Antithrombotic effect of polyphenols in experimental models; a mechanism of reduced vascular risk by moderate wine consumption. Amn, $N$. $Y$. Acad Sei. 2002-957:174-88.

[46] Waddington E, Puddey 18, Croft KD. Red wine polyphenolic compounds inhibit atherosclerosis in apolipoprotein E-deficient mice independently of effects on lipid peroxidation. Am. J, Clin. Nutr, 2004;79(1):54-61.

[47] Martin AR, Villegas I, L.a Casa C, de L Lastra CA. Resveratrol, a polyphenol found in grapes, suppresses oxidative damage and stimulates apoptosis during early coloeic inflarmation in rats, Biochem. Pharmacal, 2004;67(7):1399.410.

[48] Rimm EB, Williams P, Fosher K. Criqui M, Starmpfer MJ. Moderate aleohol intake and lower risk of coronary heart disease: meta-analysis of effects on lipids and haemostatic factors, $B . M / 1999 ; 319(7224): 1523-8$.

[49] Hendriks HF, Veenstra J, Velthuis-te Wierik EJ, Sehafsma G, Klut C: Effect of moderate dose of alcohol with evening meal os fibrinolytic factors BMU 1994:308:1003-1006.

[S0] Ridker PM, Vaughan DE, Stampfer MU, Glynn R., Hennekens CH, Association of moderate alcohol consumption and plasma concentration of endogenous tissue-type plasminogen. JAMA 1994:272-929-933.

[51] Bijnen FC, Feskens EJ, Giampaoli S, Menotti A, Fidanza F, Hornstra G, Caspersen CJ, Mosterd WL., Kromhout D. Haemostatic parameters and lifestyle factors in elderly men in Italy and The Netherfands. Thromb. Hacmout. 1996;76:411-416. 
[52] Woodward M, Lowe GDO, Rumley A, Tunstall-Pedoe H, Philippou H, Lane DA. Morrison CE. Epidemiology of coagulation factors, inhibitors and activation markers: The Third Glasgow MONICA Survey II. Relatioeships to cardiovascular risk factors and prevalent candiovascular disease. Br. J. Hacmatol, 1997:97:785-797.

[53] Renaud SC, Ruf JC. Effects of alcohol on platelet functions. Clin. Chim. Aera 1996; 246:77.89.

[54] Elwood PC, Beswick AD, OBrien JR, Yarnell JWG, Layzell JC, Limb ES, Imerrelationships between haemostatic tests and the effocts of some dietary determinants in the Cacrphilly eohort of older men. Blood Coogal. Fibrinolysis 1993;4:529-536.

[55] Pace-Aseiak CR, Rounova O, Hahn SE, Diamandis EP, Goldberg DM. Wines and grape juices as modulators of platelet agerepation in healthy human subjects. Clint Chem. 1996:246:163-182.

[56] Polette A, Lemaitre D, Lagarde M, Vericel E. N-3 fatry acid-induced lipid peroxidation in human platelets is prevented by eatechins. Thromb. Hacmost 1996:75:945-949.

[57] Rotondo S, Rajtar G, Manarini S, Celardo A. Rotilio D, de Gactano G. Evangelista V. Cerletti C. Effect of trans-resveratrol, a natural polyphenolic compound, on human polymorphonuclear leukocyte function. Ar. J. Pharmacol. 1998;123:1691-1699.

[58] Pendurthi UR, Williams JT, Rao LV. Resveratrol, a polypbenolic compound found in wine, inhibits tissue factor expression in vascular cells : A possible mechanism for the cardiovascular benefits associated with moderate consumption of wine. Arierioscler. Thromb. Vase Biol. 1999;19:419.426.

[59] Di Santo A, Merretti A. Napoleone E, Di Tomuaso R, Donati MB, de Gaetano G. Lorenzet R. Resveratrol and quercetin down-regulate tissue factor expression by human stimulated vascular celts. I. Throwe. Hoemost, 2003;1(5):1089-95.

[60] Gerritsen ME, Carley WW, Ranges GE, Shen CP, Phan SA, Ligon GF, Perry CA: Flavonoids inhibit cytokine-induced endothelial cell adhesion peotein gene expression. Am. $J$. Pathal. 1995;147:278-292.

[61] Portaluppi F, Boari B, Manfredini R. Oxidative stress in essential hypertension. Curr. Pharm. Des, 2004;10:1695-8.

[62] Taddei S, Ghiadoni L, Virdis A, Versari D, Salvetti A. Mechanisms of endothelial dysfunction: Clinical signiflcance and perentative non-pharmacological therapeutic strategies. Curr, Pharm. Des, 2003;9:2385-402.

[63] Venkov CD, Myers PR. Tanner MA, Sa M, Vaughan DE. Ethanol increases endothelial nitric oxide production through modulation of nitric oxide synthase expression. Thramb, Hacmour, 1999;81, 638-642.

[64] Fitopatrick DF, Hirschfield SL, Coffey RG. Endothelium-dependent vasorelaxing activity of wine and other grape products, Am. J. Phosiol. 1993;265(2 Pt 2) d H774-8.

[65] Andriambeloson E, Kleschyov AL, Muller B, Beretr. A. Stoclet JC, Andriantsitokaina R. Nitric oxide production and endothelium-dependent vasorelaxation induced by wine polyphenols in rat aorta. Br. J. Pharmocol. 1997:120(6):1053-8.

[66] Wallerath T, Poleo D, Li H, Forstermann U, Red wine increases the expression of buman endothelial nitric oxide synthase: a mechanisan that may contribute to its beneficial cardionascular effects, J. Am, Coll. Candiol 2003;41(3):471-\$. 
[67] Wallenath T, Li H, Godtel-Ambrust U, Schwarz PM, Förstermann U. A blend of polyphenolic compounds explains the stimulatory effect of red wine on human endothelial NO synthase. Nitric Oxide 2005;12(2):97-104.

[68] Martin S, Giannone G. Andriantsitohaina R. . Martinez MC. Delphinidin, an active compound of red wine, inhibits endothelial cell apoptosis via nitric oxide pathway and regulation of calcium homecstasis, Br, f. Pharmacel, 2003,139;1095-1102.

[69] Wollny T, Aiello L, Di Tommaso D, Bellavia V, Rotilio D, Donati MB, de Gactano G. Iacoviello L. Modulation of hacmostatie function and prevention of experimental thrombosis by red wine in rats: a role for increased nitric oxide production. Br. $J$. Pharmacol. 1999;127(3):747-55.

[70] de Lorgeril M, Salen P, Martin J, Boucher F, de Leiris J. Interactions of wine drinking with omepa-3 farty acids in coronary hear disease patients. A fish-like effect of moderate wine drinking. Am. Heart J. 2008;155:175-81.

[7I] Albert CM, Campos H, Stampler M. Ridker PM, Manson JE, Willett WC, Ma J. Blood levels of long-chain n-3 fatty acids and the risk of sudden death. N. Engl. J. Med. 2002; 346:11113-8.

[72] GISS]-Prevenxione Investigators. Dietary sapplementation with n-3 polyunsaturated fatry acids and vitamin $\mathrm{E}$ after myocardial infaretion: results of the GISSI-Prevenzione trial. Lancet 1999;354:447.55,

[73] Oskarsson H., Godwin J, Gunnar RM, Thoenas JX Jr. Dictary fish oil supplementation reduces myocardial infarct size in a canine model of ischacmia and reperfusion. J. Am. Coll. Cardind, 1993;21:1280-5.

[74] Guiraud A, de Lorgeril M, Zeghichi S, Laporte F, Salen P, Saks V, Berraud N,Bloucher F, de Leiris J. Interactions of alcobol drinking with n-3 fatty acids in rats: potential consequences for the cardiovascular system. Br. J. Nutr, 2005:29:1-8.

[75] lacoviello L. Amout J, Buntinx F, Cappuccio FP, Dagnelie PC, de Lorgeril M, Dirckx C. Donati MB, Krogh V. Siani A; European Collaborative Group of the IMMIDIET Project. Dietary habit profile in European Coenmunities with different risk of myocardial infarction: the impact of migration as a model of gene-environment interaction-the IMMIDIET study. Nusr. Afesah. Cardionase. Dis. (suppl.) 2001: 11: 122-6.

[76] di Giuseppe R, de Lorgeril M, Salen P, Laporte F, Di Castelnuevo A, Krogh V, Siani A, Amout J, Cappuceio FP, van Dongen M, Donati MB, de Gaetano G, tacoviello L: European Collaborative Group of the IMMIDIET Project. Alcohol consumption and n3 polyunsaturated fatty acids in healthy men and women from 3 European populations. Aw J Clin Nitr. 2009:89(1):354-62. 



\section{Chapter - Reference E}

\section{ALCOHOL DOSING AND TOTAL MORTALITY IN MEN AND WOMEN: AN UPDATED META-ANALYSIS OF 34 PROSPECTIVE STUDIES}

Di Castelnuovo A, Costanzo S, Bagnardi V, Donati MB, Iacoviello L, de Gaetano G. Alcohol dosing and total mortality in men and women: an updated meta-analysis of 34 prospective studies. Arch Intern Med. 2006;166:2437-45. 



\title{
Alcohol Dosing and Total Mortality in Men and Women
}

\author{
An Updated Meta-analysis of 34 Prospective Studies
}

Augusto Di Castelnuovo, ScD; Simona Costanzo, ScD; Vincenzo Bagnardi, ScD;

Maria Benedetta Donati, MD, PhD; Licia Iacoviello, MD, PhD; Giovanni de Gaetano, MD, PhD

Background: Moderate consumption of alcohol is inversely related with coronary disease, but its association with mortality is controversial. We performed a metaanalysis of prospective studies on alcohol dosing and total mortality.

Methods: We searched PubMed for articles available until December 2005, supplemented by references from the selected articles. Thirty-four studies on men and women, for a total of 1015835 subjects and 94533 deaths, were selected. Data were pooled with a weighed regression analysis of fractional polynomials.

Results: AJ-shaped relationship between alcohol and total mortality was confirmed in adjusted studies, in both men and women. Consumption of alcohol, up to 4 drinks per day in men and 2 drinks per day in women, was inversely associated with total mortality, maximum protection being
$18 \%$ in women (99\% confidence interval, $13 \%-22 \%$ ) and $17 \%$ in men (99\% confidence interval, 15\%-19\%). Higher doses of alcohol were associated with increased mortality. The inverse association in women disappeared at doses lower than in men. When adjusted and unadjusted data were compared, the maximum protection was only reduced from $19 \%$ to $16 \%$. The degree of association in men was lower in the United States than in Europe.

Conclusions: Low levels of alcohol intake (1-2 drinks per day for women and 2-4 drinks per day for men) are inversely associated with total mortality in both men and women. Our findings, while confirming the hazards of excess drinking, indicate potential windows of alcohol intake that may confer a net beneficial effect of moderate drinking, at least in terms of survival.

\section{Arch Intern Med. 2006;166:2437-2445}

Author Affiliations: Laboratory of Genetic and Environmental Epidemiology, "John Paul II" Center for High Technology Research and Education in Biomedical Sciences, Catholic University, Campobasso (Drs Di Castelnuovo, Costanzo, Donati, Iacoviello, and de Gaetano), and Department of Statistics, University of Milan-Bicocca, Milan (Dr Bagnardi), Italy.

\section{A}

N INVERSE ASSOCIATION BEtween moderate alcohol consumption and coronary heart disease has been shown in observational studies. ${ }^{1-3}$ Mechanisms supporting this association include increased high-density lipoprotein cholesterol level and fibrinolysis, decreased platelet aggregation and coagulation factors, ${ }^{4}$ and beneficial effects on endothelial function and inflammation. ${ }^{5}$ Nonetheless, abuse of alcohol is unquestionably harmful. ${ }^{6-8}$ As a consequence, strong interest exists about the possibility that at any dose, the benefit of alcohol can overcome its harmful effects. ${ }^{7,8}$

The relationship between alcohol and mortality has been depicted as a J-shaped curve, attributed to a combination of beneficial and harmful effects. ${ }^{9-11}$ Indeed, if low alcohol intake is inversely related to coronary heart disease, the other side of the coin shows an increased risk of certain cancers, cirrhosis, and death from accidents associated with increased alcohol consumption. ${ }^{6}$
Moreover, whether alcohol has a different role in men and women is still debated. In previous studies, a similar inverse association of low doses of alcohol with cardiovascular disease in men and women was noted, ${ }^{7,12}$ but a meta-analysis of total mortality revealed a J-shaped relation only for men older than 34 years or women older than 54 years. ${ }^{9}$ Herein, we perform an updated meta-analysis of prospective studies to investigate the relationship between alcohol dosing and allcause mortality, separately in men and women.

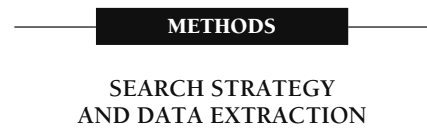

A PubMed search (www.pubmed.gov) identified studies published until December 2005, without a start date; studies were restricted to humans, and their titles and/or abstracts contained at least 1 of the following terms: alcohol, beer, wine, or spirits plus the term mortal- 


\begin{tabular}{|c|c|c|c|c|c|c|c|}
\hline Source & Country & $\begin{array}{c}\text { Follow-up, } \\
y\end{array}$ & $\begin{array}{c}\text { Age } \\
\text { Range, } \\
y\end{array}$ & $\begin{array}{c}\text { Total } \\
\text { Subjects, } \\
\text { No. }\end{array}$ & $\begin{array}{c}\text { Cases, } \\
\text { No. }\end{array}$ & $\begin{array}{c}\text { Level of } \\
\text { Adjustment* }\end{array}$ & $\begin{array}{l}\text { Subject Sex } \\
\text { and Notes }\end{array}$ \\
\hline Lin et al, ${ }^{13} 2005$ & Japan & 10 & $40-79$ & 80583 & 7334 & $1,3,5,6,7,8,9$ & $\mathrm{M}$ and $\mathrm{F}$ \\
\hline Doll et al, ${ }^{14} 2005$ & England & 23 & $48-78$ & 10741 & 6425 & 1,5 & $\mathrm{M}$ \\
\hline Nakaya et al, ${ }^{15} 2004$ & Japan & 11 & $40-64$ & 39076 & 1656 & $1,3,4,5,8,9,10,17$ & $\mathrm{M}$ and $\mathrm{F}$ \\
\hline $\begin{array}{l}\text { Britton and Marmot, }{ }^{16} \\
2004\end{array}$ & England & 11 & $35-55$ & 10214 & 282 & NR & $M$ and $F$ \\
\hline Tolstrup et al, ${ }^{17} 2004$ & Denmark & 8 & $55-65$ & 43982 & 2443 & $3,5,6,7,10,17$ & $\mathrm{M}$ and $\mathrm{F}$ \\
\hline Waskiewicz et al, ${ }^{18} 2004$ & Poland & 9.7 & $35-64$ & 5452 & 745 & $1,3,5,11,12$ & $\mathrm{M}$ and $\mathrm{F}$ \\
\hline Arndt et al, ${ }^{19} 2004$ & Germany & 10 & $25-64$ & 17165 & 693 & $1,2,5$ & M \\
\hline Malyutina et al, ${ }^{20} 2002$ & Russia & 9.5 & $25-64$ & 5645 & 815 & $1,3,5,6,11,12$ & M \\
\hline Rehm et al, ${ }^{21} 2001$ & United States & 11.3 & $\geq 18$ & 4258 & 411 & $1,3,4,5$ & $\mathrm{M}$ and $\mathrm{F}$ \\
\hline Theobald et al, ${ }^{22} 2001$ & Sweden & 26 & $18-65$ & 28001 & 4024 & NR & $\mathrm{M}$ and $\mathrm{F}$ \\
\hline Liao et al, ${ }^{23} 2000$ & United States & 6 & $\geq 40$ & 29610 & 3333 & $1,2,5,8,9,13$ & $\mathrm{M}$ and $\mathrm{F}$ \\
\hline Gaziano et al, ${ }^{24} 2000$ & United States & 5.5 & $40-84$ & 89299 & 3216 & $1,5,6,7,9,14$ & M \\
\hline $\begin{array}{l}\text { Wannamethee and } \\
\text { Shaper, }{ }^{25} 1999\end{array}$ & England & 16.8 & $40-59$ & 7272 & 1308 & $1,4,5,6,7,9,13,15,16$ & M \\
\hline Hoffmeister et al, ${ }^{26} 1999$ & Germany & 6.9 & $25-69$ & 15400 & 159 & $1,3,5$ & $\mathrm{M}$ and $\mathrm{F}$ \\
\hline Tsugane et al, ${ }^{27} 1999$ & Japan & 6 & $40-59$ & 17131 & 491 & $1,3,5,7,8,15,17$ & M \\
\hline Hart et al, ${ }^{28} 1999$ & Scotland & 21 & $35-64$ & 5766 & 1643 & $1,3,5,6,11,12,13,15,16$ & M \\
\hline Renaud et al, ${ }^{29} 1999$ & France & 15 & $40-60$ & 36250 & 3617 & $1,3,5,6$ & $\begin{array}{l}\text { M; separate data for } \\
\text { different types of } \\
\text { beverage }\end{array}$ \\
\hline Deev et al, ${ }^{30} 1998$ & $\begin{array}{l}\text { United States } \\
\text { and Russia }\end{array}$ & 13 & $40-69$ & 5565 & 1258 & $1,5,6$ & $\begin{array}{l}\text { M and F; separate } \\
\text { data for United } \\
\text { States and Russia }\end{array}$ \\
\hline Brenner et al, ${ }^{31} 1997$ & Germany & 7 & $25-64$ & 6689 & 140 & NR & M \\
\hline Yuan et al, ${ }^{32} 1997$ & China & 7.3 & $45-64$ & 17861 & 1198 & $1,3,5,17$ & M \\
\hline Keil et al, ${ }^{33} 1997$ & Germany & 7.9 & $45-64$ & 2084 & 141 & $1,5,6,8$ & $\mathrm{M}$ and $\mathrm{F}$ \\
\hline Simons et al, ${ }^{34} 1996$ & Australia & 6.4 & $\geq 60$ & 2787 & 544 & $1,5,6,8,9,12,19,21$ & $\mathrm{M}$ and $\mathrm{F}$ \\
\hline Fuchs et al, ${ }^{35} 1995$ & United States & 12 & $34-59$ & 85709 & 2658 & $1,5,7,8,9,12,17,18,19,20$ & $\mathrm{~F}$ \\
\hline $\begin{array}{l}\text { Rehm and Sempos, }{ }^{36} \\
1995\end{array}$ & United States & 15 & $25-74$ & 8662 & 2128 & $1,3,5,6,11,12,17$ & $\begin{array}{l}M \text { and } F \text {; separate } \\
\text { data for ages } \\
25-59 \text { y and } \geq 60 \text { y }\end{array}$ \\
\hline Goldberg et al, ${ }^{37} 1994$ & Japan & 15 & $51-75$ & 3793 & 819 & $1,5,10,11,12,17$ & $\begin{array}{l}\text { M; separate data for } \\
\text { ages } 51-64 \text { y and } \\
\geq 65\end{array}$ \\
\hline Gronbaek et al, ${ }^{38} 1994$ & Denmark & 11 & $30-79$ & 13285 & 2229 & NR & $\mathrm{M}$ and $\mathrm{F}$ \\
\hline Cullen et al, ${ }^{39} 1993$ & Australia & 23 & $\geq 40$ & 2066 & 965 & $1,3,5,8,9,10,11,12,13,15$ & $\mathrm{M}$ and $\mathrm{F}$ \\
\hline Klatsky et al, ${ }^{40} 1992$ & United States & 7 & All & 124740 & 4184 & $1,3,4,5,6,22$ & $\mathrm{M}$ and $\mathrm{F}$ \\
\hline Farchi et al, ${ }^{41} 1992$ & Italy & 15 & $45-64$ & 1536 & 463 & $1,3,5,6$ & M \\
\hline $\begin{array}{l}\text { Andreasson et al, }{ }^{42} \\
1991\end{array}$ & Sweden & 15 & $\geq 18$ & 49464 & 917 & NR & M \\
\hline $\begin{array}{l}\text { Boffetta and Garfinkel, }{ }^{43} \\
1990\end{array}$ & United States & 12 & $40-59$ & 239462 & 37079 & 1,5 & M \\
\hline Kono et al, ${ }^{44} 1986$ & Japan & 19 & All & 3033 & 804 & 1,5 & M \\
\hline Marmot et al, ${ }^{45} 1981$ & UK & 10 & $40-64$ & 1422 & 113 & 1 & M \\
\hline Dyer et al, ${ }^{46} 1981$ & United States & 17 & $40-55$ & 1832 & 298 & 1 & M \\
\hline
\end{tabular}

Abbreviation: NR, not reported.

*Adjustment codes: 1, age; 2, race; 3, education/profession/social class; 4, marital status; 5, smoking status; 6, body mass index; 7, physical activity; 8, hypertension; 9 diabetes mellitus; 10, baseline diseases; 11, blood pressure; 12, cholesterol level; 13, myocardial infarction or coronary heart disease; 14 , risk factors for coronary heart disease; 15 , forced expiratory volume in 1 second; 16 , siblings; 17 , dietary factors; 18 , aspirin use; 19 , family history of myocardial infarction or coronary heart disease; 20, menopausal status; 21, self-rated health; 22, coffee and tea.

ity or death. Assessment of the references was also conducted. Seventy-three publications were identified. Studies were excluded if they considered only 1 category of risk $(n=4)$ or did not report mortality separately for the sexes $(n=5)$ if they considered mortality for specific causes $(n=3)$ or if they comprised multiple reports $(n=9)$ (the longer follow-up was considered); or if the refer- ence category was not the one with the lowest alcohol intake $(n=4)$ or if relative risks or numbers of cases and person-years were not available $(\mathrm{n}=14)$. A total of 34 reports were identified. ${ }^{13-46}$ Fourteen studies* reported results sepa-

*References 13, 15-18, 21-23, 26, 33, 34, 38-40. rately for the sexes; 1 study ${ }^{37}$ reported data for 2 age groups, and 1 study ${ }^{29}$ for wine and beer. These studies contributed 2 dose-response curves each. Two studies contributed 4 curves: 1 study ${ }^{30}$ reported results separately for 2 ethnic groups and sexes, and another ${ }^{36}$ for age groups and sexes. In the end, 56 independent curves were available for metaanalysis, 37 in men and 19 in women. 
Whenever possible, adjusted relative risks were extracted; otherwise, crude relative risks and 95\% confidence intervals (CIs) were calculated from the number of events. ${ }^{16,22,31,38,42}$

The amount of a drink was taken as quantified by each author whenever possible; otherwise ( 7 studies) it was considered equivalent to $10 \mathrm{~g}$ of ethanol; considering a drink equivalent to either 12 or $14 \mathrm{~g}$ of ethanol did not change our results (data not shown).

\section{DATA ANALYSIS}

Data collected were as follows: (1) the value $x$ of alcohol intake (measured in grams per day) assigned as the midpoint of the reported ranges; $x$ was defined as 1.2 times the lower boundary for the open-ended upper categories $^{47}$; (2) frequency counts, adjusted relative risks, and 95\% CIs for each $x$ level; and (3) covariates describing the characteristics of the study. Inverse variance-weighted methods, taking into account the correlation between estimates within each study, were used. ${ }^{47}$ The models to be fitted were selected among fractional polynomial curves of the second order. ${ }^{48}$ Fractional polynomials are a family of models considering power transformations of a continuous exposure variable, restricted to a predefined set of integer and noninteger exponents. ${ }^{49}$ The regression models were $\log$ (relative risk $[R R])=\beta_{1} x^{p}+\beta_{2} x^{q}$ and the exponents $\mathrm{p}$ and $\mathrm{q}$ were selected among the following set: $\{-2.0,-1.0$, $-0.5,0.0,0.5,1.0,2.0\}$. When $\mathrm{p}=0, \mathrm{x}^{\mathrm{p}}$ is replaced by $\log (\mathrm{x})$, and when $\mathrm{p}=\mathrm{q}$, the model becomes $\log (\mathrm{R} R \mid \mathrm{x})$ $=\beta_{1} x^{p}+\beta_{2} x^{q} \log (x) .{ }^{11}$ These choices account for a rich set of possible functions, including J-shaped relations and conventional polynomials. The best fit was defined as that with the highest likelihood. This method assumes that the only source of variability is within study (fixed-effects model). To consider differences among studies as a further source of random variability, an additional component of the variance was added in weighing each observation (randomeffects model) ${ }^{50}$ The effects of covariates were evaluated, including appropriate interaction terms between covariate and exposure. ${ }^{47}$ To make some allowance for multiple comparisons, $99 \%$ CIs were used in subgroup analyses, and pairwise contrasts were adjusted following the Sidak method, as outlined by Ludbrook..$^{51}$ All analyses were carried out using an SAS

Table 2. General Characteristics and Results of Best Fitting Models

\begin{tabular}{|c|c|c|c|c|c|}
\hline Subgroup & $\begin{array}{l}\text { Curves, } \\
\text { No. }\end{array}$ & $\begin{array}{l}\text { Subjects, } \\
\text { No. }\end{array}$ & $\begin{array}{l}\text { Deaths, } \\
\text { No. }\end{array}$ & $\begin{array}{l}\text { Maximum } \\
\text { Protection, \% } \\
\text { (99\% Cl) g/d }\end{array}$ & $\begin{array}{l}\text { Reversion } \\
\text { Point, } g / d^{*}\end{array}$ \\
\hline All & 56 & 1015835 & 94533 & $19(17-20 \dagger) 6$ & 42 \\
\hline \multicolumn{6}{|l|}{ Level of adjustment } \\
\hline Not adjusted & 8 & 107653 & 7592 & $36(21-40) 10$ & 68 \\
\hline Adjusted at least for age & 48 & 908182 & 86941 & $17(15-18) 6$ & 37 \\
\hline $\begin{array}{l}\text { Adjusted for social status } \\
\text { too }\end{array}$ & 28 & 414680 & 29560 & $18(15-21) 9$ & 46 \\
\hline $\begin{array}{l}\text { Adjusted for social status } \\
\text { and dietary factors too }\end{array}$ & 10 & 126712 & 7916 & $18(12-24) 6$ & 30 \\
\hline \multicolumn{6}{|l|}{ Sexf } \\
\hline Women & 16 & 285490 & 13448 & $18(13-22) 5$ & 18 \\
\hline Men & 32 & 622692 & 73493 & $17(15-19) 6$ & 38 \\
\hline \multicolumn{6}{|l|}{ Country $\ddagger$} \\
\hline \multicolumn{6}{|l|}{ Women } \\
\hline United States & 7 & 182307 & 7576 & $19(13-24) 5$ & 22 \\
\hline Europe & 5 & 34036 & 1464 & $20(3-34) 4$ & 8 \\
\hline Australia, Japan, China & 4 & 69147 & 4408 & $12(0-23) 5$ & 27 \\
\hline \multicolumn{6}{|l|}{ Men } \\
\hline United States & 9 & 404428 & 46278 & $16(14-19) 4$ & 27 \\
\hline Europe & 14 & 121081 & 17812 & $24(20-28) 9$ & 58 \\
\hline Australia, Japan, China & 9 & 97183 & 9403 & $18(13-23) 6$ & 33 \\
\hline \multicolumn{6}{|l|}{ Type of reference group } \\
\hline $\begin{array}{l}\text { With light and/or former } \\
\text { drinkers }\end{array}$ & 21 & 247194 & 23937 & $23(20-26) 8$ & 52 \\
\hline $\begin{array}{l}\text { Without light and/or } \\
\text { former drinkers }\end{array}$ & 27 & 660988 & 63004 & $16(14-18) 5$ & 30 \\
\hline \multicolumn{6}{|l|}{ Sample sizeł } \\
\hline Small $(n \leq 6000)$ & 26 & 53901 & 11147 & $17(15-22) 5$ & 26 \\
\hline Large $(n>6000)$ & 22 & 854281 & 75794 & $15(10-20) 5$ & 36 \\
\hline \multicolumn{6}{|l|}{ Duration of follow-upł } \\
\hline Short ( $\leq 10 \mathrm{y})$ & 22 & 453161 & 25409 & $21(18-25) 6$ & 37 \\
\hline Long (>10y) & 26 & 455021 & 61532 & $15(13-27) 6$ & 34 \\
\hline \multicolumn{6}{|l|}{ Year of publication $\ddagger$} \\
\hline 1981-1998 & 25 & 500552 & 52652 & $15(13-18) 5$ & 29 \\
\hline $1999-2005$ & 23 & 407630 & 34289 & $21(18-24) 8$ & 48 \\
\hline
\end{tabular}

Abbreviation: $\mathrm{Cl}$, confidence interval.

*The reversion point is defined as the dose of alcohol at which the protection against total mortality is no longer statistically significant at the $99 \%$ confidence level.

$+95 \% \mathrm{Cl}$ rather than $99 \% \mathrm{Cl}$.

†ln the 48 adjusted studies.

macro, ${ }^{11}$ version 8.12 for Windows (SAS Institute Inc, Cary, NC).

\section{RESULTS}

\section{ALL STUDIES}

Thirty-four studies provided 56 independent dose-response curves for alcohol intake and mortality, for a total of 1015835 subjects and 94533 deaths from any cause. Thirty-seven curves (705 596 subjects and 78592 deaths) concerned men, and 19 (310 239 subjects and 15941 deaths), women. Characteristics of the studies are listed in Table 1. Briefly, 28 curves were from European, 17 from American, and 11 from other populations. Al- most half of the studies had a median follow-up longer than 10 years. A category of no alcohol intake that also excluded former drinkers was considered as the reference category for most curves $(n=30)$; the others curves used as reference those subjects who declared either no alcohol use $(n=12)$ or occasional use $(n=14)$; former drinkers were not excluded from either group.

The best fitting model was obtained at $\mathrm{p}=\mathrm{q}=0.5$, corresponding to the model $\log (\mathrm{RR})=\beta_{1} \sqrt{\mathrm{x}}+\beta_{2} \sqrt{\mathrm{x}}$ $\times \log (\mathrm{x})$. The fitted parameters (SE) were $\beta_{1}=-0.1592(0.0056)(P<.001)$ and $\beta_{2}=0.0421(0.0014)(P<.001)$ (Table 2 and Table 3). The relationship observed has to be interpreted as a J-shaped curve (Figure 1) 


\begin{tabular}{|c|c|c|c|c|c|}
\hline \multirow[b]{2}{*}{ Subgroup } & \multicolumn{4}{|c|}{ Parameters of the Best Fitted Model } & \multirow{2}{*}{$\begin{array}{c}P \text { Value } \\
\text { for } \\
\text { Difference }\end{array}$} \\
\hline & $\beta_{1}$ (SE) & $\begin{array}{c}P \\
\text { Value }\end{array}$ & $\beta_{2}(\mathrm{SE})$ & $\begin{array}{c}P \\
\text { Value }\end{array}$ & \\
\hline All & $-0.1592(0.0056)$ & $<.001$ & $0.0421(0.0014)$ & $<.001$ & \\
\hline \multicolumn{6}{|l|}{ Level of adjustment } \\
\hline Not adjusted & $-0.2927(0.0165)$ & $<.001$ & $0.0661(0.0040)$ & $<.001$ & \\
\hline Adjusted at least for age & $-0.1437(0.0059)$ & $<.001$ & $0.0388(0.0015)$ & $<.001$ & $<.001 *$ \\
\hline $\begin{array}{l}\text { Adjusted for social status } \\
\text { too }\end{array}$ & $-0.1425(0.0094)$ & $<.001$ & $0.0356(0.0022)$ & $<.001$ & $<.001 \dagger$ \\
\hline $\begin{array}{l}\text { Adjusted for social status } \\
\text { and dietary factors too }\end{array}$ & $-0.1594(0.0215)$ & $<.001$ & $0.0428(0.0055)$ & $<.001$ & $.03 \ddagger$ \\
\hline Sex§ & & & & & $<.001$ \\
\hline Women & $-0.1719(0.0184)$ & $<.001$ & $0.0533(0.0056)$ & $<.001$ & \\
\hline Men & $-0.1445(0.0063)$ & $<.001$ & $0.0388(0.0015)$ & $<.001$ & \\
\hline \multicolumn{6}{|l|}{ Country§ } \\
\hline Women & & & & & $>.54 \|$ \\
\hline United States & $-0.1829(0.0215)$ & $<.001$ & $0.0562(0.0064)$ & $<.001$ & \\
\hline Europe & $-0.2047(0.0657)$ & $<.001$ & $0.0678(0.0207)$ & $<.001$ & \\
\hline Australia, Japan, China & $-0.1044(0.0458)$ & .01 & $0.0295(0.0149)$ & .02 & \\
\hline Men & & & & & $.003 \rrbracket$ \\
\hline United States & $-0.1489(0.0088)$ & $<.001$ & $0.0431(0.0023)$ & $<.001$ & \\
\hline Europe & $-0.1923(0.0121)$ & $<.001$ & $0.0460(0.0028)$ & $<.001$ & \\
\hline Australia, Japan, China & $-0.1513(0.0180)$ & $<.001$ & $0.0406(0.0043)$ & $<.001$ & \\
\hline Type of reference group§ & & & & & $<.001$ \\
\hline $\begin{array}{l}\text { With light and/or former } \\
\text { drinkers }\end{array}$ & $-0.1825(0.0110)$ & $<.001$ & $0.0444(0.0025)$ & $<.001$ & \\
\hline $\begin{array}{l}\text { Without light and/or } \\
\text { former drinkers }\end{array}$ & $-0.1429(0.0073)$ & $<.001$ & $0.0405(0.0019)$ & $<.001$ & \\
\hline Sample size§ & & & & & .61 \\
\hline Small $(n \leq 6000)$ & $-0.1230(0.0160)$ & $<.001$ & $0.0337(0.0039)$ & $<.001$ & \\
\hline Large $(n>6000)$ & $-0.1459(0.0664)$ & $<.001$ & $0.0393(0.0016)$ & $<.001$ & \\
\hline Juration of follow-up§ & & & & & $<.001$ \\
\hline Short ( $\leq 10 y)$ & $-0.1852(0.0110)$ & $<.001$ & $0.0486(0.0027)$ & $<.001$ & \\
\hline Long (>10y) & $-0.1268(0.0070)$ & $<.001$ & $0.0347(0.0017)$ & $<.001$ & \\
\hline Year of publication§ & & & & & $<.001$ \\
\hline $1981-1998$ & $-0.1388(0.0079)$ & $<.001$ & $0.0399(0.0020)$ & $<.001$ & \\
\hline $1999-2005$ & $-0.1733(0.0094)$ & $<.001$ & $0.0432(0.0022)$ & $<.001$ & \\
\hline
\end{tabular}

*For the comparison adjusted $(n=48)$ vs not adjusted $(n=8)$.

†For the comparison adjusted for social status $(n=28)$ vs adjusted except for social status $(n=20)$.

FFor the comparison adjusted for social status and dietary factors $(n=10)$ vs adjusted for social status but not for dietary factors $(n=8)$

$\S$ In the 48 adjusted studies.

|Sidak-adjusted $P$ value for pairwise comparisons among countries for women were United States vs other, $P=.59$; United States vs Europe, $P=.94$; Europe vs other, $P=.53$

१Sidak-adjusted $P$ value for pairwise comparisons among countries for men were United States vs other, $P<.001$; United States vs Europe, $P=.002$; Europe vs other, $P=.003$

since, after an initial decrease in mortality by increasing alcohol intake (a shape depending on the negative value of $\beta_{1}$ ), the curve reaches a plateau and reverts at higher amounts $\left(\beta_{2}>0\right)$. The association with a lower mortality was apparent up to $42 \mathrm{~g} / \mathrm{d}$ (about 4 drinks per day), and the lowest mortality was seen at $6 \mathrm{~g} / \mathrm{d}$, or about half a drink daily (RR, 0.81 [95\% CI, 0.80-0.83]). The metaregression analysis was repeated using random-effects models. The model with $\mathrm{p}=\mathrm{q}=0.5$ was again selected; the curve was very similar (Figure 1), but as expected, CIs were larger. The deviances of fixed and ran- dom effects models fell from 879.4 to $154.0(P<.001$ for the difference $)$, suggesting evidence of heterogeneity among studies. In the following analyses, the role of study characteristics in explaining the interstudy heterogeneity was explored. The model with $\mathrm{p}=\mathrm{q}=0.5$ was consistently fitted.

\section{ADJUSTED STUDIES}

Forty-eight curves (908 182 subjects and 86941 deaths) were adjusted at least for age; among them, 28 were adjusted for social status too, and 10 for social status and dietary markers (Table 1). Figure $2 \mathrm{~A}$ shows the pooled curves for different levels of adjustment. The difference was highly significant $(P<.001)$, showing that part of the heterogeneity is amenable to adjustment. The association with lower mortality decreased in adjusted studies, maximum protection falling from $36 \%$ to $17 \%$ (Table 2 and Table 3), but it remained substantial and statistically significant. Adjustment for social status and dietary markers did not affect the results (Table 2 and Table 3 and Figure 2A). In addition, we compared adjusted with nonadjusted data derived from the same studies. Nonadjusted RRs were available for 34 curves. Using nonadjusted data, the pooled curve predicted a maximum protection of $19 \%$ ( $99 \%$ CI $17 \%-21 \%$ ) in comparison with $16 \%$ (99\% CI, 14\%-18\%) obtained from adjusted data (Figure 2B). Further analyses were conducted on the 48 adjusted curves.

\section{ADJUSTED STUDIES IN MEN AND WOMEN}

Among adjusted studies, 32 curves were on men and 16 on women. Overall, the curves for men and women were different $(P<.001)$; in particular, $\beta_{2}$ was greater in women, whereas $\beta_{1}$ was not (Table 2 and Table 3). As a consequence, the protection was apparent up to 3 drinks per day in men but only up to 2 drinks per day in women (Table 2 and Table 3 and Figure $3 \mathrm{~A}$ ); on the contrary, the maximum risk reduction was similar in men (17\%; $99 \%$ CI, $15 \%-19 \%)$ and women (18\%; $99 \%$ CI, 13\%-22\%). Thirteen studies provided separate curves for men and women recruited from the same population; the pooled curves for men and women were different for the range at which alcohol remained protective but comparable regarding the maximum protection (data not shown).

\section{ADJUSTED STUDIES IN DIFFERENT COUNTRIES}

In women, pooled curves obtained using data from the United States or Europe or other countries (Australia, Japan, and/or China) 
were comparable (Figure 3B and Table 2 and Table 3) ( $P>.54$ for differences between countries). In contrast, strong differences were observed in men (Figure $3 \mathrm{C}$ and Table 2 and Table 3) $(P<.003$ for each pairwise comparison, showing that part of heterogeneity in men is attributable to the set of the study). In particular, maximum risk reduction was in the range $20 \%$ to $28 \%$ in European but $14 \%$ to $19 \%$ in US studies, and the protection extended up to 6 drinks per day in European but only up to 3 drinks per day in US studies.

Further subgrouping of US data according to ethnicity provided no evidence of heterogeneity (data not shown).

\section{OTHER SUBGROUP ANALYSES}

In studies that used as reference the category of no alcohol intake and excluded former drinkers, the protection was significantly lower $(P<.001)$ (Figure 4A and Table 2 and Table 3).

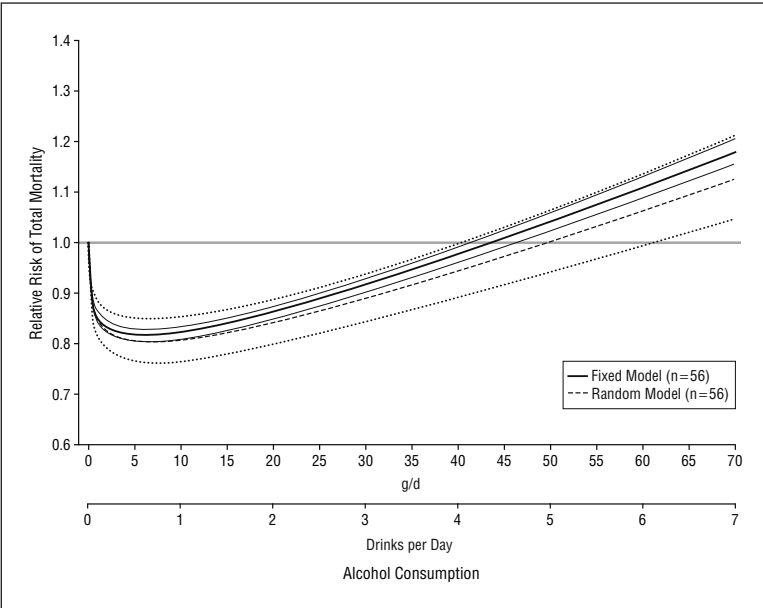

Figure 1. Relative risk of total mortality ( $95 \%$ confidence interval) and alcohol intake extracted from 56 curves using fixed- and random-effects models.
The pooled curves were similar in larger and smaller studies (Figure 4B and Table 2 and Table 3 ) $(P=.61)$.

In studies published before 1998 or with follow-up longer than 10 years, the protection was slightly but significantly lower (Figure 4C and D and Table 2 and Table 3$)(P<.001)$.

\section{COMMENT}

In this updated meta-analysis of 34 prospective studies, findings were pooled from more than 1 million subjects and almost 100000 deaths from any cause. We observed a J-shaped relationship between total mortality and alcohol intake, showing that a low level of alcohol consumption is significantly associated with reduced total mortality, while highlevel consumption is associated with increased mortality. Our metaanalysis, including 10 articles published after 2000 that could not be considered in former meta-analyses, ${ }^{9-11}$ also took advantage of a novel approach recently developed by a team of researchers, including one of us (V.B.). ${ }^{11}$ Special attention was paid to differences between sexes and to the role of confounding.

The dose-response curves are similar for both sexes when alcohol intake is light, but they differ with heavier intake; in fact, the inverse association in women apparently disappears at doses lower than

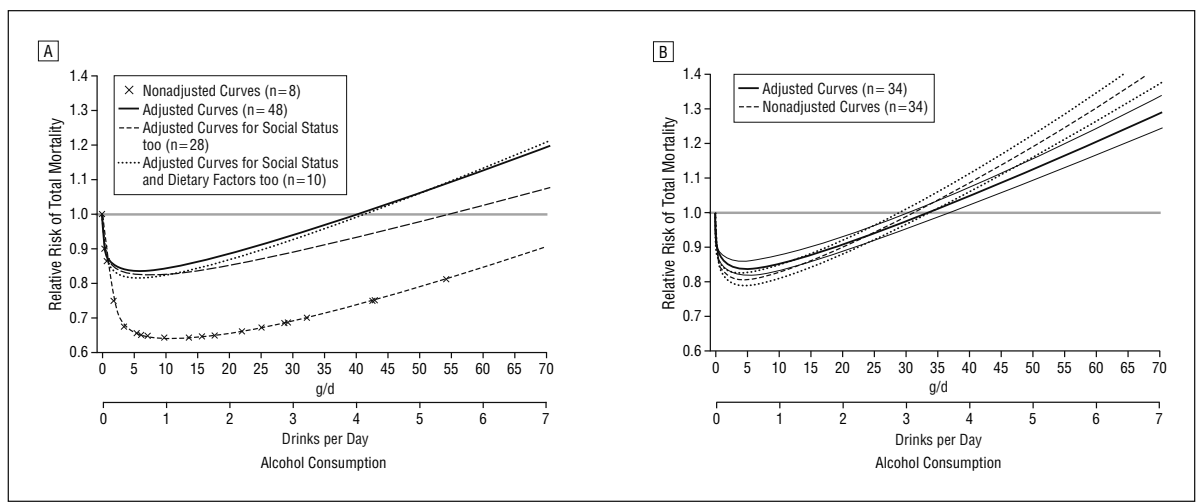

Figure 2. Relative risk of total mortality and alcohol intake curves. A, Plotted according to level of adjustment; confidence intervals overlapped and so, for greater clarity, are not represented. B, Plots include confidence intervals and show adjusted and unadjusted data from 34 curves for which adjusted and unadjusted data were available.

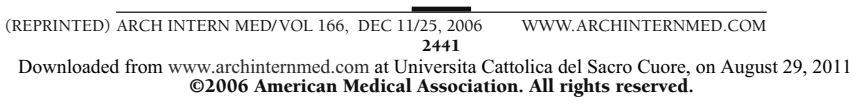




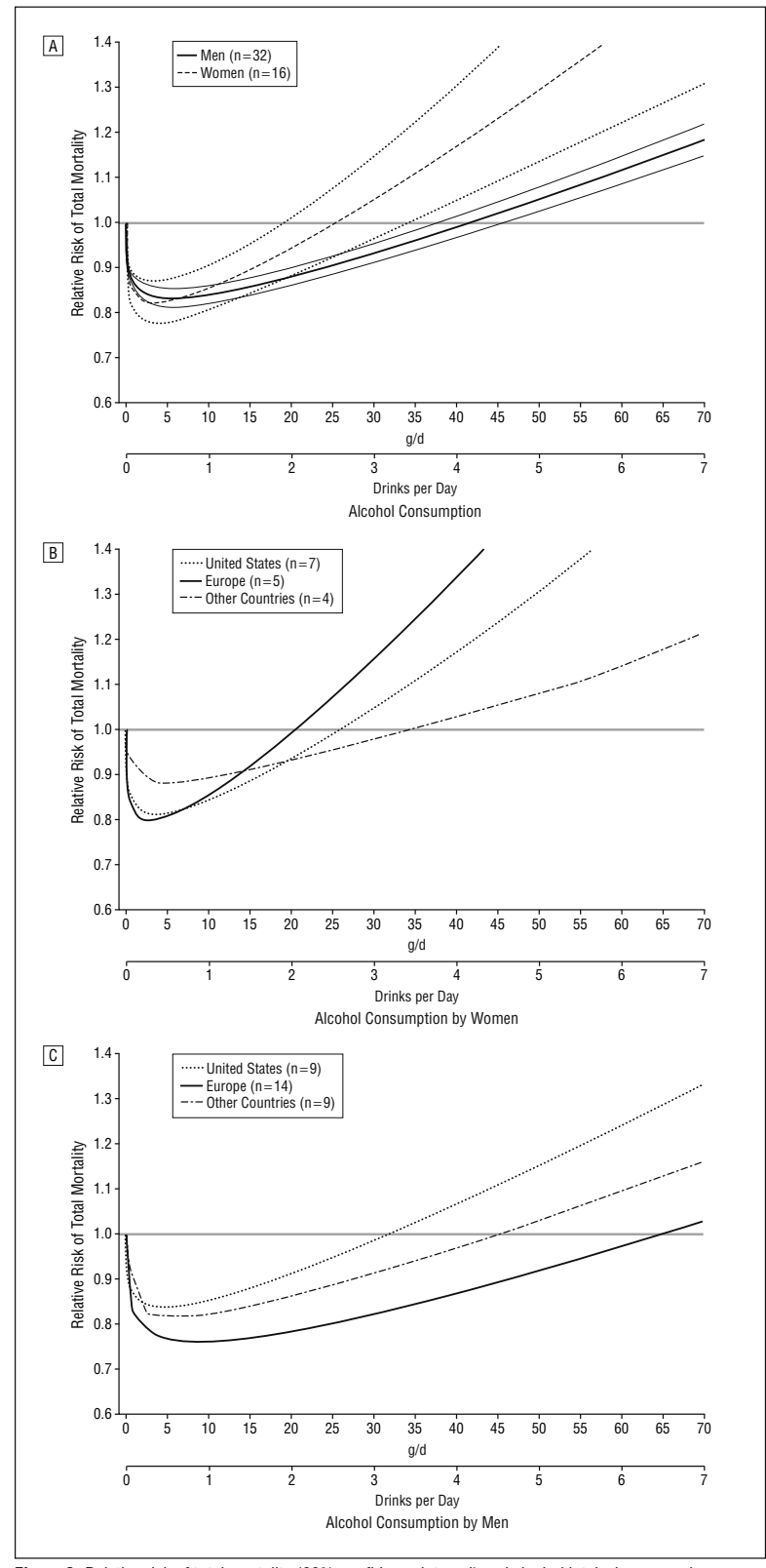

Figure 3. Relative risk of total mortality ( $99 \%$ confidence interval) and alcohol intake in men and women (A) and in women (B) and men (C) in the United States, Europe, and other countries (Australia, Japan, and/or China), extracted from adjusted curves. In B and C, confidence intervals overlapped and so for clarity were not depicted. in men, in agreement with previous findings. ${ }^{10}$ Women are more exposed than men to death for any cause at moderate to high levels of alcohol consumption, probably owing to increasing risk of cancer. ${ }^{6}$ Experimental evidence shows that when men and women consume the same amount of alcohol, women experience higher blood alcohol concentrations. Women metabolize ethanol differently and have a lower gastric alcohol dehydrogenase activity, resulting in higher blood ethanol levels and higher risk of liver disease. ${ }^{52}$ Finally, because premenopausal women have a low incidence of cardiovascular disease, the benefits of alcohol on total mortality may appear to be reduced.

The degree of association was lower in adjusted studies, as might be expected in view of several confounding factors characterizing observational studies on drinking habits ${ }^{3,8}$; however, the benefit of light to moderate drinking remained in a range of undoubted public health value (15\%-18\%). Although residual confounding cannot be excluded, ${ }^{8}$ it would be very unlikely to modify the scenario in a substantial manner. We found indeed that when adjusted and unadjusted data derived from the same studies were compared, the maximum protection conferred by light to moderate drinking only decreased from 19\% to $16 \%$; we can thus presume that even in the pessimistic hypothesis that residual confounding would have the same strength in lowering the protection as that of known confounding, the "real" (maximum) protection against total mortality associated with low levels of alcohol consumption would still be higher than $10 \%$. A similar reasoning would also apply to the harm associated with heavier drinking.

The relationship with mortality appears to be lower in US-based than in European studies, but only in men. Such a difference has no obvious explanation. Would women living in either continent follow more comparable drinking habits than men? Would it be linked to the lower amounts of alcohol consumed more regularly by women all over the world? Both the amount and the pattern of drinking is im- 


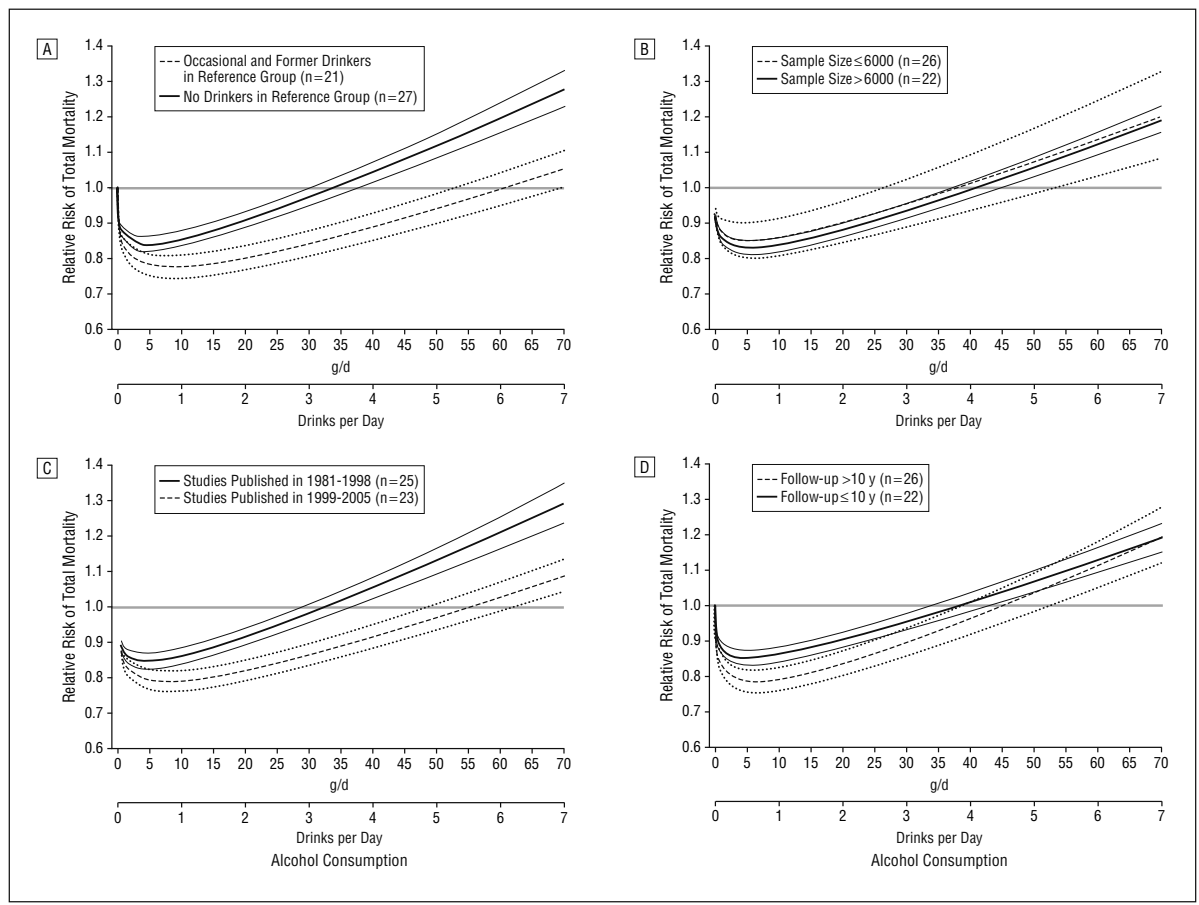

Figure 4. Relative risk of total mortality ( $99 \%$ confidence interval) and alcohol intake stratified according to type of reference category (A), sample size at baseline (B), year of publication (C), and follow-up duration (D).

portant for the effect of alcohol ${ }^{53}$; in particular, drinking wine at meals (a typical habit in European Mediterranean areas) enhances the ability of wine to prevent the development of atheromatous lesions. ${ }^{54}$ In contrast, binge or irregular drinking, most likely exerted by men, is an unhealthy habit..$^{55}$ Moreover, influence of genetics on the effect of ethanol has also been described. ${ }^{56}$ Possible differences in pattern of drinking and/or in the distribution of genetic factors might explain different results observed in studies conducted in American or European men

The results of any meta-analysis may be plagued by publication bias; nevertheless, we considered only follow-up studies on total mortality, and it is hard to hypothesize that high-quality studies would not have been published because they reported negative results. We believe therefore that publication bias-if any-might have only weakly altered our findings.

Underreporting of alcohol consumption would result in a tendency for RRs to be biased toward the null hypothesis, and this may have distorted the shape of the J-curve and the apparent threshold for harm.

The selection of nondrinkers as a reference group has been questioned because this group may include ex-drinkers who stopped drinking because of health problems. ${ }^{3,57}$ A subgroup analysis restricted to studies that excluded either ex-drinkers or very light drinkers from the reference group generated a pooled curve that indeed predicted a lower (though statistically significant) protection, confirming the importance of properly selecting the reference group in studies on alcohol and health. ${ }^{3,10,57}$

Duration of the follow-up and year of publication have been iden- tified as other sources of heterogeneity. However, stratification analyses for these characteristics resulted in pooled curves that consistently predicted a substantial reduction in total mortality, within comparable alcohol dose ranges.

Randomized controlled trials offer a more solid answer than observational studies to many questions in medicine, mainly restricted, however, to the efficacy of drugs; controlled intervention trials on diet in general and on alcohol in particular are difficult and ethically questionable to perform. ${ }^{7,57}$ One has therefore to rely on observational studies such as those analyzed here or prospective studies where participants spontaneously decrease alcohol consumption or stop drinking altogether. Interestingly, the first study of the latter type ${ }^{58}$ supports the inverse relation of moderate alcohol intake with coronary heart disease.

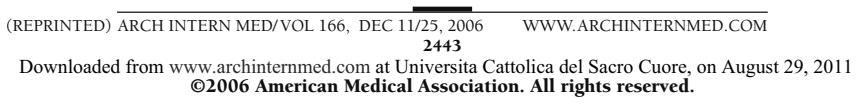


In conclusion, this metaanalysis confirms the hazards of excess drinking but also indicates the existence of potential windows of alcohol intake that may confer a net beneficial effect of drinking, at least in terms of survival, both in men and in women. Heavy drinkers should be urged to cut their consumption, but people who already regularly consume low to moderate amounts of alcohol should be encouraged to continue.

Accepted for Publication: August 30, 2006.

Correspondence: Licia Iacoviello, MD, PhD, Laboratory of Genetic and Environmental Epidemiology, "John Paul II" Center for High Technology Research and Education in Biomedical Sciences, Catholic University, Largo Gemelli 1, 86100 Campobasso, Italy (licia.iacoviello @rm.unicatt.it).

Author Contributions: All authors have read the final version and approved submission of the manuscript. Study concept and design Di Castelnuovo, Donati, Iacoviello, and de Gaetano. Acquisition of data: Di Castelnuovo and Costanzo. Analysis and interpretation of data Di Castelnuovo, Costanzo, Bagnardi, and Iacoviello. Drafting of the manuscript: Di Castelnuovo, Costanzo, and de Gaetano. Critical revision of the manuscript for important intellectual content: Bagnardi, Donati, Iacoviello, and de Gaetano. Statistical analysis: Di Castelnuovo and Bagnardi. Obtained funding: Donati. Administrative, technical, and material support: Costanzo. Study supervision: Donati, Iacoviello, and de Gaetano.

Financial Disclosure: None reported.

Funding/Support: Research for this article was funded by the Italian Ministry of University, Research, Education (MIUR), Decreto No. 158819/11/2004

Role of the Sponsor: The sponsor of the study had no involvement in study design; data collection, analysis, or interpretation; writing of the report; or in the decision to submit the paper for publication.

\section{REFERENCES}

1. Rimm EB, Klatsky A, Grobbee D, Stampfer MJ Review of moderate alcohol consumption and reduced risk of coronary heart disease: is the effect due to beer, wine, or spirits. BMJ. 1996;312: 731-736.

2. Reynolds K, Lewis B, Nolen JD, Kinney GL, Sathy $B$, He J. Alcohol consumption and risk of stroke: a meta-analysis. JAMA. 2003;289:579-588.

3. Di Castelnuovo A, Rotondo S, lacoviello L, Donati MB, de Gaetano G. Meta-analysis of wine an beer consumption in relation to vascular risk. Circulation. 2002;105:2836-2844

4. Rimm EB, Williams $P$, Fosher K, Criqui M, Stampfer MJ. Moderate alcohol intake and lower risk of coronary heart disease: meta-analysis of effects on lipids and haemostatic factors. BMJ. 1999;319: 1523-1528.

5. Estruch R, Sacanella E, Badia E, et al. Different effects of red wine and gin consumption on inflammatory biomarkers of atherosclerosis: a prospective randomized crossover trial: effects of wine on inflammatory markers. Atherosclerosis. 2004 175:117-123.

6. Corrao G, Bagnardi V, Zambon A, La Vecchia C A meta-analysis of alcohol consumption and the risk of 15 diseases. Prev Med. 2004;38:613-619.

7. Gronbaek M, Di Castelnuovo A, lacoviello L, et al. Wine, alcohol and cardiovascular risk: open issue. J Thromb Haemost. 2004;2:2041-2048.

8. Jackson R, Broad J, Connor J, Wells S. Alcoho and ischaemic heart disease: probably no free lunch. Lancet. 2005:366:1911-1912.

9. White IR, Altmann DR, Nanchahal K. Alcohol consumption and mortality: modelling risks fo men and women at different ages. BMJ. 2002 325:191.

10. Gmel G, Gutjahr E, Rehm J. How stable is the risk curve between alcohol and all-cause mortality and what factors influence the shape? a precisionweighted hierarchical meta-analysis. Eur Epidemiol 2003:18:631-642.

11. Bagnardi V, Zambon A, Quatto P., Corrao G. Flexible meta-regression functions for modeling aggregate dose-response data, with an application to alcohol and mortality. Am J Epidemiol. 2004 159:1077-1086

12. Di Castelnuovo A, lacoviello L, de Gaetano G. Alcohol and coronary heart disease. NEngl J Med. 2003;348:1719-1722.

13. Lin Y, Kikuchi S, Tamakoshi A, et al. Alcohol consumption and mortality among middle-aged an elderly Japanese men and women. Ann Epidemio 2005:15:590-597.

14. Doll R, Peto R, Boreham J, Sutherland I. Mortality in relation to alcohol consumption: a prospective study among male British doctors. Int $J$ Epidemiol. 2005;34:199-204.

15. Nakaya N, Kurashima K, Yamaguchi J, et al. Alcohol consumption and mortality in Japan: the Miyagi cohort study. J Epidemiol. 2004;14(supp 1):S18-S25.

16. Britton A, Marmot M. Different measures of atcohol consumption and risk of coronary heart disease and all-cause mortality: 11-year follow-up of the Whitehall II cohort study. Addiction. 2004 99:109-116.

17. Tolstrup JS, Jensen MK, Tjonneland A, Overvad $\mathrm{K}$, Gronbaek M. Drinking pattern and mortality in middle-aged men and women. Addiction. 2004 99:323-330.

18. Waskiewicz A, Sygnowska E, Drygas W. Relationship between alcohol consumption and cardio- vascular mortality: the Warsaw Pol-MONICA Project. Kardiol Pol. 2004;60:552-557.

19. Arndt V, Rothenbacher D, Krauledat R, Daniel U Brenner H. Age, alcohol consumption, and allcause mortality. Ann Epidemiol. 2004;14: 750-753.

20. Malyutina S, Bobak M, Kurilovitch S, et al. Relation between heavy and binge drinking and allcause and cardiovascular mortality in Novosibirsk, Russia: a prospective cohort study. Lancet. 2002;360:1448-1454.

21. Rehm J, Greenfield T, Rogers JD. Average volume of alcohol consumption, patterns of drinking and all-cause mortality: results from the US National Alcohol Survey. Am J Epidemiol. 2001; 153:64-71

22. Theobald $H$, Johansson $S$, Bygren L, Engfeldt $P$. The effects of alcohol consumption on mortality and morbidity: a 26-year follow-up study. J Stud Alcohol. 2001;62:783-789.

23. Liao Y, McGee DL, Cao G, Cooper R. Alcohol intake and mortality: findings from the National Health Interview Surveys (1988 and 1990). Am J Epidemiol. 2000;151:651-659.

24. Gaziano JM, Gaziano TA, Glynn RJ, et al. Lightto-moderate alcohol consumption and mortality in the Physicians' Health Study enrollment cohort. J Am Coll Cardiol. 2000;35:96-105.

25. Wannamethee SG, Shaper AG. Type of alcoholic drink and risk of major coronary heart disease events and all-cause mortality. Am J Public Health 1999;89:685-690.

26. Hoffmeister H, Schelp FP, Mensink GBM, Dietz $E$, Bohning $D$. The relationship between alcoho consumption, health indicators and mortality in the German population. Int J Epidemiol. 1999; 28:1066-1072.

27. Tsugane S, Fahey MT, Sasaki S, Baba S; JPHC Study Group. Alcohol consumption and all-cause and cancer mortality among middleaged Japanese men: seven-year follow-up of the JPHC study cohort I. Am J Epidemiol. 1999; 150:1201-1207.

28. Hart CL, Smith GD, Hole DJ, Haethorne VM Alcohol consumption and mortality from al causes, coronary heart disease, and stroke: results from a prospective cohort study of Scottis men with 21 years of follow up. BMJ. 1999; 318:1725-1729.

29. Renaud SC, Gueguen R, Siest G, Salamon R. Wine, beer, and mortality in middle-aged men from Eastern France. Arch Intern Med. 1999;159 1865-1870.

30. Deev A, Shestov D, Abernathy J, Kapustina A Muhina N, Irving S. Association of alcohol consumption to mortality in middle-aged U.S. and Russian men and women. Ann Epidemiol. 1998; 8:147-153.

31. Brenner H, Arndt V, Rothenbacher D, Schuberth $\mathrm{S}$, Fraisse $\mathrm{E}$, Fliedner TM. The association between alcohol consumption and all-cause mortality in a cohort of male employees in the German construction industry. Int J Epidemiol. 1997 26:85-91.

32. Yuan JM, Ross RK, Gao YTG, Henderson BE, Y MC. Follow up study of moderate alcohol intak and mortality among middle-aged men in Shanghai, China. BMJ. 1997;314:18.

33. Keil U, Chambless LE, Doring A, Filipiak B, Stieber $J$. The relation of alcohol intake to coronary heart disease and all-cause mortality in a beerdrinking population. Epidemiology. 1997;8: 150-156.

34. Simons LA, Friedlander Y, McCallum J, Simons J. Alcohol intake and survival in the elderly: a 77 
month follow-up in the Dubbo study. Aust $N Z J$ Med. 1996;26:662-670.

35. Fuchs CS, Stampfer MJ, Colditz GA, et al. Alcohol consumption and mortality among women. N Engl J Med. 1995;332:1245-1250.

36. Rehm J, Sempos CT. Alcohol consumption and all-cause mortality. Addiction. 1995;90: 471-480.

37. Goldberg RJ, Burchfiel CM, Reed DM, Wergowske $G$, Chiu D. A prospective study of the health effects of alcohol consumption in middle-aged and elderly men: the Honolulu Heart Program. Circulation. 1994;89:651-659.

38. Gronbaek M, Deis A, Sorensen TIA, et al. Influence of sex, age, body mass index, and smoking on alcohol intake and mortality. BMJ. 1994; 308:302-306.

39. Cullen KJ, Knuiman MW, Ward NJ. Alcohol and mortality in Busselton, Western Australia. Am J Epidemiol. 1993;137:242-248

40. Klatsky AL, Armstrong MA, Friedman GD. Alcohol and mortality. Ann Intern Med. 1992;117: 646-654.

41. Farchi G, Fidanza F, Mariotti S, Menotti A. Alcohol and mortality in the Italian rural cohorts of the Seven Countries Study. Int J Epidemiol. 1992;21:74-81.

42. Andreasson S, Romelsjo A, Allebeck P. Alcohol, social factors and mortality among young men. Br J Addict. 1991;86:877-887.
43. Boffetta P, Garfinkel L. Alcohol drinking and mortality among men enrolled in an American Cancer Society prospective study. Epidemiology. 1990; 1:342-348

44. Kono S, Ikeda M, Tokudome S, Nishizumi M, Kuratsune M. Alcohol and mortality: a cohort study of male Japanese physicians. Int JEpidemiol. 1986; 15:527-532.

45. Marmot MG, Rose G, Shipley MJ, Thomas BJ. Alcohol and mortality: a U-shaped curve. Lancet 1981;1:580-583.

46. Dyer AR, Stamler J, Paul 0, et al. Alcohol, cardiovascular risk factors and mortality: the Chicago experience. Circulation. 1981;64:20-27.

47. Berlin JA, Longnecker MP, Greenland S. Metaanalysis of epidemiologic dose-response data. Epidemiology. 1993;4:218-228.

48. Greenland S. Dose-response and trend analysis in epidemiology: alternative to categorical analysis. Epidemiology. 1995;6:356-365.

49. Royston P, Altman DG. Regression using fractional polynomials of continuous covariates: parsimonious parametric modelling. Appl Stat. 1994; 43:429-467.

50. DerSimonian R, Laird N. Meta-analysis in clinical trials. Control Clin Trials. 1986;7:177-188.

51. Ludbrook J. Multiple comparison procedures updated. Clin Exp Pharmacol Physiol. 1998; 25:1032-1037.
52. Ely $M$, Hardy $R$, Longford NT, Wadsworth ME Gender differences in the relationship between alcohol consumption and drink problems are largely accounted for by body water. Alcohol Alcohol. 1999:34:894-902

53. Puddey IB, Rakic V, Dimmitt SB, Beilin LJ. Influence of pattern of drinking on cardiovascular disease and cardiovascular risk factors: a review. Addiction. 1999;94:649-663.

54. Ursini F, Sevanian A. Wine polyphenols and optimal nutrition. Ann N Y Acad Sci. 2002:957:200-209.

55. Mukamal KJ, Maclure M, Muller JE, Mittleman MA. Binge drinking and mortality after acute myocardial infarction. Circulation. 2005:112: 3839-3845.

56. Djousse L, Levy D, Herbert AG, et al. Influence of alcohol dehydrogenase $1 \mathrm{C}$ polymorphism on the alcohol-cardiovascular disease association (from the Framingham Offspring Study). Am J Cardiol. 2005;96:227-232.

57. Rehm J, Gmel G. Sempos CT, Trevisan M. Alcoholrelated morbidity and mortality. Alcohol Res Health. 2003;27:39-51.

58. Gronbaek M, Johansen D, Becker U, et al. Changes in alcohol intake and mortality: a longitudinal population-based study. Epidemiology. 2004;15: 222-228. 



\section{Chapter - Reference F}

WINE, BEER OR SPIRIT DRINKING IN RELATION TO FATAL AND NON-FATAL CARDIOVASCULAR EVENTS: A METAANALYSIS

Costanzo S, Di Castelnuovo A, Donati MB, Iacoviello L, de Gaetano G. Wine, beer or spirit drinking in relation to fatal and non-fatal cardiovascular events: a metaanalysis. Eur J Epidemiol. 2011;26(11):833-50. 



\title{
Wine, beer or spirit drinking in relation to fatal and non-fatal cardiovascular events: a meta-analysis
}

\author{
Simona Costanzo • Augusto Di Castelnuovo • \\ Maria Benedetta Donati · Licia Iacoviello • \\ Giovanni de Gaetano
}

Received: 15 July $2011 /$ Accepted: 31 October 2011

(C) Springer Science+Business Media B.V. 2011

\begin{abstract}
In previous studies evaluating whether different alcoholic beverages would protect against cardiovascular disease, a J-shaped relationship for increasing wine consumption and vascular risk was found; however a similar association for beer or spirits could not be established. An updated meta-analysis on the relationship between wine, beer or spirit consumption and vascular events was performed. Articles were retrieved through March 2011 by PubMed and EMBASE search and a weighed least-squares regression analysis pooled data derived from studies that gave quantitative estimation of the vascular risk associated with the alcoholic beverages. From 16 studies, evidence confirms a J-shaped relationship between wine intake and vascular risk. A significant maximal protection-average $31 \%$ (95\% confidence interval (CI): $19-42 \%$ ) was observed at $21 \mathrm{~g} /$ day of alcohol. Similarly, from 13 studies a J-shaped relationship was apparent for beer (maximal protection: $42 \%$ (95\% CI: $19-58 \%$ ) at $43 \mathrm{~g} /$ day of alcohol). From 12 studies reporting separate data on wine or beer consumption, two closely overlapping dose-response curves were obtained (maximal protection of $33 \%$ at 25 $\mathrm{g} /$ day of alcohol). This meta-analysis confirms the J-shaped association between wine consumption and vascular risk and provides, for the first time, evidence for a similar relationship between beer and vascular risk. In the metaanalysis of 10 studies on spirit consumption and vascular risk, no J-shaped relationship could be found.
\end{abstract}

S. Costanzo - A. Di Castelnuovo - M. B. Donati .

L. Iacoviello $(\bowtie) \cdot$ G. de Gaetano

Laboratory of Genetic and Environmental Epidemiology,

Research Laboratories, Fondazione di Ricerca e Cura "Giovann

Paolo II", Largo Gemelli 1, 86100 Campobasso, Italy

e-mail: licia.iacoviello@rm.unicatt.it
Keywords Meta-analysis - Alcohol · Cardiovascular disease $\cdot$ Mortality

\section{Introduction}

The relationship between alcohol consumption and cardiovascular events or all-cause mortality in apparently healthy people or cardiovascular patients has been depicted as a J-shaped curve attributed to a dose-related combination of beneficial and harmful effects [1-7]. Numerous mechanisms have been proposed that mediate the protective effect of alcohol (ethanol) in cardiovascular disease (e.g., increased levels of high-density lipoprotein cholesterol, decreased levels of low-density cholesterol, reduction in platelet aggregation, beneficial effects on inflammation) $[8,9]$. On the other hand, anti-atherogenic and anti-thrombotic effects and regulation of endothelial function were mainly ascribed to polyphenolic and phenolic constituents of (red) wine [10] and beer [11, 12], respectively.

The influence of separate wine or beer consumption on health outcomes has been examined in various conditions: while experimental studies suggest an alcohol-independent protective role of wine-derived polyphenols on cardiovascular risk [10], epidemiological evidence of a greater effect of wine versus beer or spirits is lacking. In 2002, some of us performed a meta-analysis focused on this issue [2] and observed a J-shaped relationship for increasing wine consumption and vascular risk; however a similar association for beer could not be established. In the following years, additional studies have been published (especially on beer consumption) and a new statistical method tailored for meta-analytic investigation of non-linear dose-response effects became available [13]. 
Therefore, the aim of this study was to update (increased number of studies), to improve (more refined methodology of analysis), and to extend (including spirits as a third type of alcoholic beverage) our previous meta-analysis on the relationship between alcoholic beverages consumption and vascular risk and to include (when possible) the clinical endpoints of cardiovascular and total mortality.

\section{Materials and methods}

Search strategy and data extraction

Our meta-analysis was performed in accordance with the "meta-analysis of Observational Studies in epidemiology" reporting guidelines [14]. Articles were retrieved until March 2011, by search in PUBMED and EMBASE using at least one of the following terms alcohol, wine, beer, liquor, spirits in combination with, cardiovascular disease mortality, morbidity, survival, and death, supplemented by references of the retrieved articles and reviews. Studies were excluded if they were not in English, or only considered one category of risk (i.e., drinkers versus notdrinkers), or mortality for specific causes (except vascular mortality) or when the reference category was not the one with the lowest intake or when relative risks or numbers of cases and person-years were not available. In case of multiple reports, data from the longer follow-up were considered.

A check of abstracts identified by electronic searches using the aforementioned keywords and consequently a full text revision of selected articles considering the inclusion and exclusion criteria was performed. Ninety-seven publications were identified (Fig. 1); two of us independently reviewed articles and agreed to select 18 studies [15-32]. Events for vascular mortality included cardiovascular disease (CVD), coronary heart disease (CHD) and ischemic heart disease (IHD), whereas non-fatal vascular events comprised acute myocardial infarction (AMI), stroke and CHD. Four studies reported results separately for all-cause and vascular mortality [19, 22, 31, 32], two for fatal and non-fatal vascular disease [15, 16], 10 for non-fatal vascular disease (AMI, stroke, CHD, CVD) [17, 18, 20, 23-25, 27, 29, 30], one for all-cause [26] and two for CHD mortality as unique endpoint [21, 28] (Tables 1 and 2). In relation to beverage type, 11 studies investigated the effects of wine, beer and spirits, 2 studies investigated the effects of wine and beer, four studies wine and one study beer only (Table 2).

In seven studies, former drinkers had been excluded from reference group, whereas in other 7 studies, either the inclusion or the exclusion of former drinkers from
Fig. 1 Flow chart of the selected studies

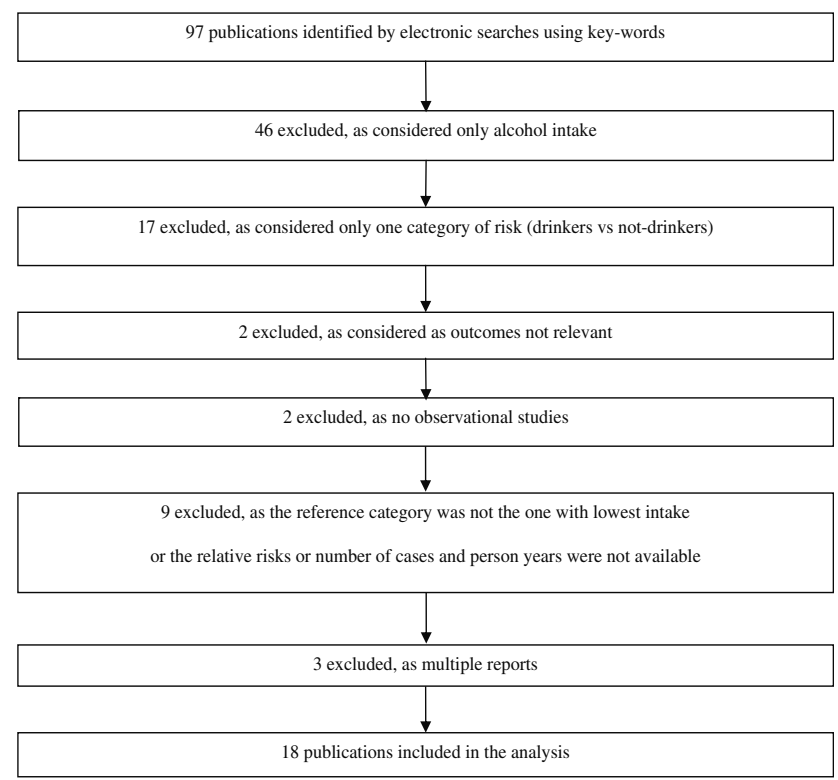




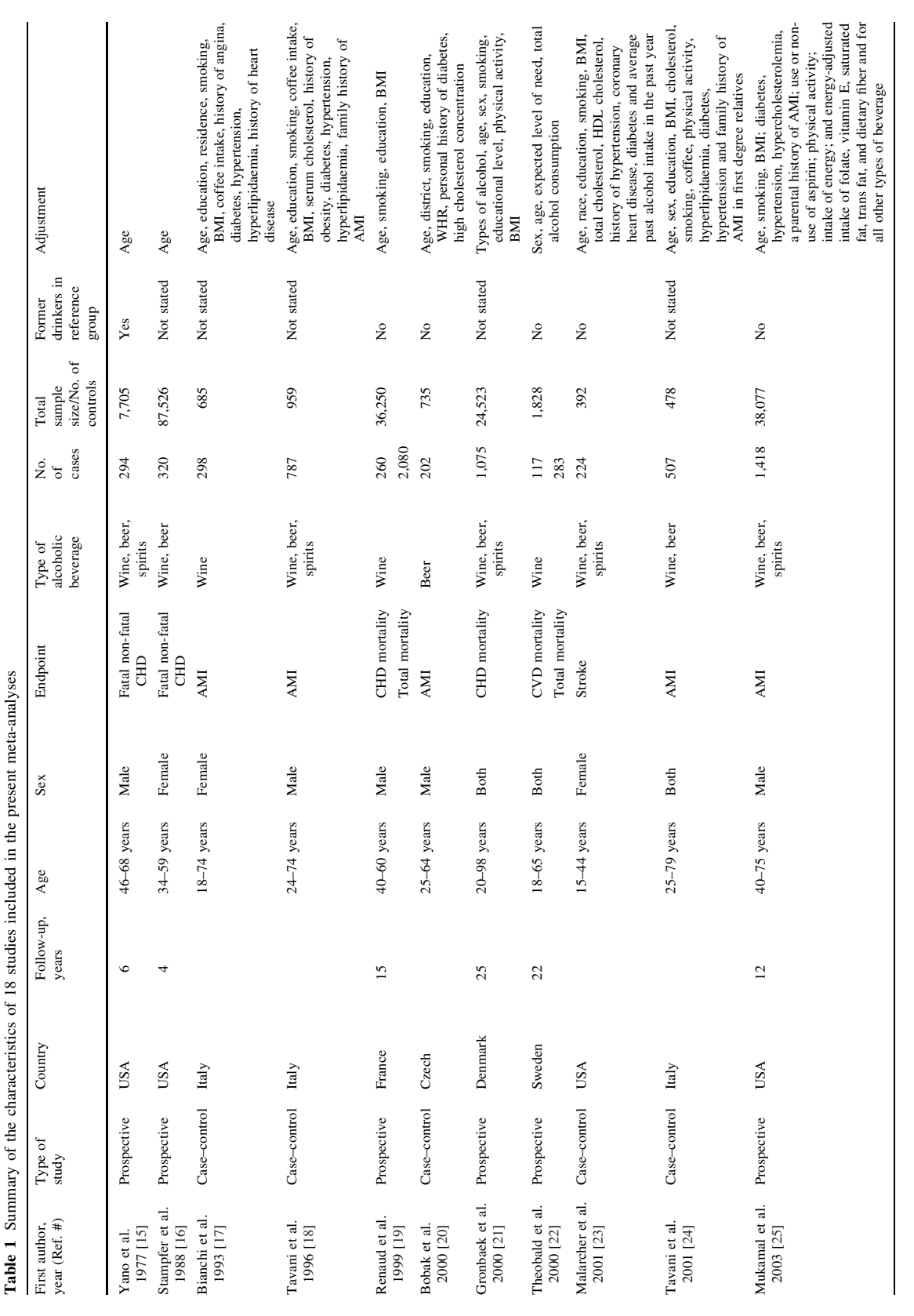




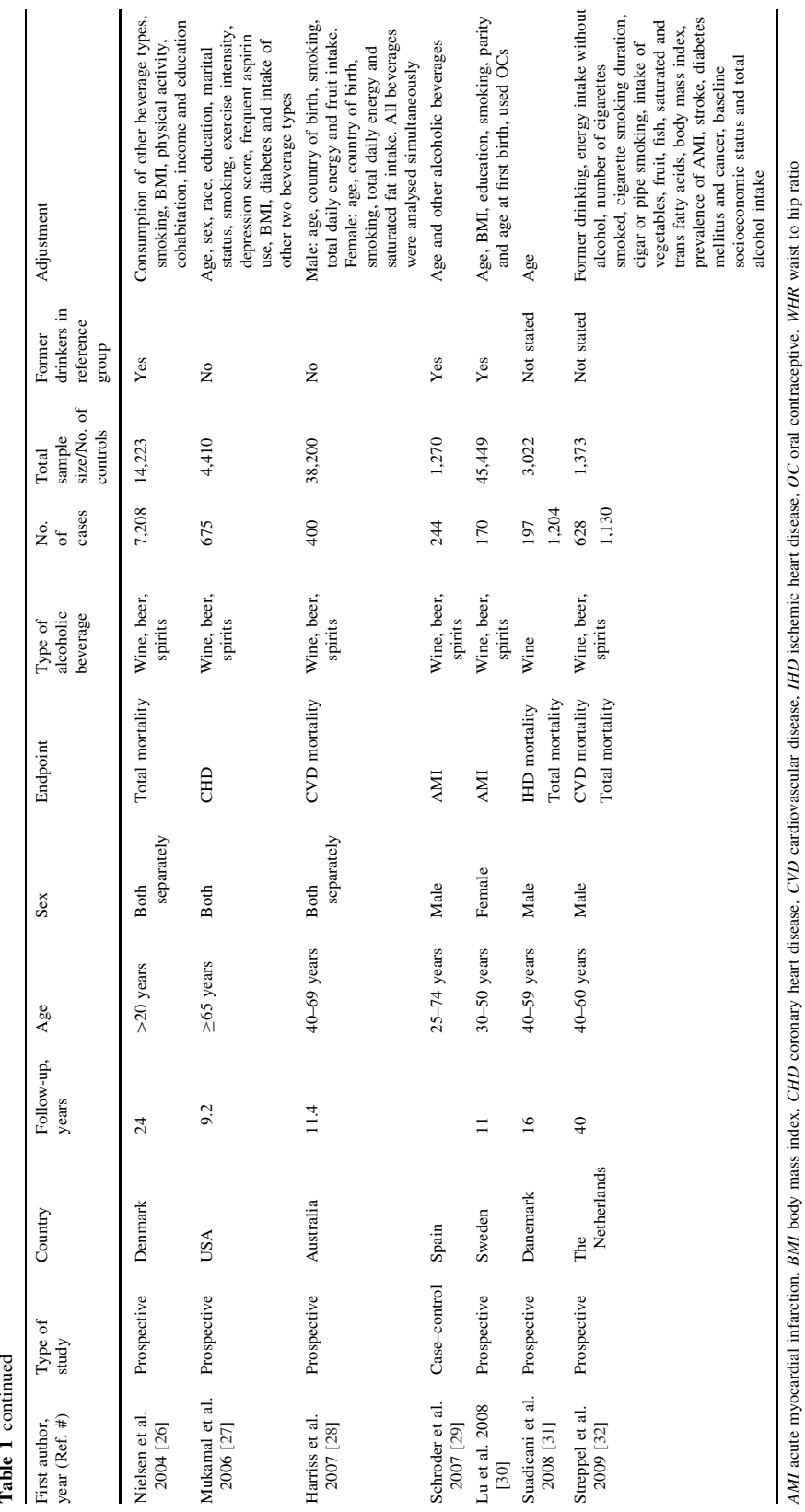

黑 Springer 
reference group was mentioned (Table 1); in 3 studies the reference group included occasional but not former drinkers [19, 20, 22].

The amount of alcohol (grams) in a "drink" was taken as quantified by each article. Adjusted relative risks (RR) for each categories of alcohol consumption were extracted (four studies reported RR adjusted for age only [15, 16, 29, 31] (Table 2)).

Data analysis

Data collected were: (a) the value $x$ of alcohol intake (g/day) assigned as the midpoint of the reported ranges; $x$ was defined as 1.2 times the lower boundary for the openended upper categories [33]; (b) frequency counts, adjusted $\mathrm{RR}$, and 95\% CI for each $x$ level; (c) covariates describing the characteristics of the study. Inverse-variance-weighed methods, taking into account the correlation between estimates within each study, were used [33]. The models to be fitted were selected among fractional polynomial curves of the second order [33]. Fractional polynomials are a family of models considering power transformations of a continuous exposure variable, restricted to a predefined set of integer and non integer exponents [34]. The regression models were $\log (\mathrm{RR} \mid \mathrm{x})=\beta_{1} \mathrm{x}^{\mathrm{p}}+\beta_{2} \mathrm{x}^{\mathrm{q}}$ and the exponents $\mathrm{p}$ and $\mathrm{q}$ were selected among the set: $(-2,-1,-0.5,0,0.5,1$, $2)$. When $\mathrm{p}=0, \mathrm{x}^{\mathrm{p}}$ is replaced by $\log (\mathrm{x})$, and when $\mathrm{p}=\mathrm{q}$ the model becomes $\log (\mathrm{RR} \mid \mathrm{x})=\beta_{1} \mathrm{x}^{\mathrm{p}}+\beta_{2} \mathrm{x}^{\mathrm{q}} \log (\mathrm{x})$ [13] The best fit was defined as that with the highest likelihood. To consider differences among studies as a further source of random variability, an additional component of the variance was added in weighing each observation (random-effects model). In sensitivity analysis, comparison of two hierarchical models was tested by the likelihood ratio test including or not in the models the interaction terms between the covariates (design of study, country setting, duration of follow-up) and alcohol intake (amount) [35]. To make some allowance for multiple comparisons, $95 \%$ CIs were used in subgroup analyses, and pairwise contrasts were adjusted following the Sidak method, as outlined by Ludbrook [36]. All analyses were carried out using a SAS macro [13] (SAS, 9.1.3 for Windows, Cary, NC: SAS Institute Inc. 1989). The hypothesis that publication bias might affect the validity of the estimates was tested by a funnel-plot-based approach. A simple test of asymmetry of the funnel plot was used according to the method proposed by Egger et al. [37]. The symmetry of funnel plots was measured applying the following linear model: $R R j / s e(R R j)=\alpha+\gamma^{*} 1 / s e(R R j)$, where $R R j / s e(R R j)$ is the standard normal deviate (RR divided by its standard error); $1 / s e(R R j)$ the precision of the estimate; and $\alpha$ and $\gamma$ are the unknown parameters of the model. The correction for publication bias was performed pooling studies after the exclusion of the ones that determined the asymmetry of the funnel plot. We assessed the quality of each study using both the Newcastle-Ottawa Scale [38] and a quality scale that also considered the assessment of alcohol drinking [39]. Estimations of the metrics "maximal protection" and "reversion point" from the pooled dose-response curves were used to help data interpretation. Imprecision in the evaluation of these metrics from fitting of data is unavoidable; thus, point estimates of these parameters should not be emphasized.

\section{Results}

From ninety-seven identified publications 79 studies were excluded with the criteria shown in Fig. 1. More than half were excluded since they did not distinguish wine, beer or spirits intake (n. 46) or only compared abstention with a unique category of alcohol intake (n. 17).

The main characteristics of the 18 studies included in this analysis are reported in Tables 1 and 2.

Wine consumption and fatal or non-fatal vascular events

From 16 studies [15-19, 21-25, 27-32] (11 prospective studies involving 288,363 individuals with 5,554 combined fatal or non-fatal cardiovascular events and 5 case-control studies involving 2,060 cases and 3,784 controls), 17 doseresponse independent relationships were obtained for wine consumption and vascular risk, since one study reported results separately for men and women [28]. Symmetric funnel plots $(\alpha=0)$ were obtained for $12.5-25$ and 25-60 g/day categories of alcohol intake (Fig. 2a); for the $1-12.5$ category a slightly deviation from symmetry was observed $(\alpha \neq 0, P=0.009)$. The best-fitting model was obtained when $\mathrm{p}=\mathrm{q}=0.5$, corresponding to the model: $\log (\mathrm{RR})=\beta_{1} \sqrt{\mathrm{x}}+\beta_{2} \sqrt{\mathrm{x}} * \log (\mathrm{x})$, for both the fixed and random models. The deviances of fixed and random effects models fell from 131.89 to $30.39(P<0.001$ for difference), suggesting heterogeneity among studies. In subsequent analyses, using a random effects model with $\mathrm{p}=\mathrm{q}=0.5$, we explored the possible role of study characteristics in explaining the inter-study heterogeneity. Fitted parameters for the random model were $\beta_{1}=-0.20$ $(\mathrm{SE}=0.059 ; \quad P<0.001)$ and $\beta_{2}=0.04 \quad(\mathrm{SE}=0.015$; $P=0.004$ ) (Table 3). The relationship observed has to be interpreted as a J-shaped curve; the association with a lower vascular risk was apparent up to $72 \mathrm{~g} /$ day and the lowest risk was seen at $21 \mathrm{~g} /$ day, $(\mathrm{RR}=0.69 ; 95 \% \mathrm{CI}$ : $0.58-0.82$ ) (Fig. 3). After the exclusion of studies determining the asymmetry in the funnel plot $[16,28,29]$ and then studies only adjusted for age [15, 16, 29, 31], the J-shape curve was confirmed (Table 3). 


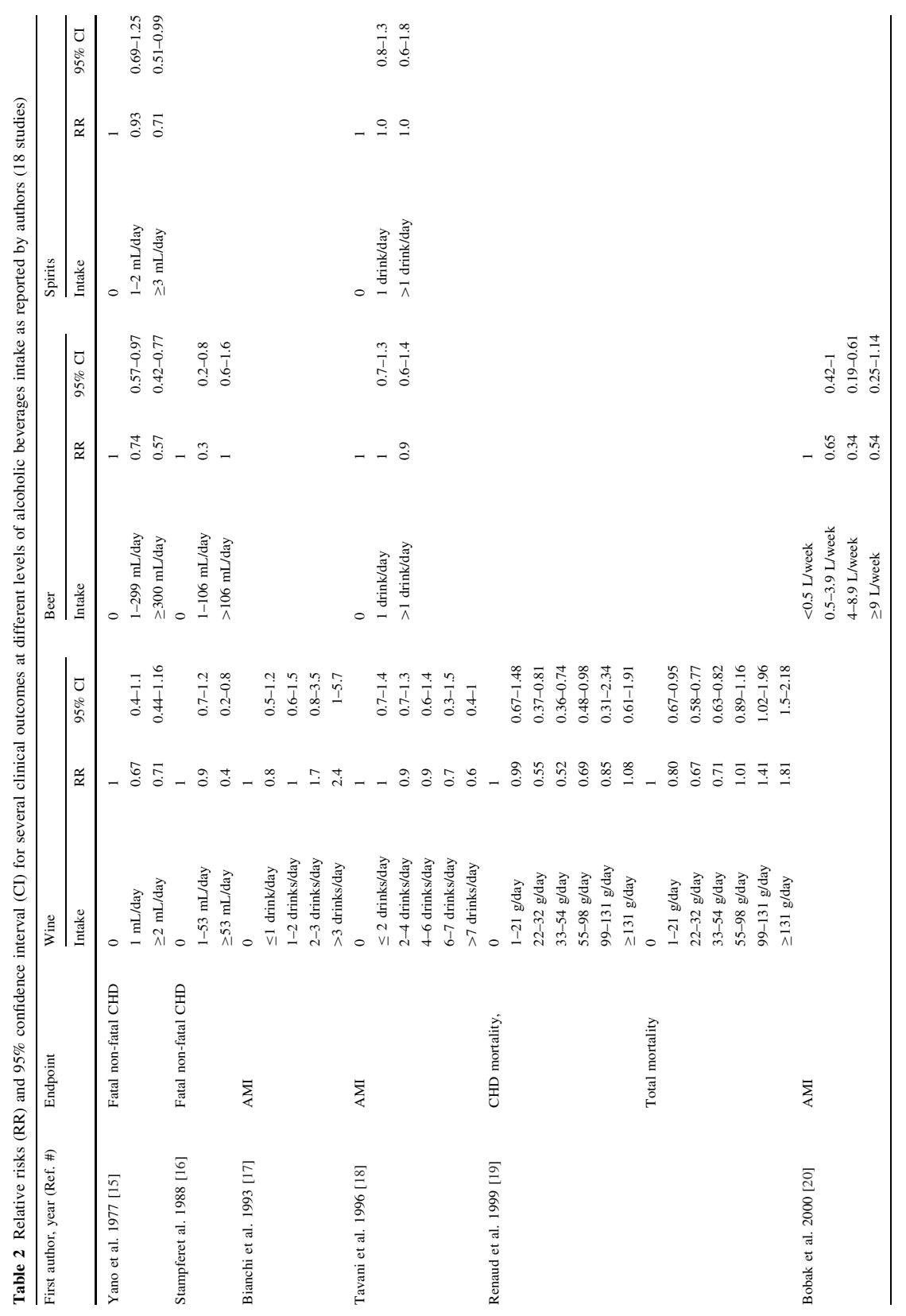

黑 Springer 


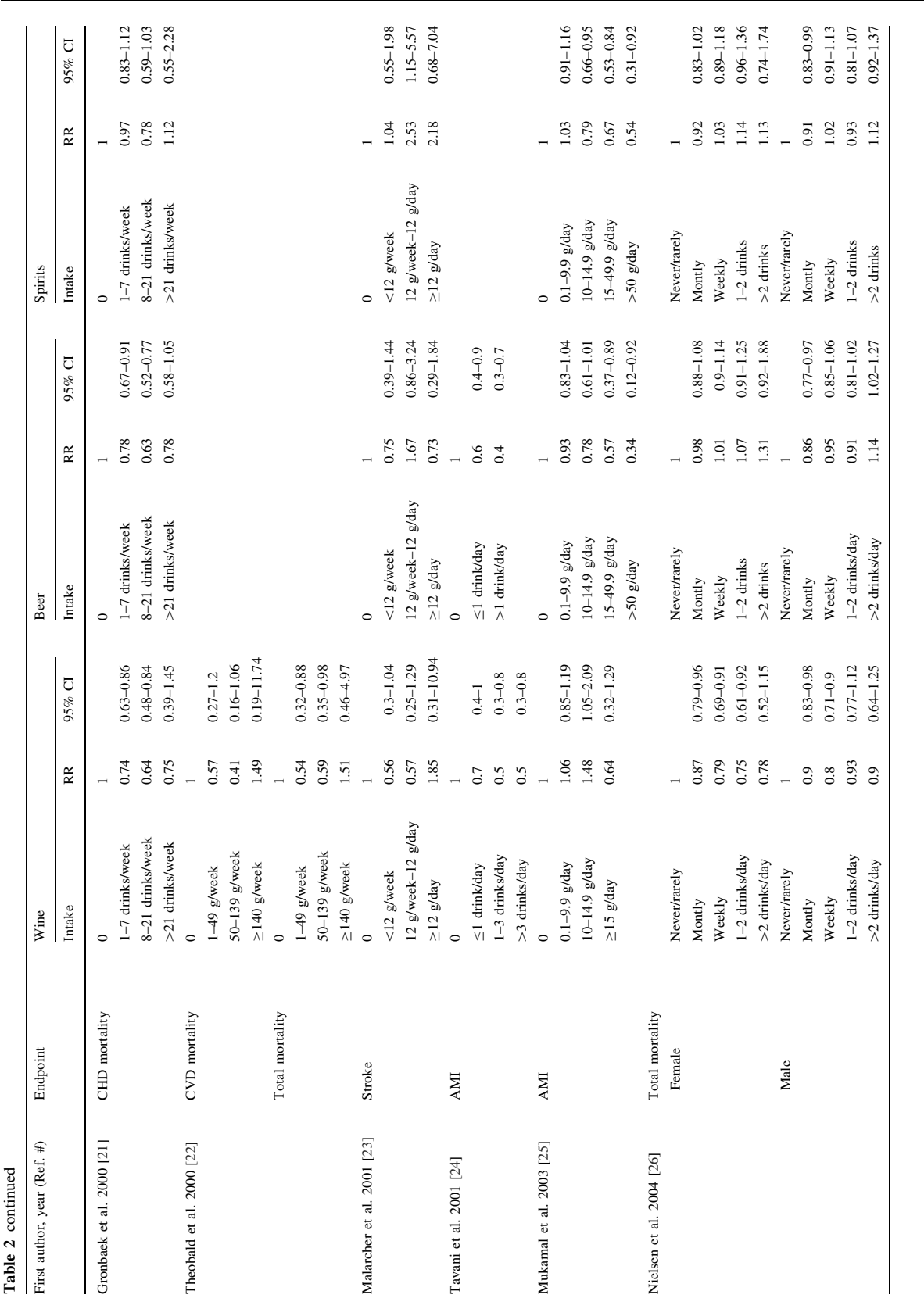




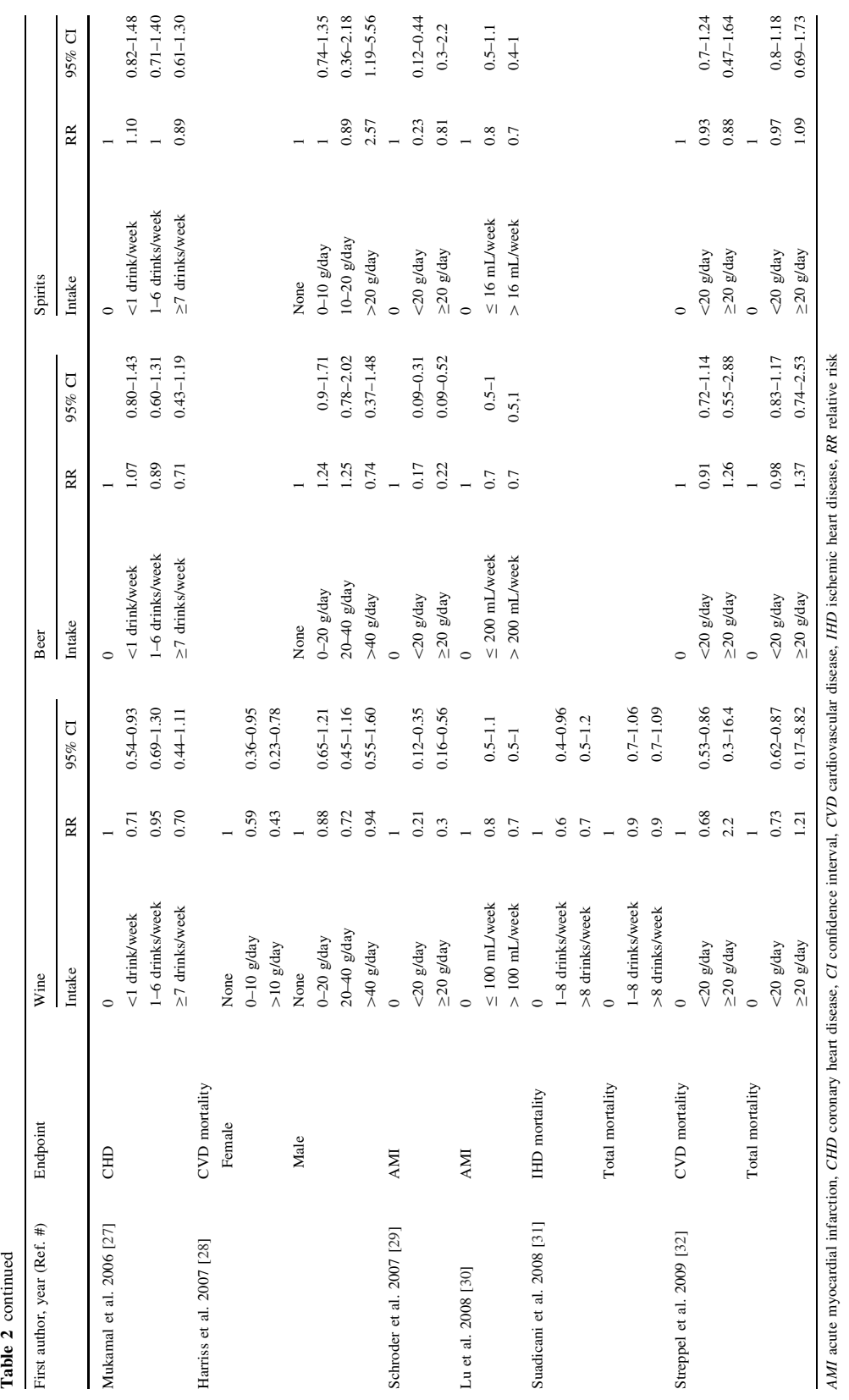




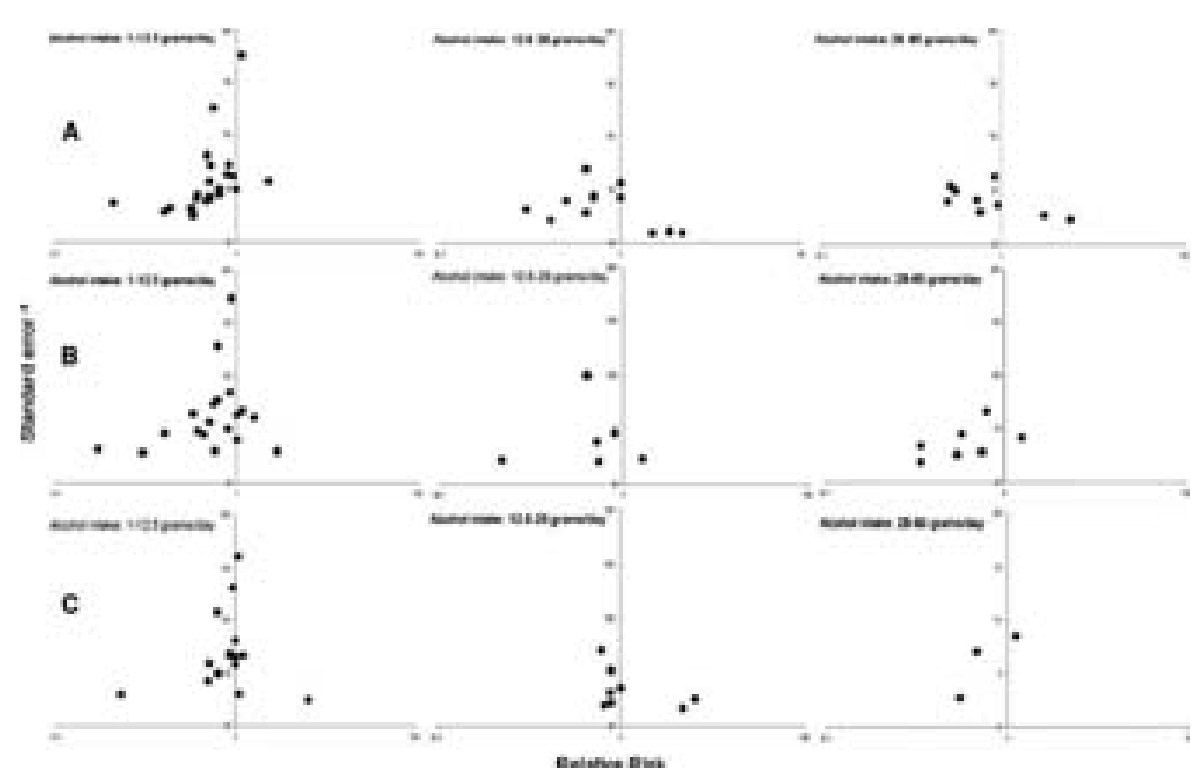

Fig. 2 Funnel plot for different intake categories (1-12.5 g/day, 12.5-25 g/day, 25-60 g/day) for meta-analyses on wine (a), beer (b) and spirit (c) consumption and vascular risk

In quality analyses, using both scales (The NewcastleOttawa Scale [38] and the score used by Tramacere et al. [39]), no heterogeneity of results was found according to the stratification of studies in low and high quality (data not shown).

When subgroup analyses were performed separately considering cohort or case-control studies, the maximal protection of about $30 \%$ in the range of $20-25 \mathrm{~g} /$ day of alcohol was confirmed in both pooled data (Table 3, $P=0.7)$. Pooled analyses of 6 studies $[19,22,23,25,27$, $28]$ that formally excluded former drinkers from the reference category, confirmed the maximal protection (28\%; 95\% CI: $9-44 \%$ ) at moderate wine consumption against vascular risk (Table 3 ). In sensitivity analyses separately investigating the relationship between wine consumption and vascular events in 5 Mediterranean [17-19, 24, 29], 5 Northern European [21, 22, 30-32] and 6 Western (USA and Australia) $[15,16,23,25,27,28]$ countries, the $\mathrm{J}$-shape curves were confirmed and appeared to be very similar among them (Sidak-adjusted $\mathrm{P}$ values for pairwise comparisons among countries were not statistically significant (Table 3)). Among cohort studies, the curves for short and long duration of follow-up were different $(P<0.001)$; in particular, $\beta_{1}$ was greater in shorter followup studies analysis, whereas $\beta_{2}$ was equal (Table 3). As a consequence, the pooled curves for the duration of followup were different for the range at which alcohol remained protective but comparable regarding the maximum protection at ligher doses.

Wine consumption and cardiovascular mortality

Six cohort studies [19, 21, 22, 28, 31, 32], involving 105,196 individuals (2,677 cardiovascular deaths), provided seven dose-response independent relationships for alcohol intake and cardiovascular mortality. The best-fitting model was obtained when $\mathrm{p}=\mathrm{q}=0.5$ for both the fixed and random models. Deviances of fixed and random effects models fell from 18.0 to $6.2(P<0.001$ for difference), indicating heterogeneity among studies. An overall J-shaped curve was obtained from the seven adjusted dose-response curves; the maximal protection was $34 \%$ at $24 \mathrm{~g} /$ day in the random-effects model (Table 3 and Fig. 4).

Wine consumption and mortality for any cause

Five cohort studies [19, 22, 26, 31, 32] (56,696 individuals and 11,905 deaths for any-cause) gathered information on wine consumption and total mortality and provided six 


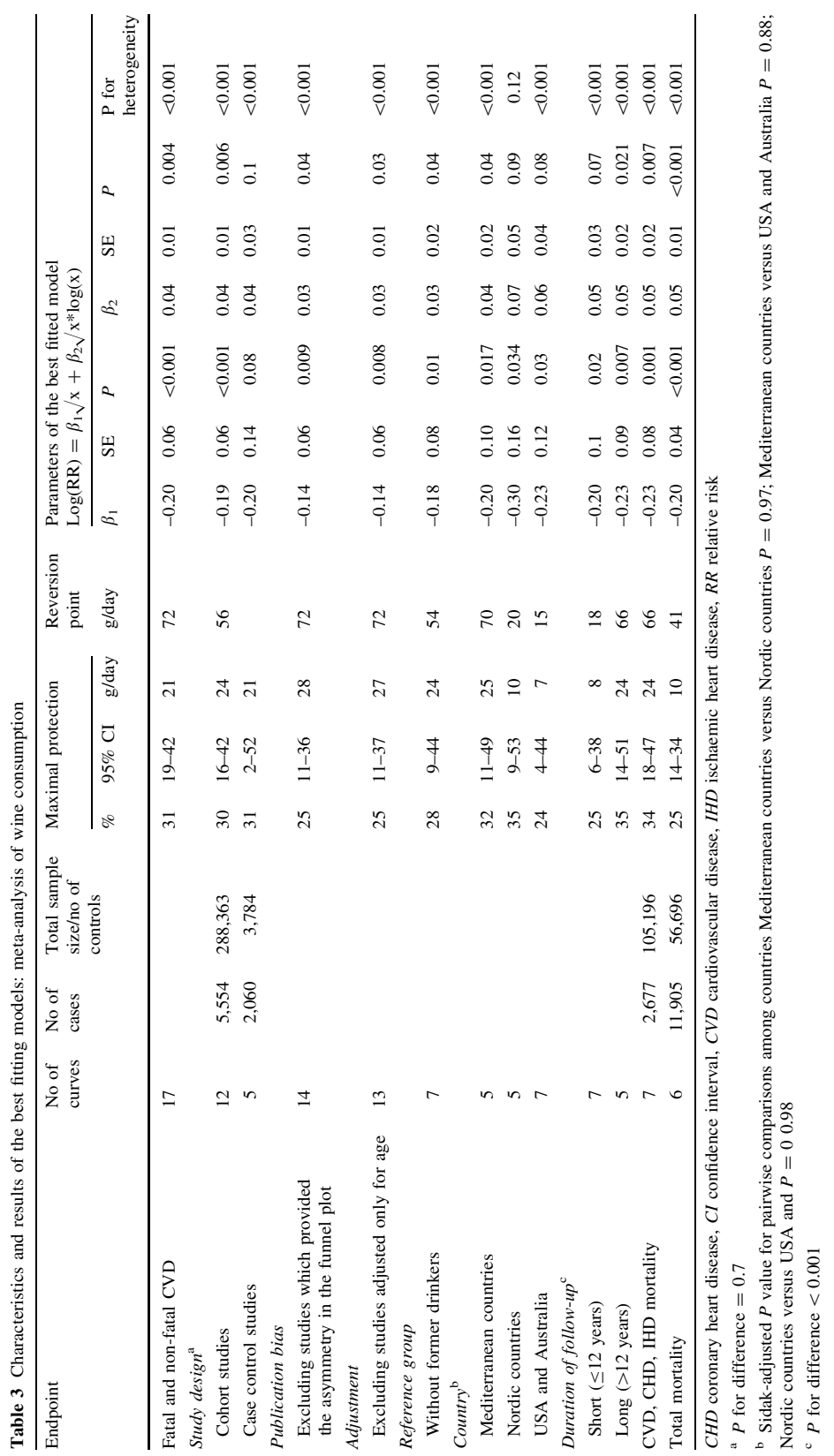


Fig. 3 Pooled curves of relative risk ( $95 \% \mathrm{CI}$ : dotted lines) of fatal and non-fatal vascular events and wine intake, extracted from 17 independent relationships using random models

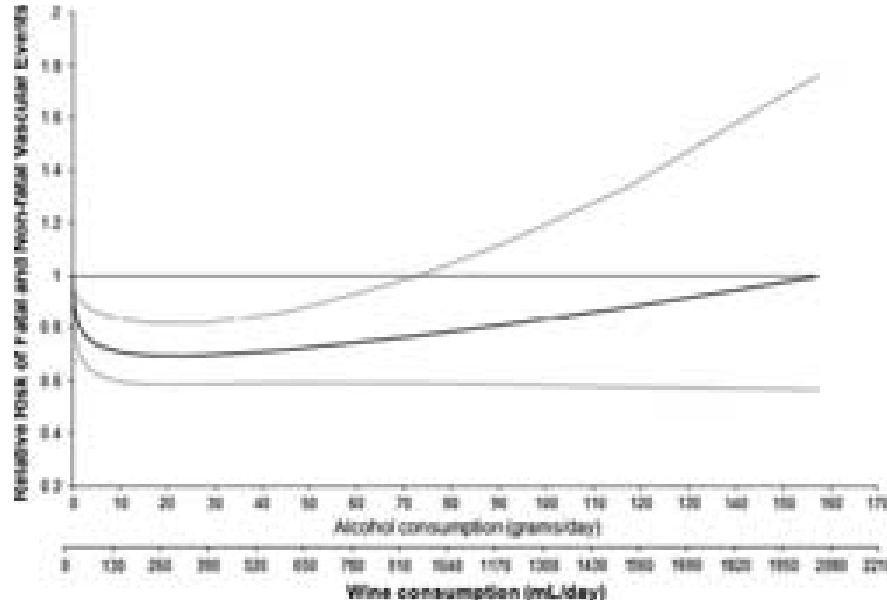

dose-response independent relationship, since one study reported results separately for men and women [26]. Random effect model was performed, using the model: $\log (\mathrm{RR})=\beta_{1} \sqrt{ } \mathrm{x}+\beta_{2} \sqrt{ } \mathrm{x} \log (\mathrm{x}) \quad(P<0.001$ for difference random vs. fixed models). In these studies, a J-shape curve was confirmed, with $25 \%$ maximal risk reduction at approximately $10 \mathrm{~g} /$ day and significant protection up to 41 g/day (Table 3 and Fig. 5).

Beer consumption and fatal or non-fatal vascular events

Thirteen studies $[15,16,18,20,21,23-25,27-30,32](8$ prospective studies involving 224,219 individuals $(4,823$ events) and five case-control studies involving 1,964 cases and 3,834 controls) provided 13 dose-response independent relationships for beer consumption and fatal or non fatal vascular events. Symmetric funnel plots $(\alpha=0)$ were obtained for all the categories of beer intake, showing the absence of publication bias (Fig. 2b). The best-fitting model was obtained when $\mathrm{p}=\mathrm{q}=1$, corresponding to the model: $\log (R R)=\beta_{1} x+\beta_{2} x * \log (x)$, for both the fixed and random models. The deviances of fixed and random effects models fell from 104.6 to 32.8 ( $P<0.001$ for difference), suggesting heterogeneity among studies. Using a random effects model with $\mathrm{p}=\mathrm{q}=1$, the possible role of study characteristics was explored to explain the interstudy heterogeneity. Fitted parameters for the random model were $\beta_{1}=-0.06(\mathrm{SE}=0.02 ; P=0.009)$ and $\beta_{2}=0.01(\mathrm{SE}=0.007 ; P=0.04)$ (Table 4$)$. The relationship observed was interpreted as a J-shaped curve; the association with a lower vascular risk was apparent up to
$55 \mathrm{~g} /$ day and the lowest risk was seen at $43 \mathrm{~g} /$ day $(\mathrm{RR}=0.58 ; 95 \%$ CI: $0.42-0.81$; Table 4 and Fig. 6$)$.

In quality analyses, using both scales mentioned above, no heterogeneity of results was found according to the stratification of studies in low and high quality (data not shown). A J-shape relationship between beer consumption and vascular risk was also confirmed by pooling data from case-control studies, with a maximal protection of about $60 \%$ at $36 \mathrm{~g} /$ day of alcohol (Table 4). However, performing a sensitivity analysis excluding the three studies only adjusted for age $[15,16,29]$ or a sub-group analysis of 5 studies $[20,23,25,27,28]$ that formally excluded former drinkers from the reference category, or by country categorization (Mediterranean [18, 24, 29], Northern European $[20,21,30,32]$ and Western $[15,16,23,25,27,28]$ countries), the characteristic J-shape relationship for beer consumption and vascular risk was no more apparent (Table 4).

As a small number of studies only investigated the relationship between beer consumption and cardiovascular $[21,28,32]$ and/or total mortality [26, 32], it was not possible to perform any meta-analysis related to these clinical end-points.

Comparison of wine and beer consumption in relation to vascular risk

From 12 studies $[15,16,18,21,23-25,27-30,32]$ (8 prospective studies involving 224,219 individuals $(4,823$ events) and four case-control studies involving 1,762 cases and 3,099 controls) that reported separate data both on 
Fig. 4 Pooled curves of relative risk (95\% CI: dotted lines) of fatal and cardiovascular mortality and wine intake, extracted from seven independent relationships using random models

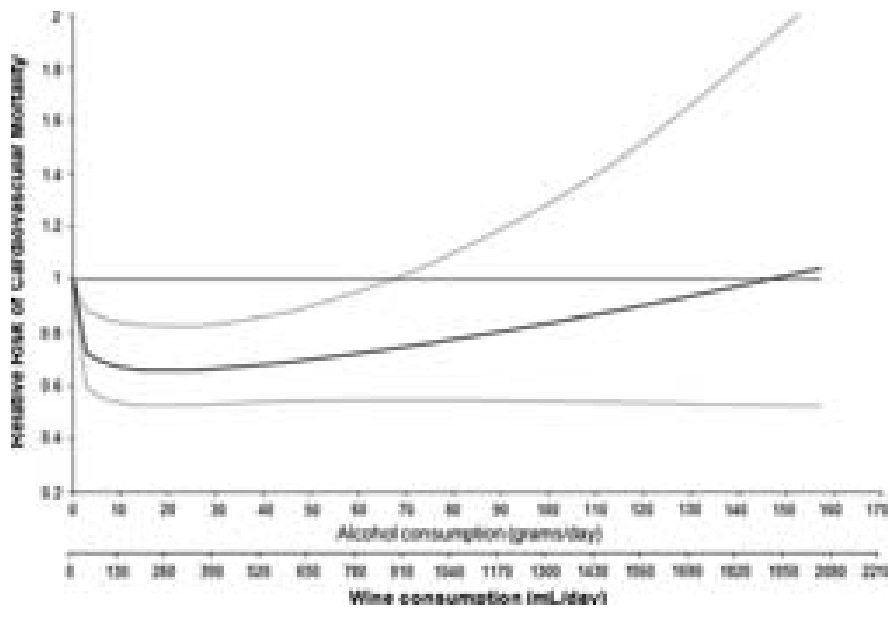

Fig. 5 Pooled curves of relative risk ( $95 \% \mathrm{CI}$ : dotted lines) of fatal and all-cause mortality and wine intake, extracted from six independent relationships using random models

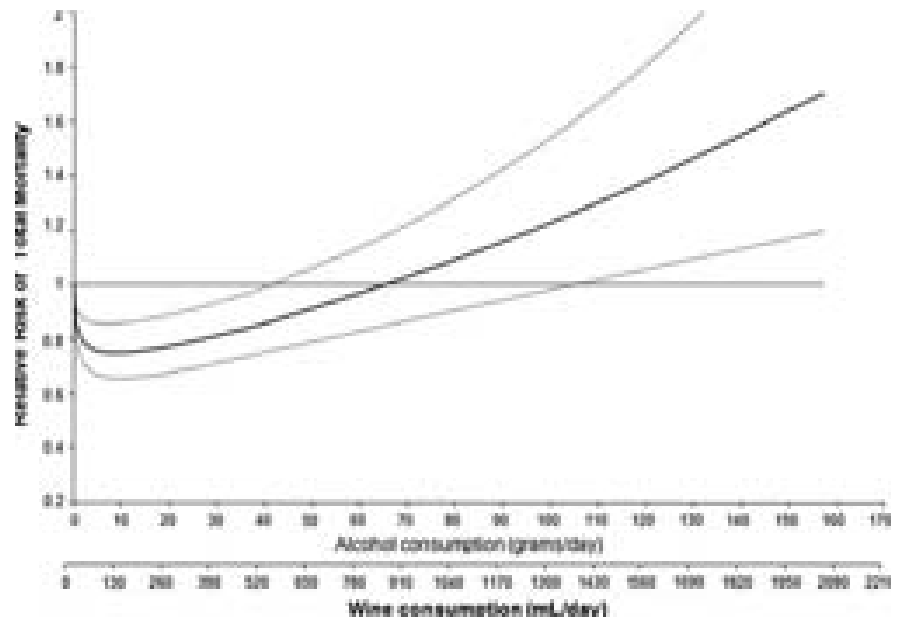

wine and beer consumption in relationship with vascular risk, two similar dose-response curves were obtained $(P=0.4$, Table 5 and Fig. 7). The two curves were closely overlapping, especially at light-moderate alcohol consumption and the maximal protection by either beverage was $33 \%$ at 25 g/day (Table 5 and Fig. 7). This similarity between wine and beer's protection persisted even when the studies that did not simultaneously adjust for different types of alcoholic beverages or total amount of alcohol, were excluded (Table $5, P=0.2$ ).
Spirit consumption and fatal and non-fatal vascular events

In a meta-analysis of 10 studies [15, 18, 21, 23, 25, 27-30, $32]$ on spirit consumption and vascular risk (seven prospective studies involving 136,693 individuals $(4,523$ events) and three case-control studies involving 1,255 cases and 2,621 controls), no J-shaped relationship could be found (Fig. 8). Symmetric funnel plots $(\alpha=0)$ were obtained for all the categories of spirit intake, showing the absence of 


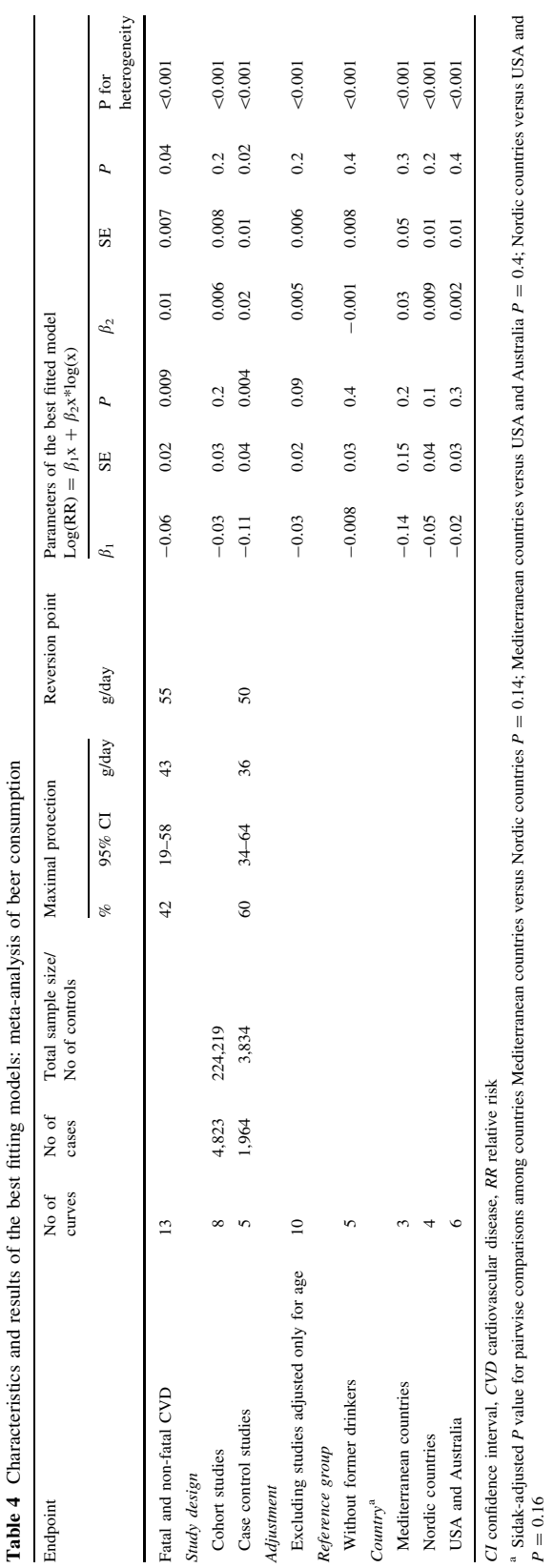

publication bias (Fig. 2c). Neither the first nor the second order terms of the model $\log (\mathrm{RR})=\beta_{1} \sqrt{ } \mathrm{x}+$ $\beta_{2} \sqrt{ } \mathrm{x} * \log (\mathrm{x})$ were statistically significant, the fitted parameters for the random model being $\beta_{1}=-0.01$ ( $\mathrm{SE}=0.10$; $P=0.4)$ and $\beta_{2}=-0.005(\mathrm{SE}=0.03 ; P=0.4)$.

As a small number of studies only investigated the relationship between spirits consumption and cardiovascular [21, 28, 32] and/or total mortality [26, 32], it was not possible to perform any meta-analysis related to these clinical end-points.

\section{Discussion}

A previous meta-analysis had shown a clear inverse doseeffect curve against vascular events for wine but not for beer intake [2]. Evidence from the current updated and extended meta-analysis confirms the significant reduction of overall vascular risk associated with wine consumption and shows, apparently for the first time, a similar J-shaped relationship between beer intake and cardiovascular risk. Moreover, the comparison of studies which included a parallel, separate evaluation of wine and beer consumption, indicates a similar protecting effect of either beverage against cardiovascular risk (Fig. 7).

Thus, in relation to health, drinking in moderation is more important than the content of the bottle, at least when wine and beer are taken into consideration.

On the contrary, no statistically significant association with vascular events was apparent for the intake of spirits up to $60 \mathrm{~g} /$ day, which is the maximum dose investigated in the 10 studies included in this meta-analysis. In several studies spirit consumption mostly occurred as binge drinking (defined as the consumption of three or more drinks within 1-2 h) and was restricted to only few days per week. This may explain the absence of association between moderate spirit consumption and cardiovascular disease observed, in contrast, for the other two alcoholic beverages both in the present meta-analysis and in a previous study [40]. It is known that drinking out of mealtimes and binge drinking are associated with increased CHD risk [41-44], both behaviours being preferentially linked to the type of alcoholic beverage consumed [45-47].

Moderate alcohol drinking reportedly induces healthy changes in lipid profile, vascular, haemostatic and endothelial cell function, platelet aggregation and inflammation $[8,9]$. On the other hand, beer and wine contains different substances that might provide additional cardiovascular benefit to that obtained by alcohol. If liquor -the drink with the purest concentration of alcohol - does not clearly decrease vascular events (the negative association between spirit intake and vascular events was non-significant in the present meta-analysis), it should not lead us to the 
Fig. 6 Pooled curves of relative risk (95\% CI: dotted lines) of fatal and non-fatal vascular events and beer intake, extracted from 13 independent relationships using random models

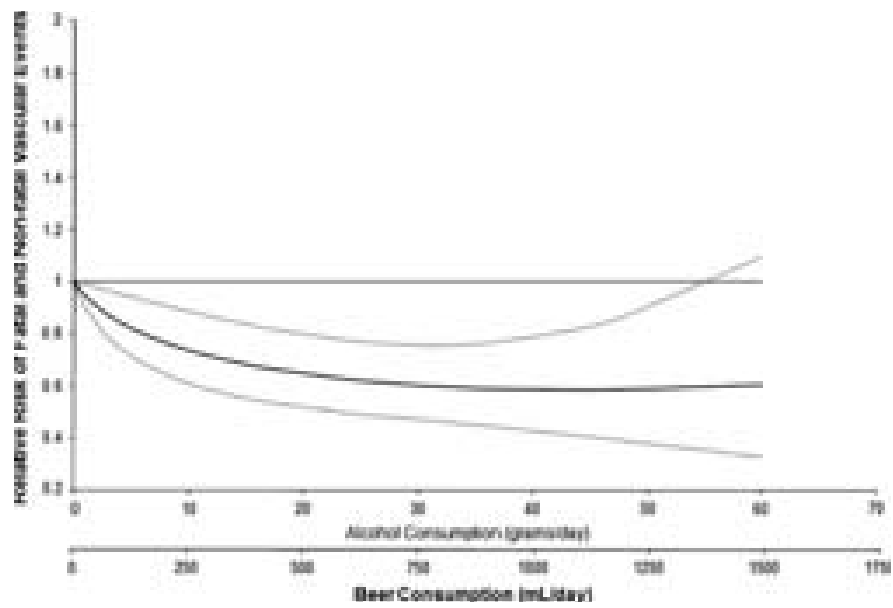

Table 5 Results of best fitting models of meta-analysis of studies reported data both on wine and beer consumption in relationship with vascular risk

\begin{tabular}{|c|c|c|c|c|c|c|c|c|c|c|c|c|}
\hline & \multirow{2}{*}{$\begin{array}{l}\text { No of } \\
\text { curves }\end{array}$} & \multicolumn{3}{|c|}{ Maximal protection } & \multirow{2}{*}{$\begin{array}{l}\text { Reversion } \\
\text { point } \\
\text { g/day }\end{array}$} & \multicolumn{7}{|c|}{ Parameters of the best fitted model $\log (\mathrm{RR})=\beta_{1} \sqrt{\mathrm{x}}+\beta_{2} \sqrt{ } \mathrm{x}^{*} \log (\mathrm{x})$} \\
\hline & & $\%$ & $95 \% \mathrm{CI}$ & g/day & & $\beta_{1}$ & SE & $P$ & $\beta_{2}$ & SE & $P$ & P for heterogeneity \\
\hline Wine consumption & 12 & 32 & $18-44$ & 25 & 70 & -0.19 & 0.07 & 0.003 & 0.04 & 0.02 & 0.03 & $<0.001$ \\
\hline Beer consumption & 12 & 33 & $13-48$ & 25 & 43 & -0.17 & 0.10 & 0.04 & 0.03 & 0.03 & 0.2 & $<0.001$ \\
\hline \multicolumn{13}{|c|}{ Adjusted studies for different types of alcohol beverages or total amount of alcohol intake } \\
\hline Wine consumption & 7 & & & & & -0.22 & 0.15 & 0.06 & 0.05 & 0.05 & 0.2 & $<0.001$ \\
\hline Beer consumption & 7 & & & & & -0.16 & 0.16 & 0.16 & 0.02 & 0.05 & 0.3 & $<0.001$ \\
\hline
\end{tabular}

$C I$ confidence interval, $R R$ relative risk

conclusion that polyphenolic constituents found in wine or beer are (mainly) responsible for the beneficial effect on vascular events [9-12, 48, 49]. In fact the proportion of subjects consuming liquors is much lower than that consuming wine or beer and patterns of liquor consumption are very different. We cannot therefore exclude that the negative association of wine and beer drinking with cardiovascular events could be (mainly) due to ethanol itself.

Effects of different alcoholic beverages on different clinical outcomes

We tried to dissect the potential benefit of wine or beer consumption on different clinical end-points. Both wine and beer consumption were comparable as far as the reduction of the risk of combined fatal and non fatal cardiovascular events was concerned. Wine drinking was also effective in reducing both cardiovascular and total mortality. The maximum intake of wine at which protection was still apparent decreased from 72 to 66 to $41 \mathrm{~g} / \mathrm{day}$ when either combined fatal and non fatal vascular events, or cardiovascular mortality or total mortality were considered as endpoint, respectively. At variance, the minimal doses of wine at which its maximal protection could be obtained were 21,24 and $10 \mathrm{~g} /$ day, respectively. Thus, while low-moderate doses are similarly protective against any clinical endpoint considered, the hardest the endpoint, the lowest the amount of wine that starts to be associated with harm. The maximum protection obtained at lightmoderate wine intake gradually vanishes at higher doses that differ according to different clinical endpoints, possibly because of increase in harmful collateral effects.

Unfortunately, the very limited data available about either beer or spirit consumption in relation to cardiovascular or total mortality, did not allow us to perform a fully meta-analytic investigation on the latter two beverages. 
Fig. 7 Curves for wine intake (solid lines) and beer intake (dotted lines) were extracted from the same studies

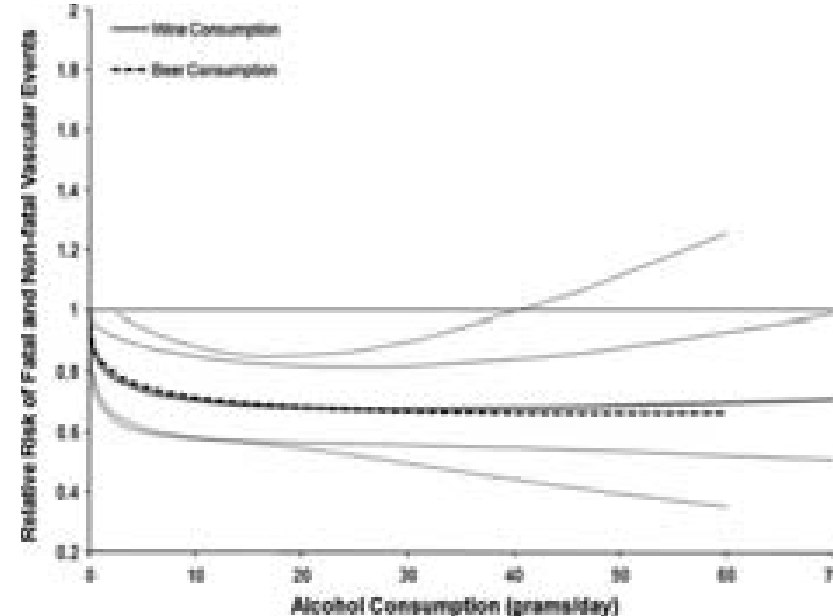

Fig. 8 Pooled curves of relative risk (95\% CI: dotted lines) of fatal and non-fatal vascular events and spirit intake, extracted from 10 independent relationships using random models

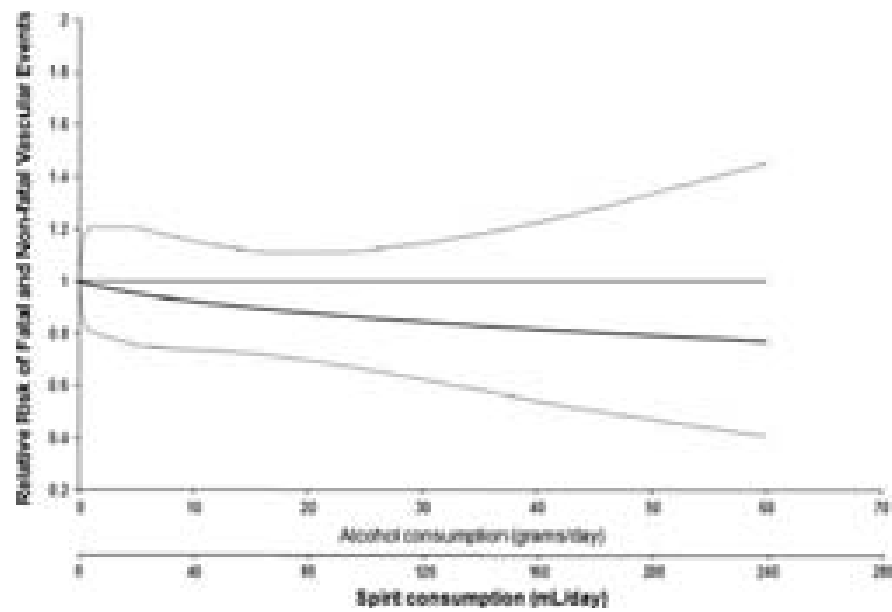

Limitations

All the studies included in our meta-analyses were observational, and could be themselves associated with a number of limitations: the alcohol patterns assessed only once at inclusion into the study, the absence of detailed history of alcohol consumption behavior and the possible changes in alcohol habits could have had an effect on the relation of alcohol consumption with cardiovascular events. Randomized controlled trials would offer a more solid answer than observational studies to many questions in medicine; the latter are mainly restricted, however, to the efficacy of drugs and are difficult and ethically questionable to perform to evaluate alcohol effects $[4,9]$. On the other hand, the results of well-designed observational studies (with either a cohort or a case-control design) do not systematically overestimate the magnitude of the effects as compared with those in randomized, controlled trials on the same topic [50]. In particular it is believed that selfreported wine or beer consumption is inaccurate. Underreporting on wine or beer drinkers would however result in a tendency for relative risks to be biased toward the null 
hypothesis, while our meta-analysis showed significant associations. The potential confounding effect of combined drinking of different types of alcoholic beverages in the same population was excluded by pooling data from studies that had taken this issue into consideration (Table 5).

Wine drinkers, at least in some Countries, tend to have a healthier lifestyle profile than beer drinkers. This uncontrolled confounding can be reasonably excluded, as the great majority of studies were adjusted for these variables (Table 1). Furthermore, a sensitivity analysis investigated the relationship between wine or beer consumption and vascular events in Mediterranean and not-Mediterranean Countries, but did find comparable results among them (Tables 3 and 4).

A weakness of all pooling studies on alcohol consumption is the heterogeneity among the reference groups, which sometimes have included lifelong teetotallers, former drinkers and/or occasional drinkers [51]. In few articles of this meta-analysis, the Authors did not clearly state if former or occasional drinkers were excluded from the reference group; however, analysis of five studies on wine consumption that formally excluded former drinkers confirmed the significant relation between drinking in moderation and vascular risk.

The results of any meta-analysis, especially in nonexperimental epidemiology, may be invalid due to publication bias [52]. The funnel plot analysis revealed symmetry for all categories of beer, spirit and wine intake, except for the lowest category of wine intake, suggesting the presence of a slight publication bias, if any. However, after the exclusion of the studies which determined the asymmetry in the funnel plot, the J-shape relationship between wine consumption and vascular risk was confirmed.

Alcohol may have different health effects in men and women [3]. Unfortunately, the paucity of data separately reported for either sexes, made it impossible to include men or women in two distinct meta-analyses [2, 4]. Standing from previous data on total alcohol intake [3, 4] optimal consumption of alcohol should be reduced in women- 1 unit a day instead of 2 units in men. However, if this difference holds separately for wine or beer remains to be investigated.

Significant protection could be extrapolated from the curves obtained up to doses of alcoholic beverages of $72 \mathrm{~g} /$ day that must be no doubt considered as a heavy intake. Besides the fact that the doses of alcohol associated with maximum protection should be chosen rather than that at which harm may start, the majority of the studies included in our meta-analyses did not in fact investigate such a large range of alcohol intake; the inferences from pooled curves at larger amounts of alcohol were a mathematical trick rather than a finding derived from experimental data. On the contrary, the conclusions obtained on the protection at light-moderate alcohol intake are quite solid as they are based on a very large amount of experimental data.

In conclusion, this meta-analysis provides further evidence for a J-shaped significant inverse association between wine consumption and vascular risk and shows a similar relationship for beer consumption. Dose-response curves from comparable studies appeared substantially similar for either alcoholic beverage. No protection was apparent instead, in association with the consumption of any spirit amount.

The hazards of excess or binge alcohol drinking should be always highlighted and heavy or binge drinkers pushed to cut their consumption to a regular, low-moderate level.

Acknowledgments Supported in part by Cervisia Consulenze and Istituto Nazionale per la Comunicazione.

Conflict of interest This was an investigator-initiated study. The partial sponsor of the study had no role in the selection of articles or conduct of the analyses or drafting of the manuscript. We disclaim any other relationships with industry that might pose a conflict of interest in connection with the submitted article.

\section{References}

1. Corrao G, Rubbiati L, Bagnardi V, Zambon A, Poikolainen K. Alcohol and coronary heart disease: a meta-analysis. Addiction. 2000;95(10):1505-23.

2. Di Castelnuovo A, Rotondo S, Iacoviello L, Donati MB, de Gaetano G. Meta-analysis of wine and beer consumption in relation to vascular risk. Circulation. 2002;105(24):2836-44.

3. Corrao G, Bagnardi V, Zambon A, La Vecchia C. A meta-analysis of alcohol consumption and the risk of 15 diseases. Prev Med. 2004;38(5):613-9.

4. Di Castelnuovo A, Costanzo S, Bagnardi V, Donati MB, Iacoviello L, de Gaetano G. Alcohol dosing and total mortality in men and women: an updated meta-analysis of 34 prospective studies. Arch Intern Med. 2006;166(22):2437-45.

5. Costanzo S, Di Castelnuovo A, Donati MB, Iacoviello L, de Gaetano G. Alcohol consumption and mortality in patients with cardiovascular disease: a meta-analysis. J Am Coll Cardiol. 2010;55(13):1339-47.

6. Reynolds K, Lewis B, Nolen JD, Kinney GL, Sathya B, HeJ. Alcohol consumption and risk of stroke: a meta-analysis. JAMA. 2003;289(5):579-88.

7. Ronksley PE, Brien SE, Turner BJ, Mukamal KJ, Ghali WA. Association of alcohol consumption with selected cardiovascular disease outcomes: a systematic review and meta-analysis. BMJ. 2011;342:d671.

8. Rimm EB, Williams P, Fosher K, Criqui M, Stampfer MJ. Moderate alcohol intake and lower risk of coronary heart disease: meta-analysis of effects on lipids and haemostatic factors. BMJ. 1999;319(7224):1523-8.

9. Di Castelnuovo A, Costanzo S, di Giuseppe R, de Gaetano G, Iacoviello L. Alcohol consumption and cardiovascular risk: mechanisms of action and epidemiologic perspectives. Future Cardiol. 2009;5(5):467-77. 
10. Gresele P, Cerletti C, Guglielmini G, Pignatelli P, de Gaetano G, Violi F. Effects of resveratrol and other wine polyphenols on vascular function: an update. J Nutr Biochem. 2011;22(3):201-11.

11. Piazzon A, Forte M, Nardini M. Characterization of phenolics content and antioxidant activity of different beer types. J Agric Food Chem. 2010;58(19):10677-83.

12. Martinez N, Urpi-Sarda M, Martinez-Gonzalez MA, AndresLacueva C, Mitjavila MT. Dealcoholised beers reduce atherosclerosis and expression of adhesion molecules in apoE-deficient mice. Br J Nutr. 2011;105(5):721-30.

13. Bagnardi V, Zambon A, Quatto P, Corrao G. Flexible metaregression functions for modeling aggregate dose-response data, with an application to alcohol and mortality. Am J Epidemiol. 2004;159(11):1077-86.

14. Stroup DF, Berlin JA, Morton SC, et al. Meta-analysis of observational studies in epidemiology: a proposal for reporting Meta-analysis of observational studies in epidemiology (MOOSE) group. JAMA. 2000;283(15):2008-12

15. Yano K, Rhoads GG, Kagan A. Coffee, alcohol and risk of coronary heart disease among Japanese men living in Hawaii. N Engl J Med. 1977;297(8):405-9.

16. Stampfer MJ, Colditz GA, Willett WC, Speizer FE, Hennekens $\mathrm{CH}$. A prospective study of moderate alcohol consumption and the risk of coronary disease and stroke in women. N Engl J Med. 1988;319(5):267-73.

17. Bianchi C, Negri E, LaVecchia C, Franceschi S. Alcohol consumption and the risk of acute myocardial infarction in women. J Epidemiol Community Health. 1993;47(4):308-11.

18. Tavani A, La Vecchia C, Negri A, D'Avanzo B, Franzoni M Tognoni G. Alcohol intake and risk of myocardial infarction in Italian men. J Epidemiol Biostat. 1996;1(1):31-9.

19. Renaud SC, Guéguen R, SiestG, Salamon R. Wine, beer, and mortality in middle-aged men from eastern France. Arch Intern Med. 1999;159(16):1865-70.

20. Bobak M, Skodova Z, Marmot M. Effect of beer drinking on risk of myocardial infarction: population based case-control study BMJ. 2000;320(7246):1378-9.

21. Grønbaek M, Becker U, Johansen D, et al. Type of alcohol consumed and mortality from all causes, coronary heart disease, and cancer. Ann Intern Med. 2000;133(6):411-9.

22. Theobald H, Bygren LO, Carstensen J, Engfeldt P. A moderate intake of wine is associated with reduced total mortality and reduced mortality from cardiovascular disease. J Stud Alcohol. 2000;61(5):652-6.

23. Malarcher AM, Giles WH, Croft JB, et al. Alcohol intake, type of beverage, and the risk of cerebral infarction in young women. Stroke. 2001;32(1):77-83

24. Tavani A, Bertuzzi M, Negri E, Sorbara L, La Vecchia C Alcohol, smoking, coffee and risk of non-fatal acute myocardial infarction in Italy. Eur J Epidemiol. 2001;17(12):1131-7.

25. Mukamal KJ, Conigrave KM, Mittleman MA, et al. Roles of drinking pattern and type of alcohol consumed in coronary heart disease in men. N Engl J Med. 2003;348(2):109-18.

26. Nielsen NR, Schnohr P, Jensen G, Grønbaek M. Is the relationship between type of alcohol and mortality influenced by socioeconomic status? J Intern Med. 2004;255(2):280-8.

27. Mukamal KJ, Chung H, Jenny NS, et al. Alcohol consumption and risk of coronary heart disease in older adults: the Cardiovascular Health Study. J Am Geriatr Soc. 2006;54(1):30-7.

28. Harriss LR, English DR, Hopper JL, et al. Alcohol consumption and cardiovascular mortality accounting for possible misclassification of intake: 11-year follow-up of the Melbourne Collaborative Cohort Study. Addiction. 2007;102(10):1574-85.

29. Schröder H, Masabeu A, Marti MJ, et al. Myocardial infarction and alcohol consumption: a population-based case-control study. Nutr Metab Cardiovasc Dis. 2007;17(8):609-15.
30. Lu M, Ye W, Adami HO, Weiderpass E. Stroke incidence in women under 60 years of age related to alcohol intake and smoking habit. Cerebrovasc Dis. 2008;25(6):517-25.

31. Suadicani P, Hein HO, Gyntelberg F. Wine intake, ABO phenotype, and risk of ischemic heart disease and all-cause mortality: the Copenhagen Male Study - a 16-year follow-up. Alcohol. 2008;42(7):575-82.

32. Streppel MT, Ocké MC, Boshuizen HC, Kok FJ, Kromhout D Long-term wine consumption is related to cardiovascular mortality and life expectancy independently of moderate alcoho intake: the Zutphen study. J Epidemiol Community Health 2009;63(7):534-40.

33. Greenland S. Dose-response and trend analysis in epidemiology: alternative to categorical analysis. Epidemiology. 1995;6(4): 356-65.

34. Royston P, Altman DG. Regression using fractional polynomials of continuous covariates: parsimonious parametric modelling. Appl Stat. 1994;43:429-67.

35. Greenland S, Longnecker MP. Methods for trend estimation from summarized dose-response data, with application to meta-analysis. Am J Epidemiol. 1992;135(11):1301-9.

36. Ludbrook J. Multiple comparison procedures updated. Clin Exp Pharmacol Physiol. 1998;25(12):1032-7.

37. Egger M, Davey Smith G, Schneider M, Minder C. Bias in metaanalysis detected by a simple, graphical test. BMJ. 1997; 315(7109):629-34.

38. Wells G, Shea B, O'Connell D. The Newcastle-Ottawa Scale (NOS) for assessing the quality of nonrandomized studies in meta-analyses. Ottawa Health Research Institute. http://www. ohri.ca/programs/clinical_epidemiology/oxford.asp.

39. Tramacere I, Scotti L, Jenab M, Bagnardi V, Bellocco R, Rota M, Corrao G, Bravi F, Boffetta P, La Vecchia C. Alcohol drinking and pancreatic cancer risk: a meta-analysis of the dose-risk relation. Int J Cancer. 2010;126(6):1474-86.

40. Rimm EB, Klatsky A, Grobbee D, Stampfer MJ. Review of moderate alcohol consumption and reduced risk of coronary heart disease: is the effect due to beer, wine, or spirits. BMJ. 1996; 312(7033):731-6.

41. Costanzo S, Di Castelnuovo A, Donati MB, Iacoviello L, de Gaetano G. Cardiovascular and overall mortality risk in relation to alcohol consumption in patients with cardiovascular disease. Circulation. 2010;121(17):1951-9.

42. Rehm J, Sempos CT, Trevisan M. Alcohol and cardiovascular disease -more than one paradox to consider. Average volume of alcohol consumption, patterns of drinking and risk of coronary heart disease- a review. J Cardiovasc Risk. 2003;10(1):15-20.

43. Trevisan M, Schisterman E, Mennotti A, Farchi G, Conti S, Risk Factor and Life Expectancy Research Group. Drinking pattern and mortality: the Italian risk factor and life expectancy pooling project. Ann Epidemiol. 2001;11(5):312-9.

44. Bagnardi V, Zatonski W, Scotti L, La Vecchia C, Corrao G. Doe drinking pattern modify the effect of alcohol on the risk of coronary heart disease? Evidence from a meta-analysis. J Epidemiol Community Health. 2008;62(7):615-9.

45. Della Valle E, Stranges S, Trevisan M, et al. Drinking habits an health in Northern Italian and American men. Nutr Metab Cardiovasc Dis. 2009;19(2):115-22.

46. Bloomfield K, Stockwell T, Gmel G, Rehn N. International comparison of alcohol consumption. Alcohol Res Health. 2003;27(1):95-109.

47. Rimm EB, Stampfer MJ. Wine, beer, and spirits: are they really horses of a different color? Circulation. 2002;105(24):2806-7.

48. Di Castelnuovo A, Costanzo S, Donati MB, Iacoviello L, de Gaetano G. Prevention of cardiovascular risk by moderate alcohol consumption: epidemiologic evidence and plausible mechanisms. Intern Emerg Med. 2010;5(4):291-7. 
49. Estruch R, Sacanella E, Badia E, et al. Different effects of red wine and gin consumption on inflammatory biomarkers of ath erosclerosis: a prospective randomized crossover trial. Effects of wine on inflammatory markers. Atherosclerosis. 2004;175(1): 117-23.

50. Concato J, Shah N, Horwitz RI. Randomized, controlled trials, observational studies, and the hierarchy of research designs. N Engl J Med. 2000;342(25):1887-92.
51. Fillmore KM, Stockwell T, Chikritzhs T, Bostrom A, Kerr W Moderate alcohol use and reduced mortality risk: systematic error in prospective studies and new hypotheses. Ann Epidemiol. 2007;17(5 Suppl):S16-23

52. Maclure M. Demonstration of deductive meta-analysis: ethanol intake and risk of myocardial infarction. Epidemiol Rev. 1993; 15(2):328-51. 


\section{Chapter - Reference G}

\section{ALCOHOL CONSUMPTION AND MORTALITY IN PATIENTS WITH CARDI OVASCULAR DI SEASE: A META-ANALYSIS}

Costanzo S, Di Castelnuovo A, Donati MB, Iacoviello L, de Gaetano G. Alcohol consumption and mortality in patients with cardiovascular disease: a metaanalysis. J Am Coll Cardiol. 2010;55(13):1339-47. 



\title{
Alcohol Consumption and Mortality in Patients With Cardiovascular Disease
}

\author{
A Meta-Analysis
}

Simona Costanzo, ScD, Augusto Di Castelnuovo, ScD, Maria Benedetta Donati, MD, PHD, Licia Iacoviello, MD, PHD, Giovanni de Gaetano, MD, PHD

Campobasso, Italy

\begin{abstract}
Objectives The purpose of this study was to quantify the relation between alcohol consumption and cardiovascular and total mortality in patients with a history of cardiovascular events.

Background Regular, moderate alcohol consumption by healthy people is associated with lower cardiovascular and all-cause mortality. No extensive meta-analysis is presently available on the possible association of alcohol consumption with secondary events in patients with cardiovascular disease.

Methods Articles were retrieved through October 2009 by search in PubMed and EMBASE. Fifty-four publications were identified, but only 8 were selected for our analyses, including 16,351 patients with a history of cardiovascular disease. Secondary events were cardiovascular or all-cause mortality. All selected studies were prospective. Data were pooled with a weighted, least-squares regression analysis of second-order fractional polynomial models.

Results

The meta-analysis on cardiovascular mortality showed a J-shaped pooled curve with a significant maximal protection (average $22 \%$ ) by alcohol at approximately $26 \mathrm{~g} /$ day. In the meta-analysis on mortality for any cause, $\mathrm{J}$-shaped pooled curves were observed in the overall analysis (average maximal protection of $18 \%$ in the range of 5 to $10 \mathrm{~g} /$ day) and in all subgroups according to either the type of patients or the characteristics of the studies.

Conclusions In patients with cardiovascular disease, light to moderate alcohol consumption (5 to $25 \mathrm{~g} /$ day) was significantly associated with a lower incidence of cardiovascular and all-cause mortality. (J Am Coll Cardiol 2010;55: 1339-47) (c) 2010 by the American College of Cardiology Foundation
\end{abstract}

Moderate, regular alcohol consumption by apparently healthy people is associated with lower cardiovascular morbidity and mortality than in abstainers (1-6). Mechanisms supporting this include beneficial regulation of lipids and fibrinolysis, decreased platelet aggregation and coagulation factors, beneficial effects on endothelial function, and in flammation and insulin resistance (7-9). The proposed mechanisms of the beneficial role of drinking in moderation in healthy people may be similarly effective in people with a history of cardiovascular disease (CVD).

The abuse of alcohol is unquestionably harmful $(2,3,6,10)$; in fact, the relationship between alcohol consumption and ischemic cardiovascular events or all-cause mortality in healthy people has been depicted as a J-shaped

From the Laboratory of Genetic and Environmental Epidemiology, "RE ARTU" Research Laboratories, "John Paul II" Centre for High Technology Research an Education in Biomedical Sciences, Catholic University, Campobasso, Italy. Supported in part by grant EA0827 from the European Research Advisory Board (ERAB).

Manuscript received November 19, 2009; revised manuscript received January 15, 2010, accepted January 18, 2010. curve attributed to a dose-related combination of beneficial and harmful effects $(1,11,12)$. The nonlinear J-shaped dose-response curve supports the hazards of excess drinking, but also indicates the potential windows of alcohol consumption that may confer a net beneficial effect, at least in terms of survival for apparently healthy subjects.

The 2006 Diet and Lifestyle Recommendations Scientific Statement from the American Heart Association Nutrition Committee (13) advises: "If you consume alcohol, do so in moderation (equivalent of no more than one drink for women or two drinks for men per day)." This is widely accepted within the scientific community, definitely when referring to healthy people. However, some concern has been raised of late regarding whether it is advisable to encourage people to drink small amounts regularly rather than abstain completely, especially among poor populations and in low-income countries where the disease burden per unit of alcohol consumption seems to be greater $(10,14)$.

It is fundamental to prevent ischemic recurrences in survivors of primary cardiovascular events. Among the factors contributing to prevention, improving lifestyle and dietary 


$\begin{aligned} & \text { Abbreviations } \\ & \text { and Acronyms }\end{aligned}$
AMI = acute myocardial
infarction
CVD = cardiovascular
disease
RR = relative risk
SE = standard error

habits play a major role. However, guidelines in this area $(15,16)$ are based on studies of apparently healthy subjects, on only few studies in cardiovascular patients, or both. Other recommendations about alcohol consumption in patients with previous CVD are based on experts' consensus rather than circumstantial evidence (17).

The United States Food and Drug Administration warns that heart disease patients should stop drinking and that people who take aspirin regularly should not drink alcohol (18). However, in the 2006 American Heart Association/American College of Cardiology Guidelines for Secondary Prevention (16), CVD patients are encouraged to maintain a lifestyle that includes alcohol in moderation.

Several observational studies evaluated the association between alcohol intake and secondary events in CVD patients (19). One meta-analysis that examined the relationship between dietary changes and mortality in patients with coronary artery disease reported a reduction in allcause mortality risk in moderate drinkers (20).

We present here the findings from 2 meta-analyses assessing the relationship between alcohol drinking and either fatal cardiovascular events or mortality for any cause in patients with a history of cardiovascular events. Our work extends that of Iestra et al. (20) because we included more recent studies and correlated alcohol intake by patients with established coronary artery disease with cardiovascular mortality in addition to total mortality. Moreover, current issues in epidemiology of alcohol consumption and health will be discussed.

\section{Methods}

Search strategy and data extraction. Articles were retrieved through October 2009 by searching in PubMed and EMBASE using the following key words: cardiovascular disease or patients in combination with alcohol, wine, beer, and spirits and with mortality, morbidity, survival, death (as Medical Subject Heading terms or text word), supplemented by references from the selected articles. Fifty-four publications were identified. Two of us independently reviewed them and selected 8 studies (21-28) of patients with a history of CVD. Studies were excluded if the qualifying primary event was different from coronary heart disease, AMI, or stroke; if only one category of alcohol intake was reported, or if it was not possible to extract quantitative data on alcohol consumption or if they were multiple reports (in that case, the report with the longer follow-up was used) (Fig. 1).

Secondary events included cardiovascular or all-cause mortality. As far as primary events are concerned, 7 studies included patients with previous CVD (1 stroke [24], 1 coronary heart disease [26], 5 AMI $[21-23,25,28])$, and 1 diabetic patient with a history of coronary heart disease (27)

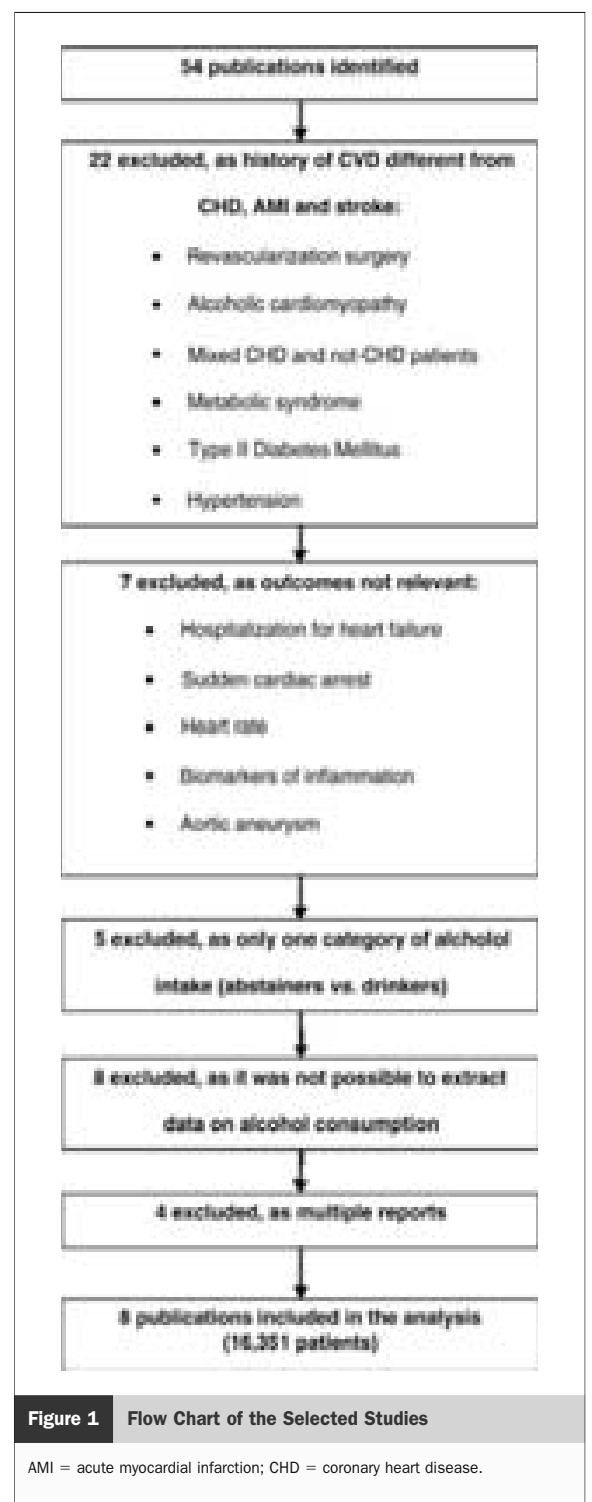

(Table 1). All selected studies were prospective (5 cohort studies $[21,22,25-27])$, and 3 were studies primarily designed as randomized control trials for specific drug therapy in CVD patients $(23,24,28)$. Seven studies reported results separately for all-cause and cardiovascular mortality 
Table 1 Characteristics of the $\mathbf{8}$ Studies Included in 1 or Both Meta-Analyses

\begin{tabular}{|c|c|c|c|c|c|c|c|c|c|}
\hline First Author, Year (Ref. \#) & Country & $\begin{array}{c}\text { Follow-Up } \\
\text { (yrs) }\end{array}$ & $\mathbf{n}$ & $\begin{array}{c}\text { Primary } \\
\text { Event }\end{array}$ & $\begin{array}{c}\text { Secondary } \\
\text { Event }\end{array}$ & $\begin{array}{c}\text { When } \\
\text { Questionnaire } \\
\text { Administered }\end{array}$ & $\begin{array}{c}\text { Former Drinkers } \\
\text { in Reference } \\
\text { Group }\end{array}$ & Sex & $\begin{array}{l}\text { Meta-Analysis } \\
\text { Inclusion }\end{array}$ \\
\hline Janszky et al., 2008 (21) & Sweden & 8.6 & 1,332 & AMI & CV-M, AC-M & A & Yes* & $\mathrm{M}, \mathrm{F}$ & Both \\
\hline Masunaga et al., 2006 (22) & Japan & 1.1 & 3,845 & AMI & AC-M & A & No & M & Total mortality \\
\hline Aguilar et al., 2004 (23) & USA & 3.5 & 2,036 & AMI & CV-M, AC-M & B & Not stated & $\mathrm{M}, \mathrm{F}$ & Both \\
\hline Jackson et al., 2003 (24) & USA & 4.5 & 1,320 & Stroke & CV-M, AC-M & B & Not stated & M & Both \\
\hline Mukamal et al., 2001 (25) & USA & 3.8 & 1,913 & AMI & CV-M, AC-M & A & Yes & $\mathrm{M}, \mathrm{F}$ & Both \\
\hline Shaper et al., 2000 (26) & England & 12.8 & 596 & CHD & CV-M, AC-M & B & No & M & Both \\
\hline Valmadrid et al., 1999 (27) & USA & 12.3 & 266 & CHD & CV-M & B & No & $\mathrm{M}, \mathrm{F}$ & CVD mortality \\
\hline Muntwyler et al., 1998 (28) & USA & 5.0 & 5,356 & AMI & CV-M, AC-M & B & Not stated & M & Both \\
\hline
\end{tabular}

*Exclusion of ex-drinkers in reference group in sensitivity analysis.

$\mathrm{A}=$ few days after the primary event $\mathrm{AC}-\mathrm{M}=$ all-cause mortality; $\mathrm{AMI}=$ acute myocardial infarction; $\mathrm{B}=$ more than 2 months after the primary event; $\mathrm{CHD}=$ coronary heart disease $\mathrm{CVD}=\mathrm{cardiovascular}$ disease; $\mathrm{CV}-\mathrm{M}=$ cardiovascular mortality.

(21,23-26,28), and 1 for all-cause mortality only (22), and 1 for CVD mortality only (27). With reference to alcohol consumption, all studies were observational. We performed 2 meta-analyses: the first included 7 studies reporting secondary risk of cardiovascular mortality and the second considered 7 studies reporting secondary risk of mortality for any cause (Table 1).

The size of a drink was taken as quantified in each article, except in 2 American studies $(23,28)$ where a size of $14.0 \mathrm{~g}$ ethanol was chosen, according to the International Center for Alcohol Policies guidelines (29). In 3 studies $(22,26,27)$ former drinkers were excluded formally from the reference group of life-long abstainers or nondrinkers, whereas in 2 studies, they were not $(21,25)$ (in one of these, the authors performed a sensitivity analysis excluding former drinkers from the reference group (21)); in the remaining 3 studies $(23,24,28)$, no statement about the reference group was made (Table 1).

Data analysis. We collected the following data: 1) the value $x$ of alcohol (grams per day) assigned as the midpoint of the ranges ( $x$ was defined as 1.2 times the lower boundary for the open-ended upper categories [30]; our results did not change on multiplying the lower boundary for the openended upper categories by 1.0 or 1.4 or 1.6 instead of 1.2 [data not shown]); 2) frequency counts, adjusted relative risk (RR), and 95\% confidence intervals for each $x$ level; and 3) covariates describing the characteristics of the study. Inverse-variance-weighted methods that account for within-study correlation estimates were used (30). The models to be fitted were selected among fractional polynomial curves of the second order (31), considering power transformations of a continuous variable restricted to a predefined set of exponents (32). The regression models were $\log (\mathrm{RR} \mid x)=\beta_{1} x^{p}+\beta_{2} x^{q}$ and $p$ and $q$ were selected out of the set $(-2,-1,-0.5,0,0.5,1,2)$, after fitting multiple models. When $p=0, x^{p}$ is replaced by $\log (x)$, and when $p=q$, the model becomes $\log (R R \mid x)=\beta_{1} x^{p}+$ $\beta_{2} x^{q} \log (x)$ (32). The best fit for $p$ and $q$ was defined as that with the highest likelihood.

To consider differences between studies as a further source of random variability, an additional component of the variance was added in weighing each observation (ran- dom effects). When there was heterogeneity, that is, when random and fixed solutions significantly differed, the analyses were carried out excluding one study at a time, and the deviances of random and fixed models were examined; a study was eliminated if its inclusion in the meta-analysis severely increased the deviances. Comparison of 2 hierarchical models was tested by the likelihood ratio test including or not in the models the interaction terms between the covariates (sex, type of primary event, design of the reference group) and alcohol intake (volume). Estimations of the metrics "maximal protection" and "reversion point" from the pooled dose-response curves were used to help data interpretation. Imprecision in the evaluation of these metrics from fitting of data is unavoidable; thus, point estimates of these parameters should not be emphasized. Pairwise contrasts were adjusted following the method of Sidak. All analyses were carried out using an SAS macro (SAS version 9.1.3 for Windows, SAS Institute, Cary, North Carolina) (32).

The hypothesis that publication bias may affect the validity of the estimates was tested by a funnel-plot-based approach. A simple test of asymmetry of the funnel plot was used according to the method proposed by Egger et al. (33). The symmetry of funnel plots was measured applying the following linear model: $R R j / s e(R R j)=\alpha+\gamma 1 / s e(R R j)$, where $R R j / s e(R R j)$ is the standard normal deviate (relative risk divided by its standard error), $1 / s e\left(R R_{j}\right)$ is the precision of the estimate, and $\alpha$ and $\gamma$ are the unknown parameters of the model.

The basic idea of this method is that, in the absence of publication bias and therefore in the presence of a symmetric funnel plot, the points will scatter about a line that runs through the origin. In this situation, an estimate of the parameter $\alpha$ would be found nearly equal to 0 .

\section{Results}

Alcohol intake and cardiovascular mortality in CVD patients. From 7 studies (21,23-28) comprising 12,819 CVD patients (Tables 1, 2), we obtained 7 dose-responseindependent relationships for alcohol and cardiovascular mortality. Symmetric funnel plots $(\alpha=0)$ were obtained for 
Table 2 Characteristics and Results of the Best-Fitting Models: Meta-Analysis of Alcohol Intake and Cardiovascular Mortality

\begin{tabular}{|c|c|c|c|c|c|c|c|c|c|c|}
\hline \multirow[b]{2}{*}{ Subgroup } & \multirow{2}{*}{$\begin{array}{l}\text { No. of } \\
\text { Curves }\end{array}$} & \multirow[b]{2}{*}{ n } & \multicolumn{2}{|c|}{ Maximal Protection } & \multirow{2}{*}{$\begin{array}{c}\text { Reversion } \\
\text { Point }{ }^{\star} \\
\text { (g/day) }\end{array}$} & \multicolumn{4}{|c|}{$\begin{array}{l}\text { Parameters of the Best-Fitted Model }= \\
\operatorname{LogRR}=\beta_{1} \sqrt{x}+\beta_{2} \sqrt{x^{*}} \log (x)\end{array}$} & \multirow{2}{*}{$\begin{array}{l}p \text { Value } \\
\text { for } \\
\text { Difference }\end{array}$} \\
\hline & & & $\%(95 \% \mathrm{Cl})$ & g/day & & $\beta_{1}$ (SE) & $\mathrm{p}$ Value & $\beta_{2}$ (SE) & p Value & \\
\hline All studies & & & & & & & & & & 0.002 \\
\hline Random model & 7 & 12,819 & $26(13-37)$ & 8 & 24 & $-0.215(0.088)$ & 0.008 & $0.052(0.031)$ & 0.047 & \\
\hline Fixed model & 7 & 12,819 & $22(13-30)$ & 8 & 26 & $-0.181(0.058)$ & $<0.001$ & $0.044(0.021)$ & 0.017 & \\
\hline Sex & & & & & & & & & & 0.90 \\
\hline Men & 3 & 7,272 & $21(11-31)$ & 13 & 23 & $-0.161(0.072)$ & 0.013 & $0.036(0.026)$ & 0.08 & \\
\hline Both sexes & 4 & 5,547 & $25(9-38)$ & 8 & 18 & $-0.219(0.098)$ & 0.013 & $0.058(0.035)$ & 0.049 & \\
\hline \multicolumn{11}{|l|}{ Type of primary event } \\
\hline AMI & 4 & 10,637 & $19(8-28)$ & 12 & 24 & $-0.136(0.065)$ & 0.018 & $0.031(0.023)$ & 0.092 & \\
\hline \multicolumn{11}{|l|}{ Type of reference group } \\
\hline Without former drinkers & 3 & 2,110 & $47(27-62)$ & 5 & 18 & $-0.538(0.165)$ & 0.019 & $0.157(0.059)$ & 0.077 & \\
\hline \multicolumn{11}{|l|}{$\begin{array}{l}\text { Alcohol intake } \\
\text { questionnaire } \\
\text { administration }\end{array}$} \\
\hline $\begin{array}{c}\text { More than } 2 \text { months after } \\
\text { the primary event }\end{array}$ & 5 & 9,574 & $21(11-29)$ & & 24 & $-0.158(0.067)$ & 0.009 & $0.037(0.025)$ & 0.067 & \\
\hline
\end{tabular}

${ }^{*}$ The reversion point is defined as the dose of alcohol at which protection against total mortality is no longer statistically significant at the $95 \%$ confidence level.

$\mathrm{AMI}=$ acute myocardial infarction; $\mathrm{Cl}=$ confidence interval.

all the categories of alcohol intake, showing the absence of publication bias (Fig. 2A).

The overall relationship between cardiovascular mortality and alcohol intake was interpreted as a J-shaped curve (Fig. 3), showing a protective effect (average 22\%) that was maximal in the range of 5 to $10 \mathrm{~g} /$ day and still was significant up to approximately $26 \mathrm{~g}$ /day (Table 2 and Fig. 3, fixed model).

The best-fitting model was obtained when $p=q=$ 0.5 , corresponding to the model: $\log R R=\beta_{1} V_{x}+$ $\beta_{2} \sqrt{ } x^{*} \log (x)$, for both the fixed and random models (Fig. 3 ). The deviances of fixed and random effects models fell from 22.30 to 12.60 ( $p=0.002$ for difference), suggesting heterogeneity among studies. The fitted parameters for the fixed model were $\beta_{1}=-0.181(\mathrm{SE}=0.058 ; \mathrm{p}<0.001)$ and $\beta_{2}=0.044(\mathrm{SE}=0.021 ; \mathrm{p}=0.017)$ (Table 2). In subsequent analyses, using a fixed effects model with $p=$ $q=0.5$, we explored the possible role of study characteristics in explaining the interstudy heterogeneity.

Three studies reported results on men only and 4 included both men and women; the subgroup analysis showed no difference between the 2 groups of studies $(\mathrm{p}=0.90)$ (Table 2). Pooled analyses of 3 studies $(21,26,28)$ that excluded former drinkers from the reference category confirmed the protection of moderate alcohol consumption against cardiovascular mortality (Table 2).

Alcohol intake questionnaires were administered quite late (more than 2 months) after the qualifying event in 5 studies $(23,24,26-28)$, but after only a few days in 2 studies $(21,25)$. In the first group of studies, a J-curve was confirmed, with a shape very similar to that obtained using all studies on CVD patients (Table 2). Similar results were found considering only studies on patients with a previous AMI (Table 2).

Alcohol intake and mortality for any cause in CVD patients. Seven studies (21-26,28), comprising 16,398 patients with previous CVD (Tables 1 and 2), provided 9 dose-response independent relationships for alcohol intake and mortality from any cause. In this meta-analysis, too, publication bias was absent (Fig. 2B).

Two studies reported results separately for 2 age groups $(22,28)$, and each contributed with 2 curves. The best-fitting model was obtained when $p=q=0.5$ for both the fixed and random models (Table 3). Deviances of fixed and random effects models fell from 119.63 to 20.72 ( $p<0.001$ for difference), indicating heterogeneity among studies. After exclusion of a Japanese study (22), deviances of fixed and random effects models fell to 30.90 and 12.29 , respectively ( $p<0.001$ for difference). In both the random and fixed-effects models, an overall J-shaped curve was obtained from the remaining 7 adjusted dose-response curves (Table 3, Fig. 4); the maximal protection was $20 \%$ and $18 \%$ in a range of 5 to $10 \mathrm{~g} /$ day in a random and fixed-effects model, respectively. Four studies included men only and 3 studies included both men and women; the subgroup analysis showed no difference between these 2 groups of studies $(p=0.47)$ (Table 3$)$.

Similar results were found considering only studies of patients with a previous AMI (Table 3). Four studies gathered information on alcohol consumption late after the qualifying cardiovascular event ( $>2$ months) $(23,24,26,28)$. In these studies, a J-shape curve was confirmed, with $24 \%$ maximal risk reduction at approximately $8 \mathrm{~g} /$ day and significant protection up to approximately $24 \mathrm{~g} /$ day (Table 3$)$. Six studies (12,553 patients) reported data both for cardiovascular and all-cause mortality $(21,23-26,28)$. The $2 \mathrm{~J}$-shaped curves overlapped at light consumption (6 to $12 \mathrm{~g} /$ day), showing maximal protection of approximately 20\% (Fig. 5).

\section{Discussion}

The main novelty of the findings presented here is that - as in apparently healthy subjects-in CVD patients too, light to 

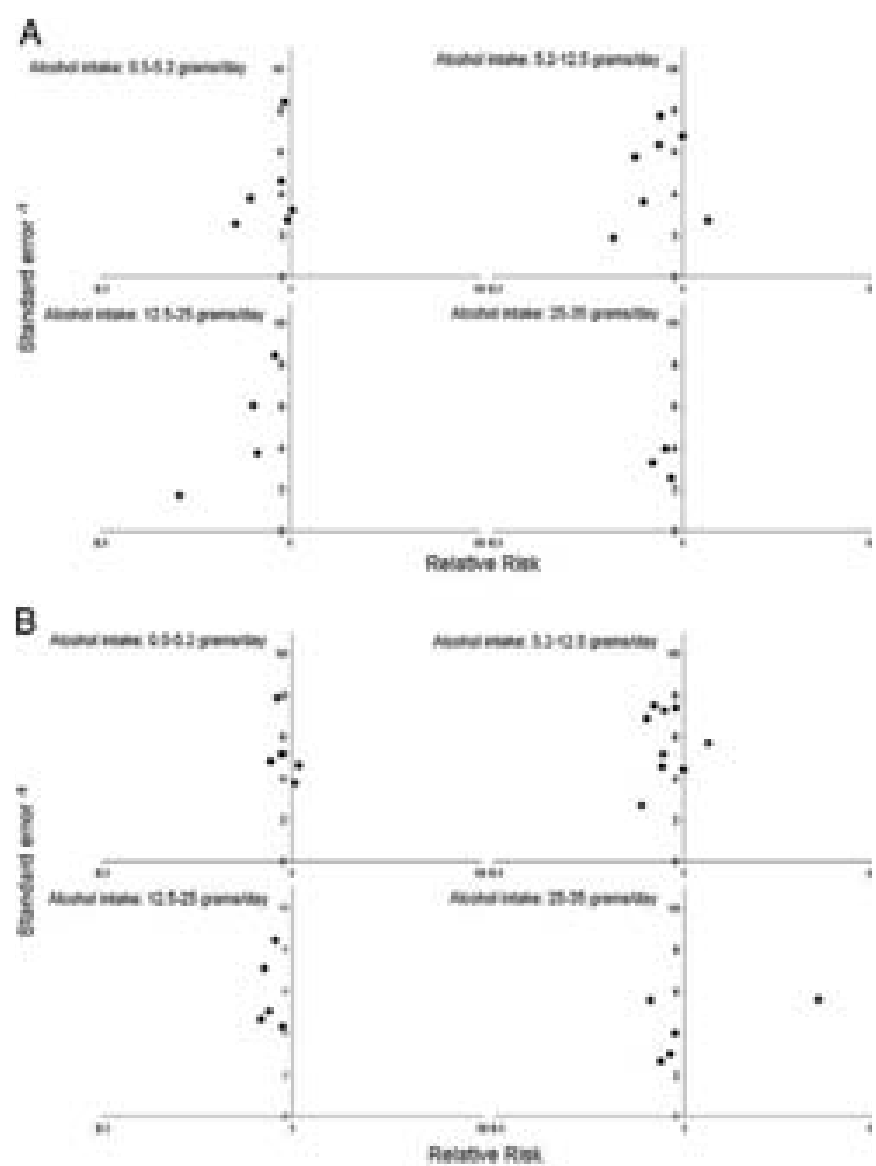

Figure 2 Funnel Plots of the Selected Studies for Both Meta-Analyses

Funnel plots for different alcohol intake categories ( 0.5 to $5.2 \mathrm{~g} /$ day, 5.2 to $12.5 \mathrm{~g} /$ day, 12.5 to $25 \mathrm{~g} /$ day, 25 to $35 \mathrm{~g} /$ day) for both meta-analyses. (A) Alcohol intake and cardiovascular mortality in cardiovascular disease (CVD) patients. (B) Alcohol intake and mortality for any cause in CVD patients.

moderate drinking ( 5 to $15 \mathrm{~g} /$ day of alcohol) is associated with significant cardiovascular or all-cause mortality risk reduction, or both. In both our meta-analyses, a significant association with reduced risk was found up to 25 $\mathrm{g} /$ day of alcohol. The J-shaped relationship between alcohol intake and total mortality was comparable with that previously reported in apparently healthy individuals (11) and can be explained as a dose-related combination of both beneficial and harmful effects. If alcohol intake within a relatively large range is inversely related to $\mathrm{CVD}$, increasing alcohol consumption is reportedly as- sociated with an increasing risk of certain cancers, cirrhosis, and death from accidents $(2,11)$. When alcohol use was recorded somewhat late after diagnosis of the primary event (more than 2 months), probably reflecting the real intake of alcohol before a secondary event, the protective effect of moderate alcohol consumption was confirmed by both meta-analyses.

From the 6 studies that reported data on both cardiovascular and all-cause mortality, 2 similar dose-response curves were obtained (Fig. 5). Most likely, as in patients with previous CVD, the main cause of death is a secondary fatal 


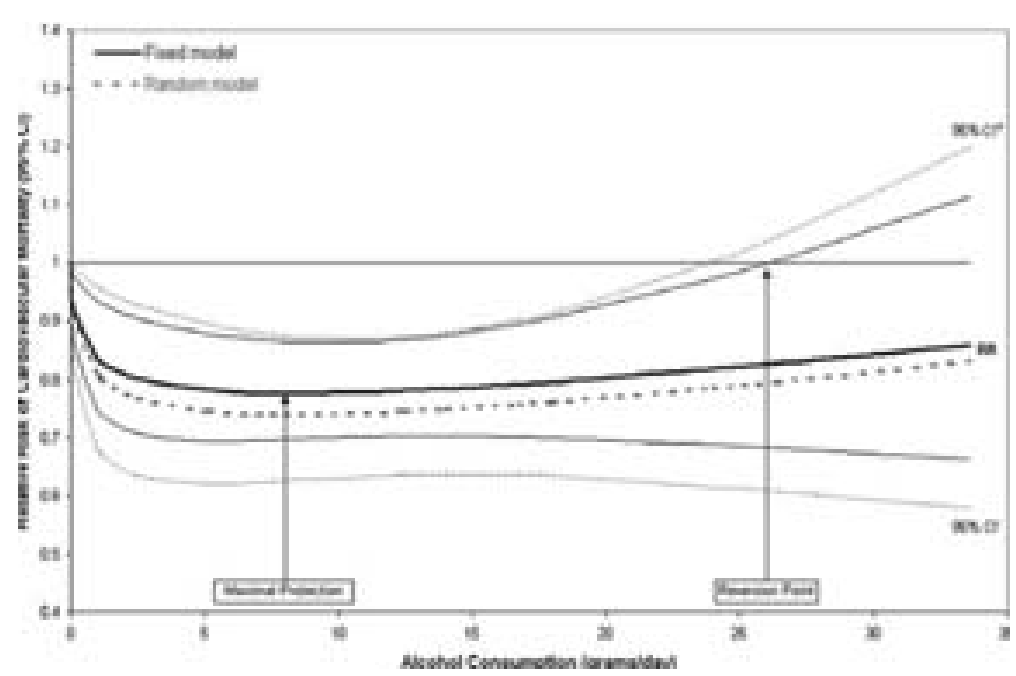

Figure 3 Alcohol Consumption in Relation to Cardiovascular Mortality in Cardiovascular Disease Patients

Pooled curves of relative risk of cardiovascular mortality and alcohol intake, extracted from 7 independent relationships using fixed (solid lines) and random (dotted lines) models. $\mathrm{RR}=$ relative risk; $95 \% \mathrm{Cl}^{-}=$lower value of confidence interval; $95 \% \mathrm{Cl}^{+}=$upper value of confidence interval.

cardiovascular event; the reduction in cardiovascular risk by moderate alcohol consumption would prevail over the less frequent noncardiovascular fatal events.
In patients with $\mathrm{CVD}$, the potential interactions with alcohol have been investigated mainly for antiplatelet or oral anticoagulant drugs (34). Alcohol and medications interact

Table 3 Characteristics and Results of the Best-Fitting Models: Meta-Analysis of Alcohol Intake and All-Causes Mortality

\begin{tabular}{|c|c|c|c|c|c|c|c|c|c|c|}
\hline \multirow[b]{2}{*}{ Subgroup } & \multirow{2}{*}{$\begin{array}{l}\text { No. of } \\
\text { Curves }\end{array}$} & \multirow[b]{2}{*}{ n } & \multicolumn{2}{|c|}{ Maximal Protection } & \multirow{2}{*}{$\begin{array}{c}\text { Reversion } \\
\text { Point } \\
\text { (g/day) }^{\star}\end{array}$} & \multicolumn{4}{|c|}{$\begin{array}{l}\text { Parameters of the Best-Fitted Model }= \\
\qquad \operatorname{LogRR}=\beta_{1} \sqrt{x}+\beta_{2} \sqrt{x^{\star}} \log (x)\end{array}$} & \multirow{2}{*}{$\begin{array}{c}\text { P for } \\
\text { Difference }\end{array}$} \\
\hline & & & $\%(\mathbf{9 5} \% \mathbf{C I})$ & g/day & & $\beta_{1}$ (SE) & p Value & $\beta_{2}$ (SE) & $p$ Value & \\
\hline Random model & 9 & 16,398 & $22(2-39)$ & 2.5 & 8 & $-0.223(0.114)$ & 0.025 & $0.070(0.039)$ & 0.035 & \\
\hline Fixed model & 9 & 16,398 & $24(16-31)$ & 2.5 & 15 & $-0.251(0.085)$ & $<0.001$ & $0.085(0.016)$ & $<0.001$ & \\
\hline Selected studies $\dagger$ & & & & & & & & & & $<0.001$ \\
\hline Fixed model & 7 & 12,553 & $18(10-25)$ & 7 & 24 & $-0.153(0.047)$ & $<0.001$ & $0.040(0.017)$ & 0.008 & \\
\hline Sext & & & & & & & & & & 0.47 \\
\hline Men & 4 & 7,272 & $18(8-28)$ & 5 & 17 & $-0.172(0.060)$ & 0.002 & $0.050(0.022)$ & 0.010 & \\
\hline Both sexes & 3 & 5,281 & $21(8-33)$ & 12 & 27 & $-0.147(0.082)$ & 0.036 & $0.032(0.027)$ & 0.121 & \\
\hline \multicolumn{11}{|l|}{ Type of primary event $\dagger$} \\
\hline AMI & 5 & 10,637 & $22(16-30)$ & 12 & 32 & $-0.167(0.053)$ & $<0.001$ & $0.038(0.018)$ & 0.020 & \\
\hline
\end{tabular}

${ }^{*}$ The reversion point is defined as the dose of alcohol at which protection against total mortality is no longer statistically significant at the $95 \%$ confidence level. $†$ Excluding the curves from the study of Masunaga et al. (22).

Abbreviations as in Table 2. 


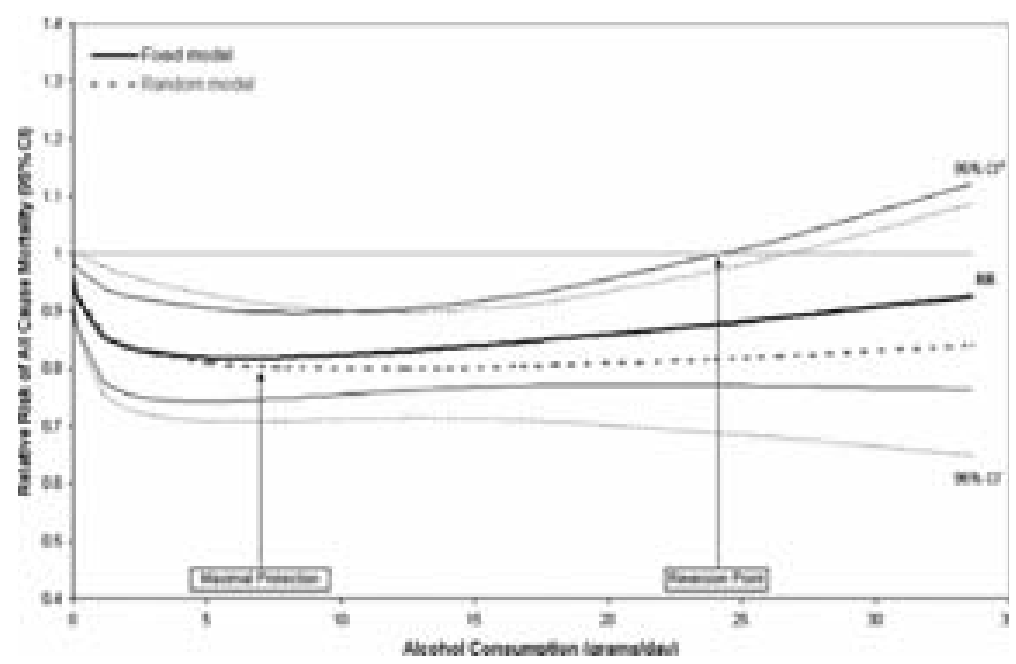

Figure 4 Alcohol Consumption in Relation to All-Cause Mortality in Cardiovascular Disease Patients

Pooled curves of relative risk of all-cause mortality and alcohol intake extracted from 7 independent

relationships using fixed (solid lines) and random (dotted lines) models. Abbreviations as in Figure 3.

in a variety of situations; absorption, distribution, or metabolism of the alcohol, medications, or both may be altered, affecting the therapeutic and adverse effects of the latter $(34,35)$. A sensitive analysis with adjusted and nonadjusted studies for drug therapy (antiplatelet or oral anticoagulant drugs) was not possible in our meta-analyses because of limited available data.

Study limitations. A first limitation of our findings is that, in the absence of randomized controlled trials, all the studies included in our meta-analyses were observational. Randomized controlled trials offer a more solid answer than observational studies to many questions in medicine, mainly restricted, however, to the efficacy of drugs; however, controlled intervention trials on diet in general and on alcohol in particular, are difficult and ethically questionable to perform $(36,37)$.

Another limitation of our analyses is the small number of studies that could be included, especially when subanalyses on interstudy heterogeneity were performed. In addition, an appropriate control for confounding variables was applied in only a few of the original studies.

An obvious weakness of our analyses-because of lack of information from the original studies - is that in only a few instances was it possible to separate former drinkers from lifetime abstainers within the nondrinking group. The inclusion of former drinkers in the reference group who might have stopped because of health problems is question- able, and may explain, at least in part, the protective effect of drinking in moderation $(1,36)$. However, analysis of the 3 studies $(21,26,27)$ that formally excluded former drinkers from the no-alcohol category confirmed the relation between drinking in moderation and secondary prevention, too, as far as cardiovascular mortality was concerned.

Any meta-analysis can be plagued by publication bias, because even high-quality studies reporting negative results often are not submitted by investigators themselves or are not accepted for publication by editors. Thus, a formal analysis of publication bias was carried out: the funnel plots appeared to be symmetric for all the categories of alcohol intake, indicating the absence of publication bias in both our meta-analyses.

Under-reporting of alcohol consumption would result in a tendency for relative risks to be biased toward the null hypothesis, and this may have distorted the shape of the curves and the apparent threshold for harm; however, both meta-analyses showed significant association.

In the largest study included in our meta-analysis, The Physicians Health Study (28), the protection associated with alcohol in moderation was greater for non-CVD than for CVD deaths, an unexpected finding. In a subgroup analysis including the 2 studies only $(26,28)$ for which data on non-CVD mortality were available, we could confirm such a finding (data not shown). Thus, the possibility of uncontrolled confounding by lifestyle, medicines, or other 


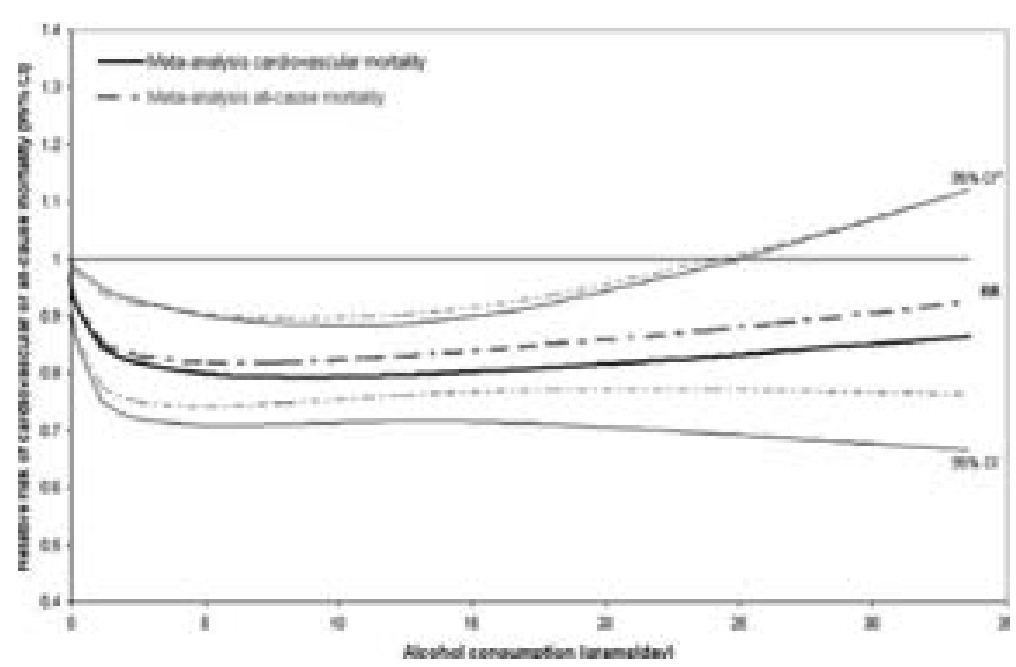

Figure 5 Comparison between Curves on Cardiovascular and All-Cause Mortality in Cardiovascular Disease Patients

Curves for vascular (dotted lines) and all-cause (solid lines) mortality among patients with previous

coronary or cerebrovascular events, extracted from the same cohort studies $(21,23-26,28)$. Abbreviations as in Figure 3 .

factors among the light-to-moderate drinking patients cannot be excluded, suggesting - at least in some studies- possible selection bias rather than a biological effect of alcohol (38).

\section{Conclusions}

Our findings provide reasonable evidence that regular and moderate alcohol intake is significantly associated with a reduction in the incidence of secondary cardiovascular events and all-cause mortality. This conclusion extends to CVD patients what has been reported previously in apparently healthy people $(1,11)$.

Cardiovascular patients should be informed that low-tomoderate alcohol consumption (1 drink/day for women or up to 2 drinks/day for men), should not be harmful to their health. However, cardiovascular patients who do not regularly consume alcohol should not be encouraged to start drinking, owing to the lack of controlled intervention trials on alcohol that are difficult and ethically questionable to perform. No question, heavy or binge drinking can have adverse health outcomes (10). If cardiovascular patients are heavy drinkers, they must strongly be advised to abstain or at least substantially reduce drinking.

Cardiologists should be aware that regular, moderate alcohol consumption, in the context of a healthy lifestyle (increased physical activity, no smoking), dietary habits (decreased dietary fat intake, high consumption of fruit and vegetables), and adequate drug therapy, would put their patients at a level of cardiovascular or mortality risk substantially lower than either abstainers or heavy or binge drinkers.

\section{Acknowledgments}

The authors thank Professor Jozef Vermylen, Catholic University, Leuven, Belgium, for his critical review of the manuscript; Dr. Vincenzo Bagnardi, University of MilanBicocca, Milan, Italy, for providing the macro SAS; and Ms. Judith Baggott for English editing.

Reprint requests and correspondence: Dr. Licia Iacoviello, Laboratory of Genetic and Environmental Epidemiology, "RE ARTU" Research Laboratories, "John Paul II" Centre for High Technology Research and Education in Biomedical Sciences, Catholic University, Largo Gemelli 1, 86100 Campobasso, Italy. E-mail: licia.iacoviello@rm.unicatt.it.

\section{REFERENCES}

1. Di Castelnuovo A, Rotondo S, Iacoviello L, Donati MB, de Gaetano G. Meta-analysis of wine and beer consumption in relation to vascular risk. Circulation 2002;105:2836-44.

2. Corrao G, Bagnardi V, Zambon A, La Vecchia C. A meta-analysis of alcohol consumption and the risk of 15 diseases. Prev Med 2004;38. 613-9.

3. Reynolds K, Lewis B, Nolen JD, Kinney GL, Sathya B, He J. Alcohol consumption and risk of stroke: a meta-analysis. JAMA 2003;289 579-88.

4. Corrao G, Rubbiati L, Bagnardi V, Zambon A, Poikolainen K. Alcohol and coronary heart disease: a meta-analysis. Addiction 2000 95:1505-23. 
5. Rimm EB, Klatsky A, Grobbee D, Stampfer MJ. Review of moderate alcohol consumption and reduced risk of coronary heart disease: is the effect due to beer, wine, or spirits? BMJ 1996;312:731-6.

6. Klatsky AL. Alcohol, cardiovascular diseases and diabetes mellitus. Pharmacol Res 2007;55:237-47.

7. Rimm EB, Williams P, Fosher K, Criqui M, Stampfer MJ. Moderate alcohol intake and lower risk of coronary heart disease: meta-analysis of effects on lipids and haemostatic factors. BMJ 1999;319:1523-8.

8. Estruch R, Sacanella E, Badia E, et al. Different effects of red wine and gin consumption on inflammatory biomarkers of atherosclerosis: a prospective randomized crossover trial. Effects of wine on inflammatory markers. Atherosclerosis 2004;175:117-23.

9. Villegas R, Salim A, O'Halloran D, Perry IJ. Alcohol intake and insulin resistance. A cross-sectional study. Nutr Metab Cardiovasc Dis 2004; 14:233-40.

10. Rehm J, Mathers C, Popova S, Thavorncharoensap M, Teerawattananon Y, Patra J. Global burden of disease and injury and economic cost attributable to alcohol use and alcohol-use disorders. Lancet 2009;373: 2223-33.

11. Di Castelnuovo A, Costanzo S, Bagnardi V, Donati MB, Iacoviello L, de Gaetano G. Alcohol dosing and total mortality in men and women: an updated meta-analysis of 34 prospective studies. Arch Intern Med 2006;166:2437-45

12. White IR, Altmann DR, Nanchahal K. Alcohol consumption and mortality: modelling risks for men and women at different ages. BM 2002;325:191.

13. Lichtenstein AH, Appel LJ, Brands M, et al. Diet and lifestyle recommendations revision 2006: a scientific statement from the American Heart Association Nutrition Committee. Circulation 2006; $114: 82-96$

14. Beaglehole R, Bonita R. Alcohol: a global health priority. Lancet 2009:373:2173-4.

15. Skinner JS, Cooper A, Feder GS, on behalf of the Guideline Development Group. Secondary prevention for patients after a myocardial infarction: summary of NICE guidance. Heart 2007;93:862-4.

16. Smith SC Jr, Allen J, Blair SN, et al. AHA/ACC guidelines for secondary prevention for patients with coronary and other atherosclerotic vascular disease: 2006 update endorsed by the National Heart, Lung, and Blood Institute. J Am Coll Cardiol 2006:47:2130-9.

17. Klatsky AL. Should patients with heart disease drink alcohol? JAMA 2001;285:2004-6.

18. American Heart Association. Alcohol, Wine and Cardiovascula Disease. Available at: http://www.americanheart.org/presenter. jhtml?identifier $=4422$. Accessed November 19, 2009.

19. Mukamal KJ. Alcohol use and prognosis in patients with coronary heart disease. Prev Cardiol 2003;6:93-8.

20. Iestra JA, Kromhout D, van der Schouw YT, Grobbee DE, Boshuizen $\mathrm{HC}$, van Staveren WA. Effect size estimates of lifestyle and dietar changes on all-cause mortality in coronary artery disease patients: systematic review. Circulation 2005;112:924-34.
21. Janszky I, Ljung R, Ahnve S, Hallqvist J, Bennet AM, Mukamal KJ Alcohol and long-term prognosis after a first acute myocardial infarction: the SHEEP study. Eur Heart J 2008;29:45-53.

22. Masunaga N, Kimura A, Miyataka M, et al. Effects of alcohol consumption on cardiovascular events in male patients with healed myocardial infarction. Circ J 2006;70:1263-8.

23. Aguilar D, Skali H, Moye LA, et al. Alcohol consumption and prognosis in patients with left ventricular systolic dysfunction after a myocardial infarction. J Am Coll Cardiol 2004;43:2015-21.

24. Jackson VA, Sesso HD, Buring JE, Gaziano JM. Alcohol consumption and mortality in men with preexisting cerebrovascular disease. Arch Intern Med 2003;163:1189-93.

25. Mukamal KJ, Maclure M, Muller JE, Sherwood JB, Mittleman MA Prior alcohol consumption and mortality following acute myocardia infarction. JAMA 2001;285:1965-70.

26. Shaper AG, Wannamethee SG. Alcohol intake and mortality in middle aged men with diagnosed coronary heart disease Heart 2000 83:394-9.

27. Valmadrid CT, Klein R, Moss SE, Klein BE, Cruickshanks KJ. Alcohol intake and the risk of coronary heart disease mortality in persons with older-onset diabetes mellitus. JAMA 1999;282:239-46.

28. Muntwyler J, Hennekens CH, Buring JE, Gaziano JM. Mortality an light to moderate alcohol consumption after myocardial infarction. Lancet 1998;352:1882-5.

29. International Center for Alcohol Policies (ICAP) 2009. Standard Drinks Available at: http://www.icap.org/PolicyIssues/DrinkingGuidelines/ StandardDrinks/tabid/126/Default.aspx. Accessed November 19, 2009.

30. Greenland S. Dose-response and trend analysis in epidemiology: alternative to categorical analysis. Epidemiology 1995;6:356-65.

31. Royston P, Altman DG. Regression using fractional polynomials of continuous covariates: parsimonious parametric modelling. Appl Stat 1994;43:429-67.

32. Bagnardi V, Zambon A, Quatto P, Corrao G. Flexible metaregression functions for modeling aggregate dose-response data, with an application to alcohol and mortality. Am J Epidemiol 2004;159: 1077-86.

33. Egger M, Davey Smith G, Schneider M, Minder C. Bias in metaanalysis detected by a simple, oraphical test. BMJ 1997:315:629-34.

34. Moore AA, Whiteman EJ, Ward KT. Risks of combined alcohol/ medication use in older adults. Am J Geriatr Pharmacother 2007;5: 64-74.

35. Weathermon R, Crabb DW. Alcohol and medication interactions. Alcohol Res Health 1999;23:40-54.

36. Rehm J, Gmel G, Sempos CT, Trevisan M. Alcohol-related morbidity and mortality. Alcohol Res Health 2003;27:39-51.

37. Gronbaek M, Di Castelnuovo A, Iacoviello L, et al. Wine, alcohol and cardiovascular risk: open issue. J Thromb Haemost 2004;2:2041-8.

38. Criqui M. Alcohol in the myocardial infarction patient. Lancet 1998 $352: 1873$.

Key Words: alcohol - cardiovascular patients " meta-analysis secondary prevention. 

Chapter - Reference H

\section{ALCOHOL CONSUMPTION IN RELATION TO VASCULAR AND TOTAL MORTALITY IN PATIENTS WITH DIABETES, HYPERTENSION OR HI STORY OF CARDI OVASCULAR DI SEASE: A META-ANALYSIS}

Costanzo S, Di Castelnuovo A, Donati MB, Iacoviello L, de Gaetano G. Alcohol consumption in relation to vascular and total mortality in patients with diabetes, hypertension or history of cardiovascular disease: a meta-analysis. Journal of Wine Research. 2011;22(2)119-22. 



\title{
Alcohol Consumption in Relation to Vascular and Total Mortality in Patients with Diabetes, Hypertension or History of Cardiovascular Disease: A Meta-analysis
}

\author{
SIMONA COSTANZO, AUGUSTO Di CASTELNUOVO, \\ MARIA BENEDETTA DONATI, LICIA IACOVIELLO and \\ GIOVANNI de GAETANO
}

\begin{abstract}
Moderate alcohol consumption by apparently healthy people or patients with cardiovascular disease is associated with lower vascular and all-cause mortality. These findings were extended by two new meta-analyses aimed at assessing the relationship of alcohol drinking with vascular and total mortality in a large series of patients, including not only patients with a history of CVD but also diabetic and hypertensive patients. Two meta-analyses were performed: the first one considered 17 studies reporting secondary risk of vascular mortality; the second one included 14 studies reporting total mortality. The meta-analysis on vascular mortality and alcohol intake showed as an 'L-shaped' curve, indicating a protective effect (average 38\%) that was maximal at about 40 and remained still significant up to 60 grams/day. F-shaped pooled curves were observed in the meta-analysis on mortality from any cause and in subgroups defined according to different types of patients or characteristics of the studies. While confirming the hazards of excess drinking, our findings indicate that in patients at high cardiovascular risk, low to moderate alcohol consumption is significantly associated with a reduced incidence of secondary non-fatal and/or fatal vascular events and all-cause mortality.
\end{abstract}

The relationship between alcohol consumption and cardiovascular fatal or non-fatal events or all-cause mortality in healthy people has been depicted as a J-shaped curve attributed to a dose-related combination of beneficial and harmful effects (Di Castelnuovo et al., 2002, 2006). Moderate alcohol consumption by apparently healthy people is associated with lower vascular morbidity, mortality and incidence of type 2 diabetes. Mechanisms supporting this association include increased high-density cholesterol and fibrinolysis, decreased platelet aggregation and coagulation factors, and beneficial effects on endothelial function, inflammation and insulin resistance. These mechanisms could be similarly effective in patients with a history of cardiovascular disease (CVD) or at high risk for vascular events, such as hypertensive (HTN) and diabetic (T2DM) patients, but observational studies in these patients have been inconclusive (Costanzo et al., 2010a). In a recent meta-analysis that examined the

Simona Costanzo, Laboratorio di Epidemiologia Genetica e Ambientale, Laboratori di Ricerca, Fondazione di Ricerca e Cura 'Giovanni Paolo II', Campobasso, Italy (E-mail: simona.costanzo@rm.unicatt.it)

ISSN 0957-1264 print/ISSN 1469-9672 online/11/020119-4 C 2011 Taylor \& Francis http://dx.doi.org/10.1080/09571264.2011.603219 
relationship between alcohol consumption and cardiovascular and total mortality in patients with CVD, a reduction in both mortality risks in moderate drinkers was reported (Costanzo et al., 2010b). These findings were extended by two new metaanalyses aimed at assessing the relationship of alcohol drinking with vascular and total mortality in a larger series of patients, including not only patients with a history of GVD but also diabetic and hypertensive patients.

\section{Methods}

Articles were retrieved up to May 2009 by search in PUBMED and EMBASE. Studies were excluded if the qualifying primary event was different from CVD, T2DM or HTN, or considered only one category of alcohol intake. Data were pooled with a weighed, least-squares regression analysis of second-order fractional polynomial models. The best-fitting regression model was: $\log ($ Relative Risk $)=\beta_{1} \sqrt{ } \mathrm{x}+$ $\beta_{2} \sqrt{ } \mathrm{x}^{*} \log (\mathrm{x})$ (Costanzo et al., 2010b).

\section{Results}

Two meta-analyses were performed: the first one considered 17 studies reporting secondary risk of vascular mortality; the second one included 14 studies reporting total mortality. Results are shown in Table 1.

\section{Meta-analysis 1: Vascular Mortality}

From 17 selected studies including 220,411 patients, seven were studies on patients with previous CVD, four on subjects with T2DM, four on hypertensive subjects and two on patients with a combination of cardiovascular risk factors and/or events. The observed overall relationship between vascular mortality and alcohol intake was interpreted as a 'L-shaped' curve, showing a protective effect (average 38\%) that was maximal at about 40 and remained still significant up to 60 grams/day. The pooled curve from studies on CVD patients predicted 22\% (95\% CI: 13\%-30\%) as maximal protection against vascular mortality at 8 grams/day of alcohol consumption. Significant protection was apparent up to 26 grams/day. Considering five studies on CVD patients where alcohol intake questionnaires were administered quite late ( $>2$ months) after the qualifying event, a J-curve was confirmed, with a shape very similar to that obtained using all studies on CVD patients. In the analysis of studies on HTN patients an L-shaped curve was identified, while for T2DM studies, no J-shaped curve could be identified as the best fitting model, most likely due to the paucity of data.

\section{Meta-analysis 2: Mortality for Any Cause}

Fourteen studies, including 201,283 patients at high cardiovascular risk, were selected (CVD $\mathcal{N}=7$, T2DM $\mathcal{N}=2$, HTN $\mathcal{N}=3$, combination of cardiovascular risk factors $\mathcal{N}=2$ ). A significant association with a lower all-cause mortality than in abstainers was apparent up to 53 grams/day, but was maximal $(\mathrm{RR}=0.79$; $95 \%$ CI: $0.75-$ 0.84 ) at the much lower dose of 10 grams/day. In the analysis of T2DM studies, a Jshaped curve was identified as the best fitting model. The pooled curve from T2DM patients showed a greater protection at smaller intake of alcohol in comparison with curves from CVD $(p=0.002)$ or HTN patients $(p<0.001)$. In the analysis of GVD patients the average maximal protection was $18 \%$ in the range of 5-10 grams/day. 


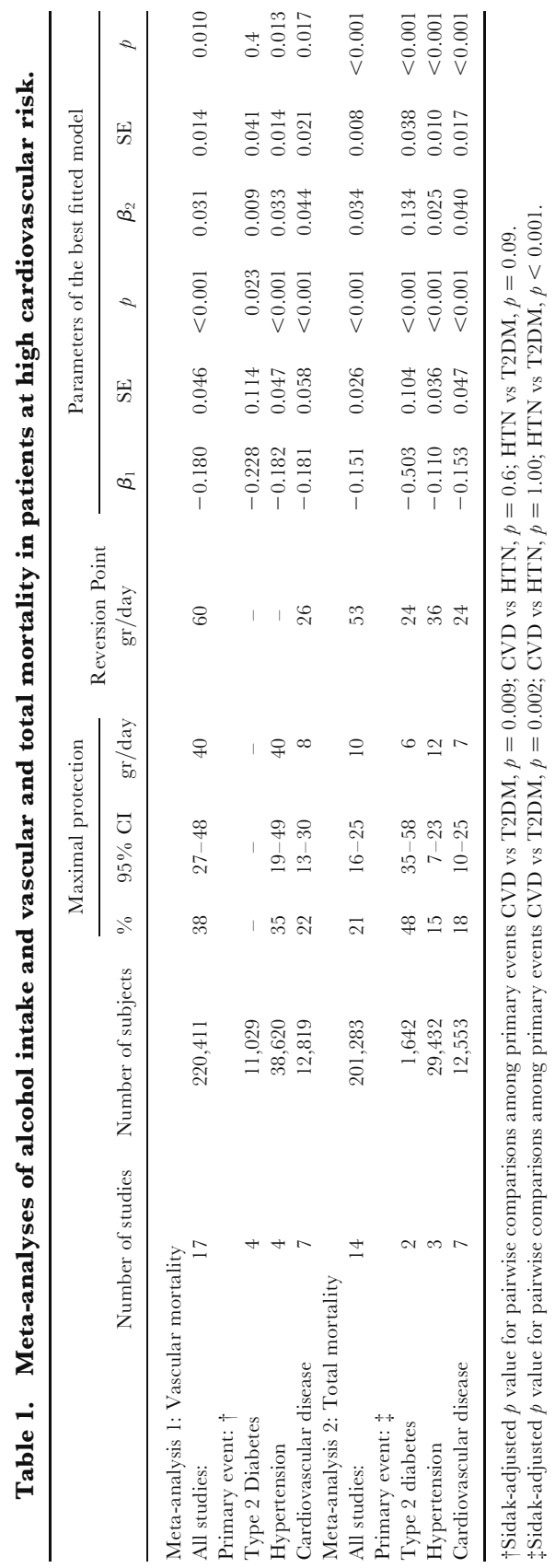


Regarding this primary event, four studies gathered information on alcohol consumption habits quite late after the qualifying event ( $>2$ months). In these studies a J-shape curve was confirmed, with $17 \%$ maximal risk reduction at 8 grams/day and significant protection apparent up to 24 grams/day.

\section{Discussion}

Analyzing the studies on CVD patients that recorded alcohol habits somewhat late after the diagnosis of the primary event, likely reflecting the real intake of alcohol before the occurrence of a secondary event, the protective effect of moderate alcohol consumption on all-cause and vascular mortality was confirmed (Costanzo et al., 2010b). In studies on T2DM or HTN patients it was not possible to identify the time of the exposure assessment in relation to the time of diagnosis of the primary event. However, these studies most likely included patients with a well established history of T2DM or HTN whose data on alcohol intake reflected the consumption following the diagnosis that placed the subjects at high cardiovascular risk. The relationship of alcohol with vascular and all-cause mortality appeared stronger in diabetics than in other patients at high cardiovascular risk or in general population. As mortality in diabetics is strongly related to cardiovascular risk, attempts to reduce it by drinking in moderation could therefore be considered. Few studies only have investigated up to now the association of alcohol consumption and the risk of CVD or mortality from any cause in hypertensive subjects. Our findings suggest that moderate drinking is associated with a lower risk of vascular and all-cause mortality in hypertensive subjects too. As alcohol abuse is a major risk factor for hemorrhagic stroke, intake of alcohol by hypertensive patients must be strictly limited to small doses. In patients at high cardiovascular risk, moderate alcohol consumption (5-10 grams/day) was significantly associated with a lower incidence of all-cause mortality. If not otherwise contraindicated, cardiovascular patients who are regular moderate alcohol drinkers should be advised to continue to drink without exceeding one-two drinks per day, as a component of a cardio-protective dietary pattern within the suggested energy intake levels. There is no question that heavy or binge drinking has adverse health outcomes.

\section{Acknowledgement}

Partially supported by a grant from the European Research Advisory Board (ERAB) (EA0827).

\section{References}

Costanzo, S., Di Castelnuovo, A., Donati, M.B., Iacoviello, L. and de Gaetano, g. (2010a) Cardiovascular and overall mortality risk in relation to alcohol consumption in patients with cardiovascular disease, Circulation, 121(17), 1951-1959.

Costanzo, S., Di Castelnuovo, A., Donati, M.B., Iacoviello, L. and de Gaetano, g. (2010b) Alcohol consumption and mortality in patients with cardiovascular disease: a meta-analysis, Fournal of the American College of Cardiology, 55(13), 1339-1947.

Di Castelnuovo, A., Costanzo, S., Bagnardi, V., Donati, M.B., Iacoviello, L. and de GaEtano, G. (2006) Alcohol dosing and total mortality in men and women: an updated meta-analysis of 34 prospective studies, Archives of Internal Medicine, 166, 2437-2445.

Di Castelnuovo, A., Rotondo, S., Iacoviello, L., Donati, M.B. and de Gaetano, G. (2002) Meta-analysis of wine and beer consumption in relation to vascular risk, Circulation, 105, 2836-2844. 


\section{Chapter - Reference I}

\section{PREVENTION OF CARDIOVASCULAR RISK BY MODERATE ALCOHOL CONSUMPTION: EPIDEMIOLOGIC EVIDENCE AND PLAUSI BLE MECHANISMS}

Di Castelnuovo A, Costanzo S, Donati MB, Iacoviello L, de Gaetano G. Prevention of cardiovascular risk by moderate alcohol consumption: epidemiologic evidence and plausible mechanisms. Intern Emerg Med. 2010;5(4):291-7. 



\title{
Prevention of cardiovascular risk by moderate alcohol consumption: epidemiologic evidence and plausible mechanisms
}

\author{
Augusto Di Castelnuovo - Simona Costanzo • \\ Maria Benedetta Donati • Licia Iacoviello • \\ Giovanni de Gaetano
}

Received: 5 August 2009/Accepted: 14 December 2009/Published online: 3 February 2010

(C) SIMI 2010

\begin{abstract}
An inverse association between moderate alcohol intake and cardiovascular risk, in particular coronary disease and ischemic stroke, has been shown in many epidemiologic studies. In addition, several other diseases are also known to occur less frequently in moderate drinkers than in non-drinkers, whereas excess of drinking is invariably harmful. However, some concern has been recently raised about the possibility that at all dosages the harm of alcohol could overcome its beneficial effects. We present here the epidemiologic and mechanistic evidence to support the protective effect of moderate alcohol intake against cardiovascular disease and all-cause mortality.
\end{abstract}

Keywords Alcohol · Wine · Vascular risk Total mortality

\section{Introduction}

There is strong and consistent epidemiologic evidence of a significant inverse association between moderate alcohol consumption and cardiovascular disease (CVD), in particular coronary disease, ischemic stroke [1-3] and peripheral arterial disease $[4,5]$.

The 2006 Diet and Lifestyle Recommendations Scientific Statement from the American Heart Association Nutrition Committee [6] recommends that: "If you

A. Di Castelnuovo $(\bowtie) \cdot S$. Costanzo - M. B. Donati

L. Iacoviello · G. de Gaetano

"RE ARTU" Research Laboratories, "John Paul II" Centre

For High Technology Research and Education in Biomedical Sciences, Catholic University, Largo Gemelli 1 ,

86100 Campobasso, Italy

e-mail: dicastel@ngi.it consume alcohol, do so in moderation (equivalent to no more than one drink for women or two drinks for men per day)". In addition, moderate ethanol consumption has now emerged as a dominant component of a Mediterranean diet score, used as a predictor of lower mortality [7]. Several not primarily vascular diseases are also known to occur less frequently in moderate drinkers than in non-drinkers [8], whereas excessive alcohol consumption is unquestionably harmful [8-10]. Although the protective effect of moderate alcohol consumption on atherothrombotic vascular disease is widely accepted by the scientific community, some concern has been recently raised, particularly at regulatory agencies level, on the possibility that at all dosages the harmful effects of alcohol might overcome its benefit [10]. The relationship between alcohol and vascular risk or total mortality has been depicted as a J-shaped curve: the risk is indeed lower at light to moderate alcohol consumption, but increases at higher doses [9]. However, if low alcohol intake is inversely related to CVD, the other side of the coin shows an increased risk of certain cancers, cirrhosis and death from accidents mainly associated with increasing alcohol consumption [8-10].

The aim of this survey is to review the epidemiologic evidence supporting the relationship of alcohol dosing with vascular risk and all-cause mortality, but we shall start by a brief discussion of the biological plausibility of some major mechanisms that might contribute to the protective effect of moderate alcohol intake against CVD.

Mechanisms of action of alcohol as a protective factor against CVD

Alcohol consumption correlates with modification of several vascular and biochemical factors that have potential 
cardioprotective benefits. Increase in high-density lipoprotein (HDL) cholesterol levels, decrease in platelet aggregation via inhibition of prostaglandin synthesis and changes in fibrinogen, tissue-plasminogen activator (t-PA), and PA inhibitor (PAI-1) levels, are thought to represent major mechanisms to reduce the risk of cardiovascular events $[11,12]$.

Increase HDL levels

The increase in HDL reportedly associated with alcohol drinking has been for a long time considered one of the main mechanisms of alcohol action. However, recent data suggest that increased HDL cholesterol through medicaments has no significant effect on vascular risk [13]. By inference, the association of alcohol with elevation of HDL per se, without considering the effects on its function, appear nowadays of reduced clinical relevance.

Oxidized low-density lipoproteins (LDL) are known to play a major role in atherosclerosis and CVD, and are a commonly used marker for oxidative damage [14]. Moderate consumption of alcohol is associated with a reduction in the LDL susceptibility both to oxidation and aggregation. In addition, alcohol-induced elevations in HDL may facilitate the transport of LDL cholesterol back to the liver for reprocessing, thus dropping the cholesterol available to endothelial activation and atheroma formation [14]. As a consequence, we can infer that moderate alcohol intake might promote reduction in the toxic effects of elevated LDL. Nonetheless, although depending on some genetic characteristics (e.g., Apo E), alcohol increases LDL plasma levels [15], an apparently paradoxical effect since LDL are considered to be a risk factor for myocardial infarction. Possibly, regulation of lipids rather than LDL elevation alone should be taken into consideration with respect to alcohol benefits. More basic studies are needed to clarify this controversial point.

\section{Antiatherogenic and antithrombotic properties}

Moderate alcohol consumption is independently associated with less extensive coronary atherosclerosis in humans. In a study on more than 2,000 patients undergoing coronary angiography, alcohol consumption was associated with a lower percent of lumen narrowing in the main coronary vessels [16].

Several studies have shown that polyphenols, mainly contained in red wine, are able to inhibit platelet arachidonic acid metabolism and biosynthesis of thromboxane A2, a potent platelet aggregation inducer and a vasoconstrictor [17]. Moderate alcohol consumption may also affect fibrinogen concentration, platelet aggregation, t-PA and PAI-1 [11, 12, 18-20].
Alcohol consumption and omega-3 polyunsaturated fatty acids

Omega-3 fatty acids ( $\omega 3$ FA) consumption reduces the risk of sudden cardiac death [21]. The Lyon Diet Heart Study showed that moderate wine consumption was associated with higher plasma levels of "marine" $\omega 3$ FA independently from the dietary intake of specific plant and marine $\omega 3$ [22]. Thus, the protection resulting from moderate alcohol drinking might be mediated through increased $\omega 3$ FA. The association of alcohol consumption with $\omega 3$ FA was lately investigated in the framework of the IMMIDIET study that enrolled an adult population of about 2,000 people from three different European regions [23]. Eicosopentaenoic acid (EPA), docosahexaenoic acid (DHA) and $\mathrm{EPA}+\mathrm{DHA}$ in plasma, on one hand and EPA and EPA+DHA in red blood cells on the other, were all positively associated with alcohol intake, independently from fish intake and other possible confounders related to life styles [23].

\section{Ethanol preconditioning}

Epidemiological data and several experimental animal studies suggest that low dose ethanol induces in the heart a chronic protective state that is independent from traditional (lipid and coagulation) risk factors [24, 25],

As reported in the FLORA study [26], the hearts of rats fed a diet rich in anthocyanins (that are part of the non alcoholic component of wine) were more resistant to regional ischemia and reperfusion insult. Because anthocyanins do not circulate a long time, it is likely that they are protective irrespective of the timing of their assumption in relation to the moment of ischemia.

However, it was also seen, at least in the rabbit [25] that if alcohol is present within the circulation during the ischemic insult, it could block its own protection. In all probability, ethanol is only a "preconditioning" agent, which means it is not protective if it is present in blood at the moment of ischemia [27].

\section{Mechanisms of action of wine}

Wine possibly acts through mechanisms that might provide additional cardiovascular benefits than that provided by ethanol. Red wine contains a wide variety of polyphenols, including phenolic acids, tannins, trihydroxy stilbenes (resveratrol), and flavonoids (catechin, epicatechin and quercetin) that influence low-density lipoprotein oxidation, platelet aggregation, endothelial function and smooth muscle cell proliferation [28-32]. Some of these molecules inhibit lipoprotein oxidation, promote nitric oxide formation by vascular endothelium, reduce serum inflammatory 
biomarkers, inhibit thromboxane A2 biosynthesis in platelets and leukotriene biosynthesis in neutrophils, and regulate lipoprotein production and secretion. These actions occur through the inhibition of various enzymes, such as phospholipase A2, cyclooxygenases, phosphodiesterase, and several protein kinases involved in cell signaling [28-38].

Mechanisms by which alcohol may increase cardiovascular risk

Heavy alcohol consumption and irregular (binge) drinking are associated with several adverse effects: fetal alcohol syndrome, liver cirrhosis, certain cancers, hypertriglyceridemia, hypertension, hemorrhagic stroke, obesity, alcohol intoxication and dependence [10,39].

Blood pressure levels and prevalence of hypertension linearly increase with alcohol consumption [8].

Excessive alcohol intake is the second main cause of hyperlipidemia in the population [40]. Overweight subjects should limit or avoid alcohol to reduce unnecessary energy intake. Increased clotting and a reduced threshold for ventricular fibrillation are the main mechanisms explaining the negative effects of heavy drinking on CVD [39].

Nevertheless, both positive and negative reported mechanisms have often been deduced from epidemiologic data, and are not real mechanisms. The actual relevance of inhibition of some enzymes and lipoprotein oxidation is indirect and often questioned. Further basic studies, able to define plausible mechanisms of action are warranted.

\section{Epidemiologic evidence that moderate alcohol consumption decreases both cardiovascular risk and total mortality}

Despite the fact that the healthy effect of moderate intake of alcohol is by now well accepted [12, 41]; important issues remain to be discussed about the relationship between alcohol and CVD, including the possible effect of confounding, the differences in types of alcoholic beverages, the optimal amount of alcohol intake, associated with health benefit, the individual or environmental modulation of the alcohol-related effects and the pattern of drinking.

The role of life style

It has been argued that uncontrolled confounding by associated lifestyle factors play a major role in the association between moderate alcohol drinking and coronary protection [42] based on the results showing that drinkers have many healthier characteristics than non-drinkers and thus have lower ischemic heart disease risk [43]. However,
Mukamal et al. [44] show that the differences between abstainers and drinkers were attenuated, eliminated, or even reversed by additional adjustment for sociodemographic factors. Moreover, a similar pattern was apparent for physical activity, a widely recommended behavior for the prevention of CVD. Despite this fact, concerns about the possibility of confounding in studies on physical activity have been largely overshadowed.

The differences among alcoholic beverages

Many epidemiologic studies have explored the hypothesis that consuming alcohol in the form of wine might confer a protection against CHD above that expected from its alcohol content [2]. As mentioned above, wine might indeed conceivably exert additional ethanol unrelated beneficial effects. Despite a large number of experimental studies that confirm such a hypothesis, epidemiologic evidence of a greater effect of wine has not been definitely established. To test such a hypothesis, our group performed two metaanalyses based on the 26 studies reporting comparisons between different alcoholic beverages (wine and beer) and the relative risk (RR) of CVD [2]. A first meta-analysis was conducted on studies that investigated the relation between vascular events and specific alcoholic beverages, irrespective of the amount consumed. Fifteen studies were included, involving 208,096 persons. The overall RR of wine drinkers with respect to non-drinkers was 0.68 [95\% confidence interval (95\% CI) 0.59-0.77], whereas the protection associated with beer drinkers showed an overall RR 0.78 , $95 \%$ CI $0.70-0.86$. However, following the exclusion of the studies that did not simultaneously adjust for different types of alcoholic beverages, there was no difference in the RRs of CVD between wine and beer drinkers $(0.75$ vs. 0.77) when compared with abstainers. In contrast, an important difference between wine and beer consumption was observed in the second meta-analysis conducted on studies reporting trend (dose-response) analysis. Ten studies were included involving 176,042 persons. In wine drinkers a clear inverse dose-effect curve ( $\mathrm{J}$ curve) was found, while all the fitted models used failed to show any significant relationship between different amounts of beer intake and vascular risk. Therefore, it was only possible to identify a daily dose of wine, namely $150 \mathrm{ml}$, under which the beneficial protection against CVD was no more significant.

If wine is better than beer or spirits remains to be elucidated. Further studies addressing this issue should be of large sample size and carefully designed, because differences between beverages, if any, are expected to be limited and might reflect differences in the risk factor patterns, traditions, or geographic distribution among categories of drinkers rather than a true difference in the protection from CVD risk. 
The most healthy amount of alcohol intake

As already mentioned, the dose-response relationship between wine or alcohol intake and rate of CVD has been depicted as a J-shaped curve [1-3, 9]. The J-shaped relationship between alcohol consumption and clinical events reflects non-drinkers having higher incidence and mortality rates than light or moderate drinkers, but similar or lower rates than heavy drinkers. In our meta-analysis [2], an "average dose-response" curve was obtained fitting a non-linear model. The observed relationship confirmed a "J-shaped" curve since, after an initial decrease in the vascular risk by increasing amounts of wine, the curve reached a plateau at higher intake, and tended to be reverted at the highest amounts explored. A maximum reduction was predicted at $750 \mathrm{ml} /$ day, but statistical significance was only reached up to the amount of $150 \mathrm{ml} /$ day, equivalent to $12-18 \mathrm{~g}$ of ethanol per day. In conclusion, epidemiologic evidence indicates that the amount of wine/alcohol for which the balance between risk and benefit is the best is in the range of 1-2 drinks a day, in agreement with American Heart Association guidelines [45].

Is the effect of alcohol different in men and women?

In our meta-analysis of studies that enrolled only men [2], the protection offered by wine was found to be surprisingly small (13\%) and not significant, in contrast with studies enrolling both sexes (47\%). No sex-related difference was observed for beer consumption. In a meta-analysis of studies on alcohol and stroke [3], greater protection in women than in men was apparent. Confronting doseresponse curves separately in men and women in a metaanalysis on alcohol and total mortality [9], we observed that the protection was apparent up to three drinks per day in men, but only up to two drinks per day in women, whereas the maximal risk reduction was similar $(17 \%$; $99 \%$ CI $15-$ $19 \%$ and $18 \%$; $99 \%$ CI $13-22 \%$, respectively). The pooled curves for men and women were different at the range at which alcohol was protective-in fact, the inverse association in women apparently disappeared at doses lower than in men-but comparable regarding the maximal protection.

Thus, a possible sex difference in the protective effect of alcohol might exist and explain apparently controversial results in different epidemiologic studies. Large studies are needed to test whether women are more susceptible indeed to the benefit of alcohol or if they more likely drink lower amounts of alcohol, thus receiving its maximal advantage [46, 47].

The role of the pattern of drinking

Experimental studies [48] suggest that drinking wine at meals provides maximal health effect, by prevention of the development of atheromatous lesions, while a binge pattern of drinking has been associated with higher risk of CHD $[49,50]$. In the large health professional follow-up study [51, 52], the authors studied the association of alcohol consumption with the risk of myocardial infarction [51] and ischemic stroke [52], focusing their investigations on the pattern of drinking (frequency and quantity of alcohol consumption). Although they failed to observe any correlation between health effect of alcohol and the proportion consumed with meals, they found a role of drinking frequency: the highest protective effect on risk of myocardial infarction was among men who drank alcohol three or more days a week, whatever the amount consumed. On the other hand, alcohol consumption of 10-30 g/day on 3-4 days/week appeared to be associated with the lowest risk of ischemic stroke when compared with abstention or other amount of alcohol intake.

Moderate regular drinking, possibly during meals appears as the ideal behavior, while binge drinking is to be absolutely avoided.

\section{Protection against total mortality}

If low alcohol intake is inversely related to CVD, the other side of the coin shows an increased risk of certain cancers, cirrhosis and death from accidents associated with increasing alcohol consumption $[1,10]$. As a consequence, one could suspect that even at lower dosages the benefit of alcohol could be overcome by its harmful effects [10, 42, 47]. To test such a hypothesis, we performed a metaanalysis including 34 prospective studies on alcohol and all-cause mortality [9]. We pooled findings from more than one million subjects and about 95,000 deaths from any cause as measured outcomes. The J-shaped relationship observed between total mortality and increasing amounts of alcohol consumed indicate that low to moderate consumption of alcohol ( $\leq 1$ drink/day in women and $\leq 2$ drinks/day in men) significantly reduces total mortality, while higher doses increase it.

Is the beneficial effect of alcohol a real one?

As mentioned above, we paid special attention to the possible effect of confounding. Twenty-nine studies showed adjusted RRs at least for age; among them, 15 were adjusted for social status too, and 6 for social status and dietary markers. Pooled curves for different levels of adjustment were significantly different $(P<0.0001)$ showing that part of heterogeneity is attributable indeed to adjustment. However, the average maximal protection observed in not adjusted studies was $36 \%$, it decreased in adjusted studies to an average of $17 \%$ (anyway a substantial and statistically significant effect). The observed 
difference between the 5 not adjusted and the 29 adjusted studies could also be due to factors different from the level of adjustment, as different groups of studies were compared. Therefore, we performed an additional analysis of adjusted or not unadjusted data obtained from the same studies. In the latter case, the effect due to known confounders (age, smoking, social status, dietary factors) led to the reduction in the maximal average protection from 19 to $16 \%$; for analogy, even in the pessimistic hypothesis that residual (possibly unknown) confounding would have a similar strength as the known one in lowering the protection, one can assume that the "real" (maximal) protection against total mortality associated with low consumption of alcohol would be higher than $10-12 \%$.

In conclusion, although the apparent protection by alcohol or wine decreases when data are adjusted, thus confirming the importance of confounding in assessing drinking effects, it largely remains in a range of undoubted public health value [9].

\section{The problem of former drinkers}

We also investigated the degree to which the inclusion of ex-drinkers in control group could influence the results of our meta-analysis on alcohol and total mortality [9]. The inclusion in the control groups of people who had stopped drinking owing to illness might induce an overestimation of the protection offered by drinking in moderation. We tested this hypothesis by comparing studies that used as reference group, the category of no alcohol intake and/or excluded former drinkers with studies which, in contrast, included in their reference group occasional or former drinkers or people reporting low occasional alcohol intake: the protection was indeed somewhat lower in the first studies, but still remained statistically significant.

\section{Should abstention be recommended to CVD patients?}

A meta-analysis on five cohorts of CVD patients [53] found a $20 \%$ reduction in all-cause mortality risk in moderate drinkers in comparison with abstainers. Janszky et al. [54] found that among survivors from a primary myocardial infarction, moderate drinkers (up to $20 \mathrm{~g}$ /day) have lower secondary cardiovascular and all-cause mortality than abstainers. Regular (non-binge) and moderate alcohol intake is significantly associated with a reduced incidence of secondary cardiovascular and all-cause mortality in patients with a history of cardiovascular events [55]. If not contraindicated, patients who drink alcohol should not exceed 1-2 drinks/day for women or up to 2-3 drinks/day for men, as a component of a balanced cardioprotective dietary pattern with appropriate energy intake levels.
A last question: should a randomized controlled clinical trial be performed on the protective effect of alcohol in CVD disease?

Randomized controlled trials usually offer a more solid answer than observational studies to many questions in medicine, but have mainly been restricted to the efficacy of drugs; controlled intervention trials on diet in general and on alcohol in particular are difficult to be performed, mainly because of selection, blinding or compliance and ethical problems [47]. The sponsor(s) of this kind of trial is also difficult to identify. Notwithstanding these difficulties, a large randomized controlled trial on alcohol, comparing a reference group of long-term abstainers, devoid of former or occasional drinkers and an "intervention" group of light to moderate no-binging drinkers, with appropriate followup, collecting not only vascular, but total mortality data too, would help in clarifying the effect of alcohol on health. Randomised controlled trials on intermediate endpoints could perhaps be more feasible and offer a valuable alternative.

At the present moment, however, one has to rely upon observational studies such as those analyzed here or prospective studies where participants spontaneously decrease or stop drinking. Interestingly enough, the first study of the latter type [56] supports the inverse relation of moderate alcohol intake with CVD.

\section{Conclusions}

Available epidemiologic data, that are limited at the moment to observational studies, confirm the hazards of excess drinking, but also indicates the existence of potential windows of alcohol intake that may confer a net beneficial effect of drinking, at least in terms of survival, both in men and in women. Methodological limitations of observational study design, the role of uncontrolled confounding and the optimal choice of the reference group are important issues to be considered. However, the protection by alcohol would anyway remain in a range of undoubted public health value, even considering all possible confounders.

In a general public health perspective, alcoholic beverages should be avoided whenever consumption would put an individual or others at risk, such as during pregnancy or before driving. Moreover, alcohol intake, even in moderation, must be avoided by young people, as they are at very low cardiovascular risk and tend to misuse alcohol (binging) $[8,57]$.

Besides insisting on the control of risk factors, abstainers should be informed that, in the absence of contraindications and in the context of healthy eating and 
lifestyle, low-moderate alcohol consumption may contribute to better health. Asymptomatic subjects at high cardiovascular risk or those who have had a cardiovascular event might also be informed of the cardiovascular risk reduction associated with low-moderate drinking. People who are already regular light-moderate alcohol consumers should be encouraged to continue. The hazards of excess drinking should be always highlighted, and heavy drinkers pushed to cut their consumption to a moderate level [6].

The rates of vascular and total mortality, as well as the development of hypertension or type 2 diabetes, are lower for people who drink low to moderate amounts of alcohol than for people who do not drink at all or drink heavily [1, 58-61]. However, some concerns have been raised about whether it is advisable to encourage adult people to drink small amounts regularly rather than abstain completely, especially among poor populations and in low-income countries where the disease burden per unit of alcohol consumption is greater [10, 62].

The cardioprotective nature of alcohol has been attributed to both its antithrombotic properties and its ability to decrease LDL levels and/or their oxidation. Moreover, wine and especially red wine, due to its polyphenol content might offer additional advantages and greater cardiovascular benefits than alcohol alone.

Genetic regulation of the individual response to alcohol has been recently proposed [63, 64].

A large randomized controlled trial on alcohol, comparing a referent group of long-term abstainers, devoid of former or occasional drinkers and an "intervention" group of light to moderate no-binging drinkers, with appropriate follow-up, collecting not only vascular, but total mortality too will without doubt help in clarifying the effect of alcohol on health.

Further investigations in this emerging field will hopefully assist in interpreting heterogeneous findings in different settings and populations.

Conflict of interest None.

\section{References}

1. Corrao G, Bagnardi V, Zambon A et al (1999) Exploring the dose-response relationship between alcohol consumption and the risk of several alcohol-related conditions: a meta-analysis. Addiction 94:1551-1573

2. Di Castelnuovo A, Rotondo S, Iacoviello L et al (2002) Metaanalysis of wine and beer consumption in relation to vascular risk. Circulation 105:2836-2844

3. Reynolds K, Lewis BL, Nolen JDL et al (2003) Alcohol consumption and risk of stroke: a meta-analysis. JAMA 289:579-588

4. Jepson RG, Fowkes FG, Donnan PT et al (1995) Alcohol intake as a risk factor for peripheral arterial disease in the general population in the Edinburgh Artery Study. Eur J Epidemiol 11:9-14
5. Vliegenthart R, Geleijnse JM, Hofman A et al (2002) Alcohol consumption and risk of peripheral arterial disease: the Rotterdam study. Am J Epidemiol 155:332-338

6. Lichtenstein AH, Appel LJ, Brands M et al (2006) Diet and lifestyle recommendations revision 2006: a scientific statement from the American Heart Association Nutrition Committee. Circulation 114:82-96

7. Trichopoulou A, Bamia C, Trichopoulos D (2009) Anatomy of health effects of the Mediterranean diet: Greek EPIC prospective cohort study. BMJ 338:b2337

8. Corrao G, Bagnardi V, Zambon A et al (2004) A meta-analysis of alcohol consumption and the risk of 15 diseases. Prev Med 38:613-619

9. Di Castelnuovo A, Costanzo S, Bagnardi V et al (2006) Alcohol dosing and total mortality in men and women: an updated metaanalysis of 34 prospective studies. Arch Intern Med 166:24372445

10. Rehm J, Mathers C, Popova S et al (2009) Global burden of disease and injury and economic cost attributable to alcohol use and alcohol-use disorders. Lancet 373:2223-2233

11. Rimm EB, Williams P, Fosher K et al (1999) Moderate alcohol intake and lower risk of coronary heart disease: meta-analysis of effects on lipids and haemostatic factors. BMJ 319:1523-1528

12. Collins MA, Neafsey EJ, Mukamal KJ et al (2009) Alcohol in moderation, cardioprotection, and neuroprotection: epidemiological considerations and mechanistic studies. Alcohol Clin Exp Res 33:206-219

13. Briel M, Ferreira-Gonzalez I, You JJ et al (2009) Association between change in high density lipoprotein cholesterol and cardiovascular disease morbidity and mortality: systematic review and meta-regression analysis. BMJ 338:b92

14. Holvoet P, Peeters K, Lund-Katz S et al (2001) Circulating oxidized LDL is a useful marker for identifying patients with coronary artery disease. Arterioscler Thromb Vasc Biol 21:844-848

15. Corella D, Tucker K, Lahoz C et al (2001) Alcohol drinking determines the effect of the APOE locus on LDL-cholesterol concentrations in men: the Framingham Offspring Study. Am J Clin Nutr 73:736-745

16. Femia R, Natali A, L'Abbate A et al (2006) Coronary atherosclerosis and alcohol consumption: angiographic and mortality data. Arterioscler Thromb Vasc Biol 26:1607-1612

17. Ruf JC, J1 Berger, Renaud S (1995) Platelet rebound effect of alcohol withdrawal and wine drinking in rats: relation to tannins and lipid peroxidation. Arterioscler Thromb Vasc Biol 1:140-144

18. Hendriks HF, van der Gaag MS (1998) Alcohol, coagulation and fibrinolysis. Novartis Found Symp 216:111-120 (discussion 120 124)

19. Ridker PM, Vaughan DE, Stampfer MJ et al (1994) Association of moderate alcohol consumption and plasma concentration of endogenous tissue-type plasminogen activator. JAMA 272:929-933

20. Wannamethee SG, Lowe GD, Shaper G et al (2003) The effects of different alcoholic drinks on lipids, insulin and haemostatic and inflammatory markers in older men. Thromb Haemost 90:1080-1087

21. Investigators GISSI-Prevenzione (1999) Dietary supplementation with n-3 polyunsaturated fatty acids and vitamin E after myocardial infarction: results of the GISSI-Prevenzione trial. Lancet $354: 447-455$

22. de Lorgeril M, Salen P, Martin JL et al (2008) Interactions of wine drinking with omega-3 fatty acids in coronary heart disease patients: a fish-like effect of moderate wine drinking. Am Heart J 155:175-181

23. di Giuseppe R, de Lorgeril M, Salen P et al (2009) European Collaborative Group of the IMMIDIET Project. Alcohol consumption and $n-3$ polyunsaturated fatty acids in healthy men and women from 3 European populations. Am J Clin Nutr 89:354-362 
24. Guiraud A, de Lorgeril M, Boucher F et al (2004) Cardioprotective effect of chronic low dose ethanol drinking: insights into the concept of ethanol preconditioning. J Mol Cell Cardiol 36:561-566

25. Krenz M, Cohen MV, Downey JM (2002) The protective and anti-protective effects of ethanol in a myocardial infarct model. Ann N Y Acad Sci 957:103-114

26. Toufektsian MC, de Lorgeril M, Nagy N et al (2008) Chronic dietary intake of plant-derived anthocyanins protects the rat heart against ischemia-reperfusion injury. J Nutr 138:747-752

27. Niccoli G, Altamura L, Fabretti A, Lanza GA, Biasucci LM, Rebuzzi AG, Leone AM, Porto I, Burzotta F, Trani C, Crea F (2008) Ethanol abolishes ischemic preconditioning in humans. Am Coll Cardiol 51:271-275

28. Soleas GJ, Diamandis EP, Goldberg DM (1997) Wine as a biological fluid: history, production, and role in disease prevention. J Clin Lab Anal 11:287-313

29. Guarda E, Godoy I, Foncea R et al (2005) Red wine reduces oxidative stress in patients with acute coronary syndrome. Int J Cardiol 104:35-38

30. Tsang C, Higgins S, Duthie GG et al (2005) The influence of moderate red wine consumption on antioxidant status and indices of oxidative stress associated with $\mathrm{CHD}$ in healthy volunteers. $\mathrm{Br}$ J Nutr 93:233-240

31. Sacanella E, Vázquez-Agell M, Mena MP et al (2007) Downregulation of adhesion molecules and other inflammatory biomarkers after moderate wine consumption in healthy women: randomized trial. Am J Clin Nutr 86:1463-1469

32. Estruch R, Sacanella E, Mota F et al (2009) Moderate consumption of red wine, but not gin, decreases erythrocyte superoxide dismutase activity: a randomised cross-over trial. Nutr Metab Cardiovasc Dis [Epub ahead of print]

33. De Curtis A, Murzilli S, Di Castelnuovo A et al (2005) Alcoholfree red wine prevents arterial thrombosis in dietary-induced hypercholesterolemic rats: experimental support for the 'French paradox'. J Thromb Haemost 3:346-350

34. Di Minno G, Silver JM (1983) Mouse antithrombotic assay: simple method for the evaluation of antithrombotic agents in vivo. Potentiation of antithrombotic activity by ethyl alcohol. J Pharmacol Exp Ther 225:57-60

35. Pace-Asciak CR, Rounova O, Hahn SE et al (1996) Wines and grape juices as modulators of platelet aggregation in healthy human subjects. Clin Chim Acta 246:163-182

36. Rotondo S, Rotilio D, Cerletti C et al (1996) Red wine, aspirin and platelet function. Thromb Haemost 76:818-819

37. Rotondo S, Rajtar G, Manarini S et al (1998) Effect of trans-resveratrol, a natural polyphenolic compound, on human polymorphonuclear leukocyte function. Br J Pharmacol 123:1691-1699

38. Estruch R, Sacanella E, Badia E et al (2004) Different effects of red wine and gin consumption on inflammatory biomarkers of atherosclerosis: a prospective randomized crossover trial. Effects of wine on inflammatory markers. Atherosclerosis 175:117-123

39. McKee M, Britton A (1998) The positive relationship between alcohol and heart disease in Eastern Europe: potential physiological mechanisms. J Roy Soc Med 91:402-407

40. Feinman L, Lieber C (1999) Ethanol and lipid metabolism. Am J Clin Nutr 70:791-792

41. Grønbaek MJ (2009) The positive and negative health effects of alcohol and the public health implications. Intern Med 265:407-420

42. Jackson R, Broad J, Connor J et al (2005) Alcohol and ischaemic heart disease: probably no free lunch. Lancet 366:1911-1912

43. Naimi TS, Brown DW, Brewer RD et al (2005) Cardiovascular risk factors and confounders among nondrinking and moderatedrinking U.S. adults. Am J Prev Med 28:369-373

44. Mukamal KJ, Ding EL, Djoussé L (2006) Alcohol consumption, physical activity, and chronic disease risk factors: a populationbased cross-sectional survey. BMC Public Health 6:118
45. Pearson TA, Blair SN, Daniels SR et al (2002) AHA guidelines for primary prevention of cardiovascular disease and stroke: 2002 update consensus panel guide to comprehensive risk reduction for adult patients without coronary or other atherosclerotic vascular diseases. Circulation 106:388-391

46. Di Castelnuovo A, Iacoviello L, de Gaetano G (2003) Alcoho and coronary heart disease. N Engl J Med 348:1719-1722

47. Gronbaek M, Di Castelnuovo A, Iacoviello L et al (2004) Wine, alcohol and cardiovascular risk: open issue. J Thromb Haemost 2:2041-2048

48. Ursini F, Zamburlini A, Cazzolato G et al (1998) Postprandia plasma lipid peroxides: a possible link between diet and atherosclerosis. Free Radic Biol Med 25:250-252

49. McElduff P, Dobson AJ (1997) How much alcohol and how often? Population based case-control study of alcohol consumption and risk of a major coronary event. BMJ 314:1159-1164

50. Kauhanen J, Kaplan GA, Goldberg DE et al (1997) Beer binging and mortality: results from the Kuopio ischaemic heart disease risk factor study: a prospective population based study. BM. 315:846-851

51. Mukamal JK, Conigrave KM, Mittleman MA et al (2003) Role of drinking pattern and type of alcohol consumed in coronary heart disease in men. N Engl J Med 348:109-118

52. Mukamal KJ, Ascherio A, Mittleman MA et al (2005) Alcoho and risk for ischemic stroke in men: the role of drinking patterns and usual beverage. Ann Intern Med 142:11-19

53. Iestra JA, Kromhout D, van der Schouw YT et al (2005) Effect size estimates of lifestyle and dietary changes on all-cause mortality in coronary artery disease patients: a systematic review. Circulation 112:924-934

54. Janszky I, Ljung R, Ahnve S et al (2008) Alcohol and long-term prognosis after a first acute myocardial infarction: the SHEEP study. Eur Heart J 29:45-53

55. Mukamal KJ (2003) Alcohol use and prognosis in patients with coronary heart disease. Prev Cardiol 6:93-98

56. Gronbaek M, Johansen D, Becker U et al (2004) A changes in alcohol intake and mortality: a longitudinal population-based study. Epidemiology 15:222-228

57. White IR, Altmann DR, Nanchahal K (2002) Alcohol consumption and mortality: modelling risks for men and women at different ages. BMJ 325:191

58. Streppel MT, Ocké MC, Boshuizen HC et al (2009) Long-term wine consumption is related to cardiovascular mortality and life expectancy independently of moderate alcohol intake: the Zutphen Study. J Epidemiol Commun Health 63:534-540

59. Djoussé L, Driver JA, Gaziano JM (2009) Relation between modifiable lifestyle factors and lifetime risk of heart failure JAMA 302:394-400

60. Forman JP, Stampfer MJ, Curhan GC (2009) Diet and lifestyle risk factors associated with incident hypertension in women. JAMA 302:401-411

61. Koppes LL, Dekker JM, Hendriks HF et al (2005) Moderate alcohol consumption lowers the risk of type 2 diabetes: a metaanalysis of prospective observational studies. Diabetes Care 28:719-725

62. Beaglehole R, Bonita R (2009) Alcohol: a global health priority. Lancet 373:2173-2174

63. Hines LM, Stampfer MJ, Ma J et al (2001) Genetic variation in alcohol dehydrogenase and the beneficial effect of moderate alcohol consumption on myocardial infarction. N Engl J Med 344:549-555

64. Latella MC, Di Castelnuovo A, de Lorgeril M et al (2009) Genetic variation of alcohol dehydrogenase type 1C (ADH1C), alcohol consumption, and metabolic cardiovascular risk factors: results from the IMMIDIET study. Atherosclerosis 207:284 290 



\section{Chapter - Reference I}

\section{CARDIOVASCULAR AND OVERALL MORTALITY RISK IN}

RELATION TO ALCOHOL CONSUMPTION IN PATIENTS WITH CARDI OVASCULAR DISEASE

Costanzo S, Di Castelnuovo A, Donati MB, Iacoviello L, de Gaetano G. Cardiovascular and overall mortality risk in relation to alcohol consumption in patients with cardiovascular disease. Circulation. 2010;121(17):1951-9. Review 



\title{
Contemporary Reviews in Cardiovascular Medicine
}

\section{Cardiovascular and Overall Mortality Risk in Relation to Alcohol Consumption in Patients With Cardiovascular Disease}

\author{
Simona Costanzo, ScD; Augusto Di Castelnuovo, ScD; Maria Benedetta Donati, MD, PhD; \\ Licia Iacoviello, MD, PhD; Giovanni de Gaetano, MD, PhD
}

\begin{abstract}
$\mathrm{A}^{\mathrm{l}}$
lcohol, in striking contrast to tobacco and illicit drugs, is linked to an extensively documented J-shaped doseeffect curve, with regular moderate consumption reducing cardiovascular and overall mortality, ${ }^{1}$ whereas excessive or binge drinking has the opposite effect. ${ }^{1,2}$ Data indicative of a lower risk of cardiovascular events among moderate drinkers in apparently healthy people are extensive and consistent, whereas the role of alcohol intake among patients with cardiovascular disease (CVD) is less clear. ${ }^{3}$

Among the factors that contribute to prevention in survivors of primary cardiovascular events, lifestyle and dietary habits play a major role. However, guidelines in this area are based either on studies of apparently healthy subjects or on a few studies of cardiovascular patients. ${ }^{4,5}$ In particular, recommendations about alcohol consumption in patients with previous CVD reflect experts' consensus rather than circumstantial evidence..$^{3,6}$ The US Food and Drug Administration warns that heart disease patients should stop drinking, and people who take aspirin regularly should not drink alcohol. ${ }^{7}$ However, in the American Heart Association/American College of Cardiology guidelines for secondary prevention, ${ }^{5} \mathrm{CVD}$ patients are encouraged to maintain a lifestyle that includes drinking alcohol in moderation. The "Diet and Lifestyle Recommendations" scientific statement from the American Heart Association Nutrition Committee ${ }^{8}$ advises, "If you consume alcohol, do so in moderation (equivalent of no more than 1 drink in women or 2 drinks in men per day)." The latter statement is largely accepted within the scientific community, definitely when referring to healthy people, although some would advise people to abstain completely rather than encouraging them to drink small amounts regularly. It has in fact been suggested that the consumption of alcohol for certain health benefits should not be encouraged, because the harm would far outweigh the gain, especially among poor populations and in low-income countries, where the disease burden per unit of alcohol consumption is greater. ${ }^{2}$

The consistent J-shaped dose-response curves observed for alcohol consumption and cardiovascular events or all-cause
\end{abstract}

mortality confirm the hazards of excessive drinking but also indicate potential windows of alcohol intake that may confer a net beneficial effect. ${ }^{1,9-13}$ Moderate ethanol consumption has lately emerged as a dominant component of a Mediterranean diet score, used as a predictor of lower mortality. ${ }^{14}$ The message for a general population might be summarized as follows: "Heavy drinkers should be urged to cut their consumption, but people who already regularly consume small to moderate amounts of alcohol should be encouraged to continue." The question here is, should one recommend moderate alcohol consumption to patients who have had an ischemic cardiovascular event?6,15-17

Randomized controlled trials to assess either the effectiveness or the harm of alcohol consumption in these patients are not feasible for several reasons, including ethical considerations, ${ }^{17}$ so we have to rely on data from observational studies. Here, we review the evidence on the beneficial or harmful effects of alcohol in patients who have experienced a first cardiovascular event and briefly discuss the major mechanisms underlying the relationship.

\section{Alcohol and Secondary Events in CVD Patients}

The reviewed studies ${ }^{18-27}$ are listed in Table 1. In a pioneering study started in 1978, Doll et al ${ }^{18}$ analyzed the association of alcohol with total mortality according to whether or not the patient had had any previous CVD or type 2 diabetes mellitus at the time of recruitment of 12321 British doctors; for those who had already had some vascular disease, there was a clear U-shaped relation between alcohol intake and total mortality. In another, larger study (152 $240 \mathrm{CVD}$, hypertensive, or diabetic patients), ${ }^{19}$ alcohol drinking reduced the risk of coronary heart disease (CHD) mortality for both sexes and in each category of intake (up to $40 \mathrm{~g} / \mathrm{d}$ ). When these 2 studies were analyzed together with 3 other cohort studies, ${ }^{25,27,28}$ a $20 \%$ reduction in all-cause mortality risk was found in moderate drinkers. ${ }^{29}$

From the "RE ARTU" Research Laboratories, John Paul II Centre for High Technology Research and Education in Biomedical Sciences, Catholic University, Campobasso, Italy.

Correspondence to Licia Iacoviello, MD, PhD, Laboratory of Genetic and Environmental Epidemiology, "RE ARTU" Research Laboratories, John Paul II Centre for High Technology Research and Education in Biomedical Sciences, Catholic University, Largo Gemelli 1, 86100 Campobasso, Italy. E-mail licia.iacoviello@rm.unicatt.it

(Circulation. 2010;121:1951-1959.)

(C) 2010 American Heart Association, Inc.

Circulation is available at http://circ.ahajournals.org

DOI: $10.1161 /$ CIRCULATIONAHA.109.865840 
Table 1. Studies Investigating Association of Alcohol Consumption With Cardiovascular or Total Mortality in CVD Patients

\begin{tabular}{|c|c|c|c|c|c|c|}
\hline Study & Country & No. & Sex & Follow-Up, y & Primary Event & Secondary Event \\
\hline Doll, $1994^{18}$ & UK & 5402 & Men & 13.0 & CVD+CV-RF & AC-M, CV-M \\
\hline Thun, $1997^{19}$ & USA & 152240 & Both & 9.0 & CVD + CV-RF & AC-M, CV-M \\
\hline Janszky, $2008^{20}$ & Sweden & 1346 & Both & 8.6 & AMI & AC-M, CV-M, CV-M+CVD \\
\hline Masunaga, $2006^{21}$ & Japan & 3845 & Men & 1.1 & AMI & AC-M, CV-M+CVD \\
\hline Aguilar, $2004^{22}$ & USA & 2036 & Both & 3.5 & AMI & AC-M, CV-M, CV-M+CVD \\
\hline Jackson, $2003^{23}$ & USA & 1320 & Men & 4.5 & Stroke & $\mathrm{AC}-\mathrm{M}, \mathrm{CV}-\mathrm{M}$ \\
\hline Mukamal, $2001^{24}$ & USA & 1913 & Both & 3.8 & AMI & AC-M, CV-M \\
\hline Shaper, $2000^{25}$ & UK & 596 & Men & 12.8 & CHD & AC-M, CV-M \\
\hline Valmadrid, $1999^{26}$ & USA & 262 & Both & 12.3 & ACS & CV-M \\
\hline Muntwyler, $1998^{27}$ & USA & 5356 & Men & 5.0 & AMI & AC-M, CV-M \\
\hline
\end{tabular}

UK indicates United Kingdom; CV-RF, cardiovascular risk factors; AC-M, all-cause mortality; CV-M, cardiovascular mortality; USA, United States of America; and ACS, acute coronary syndrome.

The main characteristics and results of studies conducted in CVD patients ${ }^{20-27}$ are summarized in Tables 1 and 2. In all of these studies, the relative risks reported were adjusted at least by age. Findings from these studies indicate that light-tomoderate alcohol consumption is associated with a decrease in the risk of cardiovascular and all-cause mortality (Figures 1 and 2; Table 2).

The inclusion in the reference groups of former drinkers who may have stopped drinking because of health problems is questionable.1,9 For the majority of studies, the reference group only included either "abstainers" or "nondrinkers" (Table 2). Former drinkers were reportedly excluded in several but not all studies. Janszky et $\mathrm{al}^{20}$ considered both "sick quitters" (drinkers who had stopped after acute myocardial infarction [AMI]) and "long-time" former drinkers (who stopped drinking before AMI). Moderate current drinkers (up to $20 \mathrm{~g} / \mathrm{d}$ ) had lower cardiovascular and all-cause mortality than abstainers, with or without the exclusion of the "long-time" former drinkers from the reference group (Table 2). Moreover, "sick quitters" had higher mortality than long-term abstainers. These findings support previous conclusions in healthy people. ${ }^{1}$

Another potential limitation in establishing the effects of alcohol in patients who have experienced a cardiovascular event is that patients may modify their drinking habits shortly after diagnosis of a CVD, usually reducing their alcohol intake. ${ }^{3}$ However, when those studies $22,23,25-27$ that recorded drinking habits more than 2 months after diagnosis of the second event (which more likely reflects the real intake of alcohol before the event) were examined, the protective effect of moderate alcohol consumption on cardiovascular and all-cause mortality could be confirmed. In the only study in men with a history of stroke, mortality was lower among patients with light-to-moderate alcohol consumption (1 to 6 drinks/wk) than among those who never or only rarely drank (Table 2). ${ }^{23}$

\section{Major Mechanisms Underlying the Association}

Alcohol influences a wide range of vascular and biochemical functions that have potential cardioprotective bene- fit. ${ }^{30-33}$ These include an increase in HDL cholesterol, a decrease in platelet aggregation/function, reduced myocardial ischemia-reperfusion injury, increased endothelial cell-dependent vasorelaxation, simultaneous activation of endothelial cell antiapoptotic and proapoptotic pathways, lower plasma levels of coagulation factor VII and fibrinogen, increased fibrinolysis, and higher levels of atrial natriuretic peptide.

Besides ethanol, other components of alcoholic beverages (polyphenols in particular) may contribute to the protective role. The effects include increased vasorelaxation of aortic rings, downregulation of tissue factor gene transcription in cultured human endothelial cells and monocytes, reduced thrombosis or inflammation, inhibition of platelet aggregation/function, inhibition of smooth muscle cell proliferation, increased fibrinolysis, and upregulation of fibrinolytic protein gene transcription in cultured human endothelial cells.

A recent study determined the proportion of CVD risk reduction explained by potential intermediate factors in a cohort of 26399 women. ${ }^{34}$ A large proportion of the lower CVD risk associated with moderate alcohol drinking appeared to be explained by factors related to glucose metabolism, lipids, and inflammation/hemostasis factors.

Mechanisms that support the beneficial role of drinking in moderation in experimental animals or apparently healthy people could be similarly effective in patients with a history of CVD. An increase in HDL cholesterol blood levels is considered one of the most plausible mechanisms. ${ }^{32}$ Nevertheless, because raising HDL cholesterol pharmacologically reportedly had no effect on vascular risk in patients at high risk for coronary events, ${ }^{35,36}$ the association of alcohol with elevated HDL cholesterol per se, without considering the effects on its function, might have less value.

Wine might exert additional antiatherogenic effects mainly attributable to the biological activities of polyphenols. ${ }^{31,37}$ In a German study, nondrinkers and heavy drinkers had higher C-reactive protein concentrations than moderate drinkers. ${ }^{38}$ In a trial on the effects of wine and gin on inflammatory biomarkers, ${ }^{39}$ plasma fibrinogen and cytokine interleukin- $1 \alpha$ decreased significantly after either beverage. 
Table 2. Relative Risks (95\% Confidence Intervals) for Cardiovascular and Total Mortality at Different Levels of Alcohol Intake in Studies of CVD Patients

\begin{tabular}{|c|c|c|c|c|}
\hline \multirow[b]{2}{*}{ Study and Alcohol Intake } & \multicolumn{2}{|c|}{ Cardiovascular Mortality } & \multicolumn{2}{|c|}{ All-Cause Mortality } \\
\hline & RR & $95 \% \mathrm{Cl}$ & RR & $95 \% \mathrm{Cl}$ \\
\hline \multicolumn{5}{|l|}{ Janszky, $2008^{20}$} \\
\hline \multicolumn{5}{|l|}{ Total $\mathrm{n}=1346$} \\
\hline Long-term abstainers & 1 & & 1 & \\
\hline Recent quitters & 4.47 & $1.60-12.5$ & 4.55 & $2.03-10.2$ \\
\hline $0-5 \mathrm{~g} / \mathrm{d}$ & 0.61 & $0.36-1.02$ & 0.77 & $0.51-1.15$ \\
\hline $5-20 \mathrm{~g} / \mathrm{d}$ & 0.62 & $0.36-1.07$ & 0.77 & $0.50-1.18$ \\
\hline$>20 \mathrm{~g} / \mathrm{d}$ & 0.69 & $0.38-1.25$ & 0.89 & $0.56-1.40$ \\
\hline \multicolumn{5}{|l|}{ Total $n=1284$} \\
\hline Abstainers & 1 & & 1 & \\
\hline Ex-drinkers & 0.86 & $0.38-1.90$ & 0.89 & $0.47-1.68$ \\
\hline $0-5 \mathrm{~g} / \mathrm{d}$ & 0.48 & $0.27-0.86$ & 0.62 & $0.39-0.97$ \\
\hline $5-20 \mathrm{~g} / \mathrm{d}$ & 0.48 & $0.26-0.89$ & 0.61 & $0.38-0.98$ \\
\hline$>20 \mathrm{~g} / \mathrm{d}$ & 0.53 & $0.27-1.02$ & 0.69 & $0.42-1.15$ \\
\hline \multicolumn{5}{|l|}{ Masunaga, $2006^{21}$} \\
\hline \multicolumn{5}{|l|}{ Age $<65$ years, $\mathrm{n}=3003$} \\
\hline Abstainers & & & 1 & \\
\hline Moderate & & & 0.60 & $0.29-1.24$ \\
\hline Heavy & & & 0.84 & $0.44-1.62$ \\
\hline \multicolumn{5}{|l|}{ Age $\geq 65$ y, n=842 } \\
\hline Abstainers & & & 1 & \\
\hline Moderate & & & 1.00 & $0.64-1.55$ \\
\hline Heavy & & & 5.16 & $3.64-7.31$ \\
\hline \multicolumn{5}{|l|}{ Aguilar, $2006,{ }^{22} n=2036$} \\
\hline Nondrinkers & 1 & & 1 & \\
\hline Light to moderate & 1 & $0.75-1.34$ & 0.91 & $0.70-1.19$ \\
\hline Heavy & 0.87 & $0.40-1.87$ & 0.66 & $0.31-1.41$ \\
\hline \multicolumn{5}{|l|}{ Jackson, $2003,{ }^{23} n=1320$} \\
\hline Rarely/never & 1 & & 1 & \\
\hline$<1$ drink/wk & 0.89 & $0.58-1.36$ & 0.88 & $0.60-1.28$ \\
\hline $1-6$ drinks/wk & 0.56 & $0.40-0.79$ & 0.64 & $0.48-0.85$ \\
\hline$\geq 1 \mathrm{drink} / \mathrm{d}$ & 0.64 & $0.46-0.88$ & 0.71 & $0.54-0.94$ \\
\hline \multicolumn{5}{|l|}{ Mukamal, $2001,{ }^{24} \mathrm{n}=1913$} \\
\hline Abstainers & 1 & & 1 & \\
\hline$<7$ drinks/wk & 0.75 & $0.55-1.02$ & 0.79 & $0.60-1.03$ \\
\hline$\geq 7$ drinks/wk & 0.67 & $0.41-1.17$ & 0.68 & $0.45-1.05$ \\
\hline \multicolumn{5}{|l|}{ Shaper, $2000,{ }^{25} \mathrm{n}=596$} \\
\hline Teetotalers & 0.98 & $0.53-1.82$ & 0.96 & $0.57-1.62$ \\
\hline Ex-drinkers & 1.39 & $0.86-2.26$ & 1.50 & $1.00-2.24$ \\
\hline Occasional & 1 & & 1 & \\
\hline Light & 0.94 & $0.65-1.35$ & 1.05 & $0.78-1.42$ \\
\hline Moderate/heavy & 1.34 & $0.91-1.98$ & 1.30 & $0.93-1.83$ \\
\hline \multicolumn{5}{|l|}{ Valmadrid, $1999,{ }^{26} \mathrm{n}=262$} \\
\hline Never-drinkers & 1 & & & \\
\hline Ex-drinkers & 0.71 & $0.34-1.49$ & & \\
\hline$<2 \mathrm{~g} / \mathrm{d}$ & 0.51 & $0.24-1.12$ & & \\
\hline $2-13 \mathrm{~g} / \mathrm{d}$ & 0.43 & $0.15-1.22$ & & \\
\hline \multirow[t]{2}{*}{$\geq 14 \mathrm{~g} / \mathrm{d}$} & 0.26 & $0.08-0.81$ & & \\
\hline & & & & (Continued) \\
\hline
\end{tabular}


Table 2. Continued

\begin{tabular}{|c|c|c|c|c|}
\hline \multirow[b]{2}{*}{ Study and Alcohol Intake } & \multicolumn{2}{|c|}{ Cardiovascular Mortality } & \multicolumn{2}{|c|}{ All-Cause Mortality } \\
\hline & RR & $95 \% \mathrm{Cl}$ & RR & $95 \% \mathrm{Cl}$ \\
\hline \multicolumn{5}{|l|}{ Muntwyler, $1998,{ }^{27} n=5356$} \\
\hline Rarely/never & 1 & & 1 & \\
\hline 1-4 drinks/mo & 0.93 & $0.74-1.18$ & 0.85 & $0.69-1.05$ \\
\hline 2-6 drinks/wk & 0.76 & $0.59-0.98$ & 0.72 & $0.58-1.89$ \\
\hline $1 \mathrm{drink} / \mathrm{d}$ & 0.83 & $0.66-1.05$ & 0.79 & $0.64-0.96$ \\
\hline$\geq 2$ drinks/d & 0.81 & $0.49-1.32$ & 0.84 & $0.55-1.26$ \\
\hline \multicolumn{5}{|l|}{ Age $<65 \mathrm{y}, \mathrm{n}=\mathrm{NR}$} \\
\hline Rarely/never & & & 1 & \\
\hline 1-4 drinks/mo & & & 0.91 & $0.62-1.32$ \\
\hline $2-6$ drinks/wk & & & 0.78 & $0.53-1.13$ \\
\hline $1 \mathrm{drink} / \mathrm{d}$ & & & 0.75 & $0.51-1.11$ \\
\hline$\geq 2$ drinks/d & & & 0.75 & $0.36-1.59$ \\
\hline \multicolumn{5}{|l|}{ Age $\geq 65 \mathrm{y}, \mathrm{n}=\mathrm{NR}$} \\
\hline Rarely/never & & & 1 & \\
\hline 1-4 drinks/mo & & & 0.84 & $0.65-1.07$ \\
\hline $2-6$ drinks/wk & & & 0.70 & $0.54-0.91$ \\
\hline $1 \mathrm{drink} / \mathrm{d}$ & & & 0.81 & $0.64-1.02$ \\
\hline$\geq 2$ drinks/d & & & 0.89 & $0.55-1.47$ \\
\hline
\end{tabular}

NR indicates not reported.

Alcohol affects several factors that maintain the equilibrium between clot formation and dissolution. ${ }^{32}$ It has been associated with increased levels of tissue plasminogen activator, lower levels of fibrinogen and antithrombin III, ${ }^{40}$ and reduced susceptibility of platelets to aggregate. ${ }^{41}$ Several polyphenols interfere with arachidonic acid metabolism in both platelets and leukocytes, which results in inhibition of platelet aggregation and reduced synthesis of prothrombotic and proinflammatory mediators. ${ }^{42}$ Polyphenols can also downregulate the expression of adhesive molecules and tissue factor activity, which results in functional effects on cell-cell interactions and procoagulant activities. ${ }^{43}$

The Lyon Diet Heart Study ${ }^{44}$ showed that moderate wine consumption in CHD patients was associated with higher

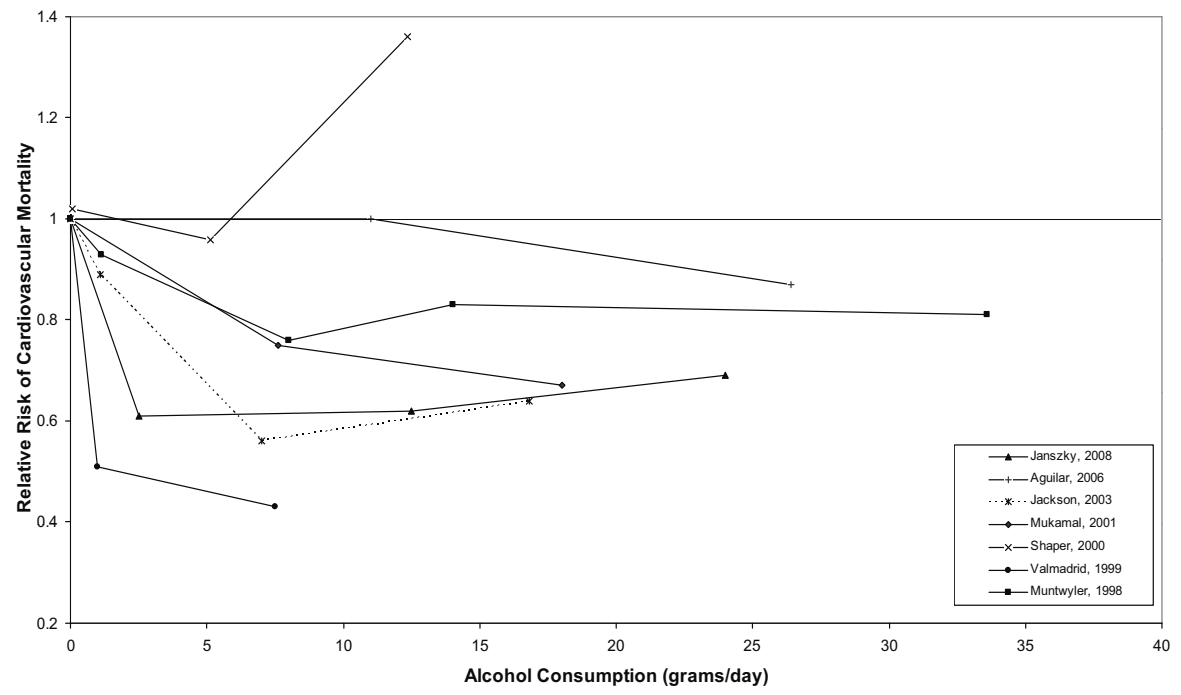

Figure 1. Relative risks of cardiovascular mortality with different intakes of alcohol in studies of CVD patients. 


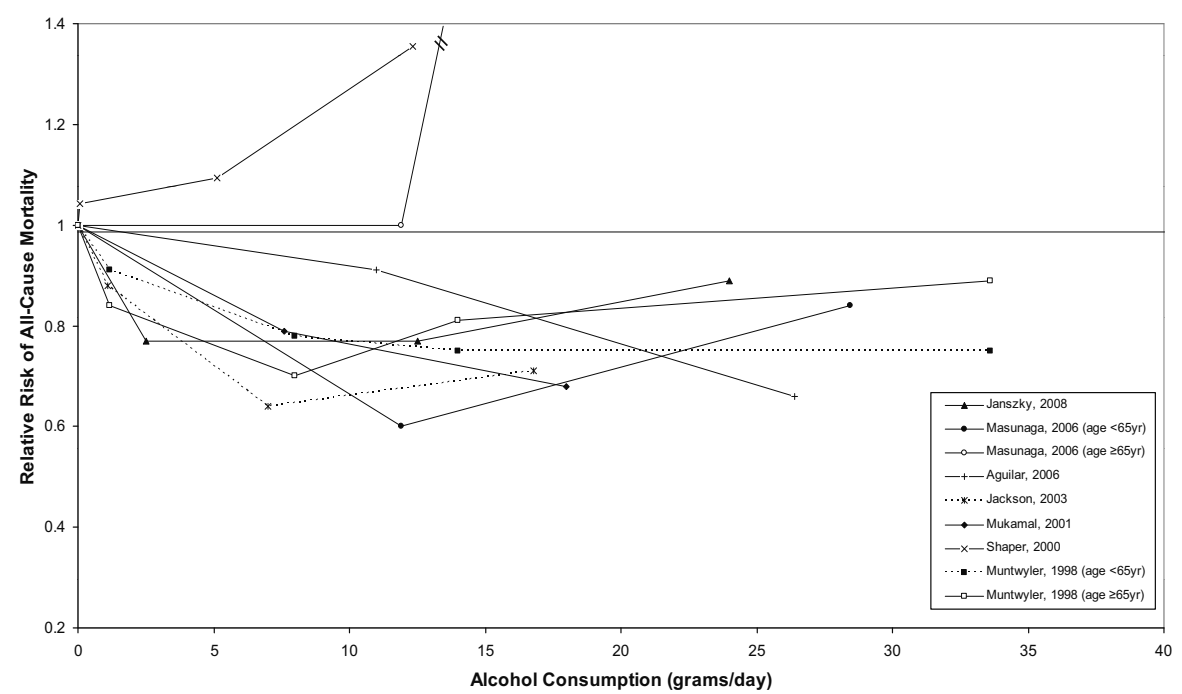

Figure 2. Relative risks of total mortality with different intakes of alcohol in studies of CVD patients.

levels of "marine" $\omega 3$ fatty acids in plasma. More recently, $\omega 3$ fatty acids in red blood cells were positively associated with alcohol (especially wine) intake in apparently healthy subjects of the IMMIDIET study (Dietary Habit Profile in European Communities With Different Risk of Myocardial Infarction: the Impact of Migration as a Model of GeneEnvironment Interaction). ${ }^{45}$ The possibility that moderate consumption of alcohol raises $\omega 3$ polyunsaturated fatty acid levels is of interest in the setting of secondary prevention, in which protection against CVD after AMI was found after supplementation with $\omega 3$ polyunsaturated fatty acids. ${ }^{46}$

Genetic regulation of individual response to alcohol was proposed on the basis of the relations between alcohol dehydrogenase type 3 polymorphisms, the level of alcohol consumption, and the risk of AMI. ${ }^{47}$ Moderate drinkers who were homozygous for the slow-oxidizing ADH1C allele had higher HDL levels and substantially less AMI. ${ }^{47}$ Additional studies are needed to elucidate the role of genetic factors in the association of alcohol with CVD risk.

\section{Detrimental Effects of Alcohol Consumption}

Abuse of alcohol, binge drinking, and drinking outside meals have all been associated with detrimental effects, such as fetal alcohol syndrome, liver cirrhosis, pancreatitis, certain cancers, cardiomyopathy, hypertriglyceridemia, hypertension, hemorrhagic stroke, overweight, alcohol intoxication, and addiction. ${ }^{2,10}$ Excess and irregular alcohol intake must be avoided by patients with CVD, because it can have serious unhealthy consequences, including exacerbation of existing pathological conditions. Alcohol abuse or binge drinking is a major cause of hyperlipidemia, ${ }^{3}$ vasoconstriction, increased clotting activity, and a lower threshold for ventricular fibrillation. ${ }^{48}$

A meta-analysis found that binge and heavy drinking are associated with excess CHD risk. ${ }^{49}$ Among CVD patients, binge drinkers, defined as those who consumed 3 or more drinks within 1 to 2 hours, had double the total and cardiovascular mortality risk of regular drinkers. ${ }^{50}$ Episodic heavy alcohol drinking is reportedly associated with risk of atrial fibrillation $^{51}$; however, recent studies obtained no evidence that long-term alcohol intake (especially moderate consumption) was an important factor in the development of atrial fibrillation, ${ }^{52}$ and moreover, no association of alcohol consumption with risk of death was found among subjects with atrial fibrillation. ${ }^{53}$

In patients with alcoholic cardiomyopathy, both abstinence and alcohol consumption (up to $60 \mathrm{~g} / \mathrm{d}$ ) improved cardiac function. ${ }^{54}$ However, abstinence continues to be recommended because of the lack of large studies on this topic. ${ }^{55}$

Few studies have investigated whether drinking with or without meals modifies the negative association between moderate alcohol consumption and CVD or total mortality. Drinking outside mealtimes is related to increases in CHD and hypertension risk, ${ }^{56}$ independent of the amounts drunk. In a large cohort, drinking wine outside meals increased mortality rates compared with drinking wine at meals. ${ }^{57}$

\section{Alcohol and Cardiovascular Medications}

Drugs and alcohol may be co-metabolized, potentially altering the absorption, distribution, or metabolism of the alcohol, medications, or both, and affecting the therapeutic and adverse effects of the latter. Alcohol and medications interact in a variety of situations that differ depending on the timing 
of alcohol and medication consumption and the drinking pattern. The majority of these interactions occur among individuals who drink heavily..$^{58,59}$

In patients with CVD, the potential interactions with alcohol have mainly been investigated for antiplatelet or oral anticoagulant drugs. ${ }^{58}$ Aspirin and other nonsteroidal antiinflammatory drugs, when combined with alcohol, can raise the risk of gastrointestinal bleeding by injuring the gastric mucosa and increasing the bleeding tendency ${ }^{58}$; however, aspirin and alcohol appeared to act as independent risk factors, with additive effects on gastrointestinal bleeding but no interaction. ${ }^{60}$ Experimental data ${ }^{61}$ suggest that wine polyphenols might interact with aspirin, because they form stable complexes in the platelet cyclooxygenase-1 enzyme channel. Mixtures of resveratrol, quercetin, and gallic acid did potentiate the platelet inhibitory effect of subinhibitory concentrations of aspirin. The activity of the cytochrome P-450 enzyme system in the liver can increase 10-fold among those who drink alcohol regularly and heavily. ${ }^{58,59}$ This speeds up the breakdown of many medications, including warfarin and clopidogrel. ${ }^{62}$ However, in a trial in men who had undergone coronary bypass surgery, moderate drinking did not adversely influence the safety of warfarin or lovastatin. ${ }^{63}$

Because most CVD patients are taking lipid-lowering drugs, a question of whether alcohol drinking can be combined with hypolipidemic treatment arises. Insufficient research has been conducted until recently to determine whether the consumption of alcohol in combination with hypolipidemic therapy should be recommended and whether it is safe ${ }^{64}$ Thus, there is a need to define the possible benefit and establish which lipid-lowering drug behaves better in such a setting.

\section{Alcohol in Hypertensive and Diabetic Patients} In the general population, ${ }^{10,65}$ the prevalence of hypertension rises linearly with alcohol consumption. Guidelines for the management of hypertension ${ }^{66}$ recommend avoiding binge drinking and suggest regular alcohol consumption, limited to no more than 2 to 3 drinks per day for men and 1 to 2 drinks per day for women, if not total abstention.

A recent analysis investigated whether reducing alcohol consumption lowered blood pressure without losing the cardiovascular benefits of drinking in moderation. ${ }^{67}$ Moderate drinking was associated with a lower risk of heart failure, AMI, and cardiovascular and all-cause mortality in hypertensive subjects. ${ }^{68,69}$ In addition, the risk related to hypertension appears to be similar regardless of the level of alcohol consumption. ${ }^{70}$ The Physicians' Health Study reported a protective effect of moderate alcohol consumption on secondary CHD outcomes in men who had hypertension at baseline. ${ }^{71}$

Diabetic patients have a CHD risk 2 to 4 times that of nondiabetic individuals. ${ }^{72}$ A meta-analysis of 15 prospective cohort studies showed a J-shaped relation between alcohol consumption and risk of developing diabetes, with a $30 \%$ lower risk in moderate alcohol consumers ( 1 to 2 drinks per day). ${ }^{12}$ Two quantitative reviews ${ }^{73,74}$ concluded that moderate alcohol consumption was associated with a lower incidence of heart disease or total mortality in patients with type 2 diabetes mellitus. Obviously, the decrease in CVD risk associated with moderate alcohol consumption in hypertensive or diabetic subjects does not reduce the importance of controlling blood pressure or blood glucose, regardless of drinking habits.

\section{Limitations of Observational Studies on Alcohol and Health or Disease}

A weakness of studies on alcohol consumption is the heterogeneity of the reference groups, which sometimes include lifelong teetotalers, ex-drinkers, and/or occasional drinkers. However, as discussed above, the lower risk associated with moderate alcohol consumption does not appear to be substantially related to the inclusion of former drinkers in the reference groups.

Those who drink in moderation may have a different lifestyle from people who do not drink, ${ }^{2}$ and the apparent healthy effects associated with moderate drinking may be mostly due to favorable risk profiles in moderate drinkers. ${ }^{1,75-77}$ In a meta-analysis on alcohol and total mortality in apparently healthy people, ${ }^{1}$ we found, however, that when adjusted and unadjusted data from the same studies were compared, the maximal protection afforded by light-tomoderate drinking only dropped from $19 \%$ to $16 \%$. In a study ${ }^{77}$ in apparently healthy US adults, moderate drinkers did indeed have better risk factor profiles than nondrinkers. Although these would explain part of the survival advantage associated with alcohol use, moderate drinkers maintained a significant survival advantage even after adjustment for all risk factors. As discussed for studies of apparently healthy people, ${ }^{1}$ it is hard to assume a stronger role of confounding or the existence of additional nontraditional confounders in CVD patients.

The association of moderate alcohol consumption with prevention of secondary events appeared to be comparable in studies that included only men and in those that enrolled both men and women. Considering the not unexpected relative paucity of data on women, it is prudent to suggest that women with CVD, similarly to healthy women, ${ }^{1}$ can safely drink less alcohol than men.

\section{Implications for Practice and Policy}

The present review provides reasonable evidence that regular and moderate alcohol intake is significantly associated with a reduction in the incidence of secondary cardiovascular and all-cause mortality in patients with a history of CVD. This conclusion extends to patients with ischemic cardiovascular disease, a finding reported repeatedly in apparently healthy people. ${ }^{1,9}$ However, the fact that regular (nonbinge) moderate alcohol consumption is not easily attainable or maintainable in all parts of the world must be taken into serious consideration. Although the encouragement of "sensible" drinking might actually make heavy drinking more acceptable, we disagree with the proposal not to give alcohol any positive connotations because people might misinterpret them. There are certainly appreciable differences between Mediterranean and Northern European or Russian habits of alcohol consump- 
tion. ${ }^{2}$ Therefore, in some low-income populations and poor countries, even if the net effect on CVD might be beneficial, the effect of alcohol on the overall burden of disease might be detrimental because of more frequent uncontrolled alcohol-use disorders, cancer, liver cirrhosis, and injury. ${ }^{2}$

\section{Conclusions}

Cardiovascular patients who do not consume alcohol should not be encouraged to start regular drinking. If not contraindicated, patients who drink alcohol should not exceed 1 to 2 drinks per day for women or up to 2 to 3 drinks per day for men as a component of a balanced cardioprotective dietary pattern with appropriate energy-intake levels. Alcohol is not recommended for young people (who are generally at very low risk of CVD), pregnant women, those at risk of alcoholism, or anyone whose activity calls for concentration, skill, or coordination. Alcohol is best avoided by people with cardiomyopathy or cardiac arrhythmias., 2,56

There is no question that heavy or binge drinking is associated with adverse health outcomes. ${ }^{2}$ If cardiovascular patients are heavy drinkers, they must be strongly advised to abstain or at least substantially reduce drinking; regular moderate drinkers need not be told to modify their drinking habits but should avoid heavy or binge drinking.

\section{Acknowledgment}

We are grateful to Professor Jozef Vermylen, Catholic University, Leuven, Belgium, for his critical review of the manuscript and Ms Judith Baggott for English editing.

\section{Sources of Funding}

This study was funded in part by a grant from the European Research Advisory Board (No. EA0827).

None.

\section{Disclosures}

\section{References}

1. Di Castelnuovo A, Costanzo S, Bagnardi V, Donati MB, Iacoviello L, de Gaetano G. Alcohol dosing and total mortality in men and women: an updated meta-analysis of 34 prospective studies. Arch Intern Med. 2006; 166:2437-2445.

2. Rehm J, Mathers C, Popova S, Thavorncharoensap M, Teerawattananon Y, Patra J. Global burden of disease and injury and economic cost attributable to alcohol use and alcohol-use disorders. Lancet. 2009;373: 2223-2233.

3. Mukamal KJ. Alcohol use and prognosis in patients with coronary heart disease. Prev Cardiol. 2003;6:93-98.

4. Skinner JS, Cooper A, Feder GS; on behalf of the Guideline Development Group. Secondary prevention for patients after a myocardial infarction: summary of NICE guidance. Heart. 2007;93:862-864.

5. Smith SC, Allen J, Blair SN, Bonow RO, Brass LM, Fonarow GC, Grundy SM, Hiratzka L, Jones D, Krumholz HM, Mosca L, Pasternak RC, Pearson T, Pfeffer MA, Taubert KA. AHA/ACC guidelines for secondary prevention for patients with coronary and other atherosclerotic vascular disease: 2006 update. $J$ Am Coll Cardiol. 2006:47:2130-2139.

6. Klatsky AL. Should patients with heart disease drink alcohol? JAMA. 2001;285:2004-2006.

7. Alcohol, wine, and cardiovascular disease. American Heart Association Web site. Available at: http://www.americanheart.org/presenter.jhtml? identifier $=4422$. Accessed March 13, 2009.

8. Lichtenstein AH, Appel LJ, Brands M, Carnethon M, Daniels S, Franch HA, Franklin B, Kris-Etherton P, Harris WS, Howard B, Karanja N, Lefevre M, Rudel L, Sacks F, Van Horn L, Winston M, Wylie-Rosett J. Diet and lifestyle recommendations revision 2006: a scientific statement from the American Heart Association Nutrition Committee. Circulation. 2006;114:82-96.

9. Di Castelnuovo A, Rotondo S, Iacoviello L, Donati MB, de Gaetano G. Meta-analysis of wine and beer consumption in relation to vascular risk Circulation. 2002;105:2836-2844.

10. Corrao G, Bagnardi V, Zambon A, La Vecchia C. A meta-analysis of alcohol consumption and the risk of 15 diseases. Prev Med. 2004;38 613-619.

11. Reynolds K, Lewis B, Nolen JD, Kinney GL, Sathya B, He J. Alcohol consumption and risk of stroke: a meta-analysis. JAMA. 2003;289: $579-588$.

12. Koppes LL, Dekker JM, Hendriks HF, Bouter LM, Heine RJ. Moderate alcohol consumption lowers the risk of type 2 diabetes: a meta-analysis of prospective observational studies. Diabetes Care. 2005;28:719-725.

13. White IR, Altmann DR, Nanchahal K. Alcohol consumption and mortality: modeling risks for men and women at different ages. BMJ. 2002; 325:191.

14. Trichopoulou A, Bamia C, Trichopoulos D. Anatomy of health effects of the Mediterranean diet: Greek EPIC prospective cohort study. BMJ. 2009;338:b2337

15. O'Keefe JH, Bybee KA, Lavie CJ. Alcohol and cardiovascular health: the razor-sharp double-edged sword. J Am Coll Cardiol. 2007;50: $1009-1014$

16. Paraskevas KI, Daskalopoulou SS, Daskalopoulos ME, Liapis CD. Secondary prevention of ischemic cerebrovascular disease: what is the evidence? Angiology. 2005;56:539-552.

17. de Lorgeril M, Salen P. Wine, alcohol and cardiovascular risk: open issue. J Thromb Haemost. 2004;2:2047-2048.

18. Doll R, Peto R, Hall E, Wheatley K, Gray R. Mortality in relation to consumption of alcohol: 13 years' observations on male British doctors. BMJ. 1994;309:911-918.

19. Thun MJ, Peto R, Lopez AD, Monaco JH, Henley SJ, Heath CW Jr, Doll R. Alcohol consumption and mortality among middle-aged and elderly U.S. adults. $N$ Engl J Med. 1997;337:1705-1714.

20. Janszky I, Ljung R, Ahnve S, Hallqvist J, Bennet AM, Mukamal KJ. Alcohol and long-term prognosis after a first acute myocardial infarction: the SHEEP study. Eur Heart J. 2008;29:45-53.

21. Masunaga N, Kimura A, Miyataka M, Nishioka N, Hirano Y, Hayashi T, Ishikawa K. Effects of alcohol consumption on cardiovascular events in male patients with healed myocardial infarction. Circ J. 2006;70: 1263-1268.

22. Aguilar D, Skali H, Moye LA, Lewis EF, Gaziano JM, Rutherford JD, Hartley LH, Randall OS, Geltman EM, Lamas GA, Rouleau JL, Pfeffer MA, Solomon SD. Alcohol consumption and prognosis in patients with left ventricular systolic dysfunction after a myocardial infarction. $J \mathrm{Am}$ Coll Cardiol. 2004;43:2015-2021.

23. Jackson VA, Sesso HD, Buring JE, Gaziano JM. Alcohol consumption and mortality in men with preexisting cerebrovascular disease. Arch Intern Med. 2003;163:1189-1193.

24. Mukamal KJ, Maclure M, Muller JE, Sherwood JB, Mittleman MA. Prior alcohol consumption and mortality following acute myocardial infarction. JAMA. 2001;285:1965-1970.

25. Shaper AG, Wannamethee SG. Alcohol intake and mortality in middle aged men with diagnosed coronary heart disease. Heart. 2000;83: 394-399.

26. Valmadrid CT, Klein R, Moss SE, Klein BE, Cruickshanks KJ. Alcohol intake and the risk of coronary heart disease mortality in persons with older-onset diabetes mellitus. JAMA. 1999;282:239-246.

27. Muntwyler J, Hennekens CH, Buring JE, Gaziano JM. Mortality and light to moderate alcohol consumption after myocardial infarction. Lancet. 1998;352:1882-1885

28. Cooper HA, Exner DV, Domanski MJ. Light-to-moderate alcohol consumption and prognosis in patients with left ventricular systolic dysfunction. J Am Coll Cardiol. 2000;35:1753-1759.

29. Iestra JA, Kromhout D, van der Schouw YT, Grobbee DE, Boshuizen HC, van Staveren WA. Effect size estimates of lifestyle and dietary changes on all-cause mortality in coronary artery disease patients: a systematic review. Circulation. 2005;112:924-934.

30. Collins MA, Neafsey EJ, Mukamal KJ, Gray MO, Parks DA, Das DK, Korthuis RJ. Alcohol in moderation, cardioprotection, and neuroprotection: epidemiological considerations and mechanistic studies. Alcohol Clin Exp Res. 2009;33:206-219.

31. Booyse FM, Pan W, Grenett HE, Parks DA, Darley-Usmar VM, Bradley KM, Tabengwa EM. Mechanism by which alcohol and wine polyphenols affect coronary heart disease risk. Ann Epidemiol. 2007;17:S24-S31. 
32. Rimm EB, Williams P, Fosher K, Criqui M, Stampfer MJ. Moderate alcohol intake and lower risk of coronary heart disease: meta-analysis of effects on lipids and haemostatic factors. BMJ. 1999;319:1523-1528.

33. Mukamal KJ, Jensen MK, Grønbæk M, Stampfer MJ, Manson JE, Pischon T, Rimm EB. Drinking frequency, mediating biomarkers, and risk of myocardial infarction in women and men. Circulation. 2005;112: 1406-1413

34. Djoussé L, Lee IM, Buring JE, Gaziano JM. Alcohol consumption and risk of cardiovascular disease and death in women: potential mediating mechanisms. Circulation. 2009;120:237-244.

35. Barter PJ, Caulfield M, Eriksson M, Grundy SM, Kastelein JJ, Komajda M, Lopez-Sendon J, Mosca L, Tardif JC, Waters DD, Shear CL, Revkin JH, Buhr KA, Fisher MR, Tall AR, Brewer B; ILLUMINATE Investigators .Effects of torcetrapib in patients at high risk for coronary events. N Engl J Med. 2007;357:2109-2122.

36. Briel M, Ferreira-Gonzalez I, You JJ, Karanicolas PJ, Akl EA, Wu P, Blechacz B, Bassler D, Wei X, Sharman A, Whitt I, Alves da Silva S, Khalid Z, Nordmann AJ, Zhou Q, Walter SD, Vale N, Bhatnagar N, O'Regan C, Mills EJ, Bucher HC, Montori VM, Guyatt GH. Association between change in high density lipoprotein cholesterol and cardiovascular disease morbidity and mortality: systematic review and meta-regression analysis. BMJ. 2009;338:b92.

37. de Gaetano G, De Curtis A, Di Castelnuovo A, Donati MB, Iacoviello L, Rotondo S. Antithrombotic effect of polyphenols in experimental models: a mechanism of reduced vascular risk by moderate wine consumption. Ann N Y Acad Sci. 2002;957:174-188

38. Imhof A, Froehlich M, Brenner H, Boeing H, Pepys MB, Koenig W. Effect of alcohol consumption on systemic markers of inflammation. Lancet. 2001:357:763-767.

39. Estruch R, Sacanella E, Badia E, Antúnez E, Nicolás JM, Fernández-Solá J, Rotilio D, de Gaetano G, Rubin E, Urbano-Márquez A. Different effects of red wine and gin consumption on inflammatory biomarkers of atherosclerosis: a prospective randomized crossover trial: effects of wine on inflammatory markers. Atherosclerosis. 2004;175:117-123.

40. Hendriks HF, Veenstra J, Velthuis-te Wierik EJ, Schaafsma G, Kluft C. Effect of moderate doses of alcohol with evening meals on fibrinolytic factors. BMJ. 1994;308:1003-1006.

41. Renaud SC, Ruf JC. Effects of alcohol on platelet functions. Clin Chim Acta. 1996;246:77-89.

42. Rotondo S, Rajtar G, Manarini S, Celardo A, Rotilio D, de Gaetano G, Evangelista V, Cerletti C. Effect of trans-resveratrol, a natural polyphenolic compound, on human polymorphonuclear leukocyte function. Br J Pharmacol. 1998;123:1691-1699.

43. Di Santo A, Mezzetti A, Napoleone E, Di Tommaso R, Donati MB, de Gaetano G, Lorenzet R. Resveratrol and quercetin down-regulate tissue factor expression by human stimulated vascular cells. J Thromb Haemost. 2003;1:1089-1095.

44. de Lorgeril M, Salen P, Martin JL, Boucher F, de Leiris J. Interactions of wine drinking with omega- 3 fatty acids in coronary heart disease patients: a fish-like effect of moderate wine drinking. Am Heart J. 2008;155: 175-181.

45. di Giuseppe R, de Lorgeril M, Salen P, Laporte F, Di Castelnuovo A, Krogh V, Siani A, Arnout J, Cappuccio FP, van Dongen M, Donati MB, de Gaetano G, Iacoviello L; European Collaborative Group of the IMMIDIET Project. Alcohol consumption and n-3 polyunsaturated fatty acids in healthy men and women from 3 European populations. Am J Clin Nutr. 2009:89:354-362.

46. Gruppo Italiano Studio della Sopravvivenza nell'Infarto miocardico. Dietary supplementation with $\mathrm{n}-3$ polyunsaturated fatty acids and vitamin $\mathrm{E}$ after myocardial infarction: results of the GISSI-Prevenzione trial. Lancet. 1999;354:447-455.

47. Hines LM, Stampfer MJ, Ma J, Gaziano JM, Ridker PM, Hankinson SE, Sacks F, Rimm EB, Hunter DJ. Genetic variation in alcohol dehydrogenase and the beneficial effect of moderate alcohol consumption on myocardial infarction. N Engl J Med. 2001;344:549-555.

48. McKee M, Britton A. The positive relationship between alcohol and heart disease in eastern Europe: potential physiological mechanisms. J Roy Soc Med. 1998;91:402-407.

49. Bagnardi V, Zatonski W, Scotti L, La Vecchia C, Corrao G. Does drinking pattern modify the effect of alcohol on the risk of coronary heart disease? Evidence from a meta-analysis. J Epidemiol Community Health. 2008;62:615-619.

50. Mukamal KL, Maclure M, Muller JE, Mittleman MA. Binge drinking and mortality after acute myocardial infarction. Circulation. 2005;112: $3839-3845$.
51. Conen D, Tedrow UB, Cook NR, Moorthy MV, Buring JE, Albert CM. Alcohol consumption and risk of incident atrial fibrillation in women. JAMA. 2008;300:2489-2496.

52. Djoussé L, Levy D, Benjamin EJ, Blease SJ, Russ A, Larson MG, Massaro JM, D'Agostino RB, Wolf PA, Ellison RC. Long-term alcoho consumption and the risk of atrial fibrillation in the Framingham Study. Am J Cardiol. 2004;93:710-713.

53. Mukamal KJ, Psaty BM, Rautaharju PM, Furberg CD, Kuller LH, Mittleman MA, Gottdiener JS, Siscovick DS. Alcohol consumption and risk and prognosis of atrial fibrillation among older adults: the Cardiovascular Health Study. Am Heart J. 2007;153:260-266.

54. Nicolás JM, Fernández-Solà J, Estruch R, Paré JC, Sacanella E, UrbanoMárquez A, Rubin E. The effect of controlled drinking in alcoholic cardiomyopathy. Ann Intern Med. 2002;136:192-200.

55. Task Force for Diagnosis and Treatment of Acute and Chronic Hear Failure 2008 of European Society of Cardiology, Dickstein K, Cohen-Solal A, Filippatos G, McMurray JJ, Ponikowski P, Poole-Wilson PA, Strömberg A, van Veldhuisen DJ, Atar D, Hoes AW, Keren A, Mebazaa A, Nieminen M, Priori SG, Swedberg K; ESC Committee for Practice Guidelines, Vahanian A, Camm J, De Caterina R, Dean V, Dickstein K, Filippatos G, Funck-Brentano C, Hellemans I, Kristensen SD, McGregor K, Sechtem U, Silber S, Tendera M, Widimsky P, Zamorano JL. ESC guidelines for the diagnosis and treatment of acute and chronic heart failure 2008: the Task Force for the Diagnosis and Treatment of Acute and Chronic Heart Failure 2008 of the European Society of Cardiology: developed in collaboration with the Heart Failure Association of the ESC and endorsed by the European Society of Intensive Care Medicine. Eur Heart J. 2008;29:2388-2442.

56. Rehm J, Sempos CT, Trevisan M. Alcohol and cardiovascular disease: more than one paradox to consider: average volume of alcohol consumption, patterns of drinking and risk of coronary heart disease: a review. J Cardiovasc Risk. 2003;10:15-20

57. Trevisan M, Schisterman E, Mennotti A, Farchi G, Conti S; Risk Factor and Life Expectancy Research Group. Drinking pattern and mortality: the Italian Risk Factor and Life Expectancy pooling project. Ann Epidemiol. 2001;11:312-319.

58. Moore AA, Whiteman EJ, Ward KT. Risks of combined alcohol/ medication use in older adults. Am J Geriatr Pharmacother. 2007;5: 64-74.

59. Weathermon R, Crabb DW. Alcohol and medication interactions. Alcohol Res Health. 1999;23:40-54.

60. Kaufman DW, Kelly JP, Wiholm BE, Laszlo A, Sheehan JE, Koff RS, Shapiro $S$. The risk of acute major upper gastrointestinal bleeding among users of aspirin and ibuprofen at various levels of alcohol consumption. Am J Gastroenterol. 1999;94:3189-3196.

61. Crescente M, Jessen G, Momi S, Holtje HD, Gresele P, Cerletti C, de Gaetano G. Interactions of gallic acid, resveratrol, quercetin and aspirin a the platelet COX-1 level: functional and modelling studies. Thromb Haemost. 2009;102:336-346.

62. Chan FK, Ching JY, Hung LC, Wong VW, Leung VK, Kung NN, Hui AJ, Wu JC, Leung WK, Lee VW, Lee KK, Lee YT, Lau JY, To KF, Chan HL, Chung SC, Sung JJ. Clopidogrel versus aspirin and esomeprazole to prevent recurrent ulcer bleeding. $N$ Engl J Med. 2005;352:238-244.

63. Mukamal KJ, Smith CC, Karlamangla AS, Moore AA. Moderate alcoho consumption and safety of lovastatin and warfarin among men: the Post-Coronary Artery Bypass Graft Trial. Am J Med. 2006;119:434-440.

64. Kolovou GD, Salpea KD, Anagnostopoulou KK, Mikhailidis DP. Alcohol use, vascular disease, and lipid-lowering drugs. J Pharmacol Exp Ther. 2006;318:1-7.

65. Sesso HD, Cook NR, Buring JE, Manson JE, Gaziano JM. Alcoho consumption and the risk of hypertension in women and men. Hypertension. 2008:51:1080-1087.

66. Chobanian AV, Bakris GL, Black HR, Cushman WC, Green LA, Izzo JL Jr, Jones DW, Materson BJ, Oparil S, Wright JT Jr, Roccella EJ; Joint National Committee on Prevention, Detection, Evaluation, and Treatmen of High Blood Pressure; National Heart, Lung, and Blood Institute; National High Blood Pressure Education Program Coordinating Committee. The Seventh Report of the Joint National Committee on Prevention, Detection, Evaluation, and Treatment of High Blood Pressure. Hypertension. 2003;42:1206-1252.

67. Bulpitt CJ. How many alcoholic drinks might benefit an older person with hypertension? J Hypertens. 2005;23:1947-1951.

68. Djoussé L, Gaziano JM. Alcohol consumption and heart failure in hypertensive US male physicians. Am J Cardiol. 2008;102:593-597. 
69. Beulens JW, Rimm EB, Ascherio A, Spiegelman D, Hendriks HF, Mukamal KJ. Alcohol consumption and risk for coronary heart disease among men with hypertension. Ann Intern Med. 2007;146:10-19.

70. Klatsky AL, Koplik S, Gunderson E, Kipp H, Friedman GD. Sequelae of systemic hypertension in alcohol abstainers, light drinkers, and heavy drinkers. Am J Cardiol. 2006;98:1063-1068.

71. Britton KA, Gaziano JM, Sesso HD, Djoussé L. Relation of alcoho consumption and coronary heart disease in hypertensive male physicians (from the Physicians' Health Study). Am J Cardiol. 2009;104 932-935.

72. Haffner SM, Lehto S, Rönnemaa T, Pyörälä K, Laakso M. Mortality from coronary heart disease in subjects with type 2 diabetes and in nondiabetic subjects with and without prior myocardial infarction. $N$ Engl $\mathrm{J} \mathrm{Med}$. 1998;339:229-234.

73. Koppes LL, Dekker JM, Hendriks HF, Bouter LM, Heine RJ. Meta-analysis of the relationship between alcohol consumption and coronary heart disease and mortality in type 2 diabetic patients. Diabetologia. 2006;49: $648-652$.

74. Howard AA, Arnstern JH, Gourevitch MN. Effect of alcohol consumption on diabetes mellitus: a systematic review. Ann Intern Med. 2004; 140:211-219.

75. Jackson R, Broad J, Connor J, Wells S. Alcohol and ischaemic heart disease: probably no free lunch. Lancet. 2005;366:1911-1912.

76. Mukamal KJ, Ding EL, Djoussé L. Alcohol consumption, physica activity, and chronic disease risk factors: a population-based crosssectional survey. BMC Public Health. 2006;6:118.

77. Lee SJ, Sudore RL, Williams BA, Lindquist K, Chen HL, Covinsky KE Functional limitations, socioeconomic status, and all-cause mortality in moderate alcohol drinkers. J Am Geriatr Soc. 2009;57:955-962.

KEY WORDS: alcohol - cardiovascular disease a diabetes mellitus hypertension $\mathbf{\square}$ prevention 



\section{Discussion}

The aim of this thesis was to review epidemiological evidence concerning the relationship of alcohol consumption with cardiovascular morbidity and mortality and total mortality both in apparently healthy population and in patients at high cardiovascular risk.

\section{A number of crucial issues have been addressed and discussed:}

\section{- The benefit of moderate alcohol consumption on coronary heart disease and cerebrovascular disease}

The relationship between alcohol consumption and cardiovascular events in healthy people has been depicted as a J-shaped curve attributed to a doserelated combination of beneficial and harmful effects.

A systematic review on alcohol consumption and cerebrovascular disease suggests a reduced risk of ischemic stroke in light-moderate drinkers, but little or no protection against hemorrhagic stroke. All cerebrovascular events substantially increase in heavy alcohol and binge consumers; moreover, heavy alcohol consumption is a risk factor for both hemorrhagic and ischemic stroke in young adults.

- Protection against total mortality. Is the effect of alcohol different in men and women?

A J-shaped relationship between total mortality and increasing amounts of alcohol consumed was observed in a meta-analysis, including altogether more than one million people and hundreds of thousands fatal events, showing that light-to-moderate consumption of alcohol significantly reduces total mortality, while higher doses increase it. Moreover, J-shaped relationship between alcohol and total mortality was found when the data were analyzed separately for men and women. The dose-response curves were similar for both sexes when alcohol intake was light, but they did differ with heavier intake; in fact the inverse association in women apparently disappeared at doses lower than in men (the protection was apparent up to three drinks per day in men, but only up to two drinks per day in women, whereas the maximal risk reduction was similar (17\%; $99 \%$ CI $15-19 \%$ and $18 \% ; 99 \%$ CI $13-22 \%$, respectively)). It means that women are more exposed to all causes of death at moderate to high level of alcohol 
consumption than men, probably due to different metabolism of alcohol and/or increasing risk of various cancers (e.g., breast cancer).

\section{- Is wine different from beer or spirits?}

There is evidence for a J-shaped association between wine or beer (but not spirits) consumption and vascular risk. Dose-response curves from comparable studies appeared substantially similar for wine and beer: one out of three people drinking an average daily amount of 25 grams of alcohol, as either wine or beer, may be maximally protected from the risk of suffering a fatal or non fatal cardiovascular event.

\section{- Should abstention be recommended to patients at high cardiovascular risk?}

A meta-analysis on cardiovascular mortality showed a J-shaped pooled curve with a significant maximal protection (average $22 \%$ ) by alcohol at about 26 grams/day.

Similarly, a meta-analysis on mortality from any cause, also showed a Jshaped pooled curve (average maximal protection $18 \%$ at 7 grams/day). So in patients with cardiovascular disease, light to moderate alcohol consumption (5-25 grams/day) was significantly associated with a lower incidence of both recurrent cardiovascular events and all-cause mortality.

Cardiovascular patients who do not consume alcohol should not be encouraged to start regular drinking. If not contraindicated, patients who drink alcohol should not exceed 1 drink per day for women or 2 drinks per day for men as a component of a balanced cardioprotective dietary pattern with appropriate energy-intake levels.

\section{- What is the optimal amount of alcohol intake?}

As already mentioned, the dose-response relationships between alcohol intake and cardiovascular morbidity and mortality and total mortality have been depicted as a J-shaped curve: non-drinkers having higher incidence and mortality rates than light or moderate drinkers, but similar or lower rates than heavy drinkers.

In conclusion, epidemiologic evidence indicates that the amount of wine/beer/alcohol for which the balance between risk and benefit is the best is in the range of 1-2 drinks per day, in agreement with the American Heart Association guidelines. 
Official definitions of standard "drinks" or "units" vary between countries. The most commonly favoured definition-also used by WHO-is 10 grams of alcohol (ethanol) per drink, but definitions vary from 8 to 14 grams of pure ethanol in a standard drink. A $250 \mathrm{ml}$ glass (half a pint) of beer ( $5 \%$ alcohol by volume), a $100 \mathrm{ml}$ glass of wine $(12 \% \mathrm{ABV})$ or a $30 \mathrm{ml}$ measure of spirits ( $40 \%$ ABV) contains 10 grams of alcohol.

\section{- I mplications for Practice and Policy}

The present thesis provides reasonable evidence that regular and moderate alcohol intake is significantly associated with a reduction in the incidence of cardiovascular and total mortality, in apparently healthy people and in patients at high cardiovascular risk. However, the fact that regular moderate alcohol consumption is not easily attainable or maintainable in all parts of the world must be taken into serious consideration. There are certainly appreciable differences between Mediterranean and Northern European or Russian habits of alcohol consumption. Therefore, in some low-income populations and poor countries, even if the net effect on CVD might be beneficial, the effect of alcohol on the overall burden of disease might be detrimental because of more frequent uncontrolled alcohol-use related disorders such as cancer, liver cirrhosis, and injury. 


\section{Conclusions}

The main message for an adult general population can be summarised as follows:

- Heavy or binge drinkers should be urged to cut and modify their consumption.

- Consumption of alcoholic beverages is not recommended to young people, pregnant women, those at risk of alcoholism, those with cardiomiopathy or cardiac arrhythmias, or anyone engaged in actions that require concentration, skill or coordination.

- There is no reason to discourage adults who are already regular lightmoderate alcohol consumers from continuing.

Although low-moderate, non-binging alcohol consumption-in the absence of contraindications and in the context of healthy eating and a healthy lifestyle-reduces the risk of coronary heart disease, it is not recommended that adult abstainers begin drinking for health reasons. This is because even moderate alcohol intake may be associated with increased risk of other harm and there is a risk that some of those who start to drink will consume more than the low-risk drinking limits. 


\section{Summary}

A consistent, significant protective effect of regular and moderate alcohol consumption in coronary heart disease and ischaemic stroke, already shown in previous epidemiological studies, has been clearly confirmed and established by the work assembled in the present thesis. The association between alcohol consumption and CHD mortality was described indeed through a J-shaped relationship, where teetotalers and heavy drinkers were at the highest risk whereas light-moderate drinkers were at the lowest risk.

Thus, if low alcohol intake is inversely related to CHD, the other side of the coin shows an increased risk for certain cancers, cirrhosis and death from accidents mainly associated with increasing alcohol consumption.

Total mortality too was significantly reduced in moderate drinkers; however, excess drinking was definitely harmful also when this hard global end-point was considered. Thus, data assembled in this thesis and previous epidemiologic datathough only derived at present from a large number of prospective observational studies - confirm the hazards of excess drinking, but also indicate the existence of potential windows of alcohol intake which may confer a net beneficial effect of drinking, in terms of survival, both in men and in women.

Regarding cardiovascular patients, if not contraindicated, regular alcohol consumers should not exceed one drink/day for women or up to two drinks/day for men as a component of a balanced cardio-protective dietary pattern, with appropriate energy intake levels. At present, according to a prudent approach, a cardiovascular patient who is teetotaler should neither be recommended, nor "prescribed" to start drinking for health gain.

In spite of a large number of experimental studies suggesting a protective role of wine-derived polyphenols on cardiovascular risk, epidemiological evidence of a similar effect of wine and beer has been now established and it seems likely that the ethanol component of different beverages is a major factor that reduces the cardiovascular risk.

The present thesis provides reasonable evidence that regular and moderate alcohol intake is significantly associated with a reduction in the incidence of cardiovascular and total mortality, in apparently healthy people and in patients at high 
cardiovascular risk. However, the fact that regular moderate alcohol consumption is not easily attainable or maintainable in all parts of the world must be taken into serious consideration. There are certainly appreciable differences between Mediterranean and Northern European or Russian habits of alcohol consumption. Therefore, in some low-income populations and poor countries, even if the net effect on CVD might be beneficial, the effect of alcohol on the overall burden of disease might be detrimental because of more frequent uncontrolled alcohol-use disorders, cancer, liver cirrhosis, and injury. 


\section{Selected Publications}

A. Costanzo S, Di Castelnuovo A, Donati MB, Iacoviello L, de Gaetano G. Moderate alcohol consumption and cardiovascular risk reduction: open issues. Italian J Pub Health $2006 ; 3: 21-28$.

B. Di Castelnuovo A, Costanzo S, Donati MB, Iacoviello L, de Gaetano G. Alcohol consumption and cardiovascular risk: an epidemiological perspective. Nutr Metab Cardiovasc Dis. 2007;17:561-4.

C. Di Castelnuovo A, Costanzo S, di Giuseppe R, de Gaetano G, Iacoviello L. Alcohol consumption and cardiovascular risk: mechanisms of action and epidemiologic perspectives. Future Cardiol. 2009;5(5):467-77. Review.

D. Costanzo S, Di Castelnuovo A, Donati MB, de Gaetano G, Iacoviello L. The relationship between alcohol consumption and cerebrovascular risk: from epidemiological evidence to biological plausibility. In: Cerebral ischemia in Young Adults. Neurology - Laboratory and Clinical Research Developments. A. Pezzini and A .Padovani Eds. Nova Biomedica, New York 2009; Chapter 6: 149-165.

E. Di Castelnuovo A, Costanzo S, Bagnardi V, Donati MB, Iacoviello L, de Gaetano G. Alcohol dosing and total mortality in men and women: an updated metaanalysis of 34 prospective studies. Arch Intern Med. 2006;166:2437-45.

F. Costanzo S, Di Castelnuovo A, Donati MB, Iacoviello L, de Gaetano G. Wine, beer or spirit drinking in relation to fatal and non-fatal cardiovascular events: a metaanalysis. Eur J Epidemiol. 2011;26(11):833-50.

G. Costanzo S, Di Castelnuovo A, Donati MB, Iacoviello L, de Gaetano G. Alcohol consumption and mortality in patients with cardiovascular disease: a metaanalysis. J Am Coll Cardiol. 2010;55(13):1339-47.

H. Costanzo S, Di Castelnuovo A, Donati MB, Iacoviello L, de Gaetano G. Alcohol consumption in relation to vascular and total mortality in patients with diabetes, hypertension or history of cardiovascular disease: a meta-analysis. Journal of Wine Research. 2011;22(2)119-22.

I. Di Castelnuovo A, Costanzo S, Donati MB, Iacoviello L, de Gaetano G. Prevention of cardiovascular risk by moderate alcohol consumption: epidemiologic evidence and plausible mechanisms. Intern Emerg Med. 2010;5(4):291-7.

J. Costanzo S, Di Castelnuovo A, Donati MB, Iacoviello L, de Gaetano G. Cardiovascular and overall mortality risk in relation to alcohol consumption in patients with cardiovascular disease. Circulation. 2010;121(17):1951-9.Review. 


\section{Curriculum Vitae}

Simona Costanzo was born in Bojano (CB), Italy, on $15^{\text {th }}$ of July, 1976.

She attended the Pharmaceutical Chemistry and Technology (School of La Sapienza University, Rome), and in 2003 discussed a thesis in the field of synthesis of pharmacologically active molecules (Title: Electrochemical carbonylation of primary amines to symmetrical N,N'-disubstituted ureas using Palladium catalys). In 2005, she obtained her Master Degree in Epidemiology (Catholic University, Rome) discussing a thesis on the relationship between alcohol consumption and total mortality (Title: Alcohol and mortality: a meta-analysis).

On 2005 she was selected to attend the Course: "Conceptual foundation of epidemiologic study design" and "Principles of genetic epidemiology", Erasmus Summer Programme, Rotterdam, The Nederland.

On 2008 she was was selected to attend the International Course in Cardiovascular Disease Epidemiology and Prevention: "World Heart Federation 41st Ten Day Teaching Seminar in Cardiovascular Disease Epidemiology and Prevention", Oxford, UK.

Since 2005, she was recruited as a fellow at the Laboratory of Genetic and Environmental Epidemiology, Research Laboratories, "John Paul II" Center for High Technology Research and Education in Biomedical Sciences of Catholic University, in Campobasso, under the supervision of Dr. L. Iacoviello and Dr. Di Castelnuovo, where she started her scientific career as statistician and epidemiologist in the field of physiopathology of cardiovascular disease and she performed the work of this thesis.

Presently she is involved in several ongoing epidemiological studies, such as the Moli-sani project (a large cohort study on nutrition/ genetic interactions in the risk of CVD and cancer), the IMMIDIET project, the Moli-flu study, the Polyphemus study.

Since 2005 she supervises and controls the quality of the Moli-sani project database (more than 24.000 subjects, more than 3,000 variables).

In 2009 she drafted the protocol of the Moli-flu study, accepted by the ECDC (European Centre for Disease Prevention and Control) and funded by EVM (European Vaccine Manufacturers). The study investigated the effectiveness of seasonal and pandemic vaccine (2009-2010) in the cohort of the Moli-sani Project. In the context of this study, she coordinated the data collection phase, she performed the statistical analysis for the interim and final reports and participated in international work-shops, where she presented the results of the study. 
She is the principal investigator of a research project (the Polyphemus project) selected by the Italian Ministry of Health (Young Italian Researchers Grant 2008), classified 43rd out of 997, Project's title: “Polyphenol-Rich Food Consumption and Short and Long-Term Prognosis after Coronary Artery Bypass Graft Surgery". The main purpose of the study is to assess whether the consumption of foods rich in polyphenols may reduce the occurrence of short-and long-term complications in patients undergoing coronary artery bypass graft. In its second phase, the project will develop an intervention to evaluate whether the supplementation of foods rich in polyphenols is associated with increased levels of n-3FA and a reduction in the risk of atrial fibrillation in patients undergoing coronary artery bypass graft.

The general aim of Dr. Costanzo's research is to evaluate the role of alcohol as protective or risk factor at different doses, both on cardiovascular system and total mortality. She works on the evaluation of cardiovascular, cancer and global risk associated with lifestyle and dietary habits, particularly with the controversial issue of alcohol and/or wine consumption. Her expertise in the field has already been recognized by invitations as speaker in international meetings focused on nutrition and health.

\section{Invited speaker:}

1. Alcohol, Wine and Prevention of CVD and Mortality: Epidemiological Evidenc. MeDiet2007. Athens, Greece, April 2007.

2. Alcohol consumption and blood pressure: results from the Moli-sani project. Winehealth 2007, Bordeaux, France, September 2007

3. Alcohol, Wine and Prevention of CVD and Mortality: Epidemiological Evidence. Wine and Health Symposium 2007. Bucharest, Romania, November 2007.

4. Donna, rischio cardiovascolare e fattori ambientali. L'esperienza dello Studio Moli-sani. Congresso Italiano di Trombosi ed Emostasi nella Donna e nel Bambino. Padova, May $22^{\text {nd }}-24^{\text {th }}, 2008$.

5. XXIV Corso di aggiornamento: Alterazioni congenite ed acquisite della coagulazione. Vino ed Alcol: tra prevenzione degli eventi ischemici e rischio emorragico. Menarini Foundation (Milan, November 2008).

6. "Alcohol and Thrombosis: to drink or not to drink?", Kraków, Poland 10th ETRO Advanced Teaching Course on Thrombosis. (October $12^{\text {th }}-17^{\text {th }}, 2009$ ).

7. Alcohol intake in relation to vascular risk and total mortality: answer from meta-analyses. Winehealth 2010, Cividale-Rossazzo-Cormons Friuli, Italy. October $3^{\text {rd }}-6^{\text {th }}, 2010$. 


\section{Publications}

1. de Gaetano G, Di Castelnuovo A, Costanzo S, Donati MB, Iacoviello L. Alcohol, cardiovascular risk and health: there is a window for benefits. J Thromb Haemost. 2006;5:1156-7.

2. Di Castelnuovo A, Costanzo S, Bagnardi V, Donati MB, Iacoviello L, de Gaetano G. Alcohol dosing and total mortality in men and women: an updated metaanalysis of 34 prospective studies. Arch Intern Med. 2006;166:2437-45.

3. Izzi B, Pampuch A, Costanzo S, Vohnout B, Iacoviello L, Cerletti C, de Gaetano G. Determinants of platelet aggregate formation with either polymorphonuclear leukocytes or monocytes in whole blood from a general population. Thromb Haemost 2007;98:1276-84.

4. Iacoviello L, Bonanni A, Costanzo S, De Curtis A, Di Castelnuovo A, Olivieri M, Zito F, Donati MB, de Gaetano G, on Behalf of the Moli-sani Project Investigators. The Moli-Sani Project, a randomized, prospective cohort study in the Molise region in Italy; design, rationale and objectives. Italian J Pub Health 2007; 4:10-8.

5. Costanzo S, Di Castelnuovo A, Donati MB, Iacoviello L, de Gaetano G. Moderate alcohol consumption and cardiovascular risk reduction: open issues. Italian J Pub Health 2006;3:21-28.

6. Di Castelnuovo A, Costanzo S, Donati MB, Iacoviello L, de Gaetano G. Alcohol consumption and cardiovascular risk: an epidemiological perspective. Nutr Metab Cardiovasc Dis. 2007;17:561-4.

7. Costanzo S, Di Castelnuovo A, Zito F, Krogh V, Siani A, Arnout J, Cappuccio FP, Miller MA, van Dongen M, de Lorgeril M, de Gaetano G, Donati MB, Iacoviello L; European Collaborative Group of the IMMIDIET project. Prevalence, awareness, treatment and control of hypertension in healthy unrelated male-female pairs of European regions: the dietary habit profile in European communities with different risk of myocardial infarction - the impact of migration as a model of gene environment interaction project. J Hypertens 2008;26:2303-11.

8. di Giuseppe R, Di Castelnuovo A, Centritto F, Zito F, De Curtis A, Costanzo S, Vohnout B, Sieri S, Krogh V, Donati MB, de Gaetano G, Iacoviello L. Regular consumption of dark chocolate is associated with low serum concentrations of $C$ reactive protein in a healthy italian population. J Nutr. 2008;138:1939-45.

9. Di Castelnuovo A, Costanzo S, di Giuseppe R, de Gaetano G, Iacoviello L. Alcohol consumption and cardiovascular risk: mechanisms of action and epidemiologic perspectives. Future Cardiol. 2009;5(5):467-77. Review. 
Centritto F, Iacoviello L, di Giuseppe R, De Curtis A, Costanzo S, Zito F, Grioni S, Sieri S, Donati MB, de Gaetano G, Di Castelnuovo A; Moli-sani Investigators. Dietary patterns, cardiovascular risk factors and C-reactive protein in a healthy Italian population. Nutr Metab Cardiovasc Dis. 2009;19(10):697-706.

10. Costanzo S, Di Castelnuovo A, Donati MB, de Gaetano G, Iacoviello L. The relationship between alcohol consumption and cerebrovascular risk: from epidemiological evidence to biological plausibility. In: Cerebral ischemia in Young Adults. Neurology. Laboratory and Clinical Research Developments. A. Pezzini and A .Padovani Eds. Nova Biomedica, New York 2009;Chapter 6:149165.

11. Di Castelnuovo A, Costanzo S, di Giuseppe R, Iacoviello L, de Gaetano G. Alcohol Consumption and Health. (C) 2009 by IMABE -Institut für medizinische Anthropologie und Bioethik, Wien Imago Hominis-Band 16 Heft 3 S.197-999. ISSN 1021-9803

12. Di Castelnuovo A, Costanzo S, Donati MB, Iacoviello L, de Gaetano G. Prevention of cardiovascular risk by moderate alcohol consumption: epidemiologic evidence and plausible mechanisms. Intern Emerg Med. 2010;5(4):291-7.

13. Costanzo S, Di Castelnuovo A, Donati MB, Iacoviello L, de Gaetano G. Alcohol consumption and mortality in patients with cardiovascular disease: a metaanalysis. J Am Coll Cardiol. 2010;55(13):1339-47.

14. Costanzo S, Di Castelnuovo A, Donati MB, Iacoviello L, de Gaetano G. Cardiovascular and overall mortality risk in relation to alcohol consumption in patients with cardiovascular disease. Circulation. 2010;121(17):1951-9. Review.

15. Vohnout B, Gianfagna F, Lorenzet R, Cerletti C, de Gaetano G, Donati MB, Iacoviello $\mathrm{L}$; on behalf of the Moli-family Study Investigators. Genetic regulation of inflammation-mediated activation of haemostasis: Family-based approaches in population studies. Nutr Metab Cardiovasc Dis. 2011;21:857-61.

16. D'Imperio M, Gobbino M, Picanza A, Costanzo S, Della Corte A, Mannina L. Influence of harvest method and period on olive oil composition: an NMR and statistical study. J Agric Food Chem. 2010;58,11043-51.

17. Costanzo S, Di Castelnuovo A, Donati MB, Iacoviello L, de Gaetano G. Recent advances on the relationship between alcohol consumption and cardiovascular mortality. Recenti prog med 2011;102:105-8. Italian.

18. di Giuseppe R, Di Castelnuovo A, Melegari C, De Lucia F, Santimone I, Sciarretta A, Barisciano P, Persichillo M, De Curtis A, Zito F, Krogh V, Donati $M B$, de Gaetano G, Iacoviello L; on behalf of the Moli-sani Project Investigators. 
Typical breakfast food consumption and risk factors for cardiovascular disease in a large sample of Italian adults. Nutr Metab Nutr Metab Cardiovasc Dis. 2010 Nov 17. [Epub ahead of print]

19. Santimone I, Di Castelnuovo AF, de Curtis A, Spinelli M, Cugino D, Gianfagna F, Zito F, Donati MB, Cerletti C, de Gaetano G, Iacoviello L on behalf of the Molisani Project Investigators. White blood cells count, sex and age are major determinants of platelet indices heterogeneity in an adult general population: results from the MOLI-SANI project. Haematologica. 2011;96(8):1180-8.

20. Di Castelnuovo A, Costanzo S, Persichillo M, Olivieri M, de Curtis A, Zito F, Donati MB, de Gaetano G, Iacoviello L. Distribution of short and lifetime risks for cardiovascular disease in Italians. Eur J Cardiovasc Prev Rehabil. 2011 May 13. [Epub ahead of print] PubMed PMID: 21571772.

21. Costanzo S, Di Castelnuovo A, Donati MB, Iacoviello L, de Gaetano G. Alcohol consumption in relation to vascular and total mortality in patients with diabetes, hypertension or history of cardiovascular disease: a meta-analysis. Journal of Wine Research. 2011;22(2)119-22.

22. Bossola M, Rosa F, Tazza L, de Curtis A, Costanzo S, Iacoviello L. P-selectin, Eselectin and $\mathrm{CD} 40 \mathrm{~L}$ over time in chronic hemodialysis patients. Hemodialysis International. Hemodial Int. doi: 10.1111/j.1542-4758.2011.00579.

23. Costanzo S, Di Castelnuovo A, Donati MB, Iacoviello L, de Gaetano G. Diet, Physical activity and cardiovascular disease prevention in Europe. Alcohol. European Heart Network 2011. www.ehnheart.org/publications/nutrition.html.

24. Di Giuseppe R, Arcari A, Serafini M, Di Castelnuovo A, Zito F, De Curtis A, Sieri $S$, Krogh V, Pellegrini N, Schünemann JH, Donati MB, de Gaetano G, Iacoviello $\mathrm{L}$, on behalf of the Moli-sani Project Investigators. Total dietary antioxidant capacity and lung function in an Italian population. Eur J Clin Nutr. 2011 Aug 31. doi: 10.1038/ejcn.2011.148.

25. Costanzo S, Di Castelnuovo A, Donati MB, Iacoviello L, de Gaetano G. Wine, beer or spirit drinking in relation to fatal and non-fatal cardiovascular events: a meta-analysis. Eur J Epidemiol. 2011;26(11):833-50.

26. Costanzo S, Gianfagna F, Persichillo M, De Lucia F, Verna A, Djidingar M, Magnacca S, Bracone F, Olivieri M, Donati MB, de Gaetano G, Iacoviello L. Pandemic and seasonal vaccine coverage and effectiveness during the 20092010 pandemic influenza in an Italian adult population (Submitted).

$(\mathrm{H}$-index $=8)$ 


\section{Acknowledgments}

It is a pleasure to thank all the people who made this thesis possible.

I would not have achieved this goal without the guidance and mentoring of Prof. Giovanni de Gaetano, Dr. Licia Iacoviello and Dr Augusto Di Castelnuovo whose expertise, understanding, and patience added considerably to my research career and PhD experience.

I want to extend my sincere gratitude to Prof. Maria Benedetta Donati for her continued support.

I wish to thank also my colleagues and friends of Lab and those who provided me with advice at times of critical need.

My final thoughts go to my family, I would not have gone so far without their love and encouragement.

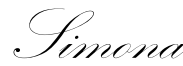


Finito di stampare

Dicembre 2011

Arti Grafiche La Regione srl

Ripalimosani (CB) 